Processamento gráfico para aplicações em saúde: técnicas, requisitos, ferramentas, desafios e oportunidades

Fátima de Lourdes dos Santos Nunes Marques 


\title{
Processamento gráfico para aplicações em saúde: técnicas, requisitos, ferramentas, desafios e oportunidades
}

\author{
Fátima de Lourdes dos Santos Nunes Marques
}

Texto sistematizado apresentado à Escola de Artes, Ciências e Humanidades da Universidade de São Paulo como parte dos requisitos para obtenção do título de Livre Docente na área de conhecimento Informação e tecnologia - Especialidade: Processamento gráfico, manipulação, armazenamento e recuperação de imagens.

USP - São Paulo

Agosto/2011 
Para minha família que torce, sofre, se alegra, se entristece e comemora! 
A Deus (sempre!), agradeço por não me deixar sozinha em momento algum.

Ao Luís, meu marido, agradeço por constantemente me oferecer demonstrações do seu amor incondicional. Agradeço também por entender as minhas ausências e respeitar o meu silêncio nos momentos difíceis.

À minha mãe, agradeço pelos ensinamentos de confiança em Deus, pelos exemplos de luta e humildade.

À minha irmã Regina, agradeço por ser um exemplo de dedicação e alto astral. Obrigada por estar sempre ao meu lado.

À minha irmã Rita, agradeço pela acolhida em São Paulo e por ser um exemplo de esforço para melhorar sempre.

Ao Toninho, meu cunhado, agradeço pela disponibilidade constante para ajudar em tudo.

Aos meus sobrinhos Mateus, Amanda e Pedro, agradeço por colocarem alegria na minha vida e pelos abraços de saudade.

A todos os meus orientados, passados e presentes, agradeço a imensa chance de aprender com vocês e compartilhar experiências não somente profissionais, mas de vida.

Aos professores e alunos do Interlab (EP-USP), agradeço pela receptividade e pela rica troca de experiências. Em especial, agradeço ao Cléber pelo auxílio na digitalização dos documentos do Memorial.

Ao professor Romero Tori, agradeço pelas dicas, sugestões e apoio constante.

Aos órgãos financiadores, Fapesp e CNPq, agradeço pela concessão de financiamento para vários projetos e bolsas relacionados aos trabalhos descritos neste documento. 
Aos coordenadores do Instituto Nacional de Ciência e Tecnologia em Medicina Assistida por Computação Científica (INCT-MACC), professores Raúl Antonino Feijoó e Artur Ziviani, agradeço pela oportunidade de participar deste marco da pesquisa em Computação aplicada à saúde no Brasil.

Aos parceiros do INCT-MACC: Professores Romero Tori (EP-USP), Hélio Pedrini (Unicamp), Márcio Delamaro (ICMC-USP) e Ildeberto Rodello (FEARP-USP) e aos nossos alunos Ana Cláudia, Cléber, Eunice, Alexandre, Obana, Ana Carolina, Marcos, André, Adriano, Matheus e Ana Carreira, agradeço por participarem desta empreitada comigo.

Aos colegas docentes do Curso de Sistemas de Informação da EACH-USP, agradeço pela vontade de construir juntos esta Escola diferenciada e pela troca de experiências.

Aos professores Marcos Lordello Chaim e Ariane Machado Lima, agradeço pelas parcerias e pelas inúmeras demonstrações de amizade e afeto.

A Você que participou de alguma forma da elaboração deste documento, ajudando na forma e/ou no conteúdo, de perto ou de longe, doando-se durante o período em que os trabalhos foram conduzidos, compartilhando alegrias e tristezas, dividindo conquistas e fracassos, mesmo que não esteja aqui citado nominalmente, receba minha eterna gratidão! 
"O fracasso dos projetos, o sofrimento, a morte, fatores que nos acabrunham, são também caminhos que conduzem a um porto. Isso é esperança."

Albert Tévoédjerè - Agenda Recriar 2011 - 25/1/2011 
A área de saúde tem sido uma das grandes beneficiadas por técnicas computacionais e, ao mesmo tempo, uma das áreas aplicadas que agem como propulsoras da Computação. Este documento tem o objetivo de apresentar e discutir técnicas e ferramentas de Processamento de Imagens e Realidade Virtual aplicadas à área de saúde, salientando-se requisitos e tecnologias, a partir de uma compilação de ferramentas e métodos desenvolvidos pela autora e sua equipe. Entre as ferramentas desenvolvidas destacam-se o framework ViMeT (Virtual Medical Training), um conjunto de classes destinadas a auxiliar na geração de ferramentas para treinamento médico, de forma rápida e com baixo custo e o framework O-FIm (Oracle for Images), que permite gerar oráculos de teste de software com saídas gráficas usando conceitos de recuperação baseada em conteúdo. É tecida uma reflexão sobre os desafios existentes para desenvolver sistemas computacionais especificamente nesse contexto de forma que, ao final, possam ser apresentadas oportunidades de pesquisa e desenvolvimento. 
The healthcare area has been one of the most benefited by computational techniques and, at the same time, one of the fields that act as propellers of Computer Science. The aim of this document is to present and to discuss techniques and tools using Image Processing and Virtual Reality applied to the healthcare area, pointing out requirements and technologies, as from a compilation of tools and methods developed by the author and her team. Among the tools developed, two are highlighted: the ViMeT (Virtual Medical Training) framework, a set of classes to assist in tools generation quickly and with low cost for medical training, and O-FIm (Oracle for Images), which generates testing oracles of software with graphical output by using content-based images retrieval. A reflection about the existing challenges to develop computer systems specifically in this context is elaborated, so that, eventually, opportunities for research and development can be presented. 
1 Introdução 1

1.1 Contextualização . . . . . . . . . . . . . . . . . . . . . . . . 1

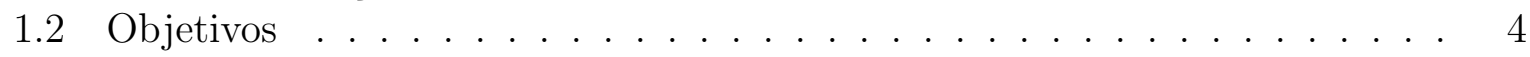

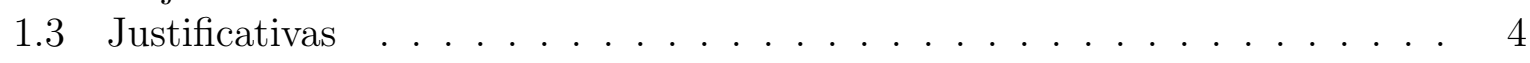

1.4 Organização do documento . . . . . . . . . . . . . . . 5

2 Aspectos Conceituais sobre PI e RV 7

2.1 Processamento de Imagens . . . . . . . . . . . . . . . . . . . . . . 7

2.1.1 Relações entre pixels . . . . . . . . . . . . . . . . . . . . . 9

2.1.2 Histograma de uma imagem . . . . . . . . . . . . . . . . . . . . . . . . 11

2.1.3 Implementação de filtros . . . . . . . . . . . . . . . . . . . . . . 11

2.1.4 Processamento de baixo nível . . . . . . . . . . . . . . . . . . 12

2.1.5 Processamento de nível médio . . . . . . . . . . . . . . . . . 15

2.1.6 Processamento de alto nível . . . . . . . . . . . . . . . . . . 16

2.2 Recuperação de Imagens Baseada em Conteúdo . . . . . . . . . . . . . . . 16

2.2 .1 Extratores . . . . . . . . . . . . . . . . . 18

2.2 .2 Funções de similaridade . . . . . . . . . . . . . . . . . . . . 19

2.2 .3 Estruturas de Indexação . . . . . . . . . . . . . . . . . . . . . . . . . . . . . . . . .

2.3 Realidade Virtual . . . . . . . . . . . . . . . . . . . . . . . 21

2.3.1 Características da Realidade Virtual . . . . . . . . . . . . . . 22

2.3.2 Dispositivos de Realidade Virtual . . . . . . . . . . . . . . . . 23

2.3.2.1 Dispositivos de entrada . . . . . . . . . . . . . 24

2.3.2.2 Dispositivos de saída . . . . . . . . . . . . . . 25

2.3.2.3 Classificações de sistemas de RV . . . . . . . . . . . . 26

2.3.2.4 Estrutura de um sistema de Realidade Virtual . . . . . . . 29

2.4 Considerações finais . . . . . . . . . . . . . . . . . . 30

3 Processamento gráfico aplicado na área de saúde 32

3.1 Processamento de Imagens . . . . . . . . . . . . . . . . . . . . . . 33

3.2 Recuperação de Imagens Baseada em Conteúdo . . . . . . . . . . . . . . . 35

3.3 Realidade Virtual . . . . . . . . . . . . . . . . . . . . . . 36

3.4 Aplicações desenvolvidas no Brasil . . . . . . . . . . . . . . . . . . . . 38

3.5 Considerações finais . . . . . . . . . . . . . . . . . . . 41 
4 Realidade Virtual em treinamento médico $\quad 42$

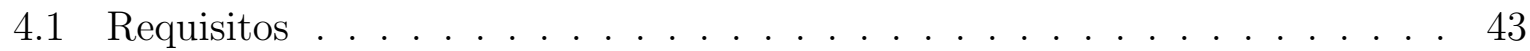

4.1 .1 Dispositivos de interação e visualização . . . . . . . . . . . . . . . . 43

4.1 .2 Objetos tridimensionais . . . . . . . . . . . . . . . 44

4.1 .3 Detecção de colisão . . . . . . . . . . . . . . . . . . . . 45

4.1 .4 Deformação . . . . . . . . . . . . . . . . . 46

4.1 .5 Estereoscopia . . . . . . . . . . . . . . . . . 47

4.1.6 Precisão e tempo de resposta . . . . . . . . . . . . . . . . 48

4.2 Tecnologias de software . . . . . . . . . . . . . . . . . . . . 48

4.3 Projeto PuMa . . . . . . . . . . . . . . . . . . . 51

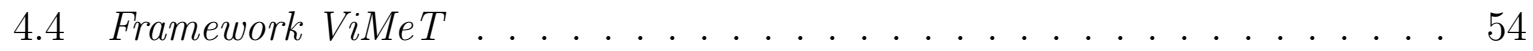

4.4.1 Ferramenta de instanciação . . . . . . . . . . . . . . 56

4.4 .2 Interação . . . . . . . . . . . . . . . . . . . 58

4.5 Geração de estudos de caso . . . . . . . . . . . . . . . . . . . 62

4.6 Atlas virtuais . . . . . . . . . . . . . . . . . . . . . . 68

4.6.1 Atlas Virtual da Mama . . . . . . . . . . . . . . . . . 68

4.6 .2 Projeto VIDA . . . . . . . . . . . . . . . . 70

4.7 Jogos sérios . . . . . . . . . . . . . . . . . . . . . . . . 73

4.8 Considerações finais . . . . . . . . . . . . . . . . . . . . . . 77

5 CAD, Visualização de Informação e CBIR $\quad 78$

5.1 Auxílio ao diagnóstico . . . . . . . . . . . . . . . . . . . . . . . 79

5.2 Visualização de Informação . . . . . . . . . . . . . . . . . . . . 82

5.2 .1 Ferramenta VRVis . . . . . . . . . . . . . . . . . . 83

5.2 .2 Ferramenta VRVis Manager . . . . . . . . . . . . . . . 86

5.3 Recuperação de Imagens Baseada em Conteúdo . . . . . . . . . . . . . . . 91

5.3.1 Imagens mamográficas . . . . . . . . . . . . . . . . . . . . 91

5.3 .2 Imagens de faces humanas . . . . . . . . . . . . . . . . . . . 94

5.3 .3 Recuperação de imagens na Internet . . . . . . . . . . . . . . . . . 99

5.3.4 Avaliação de funções de similaridade . . . . . . . . . . . . . . . . . 102

5.4 Framework O-FIm . . . . . . . . . . . . . . . . . . . . . 107

5.5 Considerações finais . . . . . . . . . . . . . . . . . . . . . 109

6 Desafios e oportunidades 112

6.1 Desafios . . . . . . . . . . . . . . . . . . . . . 113

6.1.1 Aspectos Técnicos . . . . . . . . . . . . . . . . . 113

6.1.2 Aspectos Econômicos . . . . . . . . . . . . . . . . . 116

6.1 .3 Aspectos Sociais . . . . . . . . . . . . . . . . . . 117

6.2 Oportunidades . . . . . . . . . . . . . . . . . . . 119

7 Conclusões $\quad 124$

$\begin{array}{lr}\text { Referências Bibliográficas } & 128\end{array}$ 
2.1 Ilustração do conceito de vizinhança. . . . . . . . . . . . . . . . . . . . 9

2.2 Exemplo de histograma. . . . . . . . . . . . . . . . . . . 12

2.3 Exemplo genérico de uma máscara 3 x $3 \ldots \ldots$. . . . . . . . . . . . . . . 12

2.4 Algoritmo genérico para aplicação de templates. . . . . . . . . . . . . . . 13

2.5 Exemplo de máscara para filtro de média da vizinhança. . . . . . . . . . . . 14

2.6 Exemplos de aplicação de filtros com base na vizinhança. . . . . . . . . . . . 14

2.7 Exemplo de filtro (quantização) com base no histograma da imagem. . . . 15

2.8 Esquema geral de um sistema de CBIR. . . . . . . . . . . . . . . . . 17

2.9 Exemplo de um vetor de características. . . . . . . . . . . . . . . . . . . 19

2.10 Esquemas representativos dos tipos de consultas por similaridade. . . . . . 20

2.11 Resumo do histórico da evolução da Realidade Virtual (Rizzato, 2007). . . 21

2.12 Exemplos de dispositivos de entrada. . . . . . . . . . . . . . . . . . 24

2.13 Exemplos de dispositivos de entrada. . . . . . . . . . . . . . . . . 24

2.14 Exemplos de dispositivos de entrada. . . . . . . . . . . . . . . . . . . . 25

2.15 Exemplos de dispositivos de saída. . . . . . . . . . . . . . . 26

2.16 Exemplos de dispositivos de saída. . . . . . . . . . . . . . . . 27

2.17 Exemplos de dispositivos de saída. . . . . . . . . . . . . . . . . . 28

2.18 Realidade e virtualidade contínuas (Kirner e Tori, 2004). . . . . . . . . . . 29

2.19 Visão geral de um sistema de RV (Pinho e Kirner, 1998). . . . . . . . . . . 29

2.20 Estrutura detalhada de um sistema de RV (Pinho e Kirner, 1998). . . . . . 30

2.21 Camadas de abstração em um sistema de RV (Calonego Jr et al., 2004). . . 31

4.1 Imagens de cérebro obtidas por diferentes modalidades (Sayeg, 2010). . . . 45

4.2 Objetos modelados para simulação de punção mamária (Lima, 2004). . . . 53

4.3 Interface para seleção de caso para estudo (Lima, 2004). . . . . . . . . . . 53

4.4 Interface para treinamento do procedimento de punção (Lima, 2004). .. . 54

4.5 Interface disponibilizada na finalização do treinamento (Lima, 2004). . . . 54

4.6 Diagrama do projeto arquitetural do ViMeT (Oliveira e Nunes, 2010). . . . 56

4.7 Diagrama de classes da versão atual do ViMeT (Corrêa e Nunes, 2009). . . 57

4.8 ViMeTWizard: aplicação e objetos (Oliveira e Nunes, 2010). . . . . . . . . 58

4.9 ViMeTWizard: funcionalidades e dispositivos (Oliveira e Nunes, 2010). . . 59

4.10 ViMeTWizard : geração de código e aplicação (Oliveira e Nunes, 2010). . . 60

4.11 Aplicações geradas: punção de mama (Oliveira e Nunes, 2010). . . . . . . . 60 
4.12 Aplicações geradas: punção de nádegas (Oliveira e Nunes, 2010) . . . . . . 61

4.13 Interação da versão atual do ViMeT (Corrêa e Nunes, 2009). . . . . . . . . 61

4.14 ViMeT: interação com dispositivos convencionais (Corrêa et al., 2009). . . 61

4.15 ViMeT: dispositivos não convencionais (Corrêa et al., 2009). . . . . . . . . 62

4.16 Imagens mamográficas para gerar estudos de caso (Delfino, 2007). . . . . . 63

4.17 Imagens mamográficas após a segmentação (Delfino, 2007). . . . . . . . . . 64

4.18 Posições de vértices adquiridos da imagem mamográfica (Delfino, 2007). . . 64

4.19 Código fonte para representar a mama no formato obj (Delfino, 2007). . . 66

4.20 Imagem mamográfica com o nódulo demarcado (Delfino, 2007). . . . . . . 66

4.21 Modelos wireframe da mama (Delfino, 2007) . . . . . . . . . . . . 66

4.22 Modelos wireframe do nódulo (Delfino, 2007) . . . . . . . . . . . . . 67

4.23 Ambiente Virtual para treinamento (Delfino, 2007) . . . . . . . . . . . 67

4.24 Ambiente Virtual para treinamento - modo wireframe (Delfino, 2007). . . . 68

4.25 Exemplo de navegação no Atlas Virtual da Mama (Ramos et al., 2005b). 69

4.26 Informação exibida no Atlas Virtual da Mama (Ramos et al., 2005b). . . . 70

4.27 Desenvolvimento de carcinoma (Ramos et al., 2005b) . . . . . . . . . . . . 70

4.28 Câncer desenvolvendo-se em diferentes estruturas (Ramos et al., 2005b). 71

4.29 Interação direta do usuário com estruturas 3D (Tori et al., 2009a). . . . . . 71

4.30 Arquitetura do Sistema VIDA (Tori et al., 2009a) . . . . . . . . . . . . . 72

4.31 Interface gráfica para geração de aplicações. . . . . . . . . . . . . . 73

4.32 Atlas virtual para área de Obstetrícia (Nunes et al., 2010). . . . . . . . . . 74

4.33 Interface inicial do jogo com pontuação e tempo. . . . . . . . . . . . . . . 76

4.34 Utilização de perguntas para mudar de fase. . . . . . . . . . . . . . . 76

5.1 Estrutura do sistema de visualização de estruturas fetais (Luz, 2004). . . . 79

5.2 Processamento para extração de medidas de imagens 2D de US (Luz, 2004). 80

5.3 Fluxo de processamento para gerar o Ambiente Virtual (Hermosilla, 2004). 81

5.4 Interface que recebe medidas para gerar estruturas 3D (Hermosilla, 2004). . 81

5.5 Exemplos de visualização de feto (Hermosilla, 2004) . . . . . . . . . . . . . 82

5.6 Estrutura da ferramenta VRVis (Berti, 2004). . . . . . . . . . . . . . 83

5.7 Ferramenta VRVis - seleção de parâmetros para consultas (Berti, 2004). . 84

5.8 Resultado textual de uma consulta e seleção de metáfora (Berti, 2004). . . 84

5.9 Visualização do resultado de consultas com metáforas (Berti, 2004). . . . . 85

5.10 Acesso aos dados de um registro com ferramenta VRVis (Berti, 2004). . . . 86

5.11 Estrutura da Ferramenta VRVis Manager (Santos, 2010). . . . . . . . . . . 87

5.12 Seleção e armazenamento de imagem para metáfora (Santos, 2010). . . . . 87

5.13 Interface para conexão com SGBD - VRVis Manager (Santos, 2010). . . . 88

5.14 Seleção da tabela principal e visão dos relacionamentos (Santos, 2010). . 88

5.15 Seleção de dados e parâmetros para compor cena 3D (Santos, 2010). . . . . 89

5.16 Escolha de atributos para criação de metáfora (Santos, 2010). . . . . . . . 89

5.17 Cena 3D resultante de uma consulta (Santos, 2010) . . . . . . . . . . . . 90

5.18 Cena 3D resultante de uma consulta (Santos, 2010) . . . . . . . . . . . . 91

5.19 Diagrama Entidade-Relacionamento do sistema de CBIR (Santos, 2006). . 92

5.20 Interface para recuperação de imagens (Santos, 2006). . . . . . . . . . . . 94

5.21 Esquema lógico de um sistema Fuzzy (Junges, 2006). . . . . . . . . . . . . 95

5.22 Interface para executar realimentação por relevância (Bergamasco, 2010). . 97

5.23 Interação do usuário com sistema (Bergamasco, 2010). . . . . . . . . . . . 98 
5.24 Uso da lógica Fuzzy na realimentação por relevância (Bergamasco, 2010). . 99

5.25 Fluxo para a busca de imagens na Internet (Moraes, 2010) . . . . . . . . . 100

5.26 Fluxo para a busca de imagens similares (Moraes, 2010). . . . . . . . . . . 100

5.27 Funcionamento da técnica transformação área-ponto (Moraes, 2010). . . 102

5.28 Interface para busca por conteúdo na Internet (Moraes, 2010). . . . . . . . 103

5.29 Exemplo de imagens usadas no estudo de caso (Nunes et al., 2009a). . . . . 106

5.30 Arquitetura da Ferramenta O-FIm (Oliveira et al., 2009a). . . . . . . . . 108

5.31 Interface IExtractor. . . . . . . . . . . . . . . . . . . . . . . . . . . . . . . 109

5.32 Interface ISimilarity. . . . . . . . . . . . . . . . . . . . . . . . . . . 110

5.33 Interface gráfica do framework O-FIm. . . . . . . . . . . . . . 110

5.34 Arquivo para execução de aplicação usando O-FIm (Oliveira et al., 2009a). 110 


\section{Lista de Abreviaturas e Siglas}

$\begin{array}{ll}\text { 2D } & - \text { Bidimensional } \\ \text { 3D } & - \text { Tridimensional } \\ \text { 4D } & - \text { Quadridimensional } \\ \text { ACM } & - \text { Association for Computing Machinery } \\ \text { API } & - \text { Application Programming Interface } \\ \text { AV } & - \text { Ambiente Virtual } \\ \text { AVC } & - \text { Acidente Vascular Cerebral } \\ \text { BD } & - \text { Banco de Dados } \\ \text { CAD } & - \text { Computer-Aided Diagnosis } \\ \text { CAVE } & - \text { Cave Automatic Virtual Environment } \\ \text { CBEB } & - \text { Congresso Brasileiro de Engenharia Biomédica } \\ \text { CBIR } & - \text { Content-Based Image Retrieval } \\ \text { CBIS } & - \text { Congresso Brasileiro de Informática em Saúde } \\ \text { CC } & - \text { Crânio-Caudal } \\ \text { CG } & - \text { Computação Gráfica } \\ \text { CNPq } & - \text { Conselho Nacional de Desenvolvimento Científico e Tecnológico } \\ \text { DICOM } & - \text { Digital Imaging and Communications in Medicine } \\ \text { ES } & - \text { Engenharia de Software } \\ \text { FE } & - \text { Finite Elements } \\ \text { FFD } & - \text { Free Form Deformation } \\ \text { GPU } & - \text { Graphics Processing Unit } \\ \text { GWT } & - \text { Google Web Toolkit } \\ \text { HMD } & - \text { Head-Mounted Display } \\ \text { IEEE } & - \text { Institute of Electrical and Electronics Engineers } \\ \text { INCT } & - \text { Instituto Nacional de Ciência e Tecnologia } \\ \text { JAI } & - \text { Java Advanced Imaging } \\ \text { JNI } & - \text { Java Native Interface } \\ \text { LAPIMO } & - \text { Laboratório de Processamento de Imagens Médicas e Odontológicas } \\ \text { LApIS } & - \text { Laboratório de Aplicações de Informática em Saúde } \\ \text { LOD } & - \text { Level Of Detail } \\ & -\end{array}$




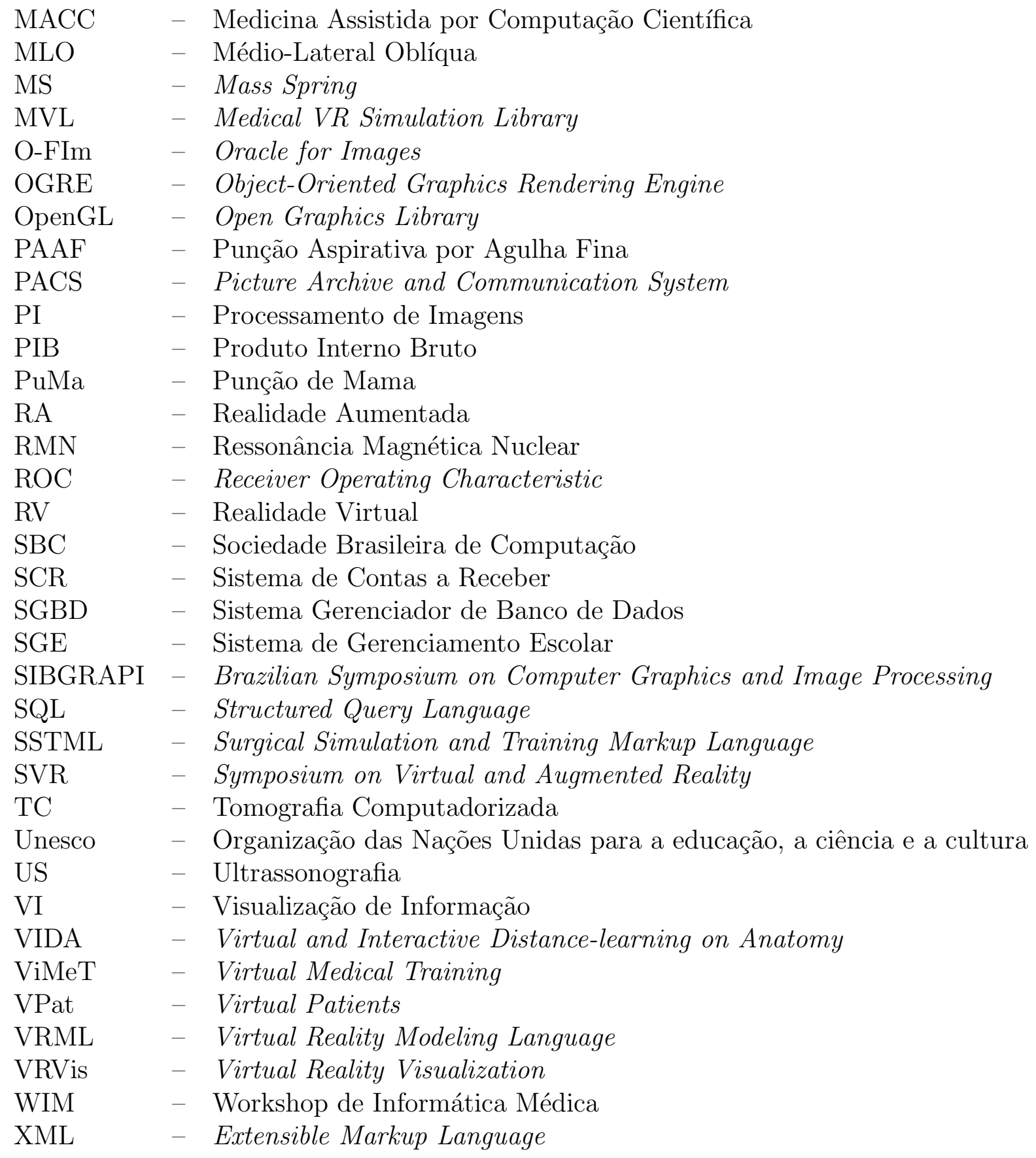




\section{Lista de Tabelas}

5.1 Extratores para recuperação de imagens mamográficas (Santos, 2006). . . . 92

5.2 Extratores de cor para imagens faciais (Bergamasco, 2010) . . . . . . . . 96

5.3 Extratores de textura para imagens faciais (Bergamasco, 2010). . . . . . 97

5.4 Extratores de forma para imagens faciais (Bergamasco, 2010) . . . . . . . . 97

5.5 Extratores para recuperação de imagens na Internet (Moraes, 2010). . . . . 101 


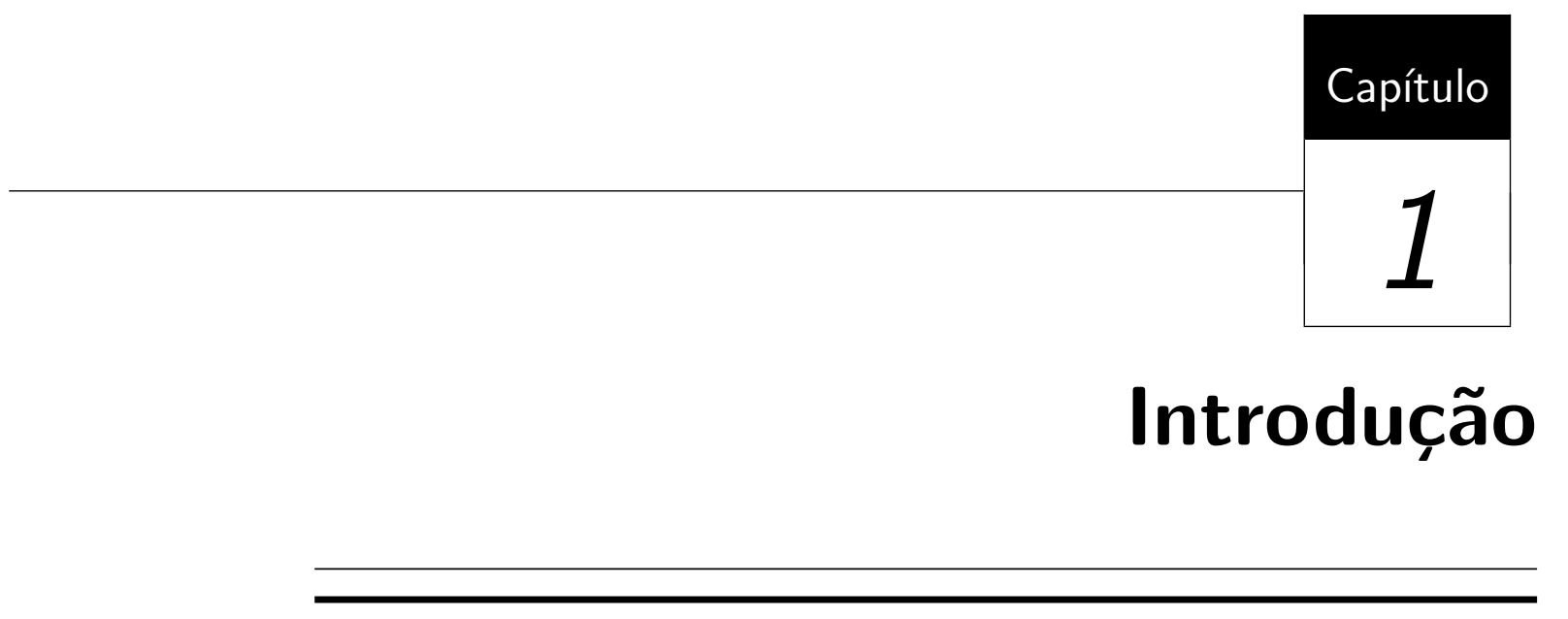

\subsection{Contextualização}

Há duas ou três décadas era possível um profissional de Computação dominar todas as técnicas e práticas da área devido à simplicidade de máquinas, sistemas operacionais e aplicações. No entanto, nos últimos anos foi percebida a intensa especialização do conhecimento na área, de tal forma que tornou-se premente a escolha do campo de atuação profissional a um estudante de graduação no final do seu curso ou até mesmo em fases mais precoces, visto que as exigências profissionais e sociais têm exigido uma integração eficaz entre competências e conhecimento (Rezende et al., 2005).

Se por um lado a especialização permite o conhecimento aprofundado em determinada área e facilita a solução de problemas dentro daquele contexto, por outro lado essa realidade faz com que o desenvolvimento de projetos automatizados torne-se cada vez mais uma atividade inter e multidisciplinar, envolvendo vários profissionais para resolver um problema que exige conhecimentos de diversos campos de atuação. A concretização de um grande Sistema de Informação, por exemplo, nos dias atuais envolve profissionais especialistas em banco de dados, engenharia de software, redes de computadores, entre outros, além dos profissionais provenientes da área de aplicação.

A Computação tem permitido a realização de tarefas inviáveis há algumas décadas. Previsões do tempo usando complexos modelos matemáticos, simulações na indústria, ferramentas de vanguarda para o ensino, armazenamento e recuperação de dados mul- 
timídia, diagnósticos precisos em tempo real, visualização de grandes volumes de dados provenientes dos mais variados fenômenos, constituem alguns exemplos de aplicações que se tornaram possíveis somente com o avanço da Computação.

Observando a evolução da Computação em termos de hardware e a complexidade das aplicações computacionais atuais, é possível afirmar que os demais campos do conhecimento contribuíram, ou até mesmo forçaram, tal desenvolvimento. Dentro desse contexto, verifica-se que a área de saúde e, especialmente a Medicina, muito tem se beneficiado com as aplicações computacionais.

Sistemas de auxílio ao diagnóstico (CAD - Computer-Aided Diagnosis) usando técnicas de processamento de imagens, reconhecimento de padrões e inteligência computacional, visualização de imagens bidimensionais e tridimensionais do corpo humano, visualização de exames sofisticados em curto espaço de tempo, recuperação de imagens baseada em conteúdo e, mais recentemente, sistemas usando tecnologias de Realidade Virtual, têm permitido diagnósticos mais precisos e rápidos, além de substanciais contribuições ao treinamento, ensino, visualização de estruturas, planejamento de terapias, simulação, entre outras ações na área de saúde.

Há alguns anos, a Sociedade Brasileira de Computação (SBC) realizou um primeiro seminário que discutiu os "Grandes Desafios em Computação no Brasil" (SBC, 2006) inspirado em iniciativas semelhantes, ocorridas em outras partes do mundo, tais como o Grand Research Challengers in Computing, realizado nos EUA e na Inglaterra (NRC, 2006).

Esses eventos promovidos ou divulgados pela SBC visam a estimular a reflexão sobre questões fundamentais da Ciência da Computação e de suas aplicações em outras áreas, que não podem ser resolvidas por pesquisas que objetivam resultados de curto prazo. Assim, foram discutidos os múltiplos enfoques necessários para resolver grandes desafios que deverão ser pesquisados a longo prazo. A identificação de grandes desafios de pesquisa estimulam a formulação de projetos que têm o potencial de produzir avanços significativos no campo científico, com aplicações sociais e tecnológicas de grande valor (SBC, 2006).

Os cinco desafios propostos pela SBC foram:

1. Gestão da Informação em grandes volumes de dados multimídia distribuídos;

2. Modelagem computacional de sistemas complexos artificiais, naturais e sócio-culturais e da interação homem natureza;

3. Impactos para a área da computação da transição do silício para novas tecnologias;

4. Acesso participativo e universal do cidadão brasileiro ao conhecimento; 
5. Desenvolvimento tecnológico de qualidade: sistemas disponíveis, corretos, seguros, escaláveis, persistentes e ubíquos.

Paralelamente, verifica-se que o desenvolvimento tecnológico vem alterando diversas práticas na área de saúde, associadas a atividades terapêuticas, cirúrgicas ou de formação e atualização profissional. Esses sistemas têm requerido alterações constantes dos fluxos de informação, dos processos de treinamento e capacitação, exigindo o desenvolvimento de novas habilidades pelos profissionais da área (Nunes e Costa, 2008b).

O trabalho inter e multidisciplinar entre especialistas da área da saúde e da área de Ciência da Computação tem gerado diversas ferramentas e ambientes computacionais. Especificamente, as tecnologias de Processamento de Imagens (PI) e Realidade Virtual (RV) vêm permeando a área da saúde, trazendo novas possibilidades de desenvolvimento de sistemas, interação, composição e visualização tridimensional (3D) de imagens.

Nos últimos anos, essas especialidades experimentaram um grande crescimento em quantidade e qualidade das aplicações para a área médica. Tal fato se deve fundamentalmente à diminuição do preço do hardware, à evolução das linguagens de programação e dos ambientes de autoria (Nunes e Costa, 2008b), refletindo diretamente no setor produtivo do país. De fato, algumas áreas de conhecimento já têm usado PI e RV em tarefas cotidianas e algumas empresas de desenvolvimento de software estão sendo criadas - compostas, em geral, por pesquisadores provenientes de universidades - com o objetivo de utilizar técnicas avançadas de Computação nos seus produtos.

Mesmo com o otimismo exposto nos parágrafos anteriores, verifica-se que no Brasil as aplicações que empregam PI e RV na área de saúde ainda são incipientes, restringindo-se, na maioria das vezes, a investigações científicas em centros de pesquisas ligados a universidades. O risco inerente no uso dessas aplicações (principalmente quando destinadas a auxiliar diagnósticos e definir terapias) é um dos grandes desafios que justificam esse aparente entrave. Se por um lado tal questão pode ser interpretada como um obstáculo, por outro lado, configura-se como grande oportunidade de desenvolvimento de pesquisa científica e possibilidade de transferência de tecnologia para o setor produtivo, podendo gerar novos produtos, patentes e empregos.

O que também decorre do contexto apresentado é a necessidade de formação de recursos humanos com capacidade para trabalhar nessas novas áreas que começam a surgir. Algumas iniciativas em relação a cursos de graduação e pós-graduação, claramente multidisciplinares, já são observadas. Exemplos são os cursos de graduação em Informática Biomédica, Informática e Saúde, Biotecnologia e Bioengenharia ${ }^{1}$, além dos diversos cursos de pós-graduação em computação aplicada ou com denominações afins percebidos no país.

\footnotetext{
${ }^{1} \mathrm{~A}$ relação de todos os cursos superiores de instituições credenciadas no Brasil pode ser obtida no endereço http://emec.mec.gov.br/.
} 


\subsection{Objetivos}

O presente documento tem o objetivo de apresentar e discutir técnicas e ferramentas de Processamento de Imagens e Realidade Virtual, aplicadas à área de saúde, salientando-se requisitos, desafios e oportunidades. A partir de uma compilação de ferramentas e métodos desenvolvidos no período iniciado após o doutorado da autora, é tecida uma reflexão sobre os desafios existentes para desenvolver sistemas computacionais especificamente nesse contexto, para que, ao final, possam ser apresentadas oportunidades de pesquisa e desenvolvimento.

Como objetivos específicos destacam-se:

- apresentar aspectos conceituais e de implementação envolvidos nas especialidades computacionais abrangidas;

- tecer um comparativo entre o estado da arte do Brasil em relação a centros de pesquisa estabelecidos internacionalmente, de forma a identificar oportunidades e desafios;

- identificar requisitos a serem preenchidos e tecnologias envolvidas na construção de ferramentas computacionais dentro do escopo considerado;

- apresentar trabalhos de pesquisa realizados que pretendem contribuir para superar os desafios da área;

- mostrar como as áreas de aplicação (no caso, a área de saúde) contribuem com o desenvolvimento da Computação e como a Computação pode alavancar o desenvolvimento das áreas de aplicação;

- discutir como o relacionamento entre essas duas grandes áreas podem contribuir para o desenvolvimento do país.

\subsection{Justificativas}

Nos últimos anos, verifica-se na comunidade científica brasileira de Computação um crescimento de técnicas e métodos desenvolvidos para resolver problemas específicos de várias áreas de aplicação. Um forte indício dessa tendência pode ser verificado analisando-se os títulos de projetos aprovados na divulgação pública dos resultados de editais dos órgãos de fomento. Outro indício é a formação de Comissões Especiais relacionadas com determinados domínios de aplicação, como biologia, saúde e música, no âmbito da Sociedade 
Brasileira de Computação² ${ }^{2}$ Recentemente, o Ministério de Ciência e Tecnologia, por intermédio do Conselho Nacional de Desenvolvimento Científico e Tecnológico (CNPq) e com parcerias de outros órgãos de fomento governamentais lançou um edital para criação de Institutos Nacionais de Ciência e Tecnologia (Edital No 15/2008 do MCT, CNPq, FNDCT, CAPES, FAPEMIG, FAPERJ e FAPESP).

Dentro do edital citado, foi aprovado o Instituto Nacional de Ciência e Tecnologia em Medicina Assistida por Computação Científica (INCT-MACC), sediado no Laboratório Nacional de Computação Científica do Ministério de Ciência e Tecnologia (LNCC/MCT) e tendo vários laboratórios brasileiros como associados da empreitada. De forma inédita no Brasil são reunidos em um grande projeto pesquisadores de todo o país que dedicam suas pesquisas ao desenvolvimento de técnicas computacionais para a área de saúde. Um dos laboratórios associados é o Laboratório de Aplicações de Informática em Saúde (LApIS) (LApIS, 2011), sediado na Escola de Artes, Ciências e Humanidades da Universidade de São Paulo (EACH-USP), que tem a autora deste documento como coordenadora.

A partir dessas considerações, verifica-se a importância que o tema tem alcançado dentro do atual estágio de desenvolvimento tecnológico, econômico e social do país, assim como no planejamento estratégico em relação ao panorama de pesquisa que visa a contribuir com este desenvolvimento. Dessa forma, a reunião de métodos e técnicas relacionados a PI e RV aplicados à área de saúde contribui para que sejam disponibilizados conteúdo e ferramentas, favorecendo o aumento da produtividade das pesquisas na área, em termos de revisão bibliográfica, desenvolvimento e documentação.

As ferramentas citadas, apresentadas ao longo do presente documento, são construídas com software livre e têm seu código aberto, de forma que a comunidade interessada na área possa obter informações e material de natureza diversas para desenvolvimento de pesquisas no campo de aplicação considerado. A partir do presente trabalho está sendo criado um portal na EACH-USP (LApIS, 2011), a fim de disponibilizar o material e as ferramentas apresentadas, de forma a contribuir efetivamente com a produtividade citada.

\subsection{Organização do documento}

Além desta Introdução, este documento é composto pelos seguintes capítulos:

- Capítulo 2 - Aspectos Conceituais sobre PI e RV: disponibiliza conceitos sobre Processamento de Imagens, Recuperação de Imagens Baseada em Conteúdo e Realidade Virtual;

\footnotetext{
${ }^{2}$ http://www.sbc.org.br
} 
- Capítulo 3 - Processamento gráfico aplicado na área de saúde: cita trabalhos recentes de Computação aplicada à área de saúde, considerando técnicas de processamento gráfico cujos conceitos foram abordados no Capítulo 2;

- Capítulo 4 - Realidade Virtual em treinamento médico: aborda tópicos sobre treinamento virtual, especificamente abrangendo a área de saúde, envolvendo pré-requisitos, técnicas, tecnologias e ferramentas desenvolvidas no âmbito das pesquisas conduzidas pela autora e sua equipe;

- Capítulo 5 - CAD, Visualização de Informação e CBIR: descreve ferramentas e aplicações que não se enquadram em treinamento virtual, mas que usam conceitos de PI e RV nas suas implementações, ora considerados separadamente, ora considerados em conjunto;

- Capítulo 6 - Desafios e oportunidades: retoma as áreas abordadas nos Capítulos anteriores, indicando obstáculos que ainda devem ser vencidos, considerando o cenário brasileiro, e que, por este motivo, constituem oportunidades tanto de pesquisa quanto de desenvolvimento de produtos industriais;

- Capítulo 7 - Conclusões: apresenta as considerações finais do documento.

Ao final, são listadas as referências bibliográficas citadas nos capítulos que compõem o documento. 


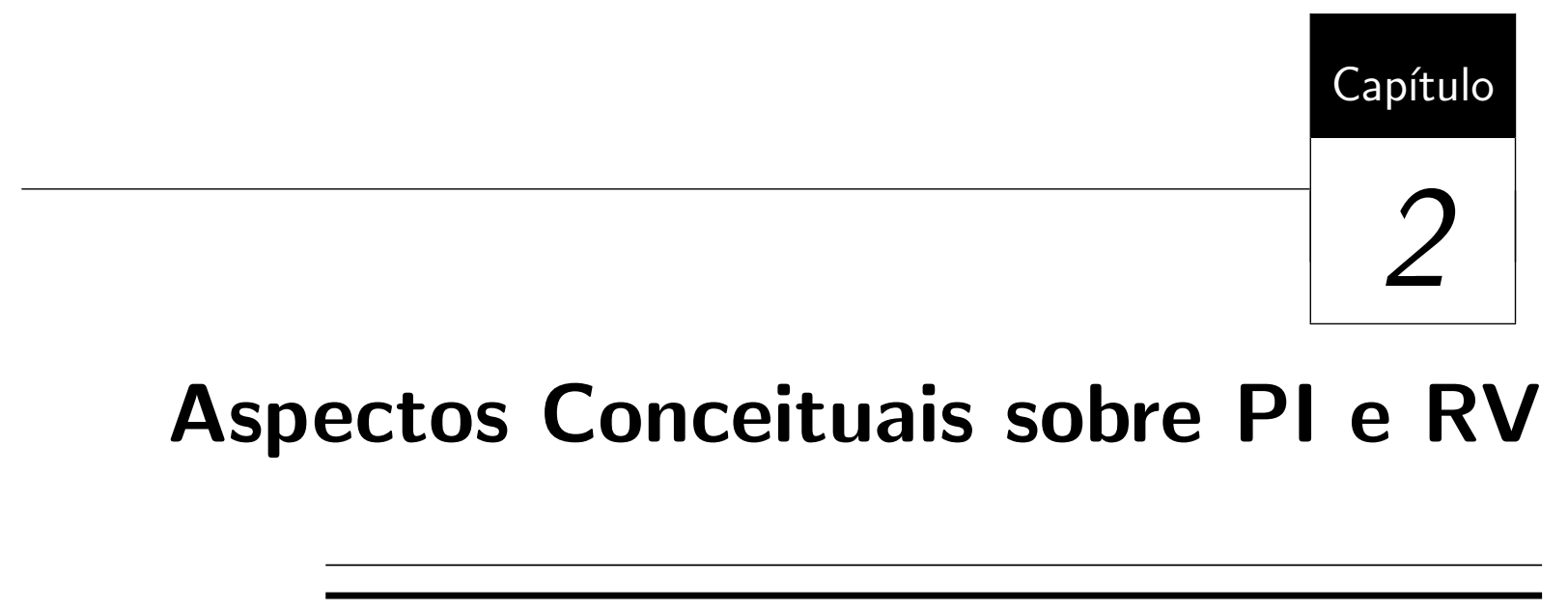

São muitas as áreas da Computação que contribuem para a definição e implementação de ferramentas para as mais diversas finalidades no âmbito da saúde. Neste capítulo são apresentados conceitos sobre Processamento de Imagens e Realidade Virtual, que constituem o foco principal do presente documento. É disponibilizada, ainda, uma introdução sobre Recuperação de Imagens Baseada em Conteúdo, que utiliza técnicas de PI, mas também exige o conhecimento de conceitos sobre bancos de dados.

Engenharia de software, banco de dados, inteligência artificial, reconhecimento de padrões, redes de computadores e sistemas distribuídos somam-se às áreas que têm contribuído com o desenvolvimento de aplicações para a saúde, complementando as anteriormente mencionadas. No entanto, essas últimas são apenas citadas pontualmente em algumas aplicações, visto que são secundárias para a compreensão das ferramentas apresentadas nos capítulos posteriores, responsáveis por compilar as pesquisas realizadas pela autora nos últimos anos.

\subsection{Processamento de Imagens}

Gonzalez e Woods (2007) definem Processamento de Imagens como um vasto conjunto de operações que podem ser aplicadas em uma representação matemática de uma imagem.

Na literatura há várias obras clássicas de PI que apresentam com propriedade as definições e os conceitos da área. Ultimamente têm surgido algumas contribuições de pesqui- 
sadores brasileiros que se dedicam, com sucesso, a apresentar conceitos de forma prática e objetiva. Dentre esses, merecem destaque Pedrini e Schwartz (2007) e Gomes e Velho (2002). O conteúdo a seguir tem como base principalmente Gonzalez e Woods (2007), Ballard e Brown (1982) e Russ (2002).

Ballard e Brown (1982) lembram que a formação da imagem ocorre quando um sensor registra a radiação que interagiu com objetos físicos. A imagem é uma representação do objeto físico que pode ser armazenada, manipulada e interpretada de acordo com as necessidades do interessado.

No domínio espacial a maioria das imagens digitais considera o espaço bidimensional, no qual define-se uma imagem como $f(x, y)$, onde $x$ e $y$ são as coordenadas espaciais. O valor de $f$ na coordenada espacial $(x, y)$ fornece a intensidade, ou seja, o brilho da imagem no ponto. Os valores assumidos em cada ponto discretizado são quantificados em um número pertencente a uma escala de valores que representam cores. Em grande parte das aplicações computacionais essas cores são relacionadas a níveis de cinza, sendo atribuído o valor zero ao menor valor de intensidade e o valor máximo $M$ à cor que representa a maior intensidade da escala usada. Comumente, o valor zero é relacionado à cor preta e o valor máximo é relacionado à cor branca. Dessa forma, pode-se representar uma imagem como uma matriz na qual cada ponto é um valor discreto, conforme é mostrado na Equação 2.1 , onde $n$ e $m$ correspondem à quantidade de colunas e linhas, respectivamente.

$$
f(x, y)=\left(\begin{array}{cccc}
f(0,0) & f(0,1) & \ldots & f(0, n) \\
f(1,0) & f(1,1) & \ldots & f(1, n) \\
\ldots & \ldots & \ldots & \ldots \\
f(m, 0) & f(m, 1) & \ldots & f(m, n)
\end{array}\right)
$$

O objetivo de definir matematicamente a imagem é a possibilidade de manipular o seu conteúdo a fim de transformá-la ou retirar dela informações importantes.

Cada ponto ou elemento constituinte da matriz-imagem é chamado de "pixel" (uma abreviação do termo em inglês picture element). O pixel é, então, a menor unidade sobre a qual é possível realizar operações. Para essas operações são definidas algumas relações básicas como vizinhança, adjacência, conectividade e distância, importantes para implementação de algoritmos utilizados durante a extração de características da imagem.

As técnicas de PI são, em geral, divididas em três níveis, cada qual com suas funções específicas: processamento de baixo nível, responsável pela remoção de dados indesejáveis e realce de dados importantes; processamento de nível médio, responsável pela identificação de formas significativas - a esse processo dá-se o nome de "segmentação" e processamento de alto nível, responsável pela ligação da imagem com alguma base de conhecimento. 
A manipulação de imagens digitais pode ser efetuada no domínio da frequência ou no domínio espacial. As técnicas de processamento de imagem que trabalham no domínio espacial são aplicadas diretamente nos pixels da imagem. As técnicas que trabalham no domínio da frequência têm como princípio básico o teorema da convolução, efetuando-se alterações na transformada de Fourier da imagem. Em geral, o domínio da frequência exige uma maior complexidade matemática, mas o processamento é mais rápido. O domínio espacial não exige grande complexidade matemática, mas requer quantidade maior de processamento. A abordagem adotada no presente documento é relacionada ao domínio espacial, no qual os pixels são considerados como uma matriz de atributos numéricos, conforme definido anteriormente. Técnicas no domínio da frequência são abordadas em Gonzalez e Woods (2007) e Russ (2002).

Para que operações possam ser definidas sobre pixels, é necessário estabelecer algumas relações básicas entre eles, listadas a seguir.

\subsubsection{Relações entre pixels}

Alguns conceitos são importantes para definir como pixels se relacionam no domínio espacial, visto que são utilizados amplamente na implementação de algoritmos de PI: vizinhança, adjacência, conectividade e distância. Na Figura 2.1 é ilustrado o conceito de vizinhança de um pixel. Seja $p$ um pixel com coordenadas $(x, y)$ :

- vizinhança de 4 do pixel $p$ - ou $N 4(p)$ : é composta por seus vizinhos de coordenadas $(x+1, y),(x-1, y),(x, y+1),(x, y-1)$;

- vizinhança diagonal do pixel $p-o u N D(p)$ : é composta por seus vizinhos de coordenadas: $(x+1, y+1),(x+1, y-1),(x-1, y+1),(x-1, y-1)$;

- vizinhança de 8 - ou $N 8(p)$ - do pixel $p$ : é composta pelo conjunto de todos os pixels vizinhos, ou seja, $N 4(p) \cup N D(p)$.

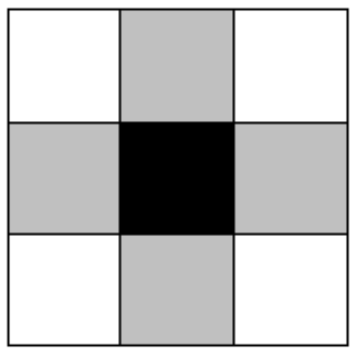

(a) Vizinhança de 4

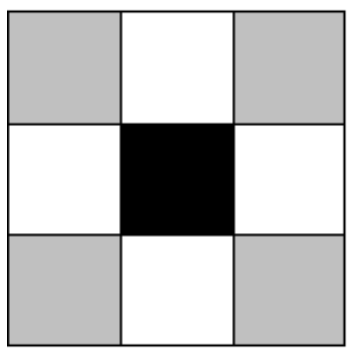

(b) Vizinhança diagonal

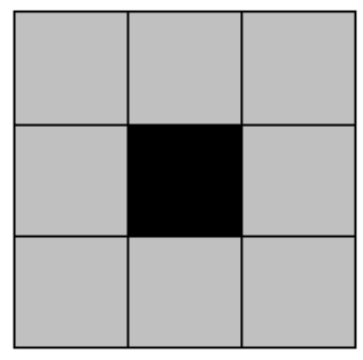

(c) Vizinhança de 8

Figura 2.1: Ilustração do conceito de vizinhança. 
A adjacência é característica de um par de pixels vizinhos que compartilham uma borda ou um vértice, sendo que:

- um par de pixels que compartilha uma borda é dito "adjacente por borda" ou "4-adjacente";

- um par de pixels que compartilha um vértice é dito "adjacente por vértice" ou "8-adjacente".

Na Figura 2.1(a), por exemplo, os pixels de cor cinza são 4-adjacentes do pixel de cor preta porque compartilham uma borda com ele. Também são 8-adjacentes porque compartilham pelo menos um vértice com este pixel. Na mesma figura, os pixels brancos são somente 8-adjacentes do pixel preto, pois compartilham somente um vértice com o mesmo.

A conectividade é um importante conceito usado para estabelecer bordas de objetos e componentes de regiões em uma imagem. Dois pixels são conectados se:

- são adjacentes e;

- obedecem a um critério de similaridade dentro de uma escala de cor, isto é, seus valores estão dentro de um conjunto pré-estabelecido de valores.

Seja $V=\left\{G_{1}, G_{2}, \ldots, G_{k}\right\}$ o conjunto de $k$ valores de níveis de cinza usado para definir a conectividade. São definidos três tipos de conectividade:

- Conectividade-4: dois pixels $p$ e $q$ com valores em $V$ e $q \in N 4(p)$;

- Conectividade-8: dois pixels $p$ e $q$ com valores em $V$ e $q \in N 8(p)$;

- Conectividade-m: dois pixels $p$ e $q$ com valores em $V$ e:

$\Rightarrow q \in N_{4}(p)$ ou

$\Rightarrow q \in N D(p)$ e $N_{4}(p) \cap N 4(q)=\emptyset$.

A distância $d(x, y)$ entre pixels é um valor mensurável, constituindo uma importante definição para grande parte dos algoritmos que manipulam a imagem. Gonzalez e Woods (2007) definem que:

- $d(x, y)=0$, se $x=y$;

- $d(x, y)=d(y, x)$

- $d(x, y)+d(y, z) \geq d(x, z)$. 
Há diversas equações empregadas para a definição de distância e na literatura novas métricas são definidas e adaptadas para aplicações específicas. Algumas das métricas mais conhecidas, aplicadas para dois pixels $p=\left(x_{p}, y_{p}\right)$ e $q=\left(x_{q}, y_{q}\right)$ são:

- Distância Euclidiana:

$$
d(p, q)=\sqrt{\left(x_{p}-x_{q}\right)^{2}+\left(y_{p}-y_{q}\right)^{2}}
$$

- Distância City Block:

$$
d(p, q)=\left|\left(x_{p}-x_{q}\right)\right|+\left|\left(y_{p}-y_{q}\right)\right|
$$

- Distância Chessboard:

$$
d(p, q)=\max \left\{\left|\left(x_{p}-x_{q}\right)\right|,\left|\left(y_{p}-y_{q}\right)\right|\right\}
$$

\subsubsection{Histograma de uma imagem}

O histograma de uma imagem é uma função que fornece a frequência de cada nível de cinza na imagem, como exemplificado graficamente na Figura 2.2. Considerando uma imagem com cores dentro de uma escala de níveis de cinza, o valor do histograma em um nível $k$, dado por $H(k)$, é a quantidade de pixels da imagem com o valor $k$ de nível de cinza.

Esse recurso é útil para identificar e auxiliar na definição de alterações globais na imagem, porém, não é possível aplicá-lo em processamentos que necessitem de conhecimento sobre a localização de pixels, uma vez que esta informação não está disponível no gráfico construído. Várias técnicas de PI têm o histograma como a estrutura básica de manipulação. Alguns exemplos são apresentados adiante.

\subsubsection{Implementação de filtros}

Os conceitos anteriores são amplamente empregados na construção de filtros para PI. No domínio espacial, um filtro nada mais é do que um cálculo matemático realizado sobre os pixels da matriz da imagem.

Um outro conceito importante antes da apresentação de alguns exemplos de filtros é o template ou, simplesmente, máscara. Gonzalez e Woods (2007) definem um template como uma máscara utilizada para a realização de operações na vizinhança de um pixel. Na prática, é uma matriz cujo elemento central é posicionado no pixel de interesse. Os elementos da vizinhança, incluindo o pixel em questão, são multiplicados pelos valores 


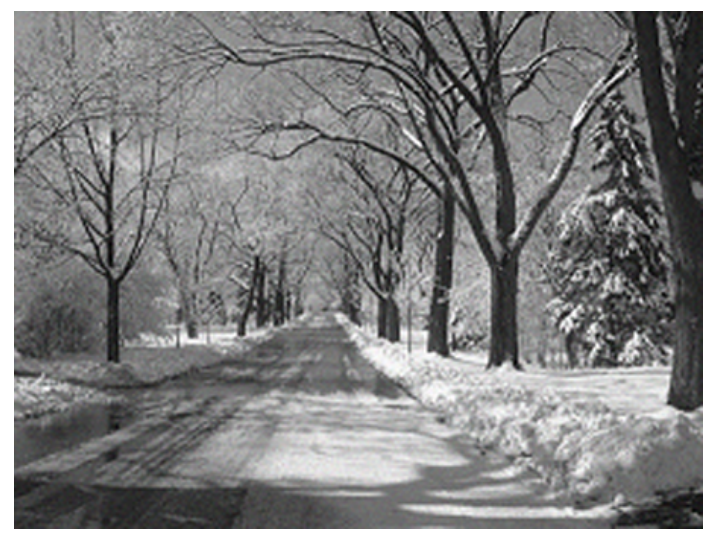

(a) imagem em níveis de cinza

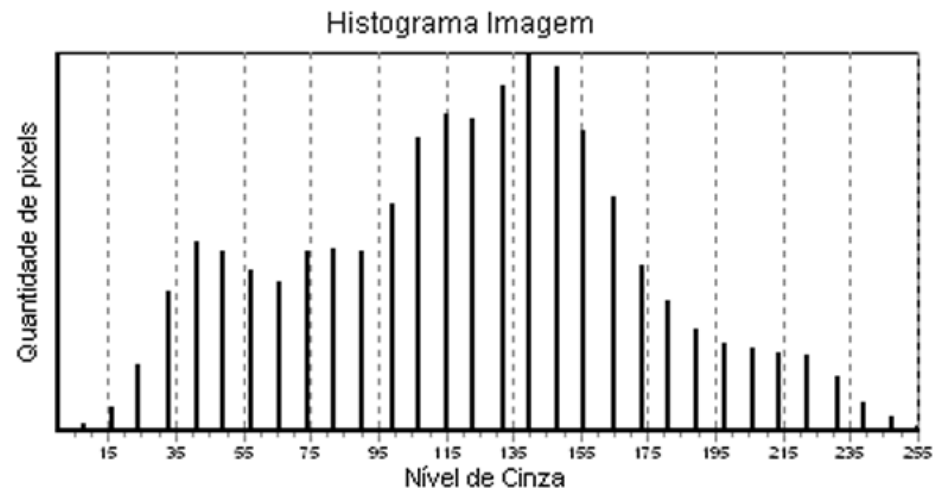

(b) histograma da imagem representada

Figura 2.2: Exemplo de histograma.

indicados nas posições correspondentes da matriz. A soma dos resultados obtidos substitui o valor do pixel de interesse na imagem resultante. Exemplificando, uma máscara de tamanho 3 x 3 pode ser representada da forma indicada na Figura 2.3.

\begin{tabular}{|l|l|l|}
\hline$w_{1}$ & $w_{2}$ & $w_{3}$ \\
\hline$w_{4}$ & $w_{5}$ & $w_{6}$ \\
\hline$w_{7}$ & $w_{8}$ & $w_{9}$ \\
\hline
\end{tabular}

Figura 2.3: Exemplo genérico de uma máscara 3 x 3 .

Considerando $w_{i}, i=1, \ldots, 9$ os coeficientes da máscara em questão e $x_{i}, i=1, \ldots, 9$ os valores dos pixels representados na máscara, o resultado que será atribuído ao pixel central resultante será: $w_{1} \cdot x_{1}+w_{2} \cdot x_{2}+\ldots+w_{9} \cdot x_{9}$. Um algoritmo genérico para aplicação de um template é apresentado na Figura 2.4.

\subsubsection{Processamento de baixo nível}

Partindo do princípio de que a vizinhança de pixels na imagem tem parâmetros físicos semelhantes, o processamento de baixo nível visa à exploração da redundância presente nessa 


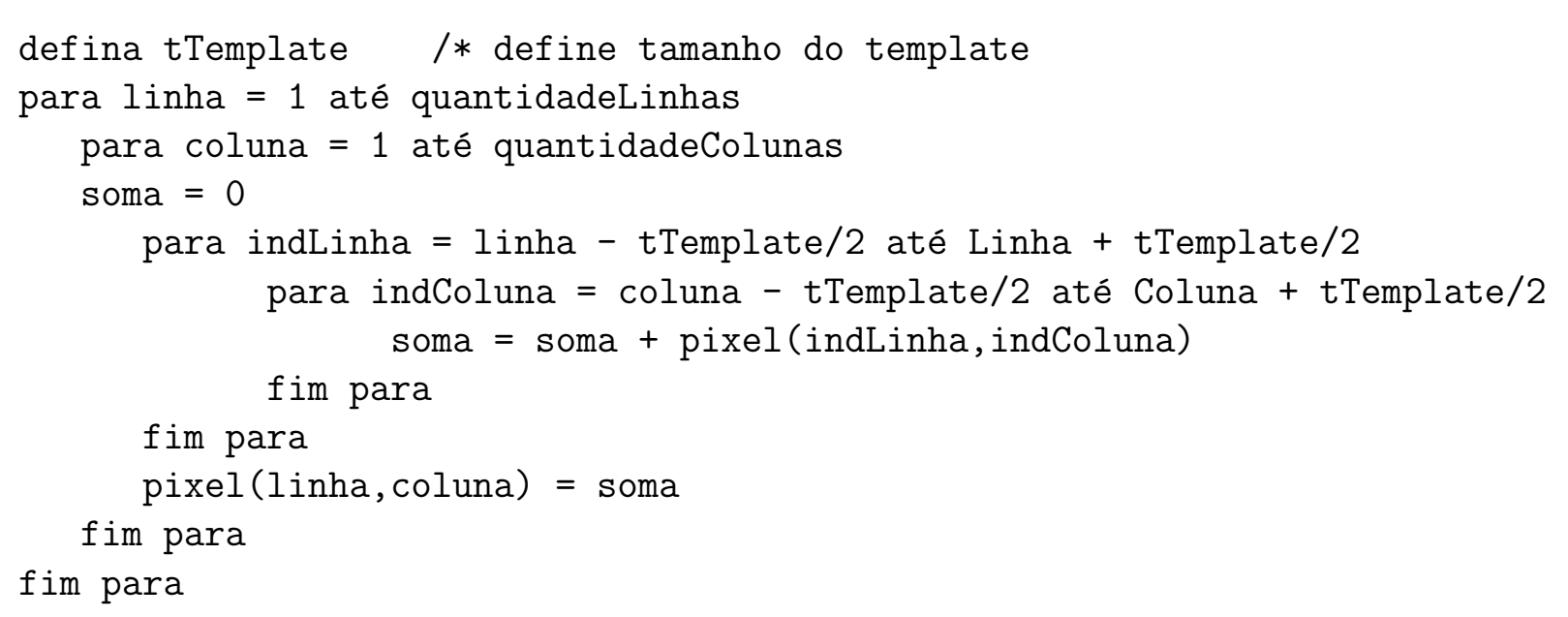

Figura 2.4: Algoritmo genérico para aplicação de templates.

vizinhança. Essa fase de processamento é utilizada para recuperar estruturas intrínsecas da imagem, como descontinuidade de superfície, orientações, profundidades, velocidade etc.

Como exemplo, operações de suavização são usadas para diminuir efeitos espúrios resultantes do processo de aquisição da imagem (ruídos, por exemplo). Uma das técnicas mais clássicas para esta finalidade é a média da vizinhança. Consiste em gerar uma imagem na qual o valor de cada pixel é obtido calculando-se a média dos valores dos pixels de uma vizinhança pré-definida. É uma técnica muito empregada para eliminação de ruídos, apresentando, porém, borramento na imagem resultante e consequente perda na definição de bordas. Considerando a imagem $f(x, y)$ com $N$ x $M$ pixels, define-se a imagem resultante $g(x, y)$ conforme apresentado na Equação 2.5.

A partir da Equação 2.5, considerando-se uma vizinhança de 3 X 3 pixels em torno do pixel de interesse, obter-se-á uma máscara como a exemplificada na Figura 2.5.

$$
g(x, y)=\frac{1}{V} \sum_{(p, q) \in S} f(p, q), \operatorname{para} x=0,1, \ldots, N-1 ; y=0,1, \ldots, M-1
$$

onde:

- $S$ é o conjunto de coordenadas de pontos na vizinhança do ponto $(x, y)$, incluindo o próprio $(x, y)$;

- $V$ é o número total de pontos na vizinhança escolhida.

De forma semelhante, a filtragem mediana é uma técnica de suavização na qual cada pixel da imagem final é substituído pelo valor mediano de uma vizinhança do pixel. O 


\begin{tabular}{|c|c|c|}
\hline$\frac{1}{9}$ & $\frac{1}{9}$ & $\frac{1}{9}$ \\
\hline$\frac{1}{9}$ & $\frac{1}{9}$ & $\frac{1}{9}$ \\
\hline$\frac{1}{9}$ & $\frac{1}{9}$ & $\frac{1}{9}$ \\
\hline
\end{tabular}

Figura 2.5: Exemplo de máscara para filtro de média da vizinhança.

nível mediano $m$ de um conjunto de valores é tal que metade dos valores no conjunto são menores que $m$ e a outra metade é constituída de valores maiores que $m$.

Na Figura 2.6 é apresentado um exemplo de aplicação dessas duas técnicas. É possível verificar que o efeito de borramento da filtragem mediana é menor quando comparado ao resultado fornecido pela média da vizinhança. Uma das vantagens da filtragem mediana é a eliminação de ruídos aleatórios com o borramento mínimo das bordas que compõem os objetos representados na imagem.

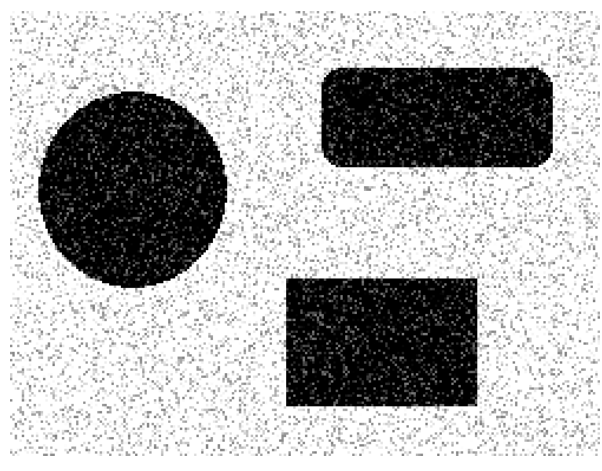

(a) imagem original

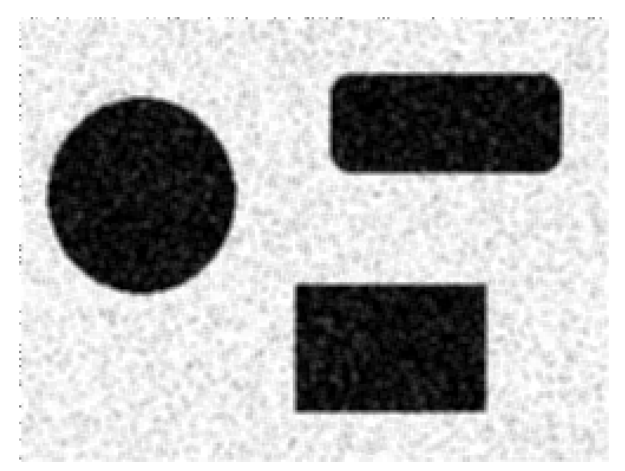

(b) imagem resultante após aplicação do filtro de média da vizinhança

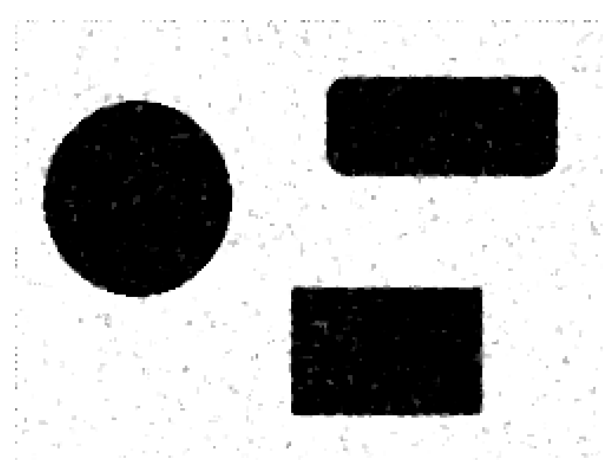

(c) imagem resultante após aplicação do filtro de mediana da vizinhança

Figura 2.6: Exemplos de aplicação de filtros com base na vizinhança.

Como exemplo de filtros que definem operações a partir do histograma da imagem, tem-se diversas técnicas de realce de imagens, as quais produzem justamente o efeito 
contrário ao provocado pela suavização. Têm o objetivo de destacar bordas e detalhes procurados na imagem.

Umas das técnicas mais clássicas de realce de imagens é a quantização, também conhecida como agrupamento do histograma, tendo o objetivo de diminuir a quantidade de cores utilizada para a representação da imagem. Percorre-se a imagem distribuindo-se os valores dos pixels em valores pré-determinados, considerando uma quantidade de cores previamente definida. O resultado é uma imagem com maior contraste, conforme pode ser verificado no exemplo da Figura 2.7. A quantidade de cores definida para o processo exerce grande influência no resultado final, destacando as formas das estruturas com maior ou menor adequação.

Em imagens médicas, por exemplo, seus efeitos podem ser úteis quando a imagem médica reproduz estruturas de interesse representadas por grupos de níveis de cinza com limites bem delineados. Nesses casos, as estruturas podem ser satisfatoriamente diferenciadas e a imagem pode auxiliar na identificação de objetos de interesse que indiquem possíveis anomalias.

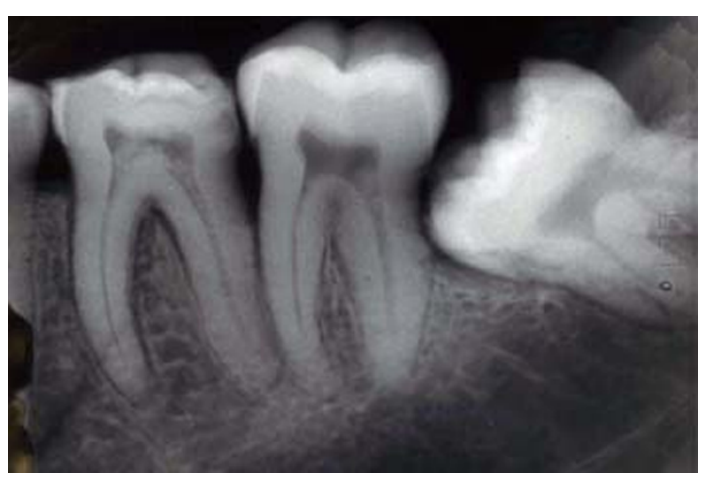

(a) imagem original

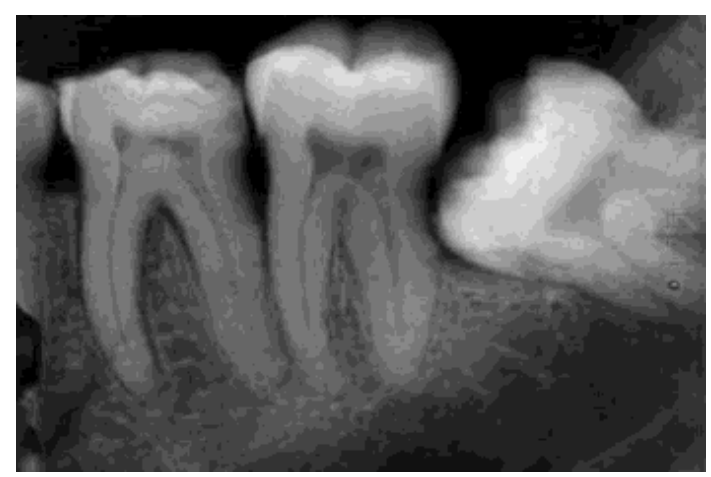

(b) imagem resultante após aplicação do filtro de quantização com 10 níveis de cinza

Figura 2.7: Exemplo de filtro (quantização) com base no histograma da imagem.

\subsubsection{Processamento de nível médio}

Os conceitos de conectividade, adjacência e distância são bastante empregados em processamento de nível médio, com a finalidade de dividir a imagem em partes significativas, destacando pontos, bordas, formas e áreas que, posteriormente, podem ser relacionados a uma base de conhecimento.

Assim como os filtros exemplificados anteriormente, outros filtros clássicos são apresentados na literatura, podendo ser conferidos em Gonzalez e Woods (2007), Ballard e Brown (1982), Russ (2002) e Pedrini e Schwartz (2007). Novos filtros são constantemente criados para fins específicos, muitos deles considerando aplicações para a área de saúde, destinados 
principalmente a construir algoritmos que auxiliem na implementação de sistemas para auxílio ao diagnóstico.

Alguns exemplos de filtros clássicos aplicados em imagens médicas podem ser conferidos em Nunes (2006).

\subsubsection{Processamento de alto nível}

Como mencionado, o processamento de alto nível tem o objetivo de relacionar os objetos resultantes do processamento de nível médio a uma base de conhecimento.

Várias técnicas da Computação são empregadas para esta finalidade, considerando áreas como inteligência artificial e reconhecimento de padrões, que não serão abordadas especificamente neste documento. Técnicas clássicas deste nível de processamento podem ser conferidas em Gonzalez e Woods (2007) e Ballard e Brown (1982).

\subsection{Recuperação de Imagens Baseada em Conteúdo}

A partir do exposto nas seções anteriores, é possível deduzir que junto com o desenvolvimento dos sistemas computacionais aplicados à saúde, cresce de forma avassaladora o volume de imagens médicas digitais armazenadas, visto que essas constituem matérias-primas essenciais para os sistemas de CAD e aplicações de RV que as usam para a construção de objetos tridimensionais.

Um problema que se delineia a partir do grande volume de imagens armazenado é como encontrar as imagens corretas no momento correto. Para auxiliar na solução desta questão, surgem os sistemas de CBIR.

De forma genérica, os sistemas de CBIR são ferramentas computacionais que visam a localizar em uma base de imagens aquelas mais similares a uma imagem de consulta, de acordo com um ou mais critérios fornecidos. Os critérios de similaridade são obtidos a partir da extração de características da imagem como cor, textura e forma. Este tipo de recuperação de informação pode ser utilizado nos mais diversos tipos de aplicações, tendo sido bastante explorado na área médica, principalmente na construção de sistemas de busca em PACS (Picture Archive and Communication System).

Assim como as demais tecnologias citadas neste documento, os sistemas de CBIR também envolvem várias áreas da Computação, sendo as principais Processamento de Imagens e Banco de Dados. A primeira já foi abordada anteriormente. A seguir são apresentados breves conceitos sobre Bancos de Dados.

Um Banco de Dados (BD) é um conjunto de dados organizados de forma sistemática, de acordo com um modelo pré-definido. Um Sistema Gerenciador de Banco de Dados (SGBD) é constituído por um conjunto de dados associado a um conjunto de programas 
para acesso a esses dados. O principal objetivo de um SGBD é proporcionar um ambiente tanto conveniente quanto eficiente para recuperação e armazenamento de informações do banco de dados.

Silberchatz et al. (2005) mencionam que sistemas de banco de dados são projetados para gerir grandes volumes de informações, o que implica na definição de estruturas de armazenamento e de mecanismos para a manipulação dessas informações. Um sistema de BD deve garantir ainda a segurança das informações armazenadas contra eventuais problemas, além de impedir tentativas de acesso não autorizadas. Se os dados são compartilhados por diversos usuários, o sistema deve garantir mecanismos eficientes de concorrência que evitem a ocorrência de resultados anômalos.

Para atingir os objetivos citados, nos SGBDs são implementados programas responsáveis por funções que vão desde armazenar os dados de forma otimizada até indexá-los e recuperá-los com eficiência quando solicitados. Se a questão for armazenamento de imagens, esses programas devem prever eficiência ainda maior devido ao grande volume de dados que essas representam.

Há várias definições para a composição dos sistemas de CBIR. De forma geral, os principais componentes são os extratores, as funções de similaridade, os algoritmos de ordenação e as estruturas de indexação, apresentadas a seguir. Na Figura 2.8 é apresentado o esquema geral de um sistema de CBIR.

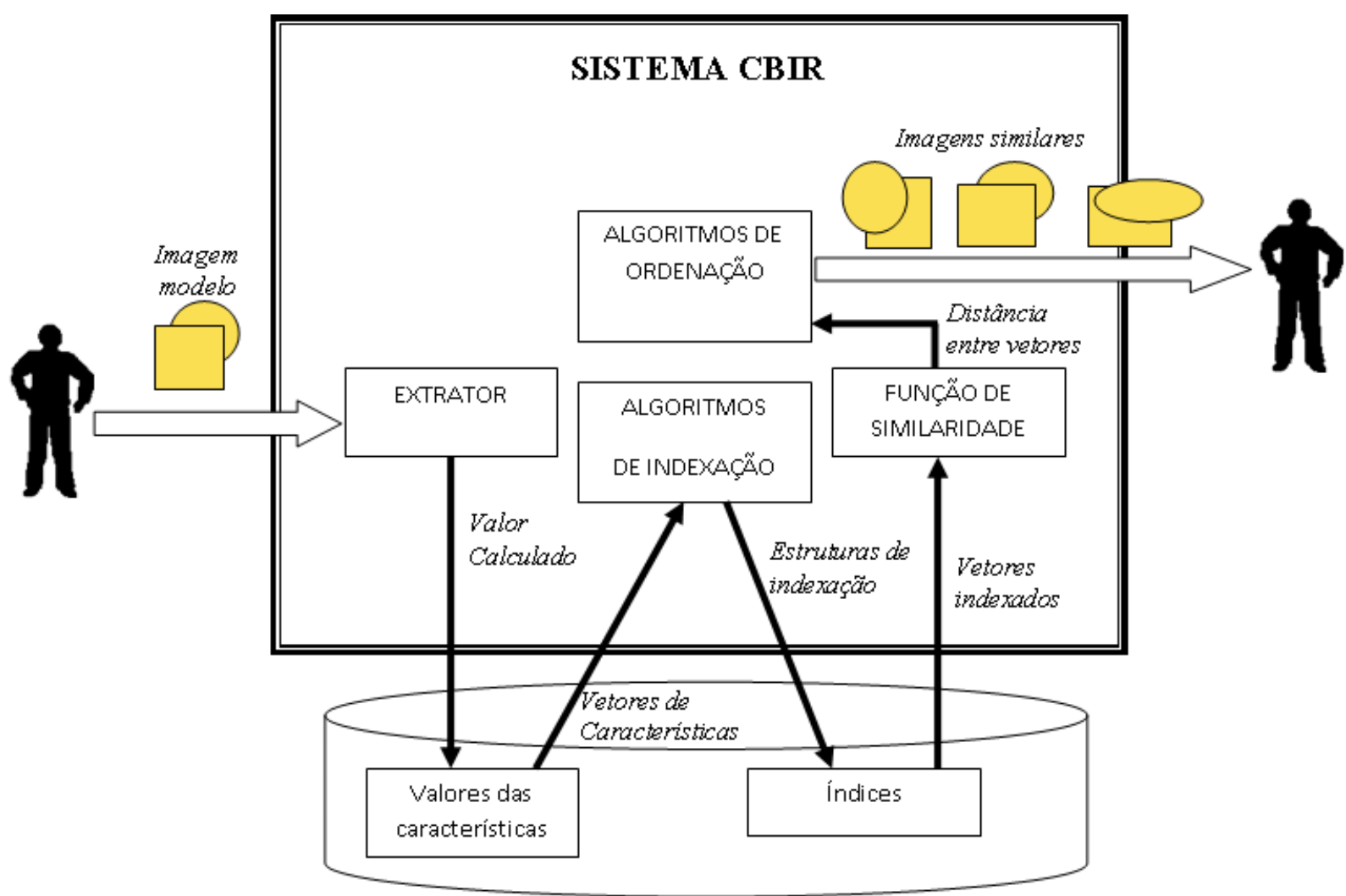

Figura 2.8: Esquema geral de um sistema de CBIR. 


\subsubsection{Extratores}

A extração de características de imagens é uma etapa fundamental em um sistema de CBIR. As características representam alguma propriedade (quantitativa ou qualitativa) relativa ao objeto, considerando-se a imagem inteira ou parte dela.

As características extraídas são utilizadas no processo de indexação e recuperação de imagens, o que as torna parcialmente responsáveis pelo sucesso da aplicação. Outro fator que deve ser levado em consideração no processo de extração é o foco da aplicação, pois dependendo do tipo de imagem e de aplicação, as características de interesse podem variar e até mesmo serem muito específicas. As técnicas de extração de características são desenvolvidas com base nas técnicas de PI e reconhecimento de padrões.

O processo de extração de características geralmente ocorre depois de uma etapa de pré-processamento e segmentação da imagem, no qual o objeto de interesse é localizado e rotulado de forma que fique isolado. Na segmentação, o objeto é separado do fundo gerando uma região ou apenas identificando as suas bordas. A partir daí o processo de extração de características fica responsável por obter aspectos inerentes ao objeto segmentado ou região de interesse, de acordo com algum critério pré-estabelecido.

Uma região pode ser representada com base em suas características internas (os elementos contidos dentro da região) ou em suas características externas (sua fronteira ou borda) (Gonzalez e Woods, 2007). A representação externa é mais adequada quando o foco está nos aspectos de forma e a representação interna é usada para representar as características refletivas, como cor e textura. As características que descrevem as imagens devem ser insensíveis às variações de tamanho, translação e rotação.

Em geral, as características extraídas são transformadas em um valor que, posteriormente, pode ser comparado com o valor obtido para a mesma característica de outra imagem (El-Naqa et al., 2004). Comumente vários extratores são desenvolvidos em um sistema de CBIR, sendo que cada um deles refere-se a um aspecto da imagem. Por exemplo, um extrator que calcula o contraste de um determinado trecho da imagem pode retornar o valor zero quando o contraste é nulo ou outro valor no intervalo entre zero e um, representando o nível de contraste entre a estrutura considerada e o fundo da imagem. Da mesma forma, um extrator para medir a área de um objeto em uma imagem, pode retornar o valor 1 quando a área considerada atingir o maior valor possível.

Considerando que cada característica obtida é representada por um número dentro de um intervalo (em geral, os valores são normalizados), o conjunto de características extraídas de uma imagem forma o seu vetor de características $V$, composto por $n$ elementos, onde $n$ é a quantidade de características armazenadas e $V_{i}$ é o valor da iésima característica daquela imagem. Assim, cada imagem é representada por um vetor de números, utilizado na sua indexação e recuperação. As características extraídas representam a ima- 
gem no momento de sua busca. Supondo que foram extraídas as características área, contraste, brilho, densidade e quantidade de nódulos de uma determinada imagem médica, cujos valores foram normalizados, a Figura 2.9 ilustra o vetor de característica que seria armazenado para representar esta imagem.

\begin{tabular}{l|c|c|c|c|} 
(área) & kontraste) & (brilho) & \multicolumn{1}{c}{ (derridade) } & $\begin{array}{c}\text { (quantidade } \\
\text { de nódubs) }\end{array}$ \\
\hline 0,8 & 0,3 & 0,9 & 0,7 & 0,5 \\
\hline
\end{tabular}

Figura 2.9: Exemplo de um vetor de características.

O conjunto de características em si não é suficiente para determinar o resultado da recuperação. Outro elemento que vai influenciar nos resultados da busca é a escolha de medidas de similaridade entre os vetores de características, detalhadas na próxima seção.

\subsubsection{Funções de similaridade}

Conforme mencionado, os atributos de uma imagem são geralmente obtidos por meio de técnicas de PI que medem uma característica da imagem e a representam por um número. Esses números formam um vetor de características da imagem. Para aplicar uma consulta por similaridade sobre os vetores de características, Razente et al. (2006) lembram que é necessário usar uma função de distância para o cálculo da similaridade, definindo-se a função de similaridade.

Uma função de distância é um algoritmo que compara dois vetores de características e retorna um valor não negativo. Existem várias funções de distância disponíveis para comparar vetores de características. Exemplos são a Distância Euclidiana (Hafner et al., 1995); (Swain e Ballard, 1991), a Distância de Mahalanobis (Manjunath e Ma, 1996); (Smith, 1997) e métricas derivadas de critérios de otimização relacionados entre si, conforme citado em Rubner et al. (1998). Vasconcelos (2004) faz uma análise sobre a eficiência da avaliação de sistemas de CBIR usando funções de similaridade probabilísticas.

Considerando-se que o valor final da distância está normalizado (entre 0 e 1), é interessante lembrar que quanto menor for este valor, mais próximos serão os vetores e, portanto, mais semelhantes serão as imagens que eles representam. Retomando o exemplo anterior, se existirem duas imagens cujos vetores de características sejam representados pelas estruturas $V_{1}=[0.8,0.3,0.7,0.9,0.5]$ e $V_{2}=[0.2,0.5,0.8,0.4,0.9]$, a aplicação da Distância Euclidiana como função de similaridade, de acordo com a Equação 2.6 (onde $i$ varia de 1 a 5), resultaria no valor 0,9055. Isso indica que as imagens são bem diferentes entre si quando consideradas todas as características no cálculo da distância.

$$
d\left(V_{1}, V_{2}\right)=\sqrt{\sum\left(V_{1 i}-V_{2 i}\right)^{2}}
$$




\subsubsection{Estruturas de Indexação}

A partir da composição do vetor de características e da definição da função de similaridade a ser empregada, o sistema está pronto para realizar as consultas. As características extraídas representam a imagem no momento de sua busca, pois é a partir delas que uma determinada imagem é recuperada do banco de imagens.

As formas mais comuns de recuperação por similaridade usam os conceitos de abrangência ou k-vizinhos mais próximos. A recuperação por abrangência retorna os elementos cuja distância estão dentro de um raio pré-determinado do elemento modelo. A recuperação pelos k-vizinhos mais próximos retorna os $k$ elementos que estão mais próximos do elemento modelo (Ciaccia et al., 1997). Na Figura 2.10 são ilustrados os dois processos, sendo que o elemento de onde partem os raios representa o elemento modelo e os demais elementos em cinza representam os elementos recuperados.

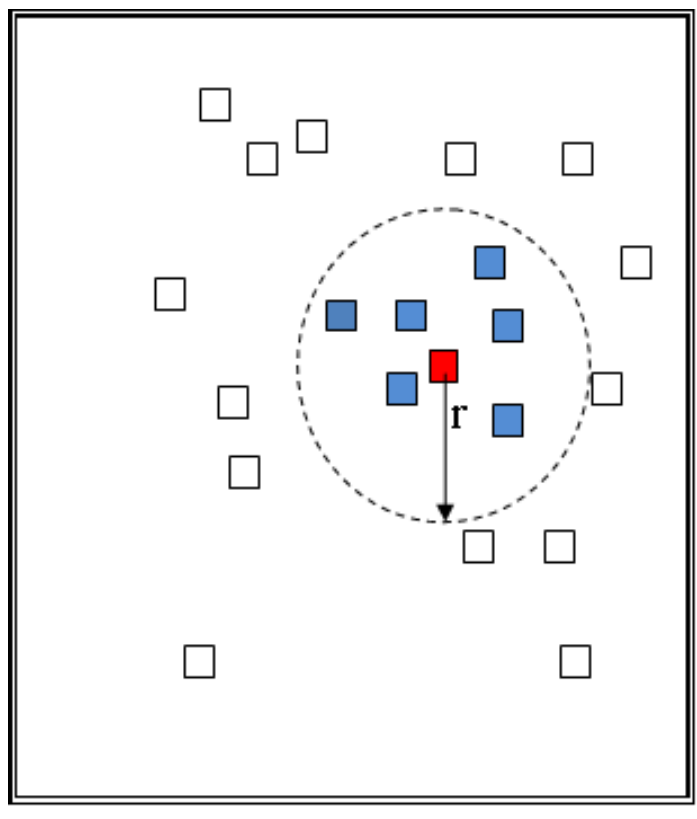

(a) Consulta por abrangência

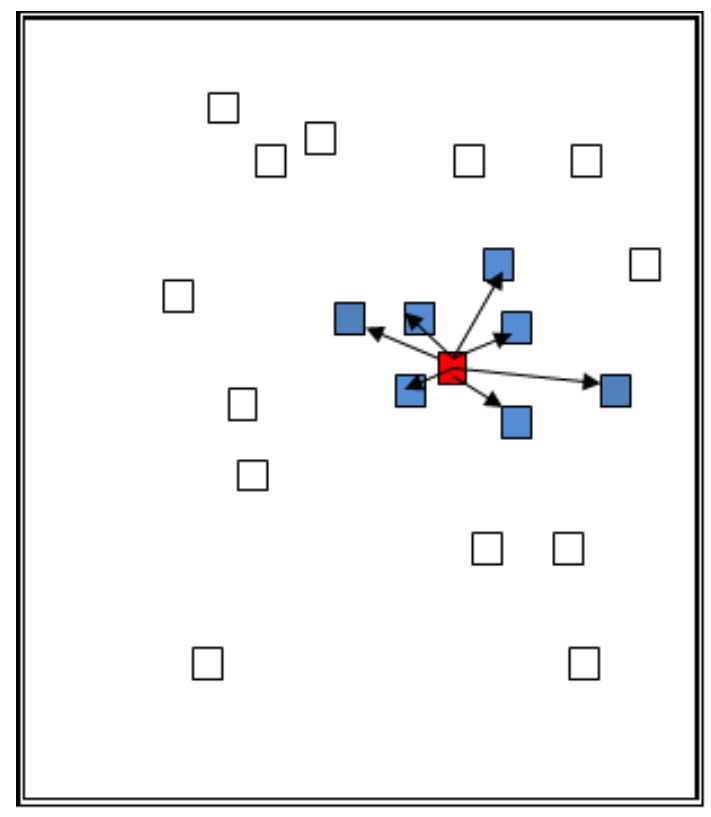

(b) Consulta pelos k-vizinhos $(\mathrm{k}=7)$

Figura 2.10: Esquemas representativos dos tipos de consultas por similaridade.

O processo de busca envolve a comparação de vetores de alta dimensionalidade, diretamente relacionada com a quantidade de características desejadas para a pesquisa. Assim, é necessária a otimização do desempenho aplicando-se estruturas de indexação adequadas, envolvendo pesquisas nas áreas de Bancos de Dados e Estruturas de Dados. Muitas vezes procura-se diminuir a dimensão dos vetores para, em seguida, construir índices adequados (Böhm et al., 2001). Estruturas de indexação que consideram apenas a distância existente entre os dados, perfeitamente adequadas ao contexto de CBIR, têm sido objetos de pesquisas há algumas décadas e aperfeiçoadas em trabalhos recentes. Nesse contexto, 
é interessante citar o trabalho pioneiro de Burkhard e Keller (1973) e os trabalhos mais recentes que definem árvores de busca de forma mais otimizada, direcionadas para aplicações de CBIR: Böhm et al. (2001), Gaede e Günther (1998), Traina Jr. et al. (2002) e Petrakis et al. (2002).

\subsection{Realidade Virtual}

Relativamente nova como objeto de pesquisa e como tecnologia aplicada no setor produtivo, a Realidade Virtual (RV) vem experimentando avanços nos últimos anos devido ao desenvolvimento de hardware e software. As origens da RV datam da década de 50, com o cinerama e o cinemascope ${ }^{1}$. Explanações sobre o histórico de aplicações baseadas em RV podem ser conferidas em Hand (1994), Jacobson (1994) e Pimentel e Teixeira (1995). Na Figura 2.11 é apresentada uma linha do tempo que resume os principais marcos da história da RV, extraído de Rizzato (2007).

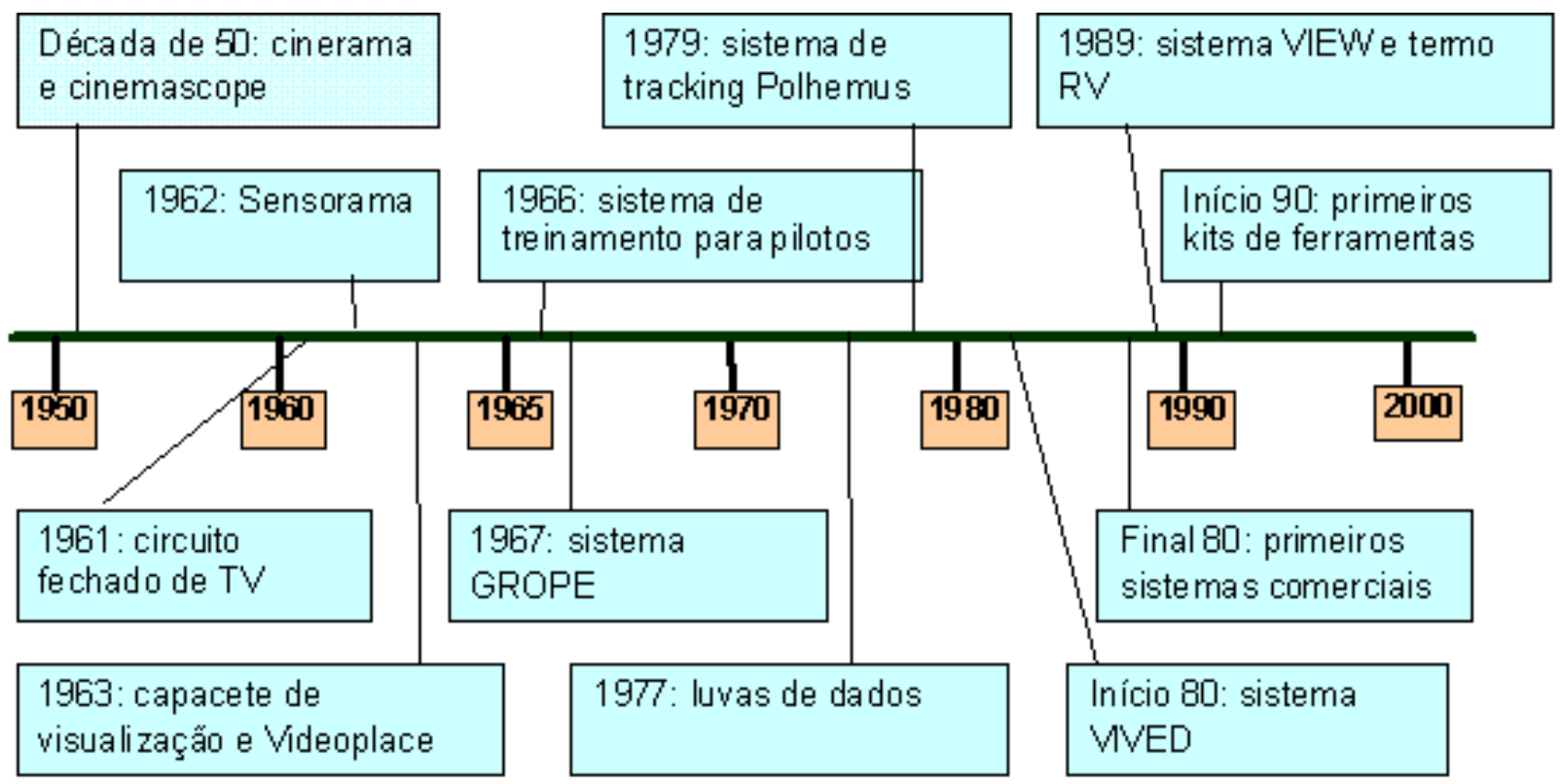

Figura 2.11: Resumo do histórico da evolução da Realidade Virtual (Rizzato, 2007).

A RV tem diversas definições e classificações e, por este motivo, ainda é comum encontrar alguma confusão entre conceitos de RV e outras áreas correlatas, como a Computação Gráfica. O que diferencia a RV é a existência de interação em tempo real, permitindo ao usuário ser o agente das transformações no Ambiente Virtual (AV).

Em Kirner e Siscoutto (2007), a RV é definida como uma "interface avançada do usuário" que acessa aplicações executadas no computador, fazendo com que seja possível a

\footnotetext{
${ }^{1}$ Essas técnicas usavam três câmeras em ângulos diferentes gerando projeção em três grandes telas inclinadas para dentro, causando a sensação de estar dentro do filme
} 
visualização, movimentação e interação do usuário, em tempo real, em ambientes tridimensionais gerados por computador. Burdea e Coiffet (2003) definem esta tecnologia como "a mais poderosa interface usuário-computador que envolve simulação em tempo real e interação por meio de múltiplos canais sensoriais. Estas modalidades sensoriais são: visual, auditiva, palpável, de cheiro e de paladar".

Aukstakalnis e Blatner (1992) apresentam a RV como uma forma pela qual usuários de computadores podem visualizar, manipular e interagir com dados complexos. No trabalho de Burdea e Coiffet (1994), é afirmado que a RV permite a criação de ambientes sintéticos, gerados por computador, e a utilização de canais multissensoriais, oferecendo ao usuário a possibilidade de realizar operações como navegação, interação e imersão. Os pesquisadores lembram ainda que, em termos de funcionalidades, a RV é uma simulação gerada por computador, usada para criar um ambiente que se pareça com o ambiente real, o qual responde a entradas dos usuários em tempo real, como gesto ou voz, propiciando, desta forma, uma interação.

Conforme definem Burdea e Coiffet (2003), a interatividade acontece em tempo real, ou seja, a aplicação detecta a ação do usuário e instantaneamente modifica o mundo virtual. Isso dá ao usuário a sensação de imersão, de fazer parte do que está sendo visto na tela.

\subsubsection{Características da Realidade Virtual}

Latta e Oberg (1994) definem que a RV envolve a criação e a experimentação de ambientes. Seu objetivo central é colocar o usuário em ambiente que não é vivenciado normalmente ou facilmente, estabelecendo relações entre ambos. Para atingir tal objetivo três aspectos são considerados: imersão, interação e envolvimento. De forma geral, a comunidade científica considera que as aplicações de RV envolvem essas três características, embora isso não seja um consenso.

Segundo Tori et al. (2006), a imersão ocorre quando são utilizados dispositivos multissensoriais, os quais capturam os movimentos do usuário e reagem a eles, causando a sensação de que a pessoa foi transportada para o domínio da aplicação, ou seja, ela se sente dentro do mundo virtual. Na RV imersiva são utilizados dispositivos como os vídeocapacetes e as cavernas, que propiciam sensações capazes de auxiliar na percepção de realismo no AV. Uma dessas características é a estereoscopia, responsável por gerar a sensação de profundidade.

A visão estéreo é um dos principais mecanismos que permite ao ser humano perceber a noção de profundidade. O olho esquerdo e o olho direito veem imagens diferentes (apesar de muito parecidas). Em Tori et al. (2006) é lembrado que o cérebro usa esta diferença para formar a imagem tridimensional, o que permite a percepção da profundidade do 
objeto. O princípio de funcionamento da maioria dos dispositivos estereoscópicos é a projeção de imagens distintas que são captadas pelos olhos esquerdo e direito do observador, imitando o funcionamento do cérebro humano. Na RV não imersiva o usuário é transportado apenas parcialmente ao mundo virtual e continua a sentir-se predominantemente no mundo real. Como exemplos de RV não imersiva tem-se aplicações visualizadas em monitores ou em telas de projeção.

A interação é a capacidade do usuário modificar o AV por meio de suas ações. A forma mais simples de interação é a navegação pelo ambiente tridimensional usando mouse 3D, na qual o usuário recebe como resposta novos pontos de vista do cenário (Kirner e Tori, 2004). Interações mais complexas ocorrem quando o usuário manipula ou altera os objetos virtuais usando dispositivos não convencionais ${ }^{2}$. Para que o usuário tenha a sensação de realismo é necessário que as reações ocorram em tempo real, com limites de tempos definidos e atrasos toleráveis pelo ser humano. É admissível um atraso em torno de 100 milissegundos para a visão, tato, força e audição. Isso equivale a taxas mínimas de 10 quadros por segundo na renderização de imagens, sendo desejado cerca de 20 quadros por segundo, e de 100 milissegundos de atraso nas reações aos comandos do usuário (Kirner e Tori, 2004).

Netto et al. (2002) definem o envolvimento como o grau de motivação que o mundo virtual proporciona a este usuário, podendo ser passivo (como a leitura de um livro), ou ativo (como participar de um jogo). Assim, as aplicações de RV devem ser projetadas a fim de proporcionar um grau de envolvimento a ponto de fazer com que o usuário tenha motivação suficiente para interagir com a AV como se estivesse em um ambiente real.

\subsubsection{Dispositivos de Realidade Virtual}

Conforme já explicitado, a RV envolve obrigatoriamente a construção de AVs tridimensionais e interação em tempo real. A interação pode ser realizada por meio de dispositivos convencionais, como mouse, teclado e monitor de vídeo. No entanto, algumas aplicações exigem maior realismo, sendo desejável o emprego de equipamentos não convencionais. Especialmente na área de saúde, os dispositivos tangíveis são desejados.

São várias as classificações para os dispositivos não convencionais. Para fins de embasamento teórico, aqui será adotada uma classificação simples, dividindo-os em dispositivos de entrada e dispositivos de saída. Mais detalhes e exemplos podem ser obtidos em Machado e Cardoso (2006).

\footnotetext{
${ }^{2}$ Há várias classificações e denominações para dispositivos de interação. Neste documento é adotado o termo convencional para dispositivos comumente encontrados nos computadores atuais como mouse, teclado e monitor de vídeo. Os demais dispositivos de interação são chamados de não convencionais.
} 


\subsubsection{Dispositivos de entrada}

Os dispositivos de entrada são aqueles que permitem identificar as ações do usuário e transmiti-las à aplicação de RV, de forma que o AV reaja em tempo real. Alguns exemplos são apresentados nas Figuras 2.12, 2.13 e 2.14.

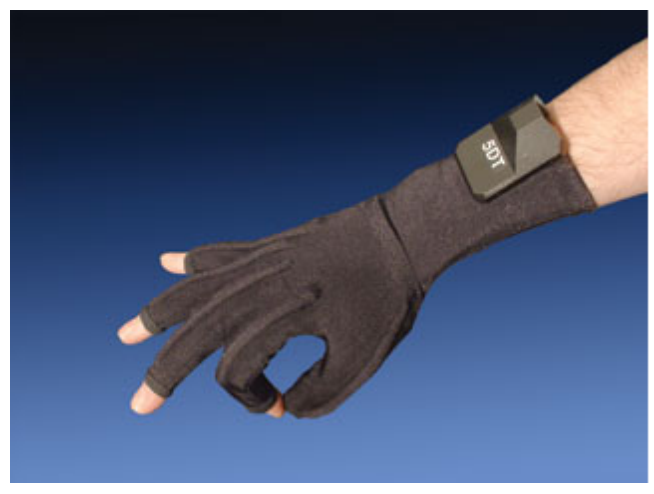

(a) Luva de Dados (http://www.5dt.com)

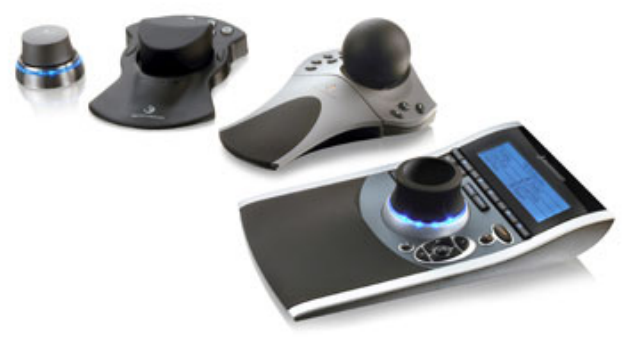

(b) Dispositivos com seis graus de liberdade (http://www.logitech.com)

Figura 2.12: Exemplos de dispositivos de entrada.

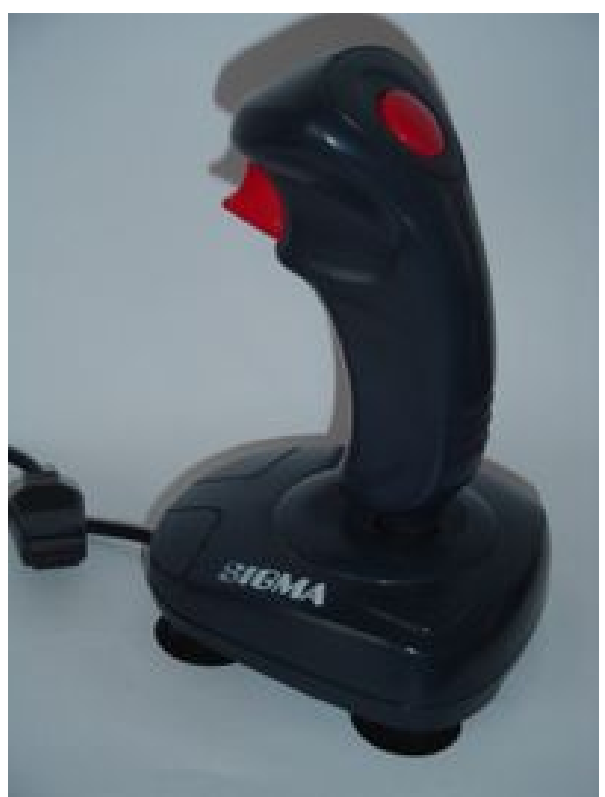

(a) Joystick (http://www.logitech.com)

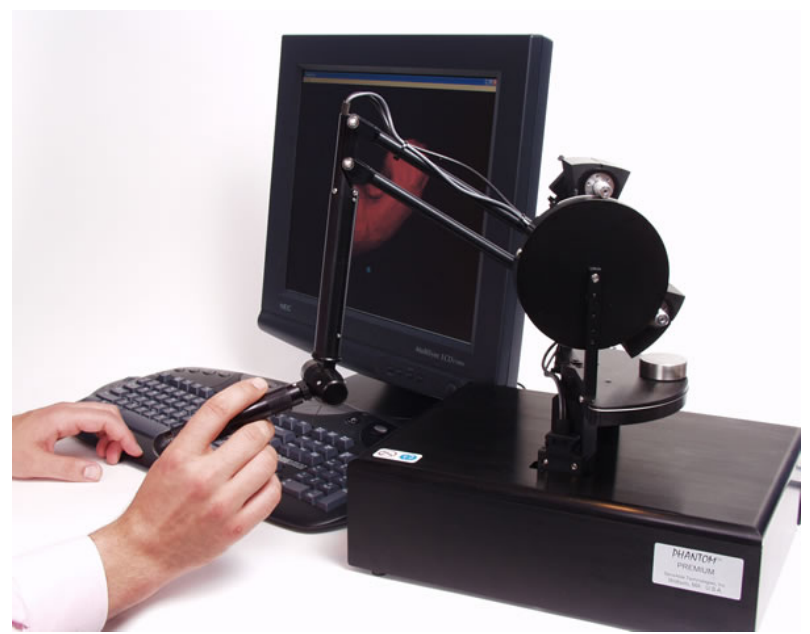

(b) Dispositivo háptico (http://www.sensable.com/)

Figura 2.13: Exemplos de dispositivos de entrada.

A luva de dados é um dos dispositivos de entrada mais comuns, que possibilita o reconhecimento dos movimentos das mãos dos usuários. Há vários tipos de luva, construídas com tecnologias também variadas, incluindo sensores que reconhecem movimentos dos dedos, posição do pulso e reação de força. 


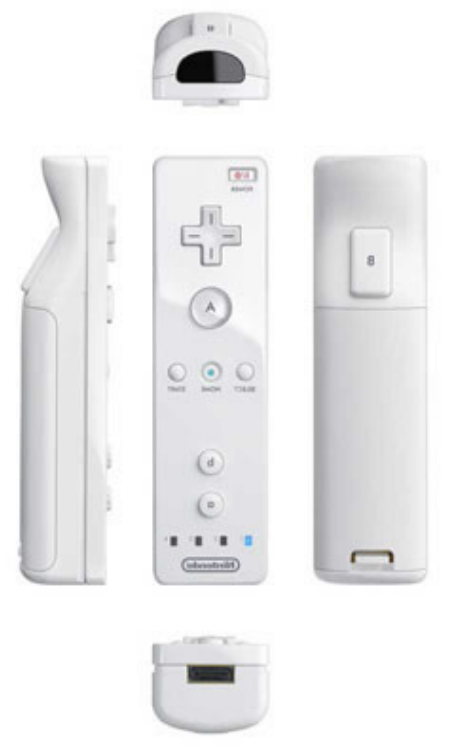

(a) Dispositivo Nintendo Wii (http://eletronicos.hsw.uol.com.br)

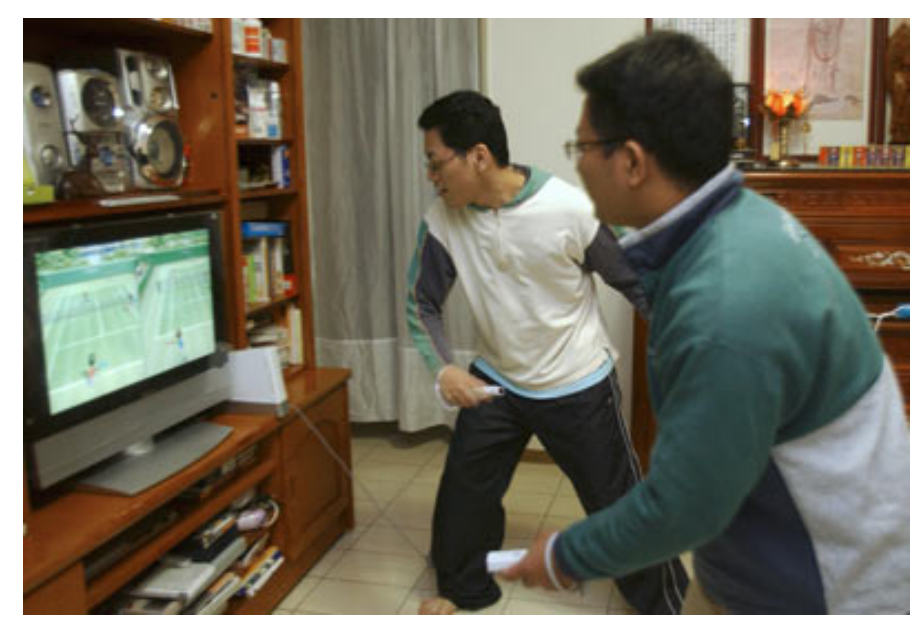

(b) Uso de Dispositivo Nintendo Wii (http://eletronicos.hsw.uol.com.br)

Figura 2.14: Exemplos de dispositivos de entrada.

Dispositivos com 6 graus de liberdade (movimentos de ida e volta nos eixos $x, y$ e z) possibilitam uma movimentação ampla do usuário. Joysticks também são exemplos de dispositivos de entrada que, embora limitem as possibilidades de movimento, podem ser úteis em muitas aplicações de RV. Há, ainda, diversos tipos de sensores de entrada biológicos que possibilitam ao sistema reconhecer entradas como comando de voz e sinais elétricos musculares.

Os dispositivos hápticos são utilizados tanto para entrada quanto para saída de dados em sistemas de RV. Sua função principal é reconhecer uma força exercida pelo usuário e retornar, de acordo, com a aplicação, uma outra força calculada a partir da força de entrada e das características da aplicação.

Nos últimos anos têm se tornado comuns os dispositivos Nintendo Wii e outros afins. Inicialmente empregados na indústria de jogos, esses têm potencial para serem empregados nos mais diversos tipos de aplicações de RV, pois permitem transmitir ao sistema os movimentos naturais do usuário. LaViola (2008) afirma que esses e outros dispositivos apresentados pela indústria de jogos têm proporcionado a popularização da RV.

\subsubsection{Dispositivos de saída}

Os equipamentos de saída têm o objetivo de disponibilizar reações do sistema ao usuário, em resposta às suas ações.

Os dispositivos mais comuns preocupam-se com as sensações visuais. Uma das sensações mais requeridas em sistemas de RV é a estereoscopia (seção 2.3.1), que possibilita 
a percepção de profundidade e, com isso, aumenta o realismo das aplicações. Os óculos estereoscópicos são os dispositivos mais empregados que proporcionam esta sensação. Há vários tipos e tecnologias de óculos estereoscópicos, desde os mais simples e baratos que usam anaglifos (lentes geralmente azuis e vermelhas que filtram essas cores durante a visualização) até os mais sofisticados, que fornecem a sensação de profundidade desejada sem esforço do usuário.

Outro dispositivo bastante empregado é o Head-Mounted Display (HMD), um capacete que pode isolar o usuário parcial ou totalmente do mundo real, sendo composto por duas pequenas telas de TV e um conjunto de lentes especiais que ajudam a focalizar imagens a alguns milímetros dos olhos do usuário

Existem ainda dispositivos mais caros, como monitores estereoscópicos e sistemas de projeção que permitem a imersão total no AV, criando aplicações por meio de projeções em telas específicas. Nesta categoria, os mais comuns são as mesas de projeção e as cavernas, ou CAVEs (Cave Automatic Virtual Environment), uma sala onde são projetados objetos 3D nas paredes, teto e chão, permitindo que usuário sinta-se efetivamente dentro do AV.

Dispositivos auditivos, cuja função é gerar sons tridimensionais aumentam artificialmente os ativadores naturais que ajudam o cérebro a localizar o som. Podem ser utilizados fones de ouvido com escoamento acústico controlado ou a instalação de microfones no ambiente e adição de sinais artificiais e sinais ambientais por meio eletrônico. Exemplos dos dispositivos de saída mencionados são apresentados nas Figuras 2.15, 2.16 e 2.17.

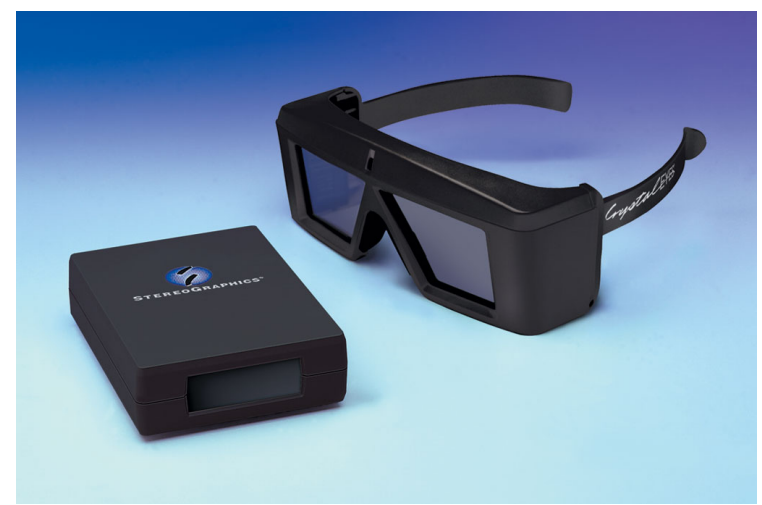

(a) Óculos estereoscópicos (www.abs-tech.com)

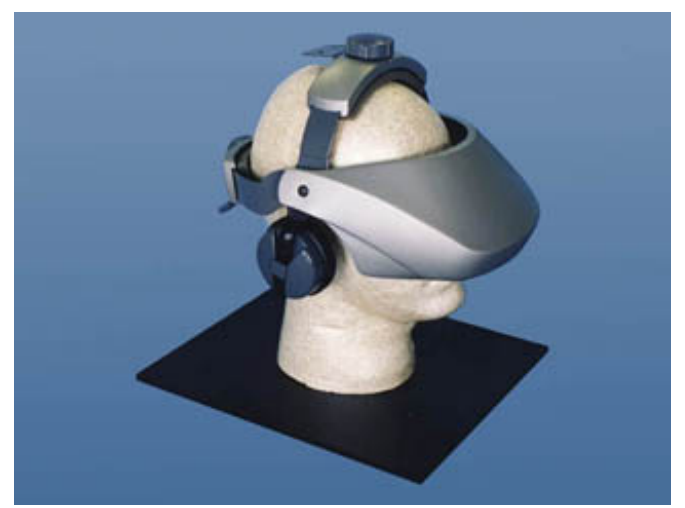

(b) capacete HMD (http://www.5dt.com)

Figura 2.15: Exemplos de dispositivos de saída.

\subsubsection{Classificações de sistemas de RV}

Se as definições de RV convergem para conceitos semelhantes, o mesmo não acontece com as classificações de sistemas de RV. Na literatura há alguns tipos de classificações que consideram o tipo de tecnologia empregada, a quantidade de usuários, o tipo de aplicação e, ainda, a utilização de tecnologias de comunicação. A seguir, citamos algumas delas. 

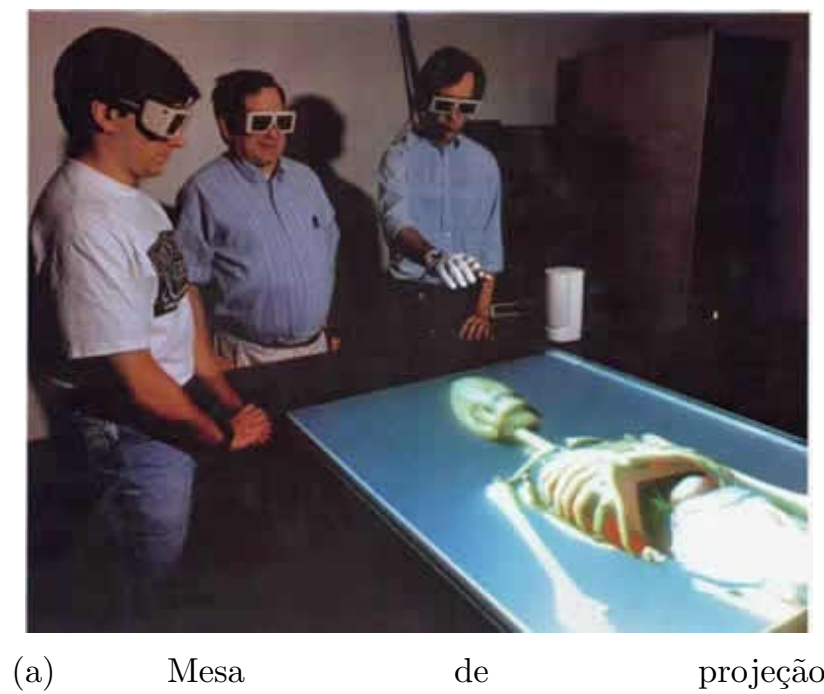
(http://eletronicos.hsw.uol.com.br)

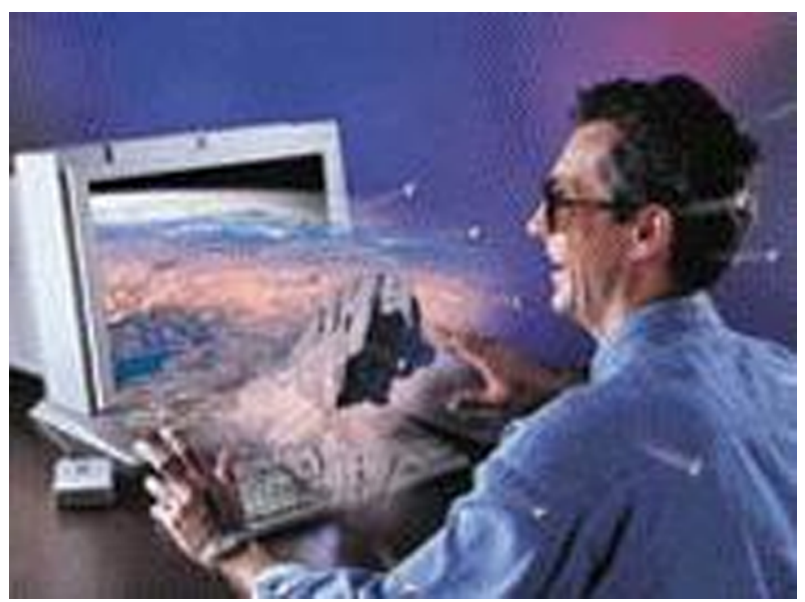

(b) Monitor estereoscópico (http://www.5dt.com)

Figura 2.16: Exemplos de dispositivos de saída.

De uma forma que extrapola a RV, Pinho e Kirner (1998) classificam os sistemas que utilizam interfaces não convencionais em: telepresença (aquele em que o usuário está presente em um ambiente real separado fisicamente dele no espaço); RV (o usuário participa de um mundo virtual gerado no computador); realidade aumentada (objetos virtuais são acrescentados no ambiente real) e realidade melhorada (são geradas informações adicionais para serem sobrepostas à imagem real).

Já Netto et al. (2002) dividem os sistemas de acordo com sua finalidade de uso em: telecolaboração (os usuários, distantes remotamente compartilham um AV); telepresença (estende as habilidades de um ser humano para um ambiente remoto); visualização de dados 3D (utilizada para desenvolvimento de aplicativos altamente complexos e de grande porte) e visualização científica (utilizados para mapear em visualizações 3D os dados gerados por simulações computacionais). 


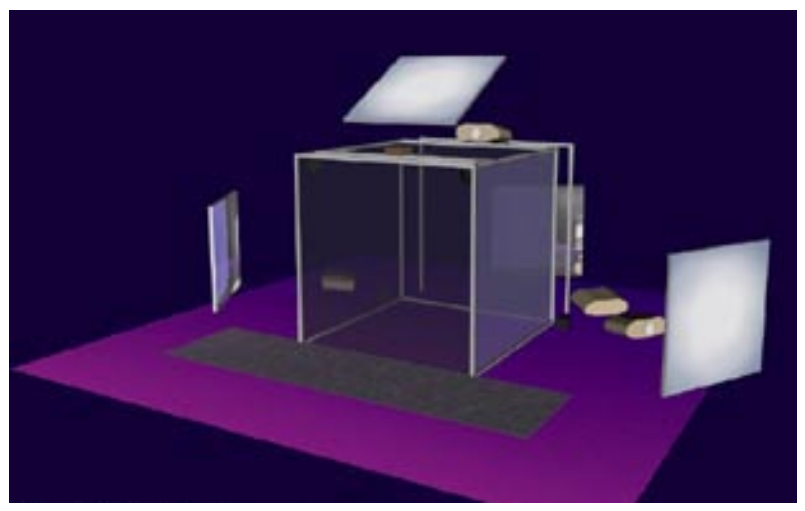

(a) Esquema de uma CAVE (www2.uol.com.br/bestcars/ artigos/projeto-2.htm)

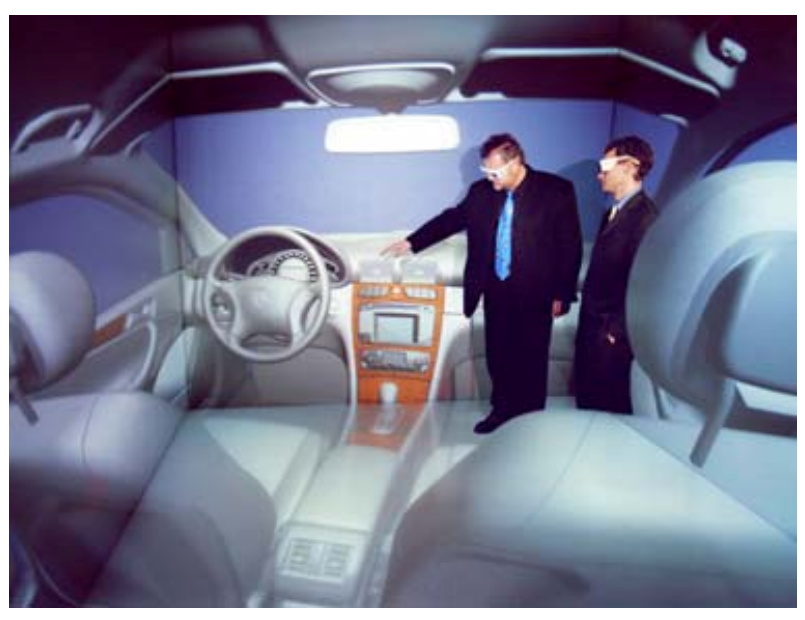

(b) Exemplo de uma CAVE (www2.uol.com.br/bestcars/ artigos/projeto-2.htm)

Figura 2.17: Exemplos de dispositivos de saída.

Um segundo tipo de classificação para sistemas de RV que considera principalmente os dispositivos utilizados pela aplicação é também apresentado pelos autores. Nessa classificação os sistemas são divididos em: RV de simulação (destinados a imitar procedimentos da vida real); RV de projeção (o usuário fica fora do mundo virtual, mas se comunica com personagens e objetos que fazem parte dele); realidade aumentada (permitem que o usuário possa ver as imagens geradas virtualmente sobre o mundo real); monitores visualmente acoplados (exibem as imagens diretamente ao usuário usando um dispositivo que acompanha os movimentos de sua cabeça) e RV de mesa (sistemas tradicionais de RV que usam grandes monitores ou sistema de projeção para exibir o mundo virtual).

Kirner e Tori (2004) consideram a proporção existente entre o real e o virtual em um sistema, classificando-os em realidade misturada, realidade aumentada, virtualidade aumentada e hiper-realidade, conforme apresentado na Figura 2.18. 


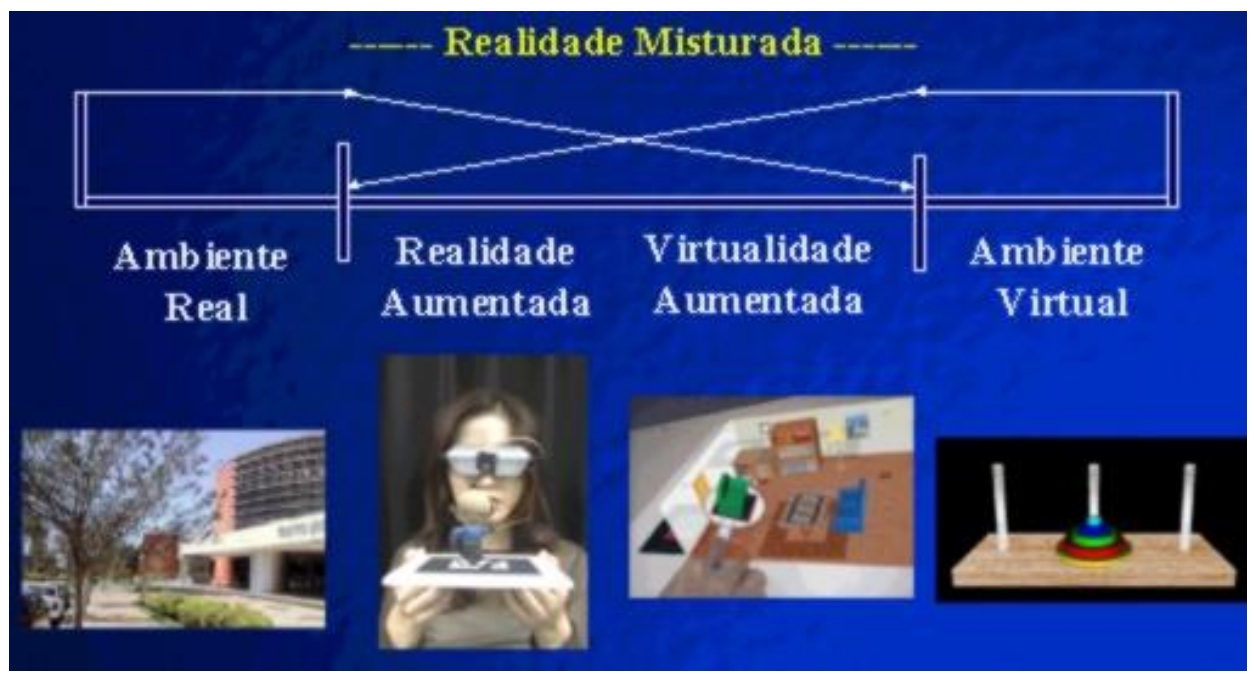

Figura 2.18: Realidade e virtualidade contínuas (Kirner e Tori, 2004).

\subsubsection{Estrutura de um sistema de Realidade Virtual}

A implementação de sistemas de RV envolve diversos componentes, tanto em nível de hardware quanto de software. Conforme apresentado na Figura 2.19, Pinho e Kirner (1998) definem que um sistema de RV é formado por dispositivos de entrada e saída, processador, aplicativo, banco de dados e pelo usuário que faz a interação com o sistema. O processador recebe as informações do usuário por meio de dispositivos de entrada e acessa o banco de dados para verificar quais instâncias do mundo virtual correspondem aos quadros que serão exibidos ao usuário. Os quadros são criados e distribuídos em tempo real.

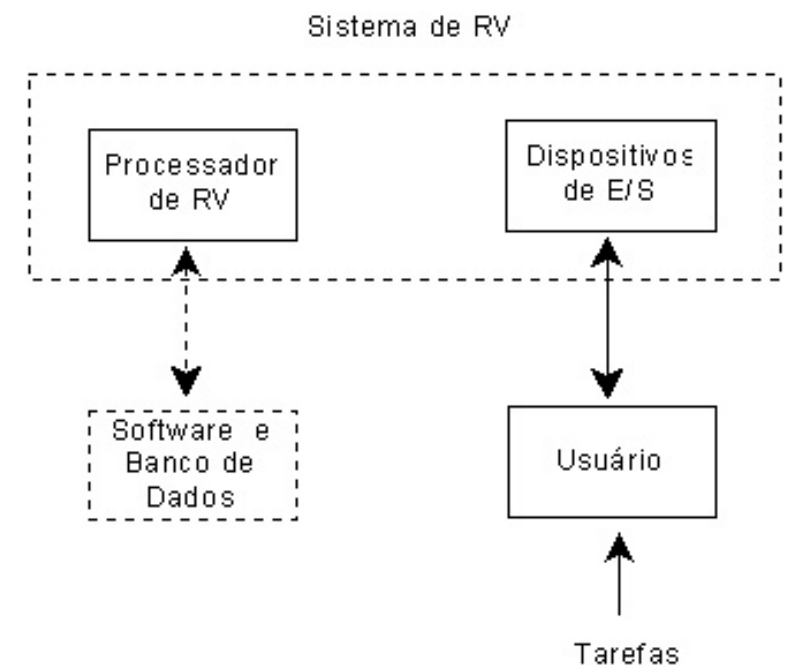

Figura 2.19: Visão geral de um sistema de RV (Pinho e Kirner, 1998).

De forma mais detalhada, Pinho e Kirner (1998) propõem que a estrutura de um sistema de RV também pode ser vista conforme mostrado na Figura 2.20. O usuário é conectado ao computador por meio de dispositivos multissensoriais, sendo que cada 
modalidade sensorial necessita de um processamento específico que permite incluí-la no sistema de RV.

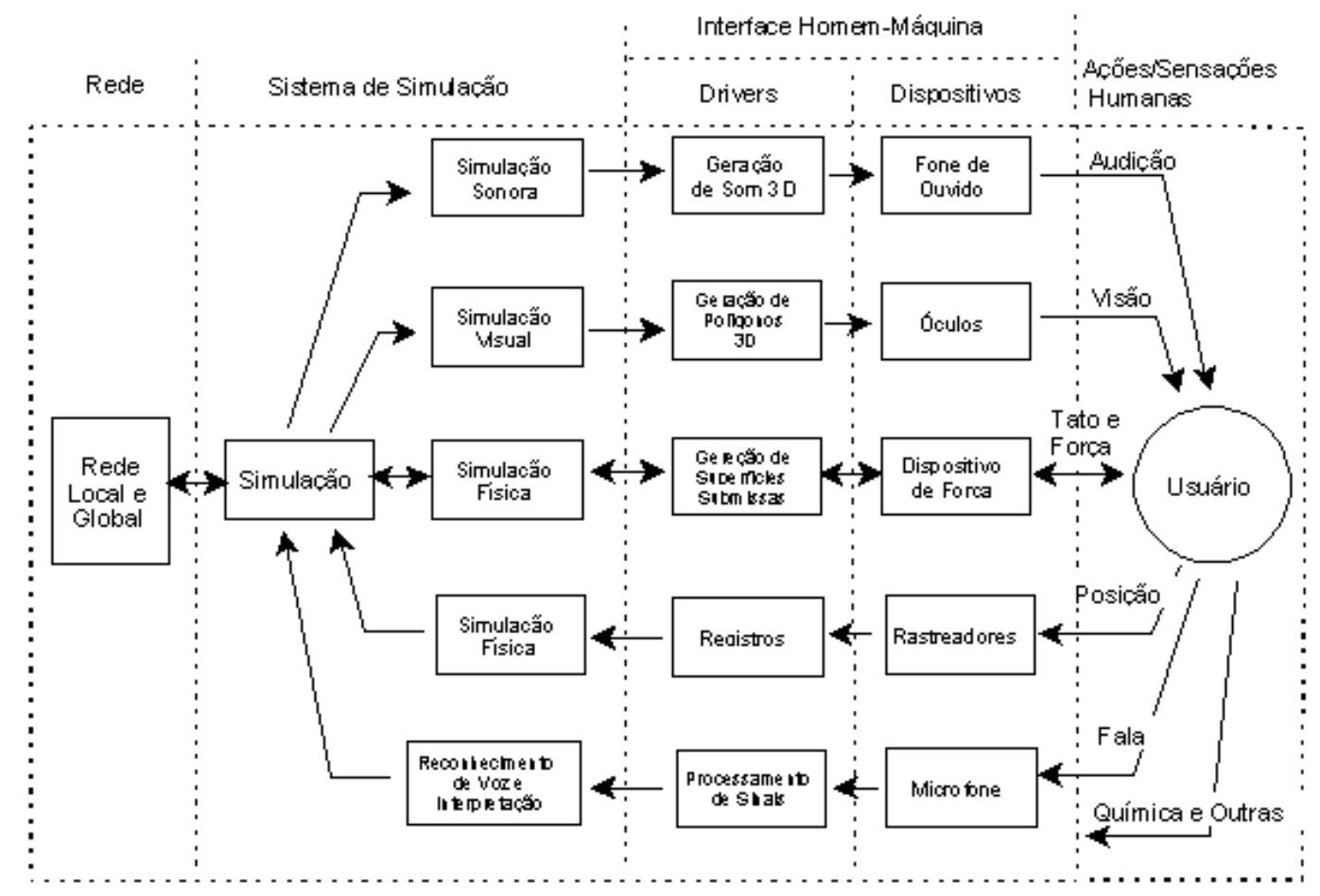

Figura 2.20: Estrutura detalhada de um sistema de RV (Pinho e Kirner, 1998).

Durlack e Mavor (1995) definem que um sistema de RV é um conjunto multimodal de interfaces usuário-computador que usa interação e técnicas de visualização considerando diversas modalidades sensoriais. O sistema sensomotor humano, como olhos, ouvidos, tato e fala, são conectados ao computador por meio de dispositivos que fazem a interface do usuário com o computador. Tais dispositivos geram saída ou recebem uma entrada do usuário por meio de um controlador para cada forma sensorial.

Calonego Jr et al. (2004) enfatizam que as aplicações gráficas tridimensionais exigem grande esforço computacional, mas é possível distribuir esse esforço entre processadores alocados em placas gráficas ou na placa principal do computador. Para que uma aplicação de RV tenha mais portabilidade, os autores propõem a utilização de um modelo de desenvolvimento com base no conceito de camadas, de acordo o diagrama disponibilizado na Figura 2.21.

\subsection{Considerações finais}

Neste capítulo foram apresentados os conceitos básicos referentes a PI, CBIR e RV que constituem a base teórica para compreender o conteúdo dos próximos capítulos. 


\begin{tabular}{|c|}
\hline Aplicações de RV \\
\hline Pacotes de RV \\
\hline Biblioteca Gráfica \\
\hline Sistema Operacional \\
\hline Dispositivo Gráfico \\
\hline
\end{tabular}

Figura 2.21: Camadas de abstração em um sistema de RV (Calonego Jr et al., 2004).

Em relação a PI, é importante destacar a forma como podem ser criados filtros genéricos para aplicar na imagem considerando o domínio espacial. As técnicas de PI constituem uma das bases computacionais para o tópico abordado na sequência, CBIR, visto que os extratores são construídos a partir delas.

Em relação a RV, além dos conceitos básicos, foram apresentados dispositivos de entrada e saída, além de características dos sistemas da área e suas classificações, que constituem tópicos importantes dentro do contexto deste trabalho.

O próximo capítulo apresenta aplicações considerando as três áreas aqui abordadas, abrangendo pesquisas realizadas no Brasil e no mundo. 


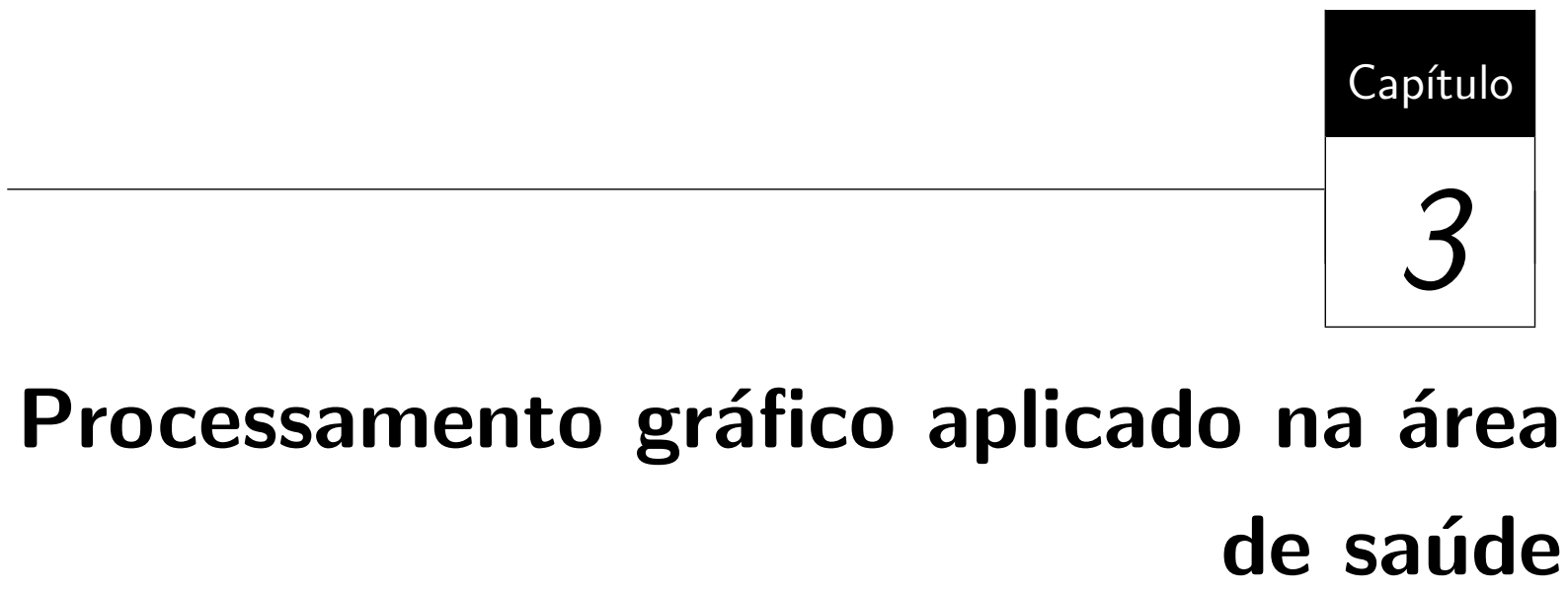

Nos últimos anos as aplicações de Computação na área de saúde vêm ganhando espaço em centros de pesquisa e muitas delas já se tornam produtos destinados à educação de profissionais e/ou ao auxílio ao diagnóstico. O nível de sofisticação exigido em tais aplicações faz com que técnicas computacionais inéditas sejam desenvolvidas e contribuam para o desenvolvimento da própria área de Computação, por meio da extrapolação de sua aplicação em áreas diversas.

Com o uso de técnicas de PI é possível diminuir ruídos, realçar e identificar estruturas, reconhecer padrões e, assim, auxiliar diagnósticos. A grande beneficiada com a RV é a educação médica, para a qual simulações e aplicações de simulação de procedimentos podem reduzir custos de treinamento, com flexibilidade e repetição de ações inúmeras vezes e por número ilimitado de usuários (Machado, 2003).

E, por fim, é também na área de imagens médicas que as técnicas de CBIR têm encontrado suas principais aplicações, proporcionando uma forma diferenciada de buscar conhecimento em bases de imagens e, consequentemente, contribuir com o diagnóstico.

Considerando esses contextos, na literatura há inúmeros exemplos de aplicações usando PI, RV e CBIR. A seguir são apresentados alguns deles, delimitando o foco em auxílio ao diagnóstico e treinamento médico, apesar de serem muitas as possibilidades de aplicação em outras atividades. Procura-se dar ênfase a trabalhos recentes dentro do escopo citado, 
sendo apresentadas pesquisas desenvolvidas em centros internacionais e no Brasil. Não é intenção esgotar a vasta lista de trabalhos disponibilizados na literatura e nem mesmo conduzir uma revisão sobre o assunto, mas mostrar a grande abrangência de objetos estudados, por meio da citação de trabalhos encontrados nas principais bases científicas da área de Computação.

Com a finalidade de facilitar a localização em relação aos assuntos abordados, inicialmente são apresentados trabalhos de laboratórios do exterior, divididos em seções, mantendo a sequência apresentada no capítulo 2. Foram consideradas as bibliotecas digitais do Institute of Electrical and Electronics Engineers(IEEE) ${ }^{1}$ e da Association for Computing Machinery $(\mathrm{ACM})^{2}$ para compor esta análise exploratória. Em seguida, são apresentados os trabalhos das três áreas (PI, RV e CBIR) desenvolvidos no Brasil.

\subsection{Processamento de Imagens}

Na literatura são diversos os sistemas citados visando ao auxílio ao diagnóstico que têm as imagens médicas como principal fonte de dados. Em geral, tais ferramentas têm como objetivos a melhoria de imagens, a detecção e a classificação de estruturas e anomalias. Embora os mais citados na literatura digam respeito à detecção precoce de câncer de mama e pulmão, outras patologias são contempladas, conforme apresentado a seguir.

$\mathrm{Na}$ área de diagnóstico de câncer de mama, um dos grupos mais estabelecidos é o do Laboratório Kurt Rossman, da Universidade de Chicago, que desenvolve CAD desde meados da década de 80. Membro deste grupo, Giger (2000) define o diagnóstico auxiliado por computador como aquele no qual o radiologista usa os resultados de uma análise computadorizada de imagens médicas como uma "segunda opinião" na detecção de lesões e na elaboração do diagnóstico.

Os trabalhos dessa equipe resultaram no primeiro CAD disponível comercialmente nos Estados Unidos para diagnóstico de câncer de mama. Uma visão geral de trabalhos sobre CAD e diagnóstico de câncer de mama auxiliado por computador desses pesquisadores pode ser conferida em Doi (2006) e Doi (2007), mostrando o quanto o uso desses sistemas pode contribuir para a diminuição de erros em diagnósticos usando imagens médicas. Além de detecção de câncer de mama, atualmente os pesquisadores deste Laboratório dedicam-se a CAD para câncer de pulmão e sistemas utilizando imagens provenientes de colonoscopia, angiografia digital, radiografia de ossos e angiografia, conforme pode ser conferido em Kurt Rossman (2010).

\footnotetext{
${ }^{1}$ http://ieeexplore.ieee.org

${ }^{2}$ http://portal.acm.org
} 
Considerando o contexto mais recente de desenvolvimento de sistemas para o auxílio ao diagnóstico de câncer de mama, Xiang-min et al. (2007) propuseram um CAD para identificação e classificação de doenças mamárias, usando características de forma de microcalcificações e densidade de nódulos. Yapa e Koichi (2007) apresentaram um algoritmo para identificar componentes conectados em mamogramas.

Para o diagnóstico de doenças pulmonares também há vasta literatura em relação a CADs. Com base nos padrões de tecidos do pulmão e segmentação utilizando características de textura, Shojaii et al. (2007) desenvolveram um CAD para diagnosticar cinco tipos de doenças de pulmão a partir de imagens de Tomografia Computadorizada (TC) pediátricas. Campadelli et al. (2005) desenvolveram técnicas de segmentação e classificação de nódulos pulmonares e Antonelli et al. (2005) apresentaram técnicas para extrair o parênquima pulmonar de imagens de TC a fim de identificar o volume de tal órgão.

Já considerando resultados na rotina médica, Rao et al. (2007) apresentaram o Lung$C A D$, um sistema usado clinicamente para detectar nódulos pulmonares sólidos, em imagens de TC de tórax, fornecendo, de acordo com os pesquisadores, resultados que confirmam o aumento da eficácia no diagnóstico quando radiologistas usaram o sistema citado.

As doenças cardíacas foram objetos de pesquisa de Dimitrova et al. (2007), que apresentaram uma interface para auxílio ao diagnóstico dessas patologias usando processamento de imagens multimodais, considerando ultrassom intravascular, angiogramas e eletrocardiogramas. O sistema proposto utiliza técnicas de segmentação para identificar bordas de vasos para avaliação de estenoses e, em seguida, técnicas de reconstrução de imagens para obter objetos 3D.

Também considerando anomalias cardíacas, Sonka et al. (2006) desenvolveram um sistema CAD para identificar riscos de aneurisma em imagens de Ressonância Magnética Nuclear (RMN) quadridimensionais (4D), no qual características da superfície e do movimento da aorta são identificadas por meio de técnicas de segmentação.

Usando PI e redes neurais, o trabalho de Zhang e Wang (2007) apresentou um CAD para classificar imagens de TC do cérebro em normais ou anormais, usando características de cor, forma e textura e o aspecto de simetria observado em cérebros humanos. Demir et al. (2005) apresentaram uma representação baseada em grafos para auxílio ao diagnóstico de câncer de cérebro usando imagens histopatológicas.

Na área de deteç̧ão de carcinomas de pele, Chaudhry et al. (2007) utilizaram atributos de textura e transformada wavelet para discriminar diferentes tipos de achados patológicos.

Em oftalmologia, Li et al. (2008) disponibilizaram uma abordagem para diagnosticar catarata nuclear com base nas características de cores e reflexos de imagens provenientes de lâmpada de fenda. 
Uchiyama et al. (2007) apresentaram um sistema CAD para detectar infarto lacunar assintomático em imagens de RMN com o objetivo de prevenir esta doença, utilizando técnicas diversas para segmentação de imagens, como crescimento de região, transformada top-hat e binarização de múltiplas fases.

É interessante destacar, ainda, os trabalhos de Estabridis e Figueiredo (2007) para o diagnóstico de retinopatia diabética; de Hao et al. (2008), destinado a auxiliar diagnóstico de hemorragia intracranial infantil e de Fang et al. (2006), que analisa padrões de imagens 3D de faces para identificar síndrome do álcool fetal em imagens de ultrassom.

Finalmente, como procedimento auxiliar na construção de sistemas CAD, Wang et al. (2008) propuseram uma técnica para eliminar ruídos e extrair contornos de imagens médicas, composta de duas partes: filtragem mediana em conjunto com transformada wavelet para eliminar ruídos na primeira parte e detecção de bordas e rastreamento do contorno para definição das estruturas, na segunda parte.

\subsection{Recuperação de Imagens Baseada em Conteúdo}

Os conceitos de CBIR vêm sendo aplicados em diversas áreas. Na área de saúde, essa categoria de busca tem sido mais uma aliada ao auxílio ao diagnóstico. Uma compilação das contribuições que têm sido disponibilizadas neste campo de pesquisa, realçando os desafios ainda existentes, pode ser conferida em Datta et al. (2008). A seguir são apresentados alguns trabalhos recentes abrangendo aplicações de CBIR para a área de saúde.

Para auxiliar na tomada de decisão clínica em oftalmologia, Acton et al. (2008) propuseram o uso de métodos de CBIR como estratégia de apoio à medicina baseada em evidências e melhoria do raciocínio baseado em casos. Usando imagens de RMN, análise de componentes principais e análise de discriminantes lineares, Dube et al. (2006) apresentaram um sistema para recuperar imagens de tumores de cérebros, classificando-as em imagens que continham lesões e imagens que não as continham.

Imagens de cérebro também constituíram o alvo do trabalho de Moustakas et al. (2005), autores de um sistema que fornece similaridade genérica e informações semânticas, além de Wan Ahmad e Fauzi (2008), que teceram um comparativo entre diferentes extratores que usam características de cor, textura, forma e intensidade.

Lamard et al. (2007) desenvolveram um sistema de CBIR sem extrações de características, mas usando assinaturas provenientes da distribuição proporcionada pela transformada wavelet. De acordo com os pesquisadores, o sistema conseguiu diferenciar com eficiência imagens médicas de uma base contendo imagens de faces, retinopatia e mamografia. 
Atributos de cor e textura foram usados por Zhu et al. (2006) para auxiliar no diagnóstico baseado em características da língua, usadas em técnicas de terapia da Medicina Chinesa.

Outro campo de pesquisa recentemente abordado para completar informações provenientes de extratores é o uso de ontologias, visando a preencher um espaço deixado entre as características obtidas por meio de técnicas de PI e os conceitos de alto nível exigidos pelo usuário. Com esta constatação, Ren e Barnaghi (2007) mostraram o uso de ontologias associado a um sistema de CBIR para recuperar corretamente imagens mamográficas em uma base de imagens.

Zhou et al. (2008) também abordaram essa questão discutindo a representação de aspectos de semântica, anatomia e patologias por meio de ontologias e avaliando o uso potencial de ontologias estabelecidas na literatura, relacionadas à área médica, como auxílio para melhorar o desempenho de sistemas de CBIR.

Considerando que os sistemas CBIR têm características comuns, Rahman et al. (2007) usaram um framework que disponibiliza métodos de aprendizagem de máquina e extratores estatísticos, direcionados para diferenciar imagens médicas provenientes de classes pré-definidas.

\subsection{Realidade Virtual}

Dentro do contexto de RV, o treinamento de procedimentos é o principal alvo das aplicações mais recentes. Hutchins et al. (2005) asseguram que o uso de sistemas de RV para treinamento médico proporcionam um aprendizado efetivo e transferência do aprendizado para ambientes reais. Os pesquisadores chegaram a tais assertivas por meio de análise qualitativa de evidências presentes em videotapes produzidos durante treinamentos virtuais usando um sistema colaborativo de simulação cirúrgica.

A transferência de aprendizado do virtual para o real também é assegurada por Johnsen et al. (2007), que conduziram experimentos de treinamento médico, considerando tanto pacientes virtuais quanto pacientes reais, concluindo que as habilidades adquiridas por meio do treinamento virtual são efetivamente transferidas para o ambiente real de treinamento.

Heng (2005) afirma que tradicionalmente estudantes de Medicina treinam diagnósticos, terapias e habilidades cirúrgicas em pacientes, mas as mudanças na economia relacionada à Medicina, os avanços nas cirurgias minimamente invasivas e a redução do tempo de hospitalização têm diminuído a disponibilidade de pacientes para os treinamentos. Por isso, os treinamentos com RV podem ser mais eficientes, atrativos e flexíveis. A partir dessas premissas, a autora apresenta trabalhos relacionados a aplicações para cirurgia 
do joelho (artroscopia virtual), treinamento de acupuntura e estudo de anatomia. As aplicações contemplam detecção de colisão e deformação em tempo real, além de retorno de força por meio de dispositivos hápticos. As duas primeiras aplicações usam objetos sintéticos para representar o corpo humano e os equipamentos médicos, enquanto que a última usa imagens fornecidas pelo projeto Visible Human (Ackerman, 1999).

Usando imagens reais provenientes de RMN, técnicas de segmentação e reconstrução de imagens para obter objetos 3D, Tang et al. (2007) apresentaram um sistema de neurocirurgia virtual, no qual o usuário pode navegar em um ventrículo virtual usando mouse convencional.

Goh (2005) conduziu uma revisão sobre o uso de RV nesta área, apresentando aspectos de educação, treinamento, planejamento pré-operativo e ensaios. Outra revisão focalizando a área de treinamento em intervenções cerebrais é apresentada por Nowinski (2005). Bastante interessante é a conclusão deste pesquisador, afirmando que sistemas simples e de baixo custo, sem grande sofisticação, atendem as necessidades de estudantes de Medicina e médicos.

$\mathrm{Na}$ área de ortopedia, Cote et al. (2008) disponibilizaram um simulador de cirurgia de escoliose, contemplando modelos biomecânicos específicos para cada paciente em um ambiente imersivo, colaborativo e com retorno háptico.

Em Yaacoub et al. (2007) foram avaliados métodos de detecção de colisão e foi proposta uma técnica usando programação linear para detectar colisão em tempo real visando a aplicações de simulação de cirurgia artroscópica do pulso.

Na Ásia é comum o desenvolvimento de sistemas de RV para treinamento de técnicas empregadas na Medicina Chinesa. Um sistema de treinamento para acupuntura foi apresentado por Kanehira et al. (2008), usando um dispositivo específico com sensores para simular a agulha real, além de fornecer um julgamento dos procedimentos executados em tempo real. Nesse contexto, Heng et al. (2006) também apresentaram um simulador de acupuntura que emprega redes de Petri com lógica fuzzy, a fim de permitir treinamento de estudantes para o tratamento de doenças diversas por meio desta técnica oriental.

Um dos tópicos que pode limitar a implementação de ferramentas para a área de treinamento médico é a ausência de objetos físicos que simulem dispositivos médicos com realismo. Como forma de suprir esta necessidade, McColl et al. (2006) desenvolveram uma interface mecânica para uso em aplicações de simulação de cirurgias de laparoscopia, capaz de considerar diversos atributos relacionados à sensação háptica. Os pesquisadores afirmaram que a inclusão de tal dispositivo aumentou em $12 \%$ a precisão do treinamento virtual. 
O uso de dispositivo específico com retorno háptico também foi abordado em Jung et al. (2008), que evidenciaram a importância da interação em simulações de endoscopia, broncoscopia e rinoscopia.

O realismo requerido como retorno para tais equipamentos é um desafio a ser vencido, envolvendo, na maioria das vezes, complexos modelos matemáticos que tratam simulação de deformações e colisões. Para suprir esta necessidade, Lindblad e Turkiyyah (2007) propuseram um framework que emprega o método de elementos finitos para implementar realismo em interações em tempo real, visando à simulação de incisões com retorno háptico.

A preocupação com realismo e interfaces adequadas também é explicitada no trabalho de Gallo et al. (2008), que propuseram o uso de um dispositivo manual sem fio e reconhecimento de voz como uma forma intuitiva de interação para manipulação de volumes reconstruídos a partir de dados médicos.

Relacionado com laparospia virtual, Soler et al. (2008) apresentaram um sistema que permite a visualização de objetos 3D reconstruídos a partir de imagens de TC ou RMN, além de disponibilizar informações adicionais ao usuário por meio de notas incluídas no sistema usando Realidade Aumentada.

Delingette e Ayache (2005) simularam cirurgia hepática minimamente invasiva, disponibilizando módulos para planejamento cirúrgico e treinamento dos movimentos necessários durante a cirurgia.

Outras áreas correlatas à Medicina também são contempladas. Resultante de um trabalho colaborativo entre 11 instituições pertencentes a 6 países europeus, La Mura et al. (2007) apresentaram um sistema de simulação de atendimento médico emergencial, tendo como cenário um estádio que deve ser evacuado.

Deutsch et al. (2006) apresentaram a evolução de pacientes após o uso de sistemas de telerreabilitação com tecnologias de RV. O sucesso das aplicações de telerreabilitação também é afirmado por Virk e McConville (2006), que propuseram um sistema de RV para melhorar o controle postural e minimizar tombos em pessoas idosas.

\subsection{Aplicações desenvolvidas no Brasil}

No Brasil, as principais publicações a respeito de aplicações das especialidades anteriormente abordadas são divulgadas por meio de eventos científicos de cada área - principalmente Brazilian Symposium on Computer Graphics and Image Processing (SIBGRAPI, recentemente renomeado para Conference on Graphics, Patterns and Images), Symposium on Virtual and Augmented Reality (SVR) e alguns outros workshops - ou eventos relacionados à computação aplicada à área de saúde ou Engenharia Biomédica como Workshop 
de Informática Médica (WIM), Congresso Brasileiro de Informática em Saúde (CBIS) e Congresso Brasileiro de Engenharia Biomédica (CBEB).

Embora haja vários grupos de pesquisa trabalhando com PI, CBIR e RV, as aplicações citadas a seguir se restringem a considerar alguns dos artigos de pesquisadores brasileiros que focalizam suas aplicações na área de saúde. Salienta-se, entretanto, que esta seleção tomou por base os artigos publicados nos eventos citados nos últimos anos que mais estavam relacionados com o escopo delimitado no presente trabalho. Obviamente não esgota todas as publicações existentes. Nas citações a seguir também são consideradas publicações de pesquisadores brasileiros inseridas em eventos do IEEE e da ACM.

$\mathrm{Na}$ área de PI, focalizando aplicações de auxílio ao diagnóstico, é importante citar o trabalho de Pires et al. (2006), que apresentaram um método para interpolação de fatias de imagens de CT; Duque et al. (2007), que propuseram um método para detectar regiões ativas do cérebro usando imagens de RMN; Favretto et al. (2008), que desenvolveram um método rápido para registro de imagens 3D de cérebro provenientes de RMN; Parraga et al. (2007), que construíram um atlas 3D com base na análise de campos densos de deformação, além de Matsumoto et al. (2008) e Sales et al. (2008), que propuseram técnicas integradas para auxílio ao diagnóstico de doenças cardíacas.

Especificamente em relação a sistemas CAD para detecção de câncer de mama, destacam-se os trabalhos de Matheus e Schiabel (2010), Nunes et al. (2007b), Guliato et al. (2008b) e Guliato et al. (2008a). Essa área continua sendo bastante explorada em trabalhos recentes.

Usando técnicas de PI, mas abordando sistemas de CBIR, Dorileo et al. (2008) usaram características de cor e textura para diferenciar lesões de pele. A recuperação de imagens mamográficas também foi objeto de estudo de Felipe et al. (2006), que usaram momentos de Zernike para reconhecimento de padrões invariantes sem necessidade de segmentação prévia das imagens.

Uma área recentemente explorada em CBIR é a realimentação de relevância (ou relevance feedback), na qual o usuário intervém no sistema para indicar quais são, de fato, as imagens relevantes dentre um conjunto de resultados disponibilizados em uma consulta. As indicações realimentam o sistema a fim de melhorar o desempenho do mesmo. Nesse contexto, Rosa et al. (2008) conduziram experimentos com radiologistas que identificaram imagens relevantes de nódulos em mamogramas, concluindo que a técnica aumentou em torno de $40 \%$ a precisão do sistema.

Os componentes de sistemas CBIR aplicados a imagens médicas são intensamente explorados por equipes do Instituto de Ciências Matemáticas e de Computação (ICMC-USP), Faculdade de Medicina de Ribeirão Preto (FMRP-USP), Instituto do Coração do Hospital das Clínicas da Faculdade de Medicina da USP (INCOR-USP) e do Instituto de Compu- 
tação da Universidade Estadual de Campinas (IC-Unicamp), entre outros, destacando-se como trabalhos mais recentes: Traina Jr et al. (2007), Furuie et al. (2007), Felipe et al. (2008), Razente et al. (2008), Ribeiro et al. (2008), Barione et al. (2008), Torres et al. (2009), Silva et al. (2010) e Andaló et al. (2010).

Na área de RV, percebe-se que também vem crescendo em qualidade e quantidade os trabalhos realizados por pesquisadores brasileiros.

O AnatomI (Cunha et al., 2006) é um atlas digital de uso livre e permite, de forma interativa, a manipulação e o estudo de estruturas tridimensionais do corpo humano com textos descritivos contendo informações sobre cada estrutura. Com o objetivo de facilitar o estudo de anatomia e fisiopatologia do câncer de mama, Ramos et al. (2005b) apresentaram um atlas virtual que permite o acesso a uma base dados, fornecendo informações sobre as estruturas durante a navegação, além de possibilitar a visualização do crescimento de tumores malignos em estruturas mamárias selecionadas pelo usuário.

A implementação de um sistema voltado para o tratamento de fobias de direção foi abordada por Paiva et al. (2005). De acordo com os autores, a principal contribuição do sistema é a flexibilidade que permite a customização de rotas conforme o perfil do paciente.

Um grupo de pesquisadores da Universidade Federal do Rio de Janeiro (UFRJ) e da Universidade Estadual do Rio de Janeiro (UERJ) vem conduzindo experimentos com ambientes virtuais 3D para estimular a realização de atividades rotineiras em pessoas com sequelas de atenção e percepção, causadas por Acidente Vascular Cerebral (AVC). Conforme descrito em Cardoso et al. (2006), os pacientes têm aceitado com muito entusiasmo o trabalho nos ambientes virtuais e os resultados obtidos têm apresentado uma significativa recuperação dos níveis de atenção e concentração nas atividades cotidianas.

$\mathrm{Na}$ área de treinamento odontológico, destacam-se o sistema de treinamento de tratamento ortodôntico de Rodrigues et al. (2006) e os trabalhos sobre cirurgias maxilofaciais citados por Trevisan et al. (2007), Trevisan et al. (2008) e Olszewski et al. (2008).

Considerando treinamentos e simulações cirúrgicas, destacam-se ainda os trabalhos de Balaniuk et al. (2006), que apresentaram simulação cirúrgica da mama para efeitos cosméticos; Alberio e Oliveira (2006), que propuseram um ambiente para simular cirurgia cardíaca e o sistema para treinamento de exames ginecológicos de Souza et al. (2006).

Conforme explorado nos próximos capítulos, construir aplicações para a saúde exige grande esforço, desde a análise de requisitos até a implementação e a validação. Por isso, alguns pesquisadores têm oferecido componentes de software com funcionalidades específicas para a área de saúde, contribuindo para o aumento de produtividade na implementação de ferramentas específicas dentro de alguns domínios. É o caso de Frameworks para au- 
xiliar na produção de ferramentas, abordados por Nunes et al. (2007a), Oliveira e Nunes (2010) e Cunha et al. (2006).

\subsection{Considerações finais}

Após a apresentação de conceitos sobre PI, CBIR e RV no capítulo anterior, este capítulo teve o objetivo de apresentar trabalhos desenvolvidos dentro dessas três áreas de pesquisa, especificamente destinados à área de saúde, que constitui o foco do presente documento, procurando-se citar trabalhos recentes realizados em diversos países e também no Brasil.

A partir dos trabalhos apresentados, é possível verificar que, embora nos últimos anos tenha crescido a quantidade e a qualidade das aplicações em saúde envolvendo as áreas abordadas, os resultados obtidos no Brasil são, na sua maioria, ainda limitados a escopos de pesquisa acadêmica. Esse fato é deduzido quando observa-se que a quase totalidade dos artigos publicados não cita a inserção das aplicações na rotina dos profissionais de saúde. Enquanto em vários países essas aplicações já se tornam produtos que fazem parte da rotina de trabalho de profissionais da saúde, de forma geral os grupos de pesquisa brasileiros ainda não conseguiram transferir efetivamente para o setor produtivo, e nem mesmo para a educação médica, os resultados de suas pesquisas (ou, então, tal fato não foi reportado nos artigos citados).

Nos próximos capítulos são apresentados requisitos para construir aplicações de RV para treinamento médico, além de alguns resultados obtidos pela pesquisadora e sua equipe, envolvendo as áreas citadas. Em seguida, no capítulo 6, é tecida uma reflexão mais aprofundada sobre os desafios e as oportunidades no cenário brasileiro, de forma a apresentar os diversos aspectos que necessitam de pesquisa e desenvolvimento para que os resultados obtidos possam, de fato, trazer benefícios sociais e econômicos ao país. 


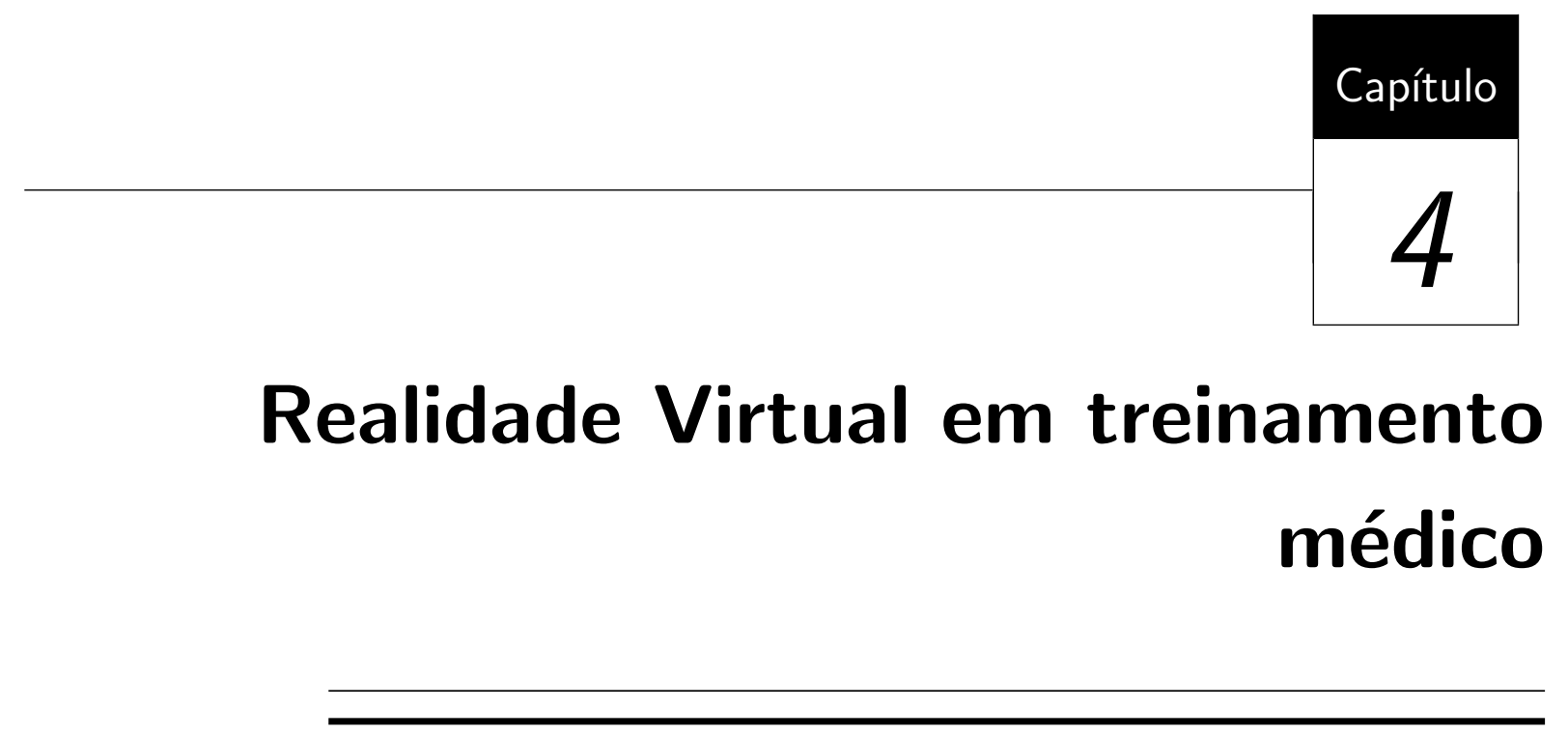

A dificuldade em obter materiais físicos (como cadáveres e cobaias), o alto custo de manutenção desses materiais, a possibilidade de repetição do treinamento, entre outras razões, tornam o treinamento virtual uma alternativa efetiva para o aprendizado na área de saúde.

A tridimensionalidade e a interação fornecidas pelas técnicas de RV, além da possibilidade de extrapolar os procedimentos reais por meio de ações e visualizações permitidas somente em aplicações de simulação, são atrativos que tornam essa tecnologia promissora para a implementação de aplicações destinadas ao treinamento virtual.

É interessante citar, adicionalmente, a tecnologia de Realidade Aumentada (RA), que além das características da RV, permite anexar objetos virtuais a cenas do mundo real, como já mencionado no capítulo 2 (Azuma, 1997).

No entanto, a construção dessas ferramentas não constitui uma tarefa trivial. Há vários requisitos que devem ser contemplados para que as aplicações geradas apresentem características próximas às reais.

Neste capítulo, primeiramente são discutidos alguns desses requisitos e algumas das tecnologias de software mais utilizadas atualmente que facilitam alcançar tais exigências. A elaboração desses requisitos constitui uma contribuição da autora, tecida a partir da experiência obtida durante as pesquisas conduzidas para construir ferramentas para treinamento médico. Em seguida, são apresentados resultados obtidos por pesquisas con- 
duzidas pela autora e sua equipe. Em cada seção são incluídas as principais publicações referentes ao tema abordado.

\subsection{Requisitos}

O uso de ferramentas de treinamento virtual na rotina da educação na área de saúde exige a reprodução de sensações próximas às reais, ou seja, as ferramentas devem ser capazes de gerar a sensação de presença em seus usuários, a qual ser obtida por meio do estímulo dos sentidos humanos (tato, visão e audição).

Conforme afirmado em Nunes e Costa (2008a), a sensação de presença é dependente não somente das qualidades físicas (resolução, realismo, interatividade, tempo de resposta), mas também da bagagem psicológica do usuário. Cada pessoa reage de maneira diferente quando exposta à mesma situação real ou virtual (Baños et al., 2000). Mesmo considerando este componente de individualidade, North et al. (1998) observam que a concentração nas atividades realizadas no AV está diretamente relacionada com o nível de interação e com a adequação dos equipamentos de entrada e saída.

\subsubsection{Dispositivos de interação e visualização}

É possível construir ferramentas fazendo uso de dispositivos convencionais de entrada e saída como mouse, teclado e monitores comuns. No entanto, a maioria das aplicações destinadas a treinamento de procedimentos somente oferece realismo se houver emprego de dispositivos que proporcionem imersão e interação adequadas.

De grande utilidade são os rastreadores de posição, dispositivos que fornecem posicionamento em tempo real e orientação de movimento de objetos ou pessoas. As luvas de dados também têm sido amplamente empregadas em experimentos nos quais é necessária a manipulação de objetos. Conforme já mencionado no capítulo 2, esses dispositivos podem capturar os movimentos das mãos e dos dedos, fazendo com que as respostas do ambiente sejam compatíveis com tal movimentação.

Considerando a necessidade de reproduzir ações adequadas para interação, de especial importância para as ferramentas destinadas ao treinamento virtual de procedimentos são os equipamentos hápticos, que permitem medir a intensidade de força imprimida pelo usuário e proporcionar um feedback em função da força aplicada. São bastante utilizados em aplicações que simulam a manipulação de dispositivos médicos para realização de procedimentos clínicos e cirúrgicos.

Para proporcionar visão estereoscópica, que favorece a percepção de profundidade, são utilizados dispositivos diversos. Óculos estereoscópicos construídos com tecnologias e preços variados são os mais comuns. Outro equipamento muito utilizado na área médica 
é vídeocapacete, o HMD (capítulo 2), que permite isolar o usuário do mundo real e projetar imagens capazes de propiciar alto grau de presença. Entretanto, está no grupo de equipamentos de saída que mais gera problemas de saúde em seus usuários, tais como náuseas e tonturas (Reitinger et al., 2007). Os HMDs são utilizados em variados tipos de aplicações médicas, desde tratamentos de fobias e problemas neuropsiquiátricos até a visualização de imagens para procedimentos cirúrgicos, por meio de técnicas de Realidade Aumentada (Reitinger et al., 2007). Dentro dessa categoria também estão as CAVEs, que, além de sensores de movimento, podem utilizar som 3D, gerando sensações bastante reais. Sua grande vantagem é permitir que várias pessoas compartilhem simultaneamente a mesma experiência (Tarr e Warren, 2002).

\subsubsection{Objetos tridimensionais}

Conforme mencionado em Nunes e Costa (2008a), nas ferramentas de treinamento virtual na área de saúde objetos 3D são usados para representar pacientes, equipamentos, ambientes (consultórios, salas de cirurgia) e órgãos humanos.

As ferramentas para modelagens 3D oferecem inúmeros recursos para a construção desses objetos sintéticos. Por meio de elaboração artística de malhas é possível gerar objetos com características bem próximas das reais. No entanto, se o treinamento exigir casos específicos, como, por exemplo, a simulação de um procedimento cirúrgico para um determinado paciente, o ideal é que os objetos sejam construídos a partir de dados provenientes de imagens médicas reais, geradas por meio de modalidades de imagens médicas.

As modalidades de diagnóstico por imagens se estabeleceram há algum tempo, valendo-se de uma variedade de técnicas de aquisição como Tomografia Computadorizada (TC), Ressonância Magnética Nuclear (RMN) e Ultrassonografia (US), sendo que cada uma delas considera diferentes características do corpo humano para formar a imagem.

$\mathrm{Na}$ TC, a imagem deriva do tratamento informatizado dos dados obtidos numa série de projeções angulares de raios-X. De maneira simplificada, a imagem apresentada traduz uma seção transversal (uma "fatia") do corpo do indivíduo, conforme citam Wagner et al. (2003).

A RMN é uma técnica que permite determinar propriedades de uma substância por meio da correlação da energia absorvida com a frequência, na faixa de MegaHertz, do espectro eletromagnético. Usa propriedades dos núcleos dos átomos ou íons para mapear os tecidos, sob a influência de um campo magnético, produzindo imagens de alta qualidade (Hennel e Klinowski, 1993).

A US é uma modalidade de imagem médica que aproveita o eco produzido pelo som para compor, em tempo real, as sombras produzidas pelas estruturas e órgãos do orga- 
nismo. Ao encontrarem um anteparo, as ondas sonoras são refletidas, retornando ao seu ponto de origem. Se for medido o tempo despendido desde a emissão até a recepção do sinal de retorno, pode-se determinar com boa precisão a distância percorrida, sendo possível a tradução em uma escala de cinza, que formará a imagem dos órgãos internos (Handolin et al., 2007). Exemplos de imagens geradas por essas modalidades são apresentados na Figura 4.1.

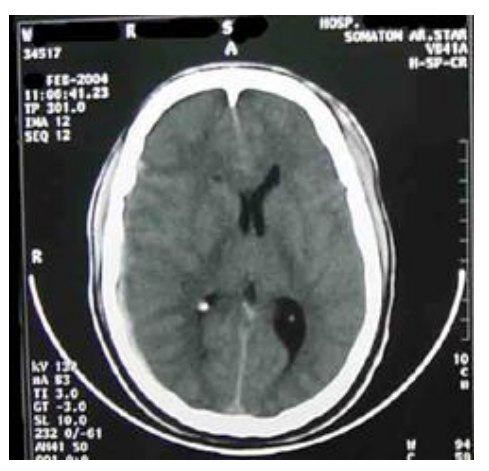

(a) Tomografia Computadorizada

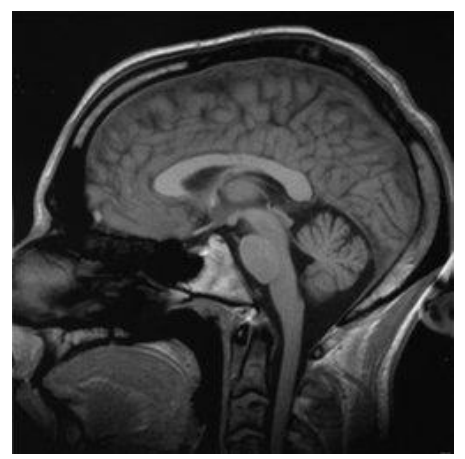

(b) Ressonância Magnética Nuclear

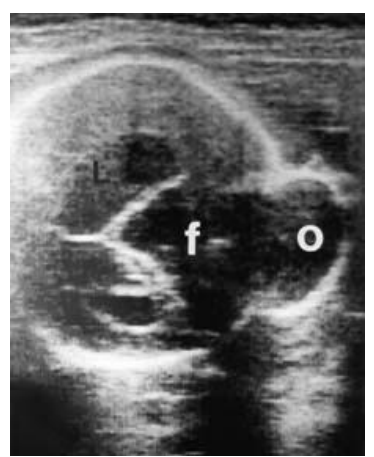

(c) Ultrassonografia (cérebro de feto)

Figura 4.1: Imagens de cérebro obtidas por diferentes modalidades (Sayeg, 2010).

As modalidades que geram seções transversais (RMN, TC, entre outras) permitem um mapeamento direto para objetos virtuais 3D, aplicando-se técnicas de reconstrução de imagens. Para aquelas que geram apenas algumas visões, como US 2D e mamografia, é possível aplicar técnicas de simulação dos objetos 3D a partir de medidas extraídas das imagens 2D. Um exemplo desse tipo de simulação é apresentado na seção 4.5.

\subsubsection{Detecção de colisão}

Para muitas aplicações construídas para a área de saúde, principalmente quando o objeto de pesquisa é a simulação de procedimentos, aspectos como precisão, tempo de resposta, conhecimento do local de impacto e verificação de interpenetração entre os objetos são fundamentais. Por isso, a detecção de colisão torna-se um fator extremamente relevante nessa classe de aplicações.

Lau et al. (2002) classificam a detecção de colisão em dois grandes grupos: detecção em objetos rígidos, que envolve o teste de penetração de um objeto em outro e detecção em objetos deformáveis (superfícies flexíveis), que trata, além da interação entre os objetos, das deformações causadas por esta interação. Na detecção de colisão em objetos rígidos, podem ser utilizadas três aproximações: subdivisão hierárquica do espaço, subdivisão hierárquica do objeto e cálculo incremental da distância. 
Os métodos de colisão em objetos deformáveis, por sua vez, são baseados na subdivisão hierárquica do objeto, a qual pode considerar objetos de dois tipos: representados por polígonos encadeados e representados por superfícies paramétricas (mapeamentos de algum subconjunto do plano ao espaço). No primeiro caso, os objetos são deformados alterando-se as posições dos vértices dos polígonos. Já os representados por superfícies paramétricas são, geralmente, deformados pela alteração do controle de pontos da superfície (Lau et al., 2002).

\subsubsection{Deformação}

Ambientes Virtuais para treinamento em saúde podem ser compostos de objetos estáticos, os quais mantêm a mesma forma durante toda sua existência e dinâmicos, que mudam de posição, forma ou aparência devido a alguma ação ocorrida. Para que um AV seja realista, é necessário planejá-lo da forma mais próxima ao cotidiano, definindo suas ações e reações.

A deformação é uma das reações a serem analisadas, sendo que o comportamento dos objetos deformados é representado por uma simulação geométrica, física ou híbrida. Choi et al. (2002) definem a simulação geométrica como aquela baseada em manipulações de dados geométricos como vértices e pontos. A simulação física utiliza a dinâmica, ramo da física que estuda as relações entre as forças e os movimentos que são produzidos por essas, ou seja, se preocupa com a causa e a consequência dos estímulos inseridos em um ambiente (Ramalho Jr. et al., 1993).

Conforme verificado em Pavarini (2006), na literatura três técnicas são mais citadas para se obter deformação de objetos em aplicações de RV: Deformação Livre de Forma (Free Form Deformation - FFD) (Gibson e Mirtch, 1997), Massa-Mola (Mass Spring $M S)(Z i l l, 2003)$ e Elementos Finitos (Finite Elements - FE)(Gladlin, 2003).

Na FFD, o objeto é envolvido por uma grade que sofre deformação. Mesmo sendo versátil, Choi et al. (2002) afirmam que nesse método é difícil limitar as deformações para pequenas regiões, dificultando a obtenção de realismo na cena.

A característica principal dos Elementos Finitos é a discretização da malha de um domínio contínuo em um conjunto de subdomínios discretos. A discretização do domínio é o primeiro passo em qualquer análise de elementos finitos, pois a maneira na qual o domínio é discretizado afetará as exigências de armazenamento no computador, o tempo de processamento e a precisão dos resultados numéricos (Hirota et al., 1999). A teoria da elasticidade afirma que a deformação de um corpo é proporcional à tensão aplicada desde que o limite elástico do material não seja excedido (Zill, 2003). A análise de qualquer tipo de estrutura pode ser feita pela integração das equações da teoria da elasticidade. 
As dificuldades para realizar essa integração levam, porém, à formulação de modelos matemáticos aproximados (Hirota et al., 1999).

Por fim, o método Massa-Mola é uma técnica baseada na física que permite a remodelagem de objetos deformados usando nós de massa conectados por molas. A mola pode ser considerada como uma estrutura que possui elasticidade e permite a deformação quando nela é exercida uma pressão. A força de uma mola é normalmente linear, baseada na lei de Hooke, mas molas não lineares podem ser usadas para simularem tecidos como pele humana, que exibem um comportamento não elástico (Zill, 2003).

\subsubsection{Estereoscopia}

Em RV, a sensação de imersão é otimizada usando-se conceitos de estereoscopia (capítulo 2). Há vários métodos para se obter esta sensação.

Johanson (2001) apresenta a técnica de vídeo estereoscópico, no qual posicionam-se duas câmeras em posições distintas, que geram imagens ligeiramente deslocadas.

O método de polarização da luz baseia-se na utilização de filtros, fazendo com que as imagens de um par estereoscópico sejam projetadas em planos verticais e horizontais (Machado, 2003). Outra técnica é a utilização de óculos obturadores com lentes de cristal líquido, que ficam instantaneamente transparentes ou opacas de acordo com um sistema de controle prévio, sincronizados com a imagem projetada.

Destaca-se, ainda, a visualização do par estéreo Lipton (2005), na qual são apresentadas duas imagens, lado a lado, de forma com que cada imagem seja posicionada levando em conta a distância entre os olhos do observador.

O método de estereoscopia que utiliza cores e diferentes profundidades codificadas é denominado "Disparidade Cromática". Essa técnica baseia-se na utilização de lentes especiais, as quais realizam a codificação das profundidades por meio de suas cores. As lentes mudam a trajetória da luz que as atravessa de acordo com a cor do objeto, gerando o efeito estéreo.

Na técnica de anaglifos os objetos são obtidos por uma combinação finita (azul-vermelho ou verde-vermelho) de cores, gerando uma sensação de profundidade e imersão no ambiente. O emprego dessa técnica requer a disponibilização de um par de imagens em cores diferentes, correspondente a duas perspectivas de um mesmo objeto. Essas serão vistas, respectivamente, pelas lentes com as mesmas cores, que atuarão como filtros para a visualização. 


\subsubsection{Precisão e tempo de resposta}

$\mathrm{Na}$ área de treinamento em saúde, há várias vertentes que podem ser abordadas pelas aplicações. Alguns exemplos são treinamento de tarefas administrativas para profissionais da saúde (Lynko, 2011), treinamento de hábitos alimentares (Thrive, 2011) ou de higiene (Bertrand et al., 2010) e, bem mais comumente, treinamento de procedimentos como os descritos em Machado (2003), Heng (2005) e Cote et al. (2008). Independentemente do procedimento que constitui o objeto de pesquisa, para que os simuladores sejam realistas, é necessário que a resposta ocorra em tempo real e que os métodos implementados forneçam precisão.

Em Computação, a expressão tempo real, em geral, refere-se à interação simultânea entre sistemas ou pessoas, com intervalos muito curtos ou com implicações sérias em relação ao nível do atraso. É, portanto, uma operação em que o par ação/reação deve demorar menos tempo que o atraso máximo permitido pelo sistema (Shaw, 2003). Assim, não há uma medida exata de tempo que indica se a execução de um sistema está atingindo o requisito de tempo real, visto que tal mensuração depende do sistema sob avaliação.

Em RV, as aplicações devem atender ao requisito de fornecer uma resposta dentro de um tempo máximo a fim de que o usuário tenha a sensação de que a reação do sistema é imediata à ação executada no AV. Este fator não é obtido trivialmente, visto que a manipulação de malhas que representam objetos 3D, a interação por meio de dispositivos convencionais e não convencionais e o uso de bibliotecas gráficas contribuem para a adição de atrasos no sistema.

A precisão é outro requisito que merece ser citado. Ao contrário de outros campos de aplicações, como indústria e entretenimento, a área de saúde, muitas vezes, usa objetos virtuais que representam partes do corpo humano de tamanho diminuto. Em uma aplicação de simulação de biópsia, por exemplo, erros na ordem de milímetros são inadmissíveis. A necessidade de realismo exige que muitos sistemas, principalmente aqueles que simulam procedimentos, forneçam precisão em relação à modelagem e manipulação de objetos. E este requisito pode ser conflitante com a necessidade de respostas em tempo real. O planejamento adequado de aplicações deve prever uma relação de equilíbrio entre esses fatores a fim de que a utilização dos sistemas desenvolvidos torne-se viável.

\subsection{Tecnologias de software}

Como pode ser observado, os requisitos que merecem atenção durante a construção de ferramentas para treinamento em saúde usando RV podem fazer com que o processo de implementação seja demorado e com alto custo. No entanto, diversas tecnologias têm sido disponibilizadas a fim de auxiliar nas implementações, permitindo reuso de software. A 
seguir são citadas algumas disponibilizadas gratuitamente, sendo que o critério de seleção foi identificar as mais citadas na literatura durante a condução das pesquisas descritas mais adiante.

A Virtual Reality Modeling Language (VRML) é provavelmente a linguagem mais simples para aqueles que estão iniciando a experiência de implementar ambientes 3D interativos. É uma linguagem independente de plataforma que permite a criação de AVs com características de animação, movimentos de corpos e interação entre usuários (Ames et al., 1997). É executada em navegadores da Internet, sendo necessários plugins, também disponíveis gratuitamente. A linguagem trabalha com geometria 3D e suporta transformações (rotação, translação, escala), texturas, luz e sombreamento, além do mecanismo de Nível de Detalhe ( $L O D$, level of detail), responsável por disponibilizar a quantidade necessária de dados para um objeto com base na sua importância na cena. Embora considerada ultrapassada por alguns pesquisadores por ter o X3D como sua evolução (Web3D Consortium, 2011), esta linguagem ainda é bastante empregada para o ensino de RV para iniciantes.

A Direct3X (Microsoft, 2011) é uma coleção de APIs (Application Programming Interface) utilizada principalmente para desenvolver aplicativos 3D interativos e em tempo real. Entre seus principais recursos úteis para implementar aplicações de RV em saúde estão bibliotecas para inserção de dispositivos de interação como joysticks e controladores de jogos (DirectInput), comunicação em rede (DirectPlay) e manipulação de sons 3D (DirectSound3D).

A Open Graphics Library (OpenGL), descrita por Kilgard (1997), é uma API multiplataforma e multilinguagem para a escrita de aplicações capazes de produzir gráficos computacionais bidimensionais e tridimensionais, composta por um conjunto de funções que permitem aos desenvolvedores acessar os recursos gráficos sem atingir o nível de hardware. Fornece suporte a recursos de iluminação, mapeamento de textura, transparência, animação, entre outros. A API fornece ainda um pequeno conjunto de primitivas gráficas para construção de modelos, tais como pontos, linhas e polígonos.

A API Java3D é disponibilizada pela Sun Microsystems Inc. (Sun Microsystems, 2011), recentemente incorporada pela empresa Oracle, destinada à construção de aplicações e applets em linguagem Java. Fornece suporte a som 3D, animação, interação, renderização paralela e otimizada. Consiste em uma hierarquia de classes que permite ao programador trabalhar com construções de alto nível para criar e manipular objetos 3D geométricos. Além disso, disponibiliza classes e métodos para a implementação de drivers necessários ao desenvolvimento de aplicações que utilizam dispositivos não convencionais para interação, visualização e navegação.

$X 3 D$ é um formato de arquivo livre utilizado para representar cenas e objetos 3D usando XML (Extensible Markup Language). É um padrão desenvolvido pelo Web3D 
Consortium, um forum destinado à criação de padrões abertos para especificações para a Web3D (aplicações tridimensionais para a Internet). De acordo com o Web3D Consortium (2011), o X3D fornece um sistema de armazenamento, recuperação e execução de objetos gráficos em tempo real, oferecendo uma arquitetura capaz de suportar uma grande quantidade de domínios e cenários do usuário. Para muitos pesquisadores, incluindo aqueles participantes do próprio Web3D Consortium, o X3D é uma evolução da $V R M L$.

A OGRE (Object-Oriented Graphics Rendering Engine) (Ogre3D, 2011) destaca-se por poder ser utilizada em diferentes plataformas com diversas configurações. Além disso, ela provê diversos plugins e ferramentas para gerar aplicações gráficas, fornecendo recursos para implementar texturas, iluminação, animação, entre outros.

Outra biblioteca gratuita é a Panda3D que permite adicionar código escrito na linguagem Phyton. Oferece rotinas de renderização gráfica, suporte a estereoscopia com anaglifo e multiplexação, dentre outras funcionalidades, além de permitir ligar seu código a rotinas em C++ (Panda3D, 2011).

Especificamente para RA, a biblioteca mais conhecida atualmente é a ARToolKit (ARToolKit, 2011), que visa a oferecer um conjunto de ferramentas para suporte à captura e à sobreposição de imagens em cenários reais. Fornece suporte ao rastreamento óptico e implementa técnicas de visão computacional para capturar e identificar marcadores, utilizados para posicionar e manipular objetos virtuais nas cenas que compõem o AV. Além disso, disponibiliza utilitários para configurar e testar o sistema de captura e reconhecimento dos marcadores.

A partir dessas ou de outras linguagens e bibliotecas, alguns grupos de pesquisa têm trabalhado para construir pacotes de software específicos para o desenvolvimento de aplicações de RV e RA para a área de saúde.

Uma dessas bibliotecas é a MVL (Medical VR Simulation Library) (Kuroda et al., 2005), que oferece métodos para manipulação múltipla de dispositivos e deformação interativa, além de suporte a dispositivos hápticos. Outra biblioteca é a SSTML (Surgical Simulation and Training Markup Language) (Bacon et al., 2006) que permite a integração de diferentes linguagens no processo de desenvolvimento e é voltada para a simulação de procedimentos cirúrgicos.

O framework Julius é uma arquitetura de software para visualização, simulação e navegação na área médica. De acordo com os autores, provê interfaces para combinar várias funcionalidades, permitindo construir aplicações de cirurgias guiadas por computador em ambientes simples, assim como drivers para rastreadores e dispositivos hápticos (Keeve et al., 2001). Outro framework nesta área é o MeVisLab, desenvolvido para fornecer algoritmos de processamento de imagens, visualização de métodos de interação, com foco em imagens médicas (Muhler et al., 2010). 
No Brasil, algumas iniciativas estão sendo conduzidas nesse contexto. O VPat ( Virtual Patients) é um framework desenvolvido com o propósito de suportar aplicações de computação gráfica na área médica, com o objetivo de permitir que sistemas de visualização e exploração de dados médicos possam ser fácil e rapidamente projetados e desenvolvidos (Freitas et al., 2003).

A biblioteca CyberMed (Machado et al., 2009) tem como objetivo apoiar o ensino e o treinamento médico por meio de explorações interativas do corpo humano e da simulação realista de procedimentos médicos em um AV imersivo.

O ViMeT (Virtual Medical Training), descrito em Oliveira e Nunes (2010), é um framework que fornece aplicações semiprontas para simular exames de biópsia, sendo apresentado mais detalhadamente na seção 4.4 .

Neste tópico foi dado destaque às tecnologias gratuitas, visto que as pesquisas desenvolvidas pela autora do presente documento e sua equipe seguem este paradigma, conforme é apresentado nas próximas seções.

\subsection{Projeto PuMa}

Como embrião da linha de pesquisa de RV aplicada em saúde, o projeto $P u M a$ (Punção de Mama) teve o objetivo de implementar um protótipo de ferramenta para simular o procedimento de punção (biópsia) mamária e, assim, verificar os requisitos necessários para que fosse possível construir ferramentas para essa finalidade com grau de realismo adequado às necessidades do usuário. Boa parte dos requisitos mencionados na seção anterior derivou-se da experiência deste projeto. Fez parte da construção deste protótipo a dissertação de mestrado de Lima (2004).

De acordo com Freitas Jr. et al. (1995), a punção de mama consiste em um procedimento ambulatorial de baixo custo, baseado no uso de uma agulha de fino calibre (com diâmetro interno que varia de 0,6 a $0,8 \mathrm{~mm}$ ). A agulha é introduzida na pele, em direção à lesão, com o intuito de coletar células para posterior avaliação de sua morfologia, quantidade e distribuição, por meio de exame citológico. Com movimentos de vaivém da agulha em diversas direções dentro do tumor, ao mesmo tempo em que se puxa o êmbolo da seringa para a aspiração do material celular no interior do tumor, o material é coletado e colocado posteriormente em uma lâmina de vidro (INCA, 2011).

Quando se trata da glândula mamária, o procedimento mais indicado é a punção aspirativa por agulha fina (PAAF). Freitas Jr. et al. (1995) salientam que a PAAF é uma das aplicações mais comuns para uso em nódulo cístico (nódulo líquido), pois pode diferenciar imediatamente este de nódulos sólidos e, ao mesmo tempo, age como tratamento definitivo do primeiro, porque permite a aspiração do líquido nele contido. 
Azzarelli et al. (1983) esclarece que tanto a precisão quanto a confiabilidade da PAAF dependem de alguns aspectos relacionados ao tumor, tais como o tamanho, a mobilidade e a localização, fatores que implicam em um certo grau de dificuldade na realização do exame. Por isso, a destreza do médico ao fazer as incisões nos locais certos é que determinará a eficácia do procedimento. Incisões erradas podem causar demora, coleta de material errôneo ou insuficiente, além de desconforto ao paciente.

Usualmente, o treinamento para a execução dos procedimentos de punção é feito sob a forma de observação, no qual o estudante apenas analisa o profissional experiente na realização do mesmo em pacientes. É comum, ainda, o treinamento para a manipulação dos equipamentos utilizados no exame ser conduzido usando-se cobaias, embora haja movimentos para limitar esta prática (Pinheiro e Acra, 2007). O objetivo do treinamento é que o aprendiz adquira domínio da seringa e da agulha para ser capaz de encontrar a localização exata do local de inserção do instrumento (seringa) e executar a punção do material.

O protótipo construído no projeto PuMa usa RV não imersiva em uma plataforma convencional, com as interações disponibilizadas pelo mouse e a visualização em monitor de vídeo, tendo sido implementado usando a API Java3D (Lima et al., 2004b).

Foram construídos objetos tridimensionais para representar uma mama normal, usado no início do treinamento e uma mama deformada (a deformação, neste caso, não ocorre em tempo real, mas por meio da substituição de objetos). Para a representação do nódulo (que é a estrutura de interesse no exame de punção) na cena 3D, foi utilizada uma esfera simples, com a possibilidade de definir seu raio, a fim de permitir treinamento com casos relativamente variados. Na representação da cena não é possível ver o nódulo, visto que este se encontra no interior da mama, coberta pela pele e outras estruturas da mesma.

Para representar o instrumento médico utilizado no procedimento, foi modelada uma seringa comum, dividida em partes (agulha, tubo e êmbolo), a fim de permitir manipulação de partes específicas durante a execução do treinamento. A fim de verificar se o aprendiz conseguiu alcançar o objetivo (atingir o nódulo) foi implementada detecção de colisão na agulha que compõe a seringa virtual (Lima et al., 2004b). Na Figura 4.2 são apresentados os objetos modelados citados.

Alguns casos com dados de pacientes foram armazenados em um banco de dados, permitindo a escolha de um determinado caso para treinamento (Figura 4.3). A Figura 4.4 apresenta a interface de trabalho para o usuário executar o treinamento. A aplicação fornece as imagens mamográficas do caso selecionado, visto que no exame real o médico faz uso de tais imagens para determinar o local para a incisão da seringa e posterior punção do material do nódulo. A interação do usuário é realizada com o mouse, sendo possível os 


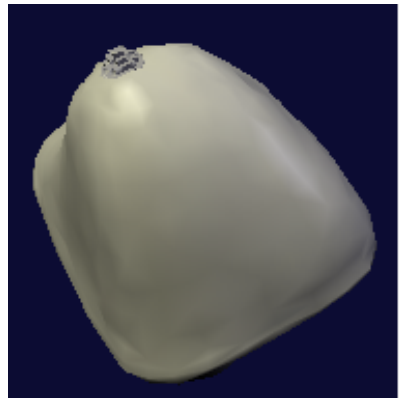

(a) mama - inicial e deformada

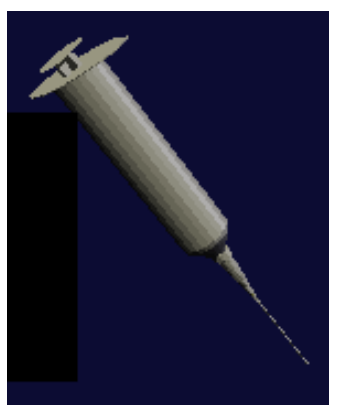

(c) seringa

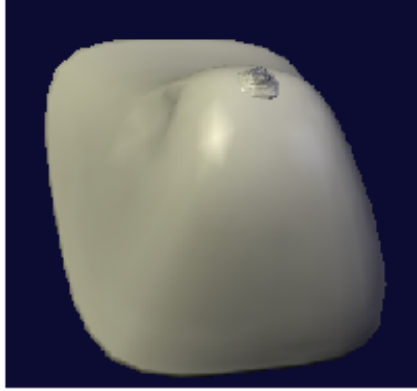

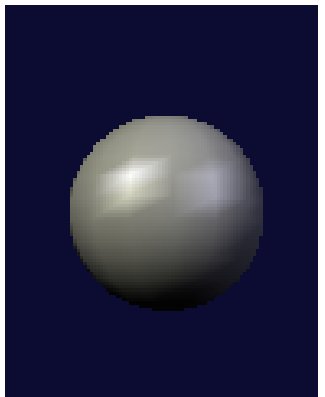

(b) nódulo

Figura 4.2: Objetos modelados para simulação de punção mamária (Lima, 2004).

movimentos de translação e rotação. A Figura 4.5 apresenta a interface disponibilizada quando o exame está terminado.

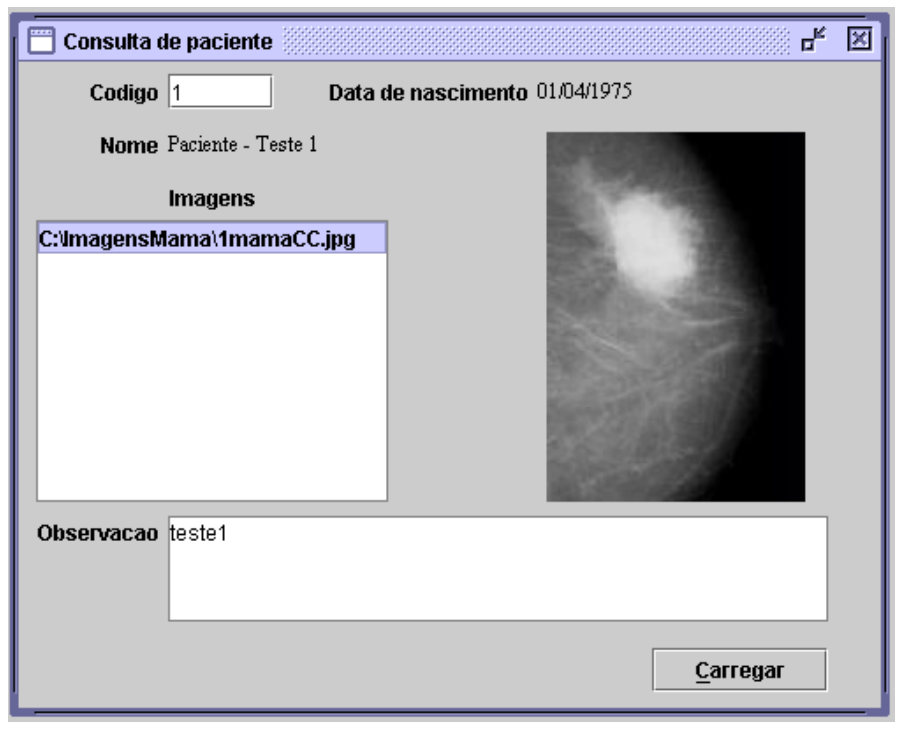

Figura 4.3: Interface para seleção de caso para estudo (Lima, 2004).

O protótipo aqui apresentado foi uma das primeiras aplicações de RV para a área médica no Brasil. Assim, não havia muita bibliografia disponível sobre tecnologias e requisitos para a construção de ferramentas desta categoria. Por isso, este projeto forneceu um 


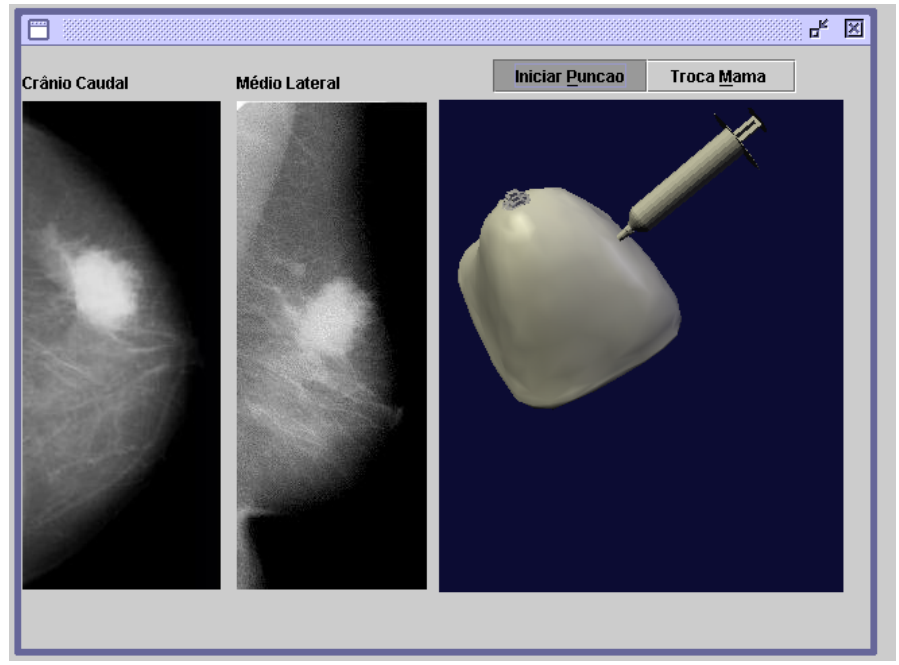

Figura 4.4: Interface para treinamento do procedimento de punção (Lima, 2004).

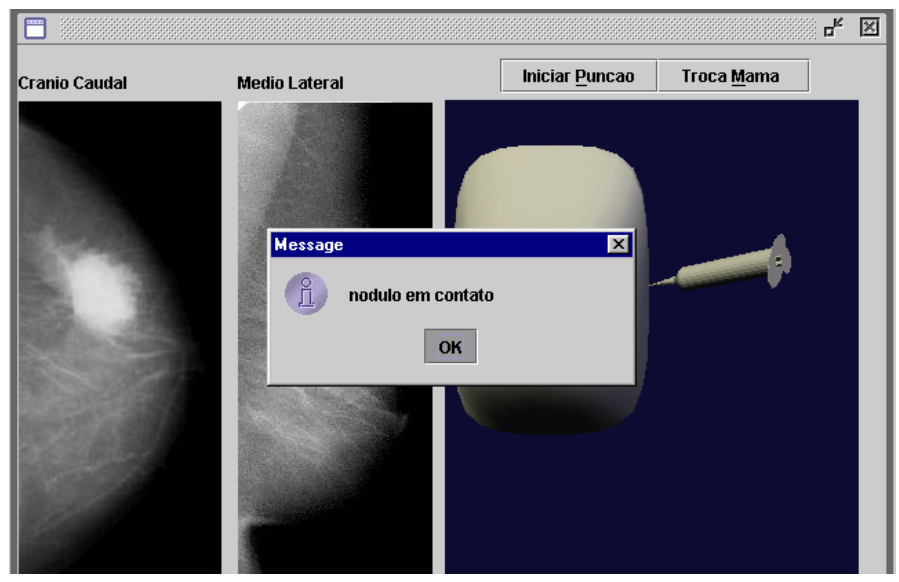

Figura 4.5: Interface disponibilizada na finalização do treinamento (Lima, 2004).

embasamento para suprir essas lacunas, possibilitando identificar pontos que deveriam ser melhorados, como visualização com estereoscopia e interação, assim como funcionalidades necessárias comuns a aplicações desta natureza, como detecção de colisão com precisão e deformação em tempo real. A partir da identificação dessas necessidades, vários projetos foram iniciados, culminando na execução do framework ViMeT, descrito a seguir. Os resultados deste projeto foram divulgados nas seguintes publicações: Lima e Nunes (2004), Lima et al. (2004a) e Lima et al. (2004b).

\subsection{Framework ViMeT}

Um framework orientado a objetos consiste em um conjunto de classes abstratas e/ou concretas usadas para o desenvolvimento de uma aplicação com domínio específico, com 
o objetivo de se obter a máxima reutilização no desenvolvimento de aplicações (Johnson, 1997).

Bastos et al. (2004) enfatizam que os frameworks de RV permitem que o usuário se concentre no desenvolvimento da aplicação propriamente dita, visto que, em geral, oferecem abstração de dispositivos, abstração de sistema de projeção, grafos de cena especializados, heurísticas de interação com o AV, suporte a sistemas distribuídos e renderização distribuída.

O ViMeT é um framework orientado a objetos, em desenvolvimento, elaborado a partir de três aplicações desenvolvidas previamente: detecção de colisão com precisão, deformação em tempo real e estereoscopia.

Na detecção de colisão com precisão foi desenvolvida uma técnica que, a partir de um refinamento dos métodos BoundingBox e BoundingSphere ${ }^{1}$, fornecidos pela API Java3D, permite detectar precisamente, e de forma configurável, o momento de encontro entre dois objetos no AV. Para o refinamento é utilizado o conceito de Octrees: divide-se a área de detecção de colisão em octantes e depois escolhe-se o octante não vazio cujo centro apresenta a menor distância em relação ao centro do objeto em colisão. Este processo é repetido até que o refinamento atinja uma distância pré-estabelecida (Kera, 2005).

A aplicação desenvolvida para executar deformação em tempo real emprega o método Massa-Mola (seção 4.1.4). A partir da identificação de um vértice inicial para a deformação, são calculadas as novas posições do vértice e dos seus vizinhos, considerando parâmetros fornecidos pelo usuário empregados em equações provenientes da Física (Pavarini, 2006).

Em relação à visualização com estereoscopia, atualmente o ViMeT contempla a técnica de anaglifos (seção 4.1.5), considerando o seu baixo custo e a indisponibilidade de outros dispositivos para implementar técnicas mais elaboradas (Botega, 2005).

De posse das aplicações citadas, o ViMeT foi projetado a partir de uma análise de domínio, resultando nas seguintes especificações atualmente atendidas:

- AV dinâmico, com dois objetos modelados: um para representar o órgão humano e outro para representar o instrumento médico;

- inclusão das funcionalidades de estereoscopia, detecção de colisão e deformação descritas anteriormente, mas de tal forma que seja possível adicionar posteriormente outras técnicas para essas funcionalidades;

- armazenamento dos dados (parâmetros de objetos e funcionalidades selecionados) das aplicações geradas;

\footnotetext{
${ }^{1}$ Esses métodos envolvem os objetos por cubos e esferas, respectivamente, indicando a ocorrência de colisão quando essas primitivas se interpenetram.
} 
- disponibilização de uma interface gráfica para auxiliar no processo de instanciação;

- integração de dispositivos não convencionais para interação.

Na Figura 4.6 é apresentado o diagrama do projeto arquitetural do ViMeT que tem como função fornecer uma visão geral da estrutura do framework. Nele é possível observar a utilização de um SGBD, uma camada que representa as classes, uma camada que representa a ferramenta de instanciação (denominada ViMeTWizard e detalhada adiante) e as duas formas de instanciação possíveis (Oliveira e Nunes, 2010).

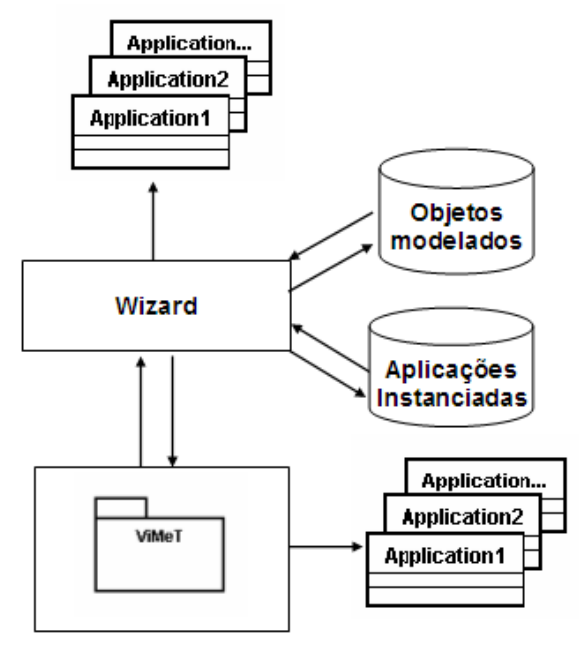

Figura 4.6: Diagrama do projeto arquitetural do ViMeT (Oliveira e Nunes, 2010).

A fim de permitir a atualização do framework, sua implementação foi planejada de forma que cada funcionalidade estivesse contida em uma ou mais classes, sendo definida uma classe (Environment) responsável por criar o AV e acoplar as funcionalidades selecionadas para uma determinada aplicação. O diagrama de classes apresentado na Figura 4.7 ilustra as classes da versão atual do ViMeT.

\subsubsection{Ferramenta de instanciação}

Uma vez que o ViMeT é constituído por uma coleção de classes, novas aplicações podem ser criadas simplesmente instanciando-se as classes e utilizando os métodos que essas disponibilizam. Os passos para tal instanciação são exemplificados em um manual construído para esta finalidade. Está disponível, ainda, a documentação no formato Javadoc de todas as classes e métodos (http://www.each.usp.br/lapis/ViMeT.htm).

Os usuários de um framework são os desenvolvedores de software que têm conhecimento do paradigma utilizado pela linguagem de programação. No entanto, conhecer profundamente classes e métodos é um processo que demanda tempo e, consequentemente, pode diminuir a produtividade almejada pelo reuso de software. 


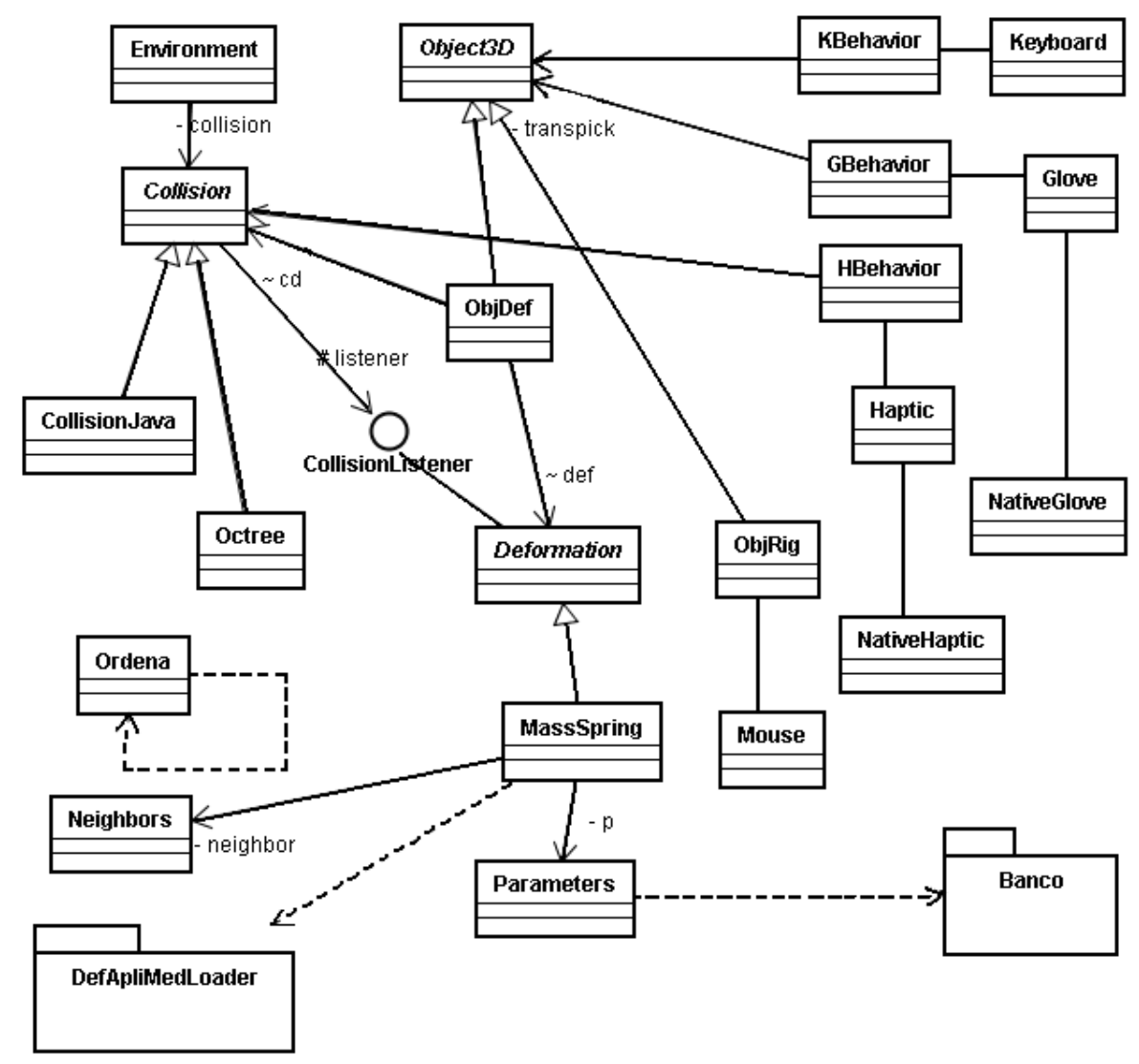

Figura 4.7: Diagrama de classes da versão atual do ViMeT (Corrêa e Nunes, 2009).

Visando a contribuir com o aumento de produtividade, foi desenvolvida uma ferramenta, denominada ViMeTWizard, que executa a instanciação automatizada das classes do ViMeT, culminando na geração do código (em linguagem Java) de uma aplicação semipronta, a partir de parâmetros definidos pelo usuário (Nunes et al., 2007a). Esses parâmetros são armazenados em um banco de dados, permitindo posterior recuperação. Assim, é possível gerar uma nova aplicação com os mesmos parâmetros de uma aplicação anteriormente construída.

Nas Figuras 4.8, 4.9 e 4.10 são apresentadas interfaces que auxiliam no processo de instanciação. Primeiramente o usuário fornece o nome da nova aplicação. Em seguida, deve selecionar os objetos modelados que representarão o órgão humano e o instrumento médico utilizado no exame de biópsia; esses objetos devem ser previamente modelados e ter seus dados armazenados no banco de dados (Figura 4.8).

Na sequência, são definidas as funcionalidades desejadas para a aplicação (detecção de colisão, deformação e estereoscopia) e as técnicas disponíveis para cada uma delas. Como já mencionado, o paradigma de orientação a objetos permite que classes sejam adicionadas disponibilizando novas funcionalidades e técnicas; quando isso ocorre, é necessário que esta guia seja alterada a fim de disponibilizar os novos artefatos de software na instanciação 


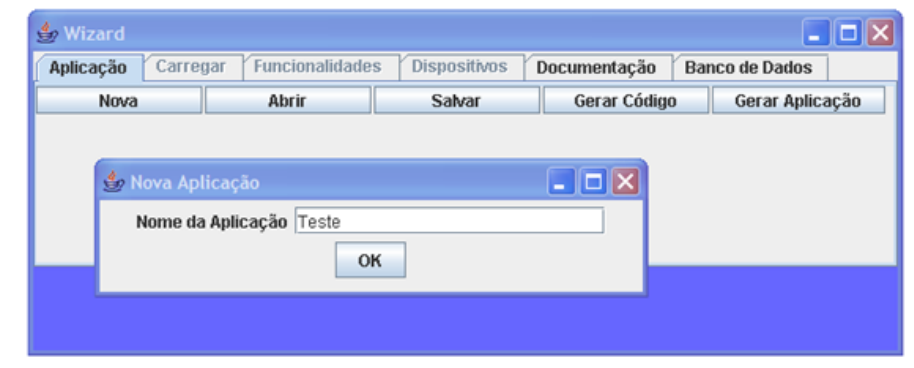

(a) Guia para selecionar dados da Aplicação

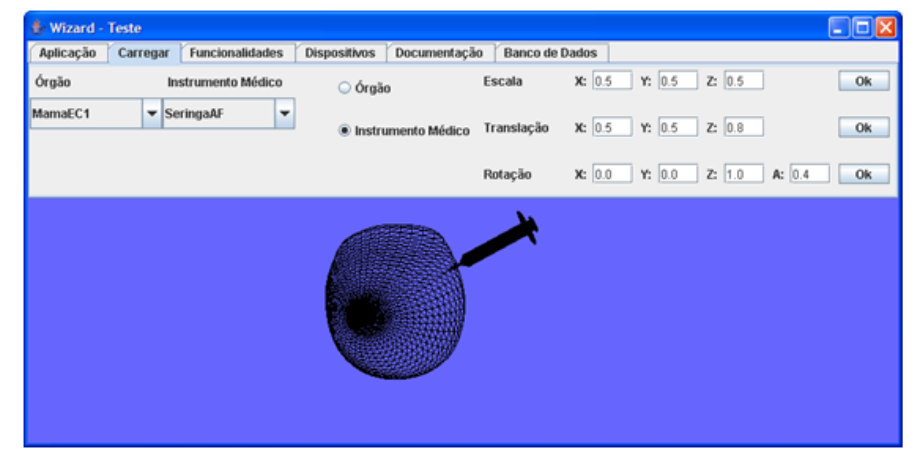

(b) Seleção de Objetos

Figura 4.8: ViMeTWizard: aplicação e objetos (Oliveira e Nunes, 2010).

automatizada proporcionada pela ViMeTWizard. Após selecionar as funcionalidades, há a possibilidade de escolher os dispositivos de interação desejados, conforme apresentado na Figura 4.9 (mais detalhes sobre a interação são apresentados na próxima seção).

Por fim, o código é gerado e compilado, disponibilizando uma aplicação de biópsia que pode ser customizada de acordo com as necessidades do usuário (Figura 4.10).

Exemplos de aplicações geradas usando a ferramenta ViMeTWizard estão disponibilizados nas Figuras 4.11 e 4.12 .

\subsubsection{Interação}

Considerando que em aplicações de treinamento médico a interação exerce um papel fundamental, esta seção visa a detalhar as formas de interação atualmente disponíveis no ViMeT.

Conforme definem Freitas et al. (2003), a interação em AVs dinâmicos ocorre quando o usuário realiza operações de seleção, manipulação e navegação no mundo sintético 3D, por meio das denominadas técnicas de interação. Essas técnicas consistem em comandos e dados definidos na implementação do sistema de RV, enviados a este para a execução de determinadas tarefas.

De acordo com o descrito em Corrêa et al. (2008), o módulo de interação do ViMeT adota inicialmente mouse e teclado como dispositivos convencionais, e luva de dados e 


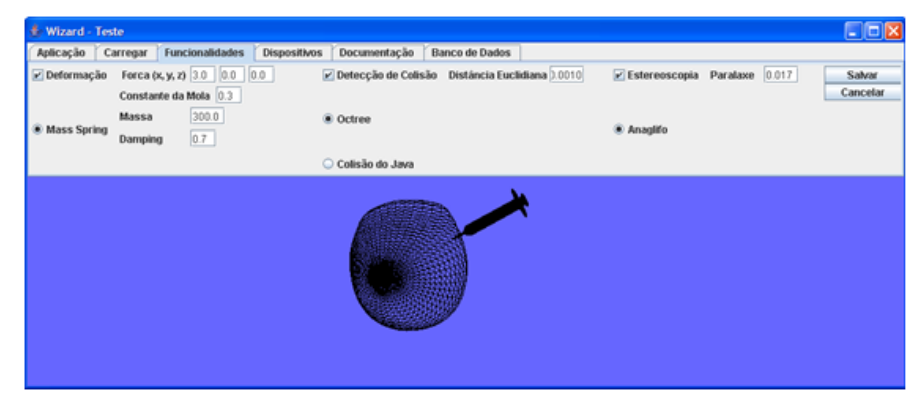

(a) Seleção de Funcionalidades

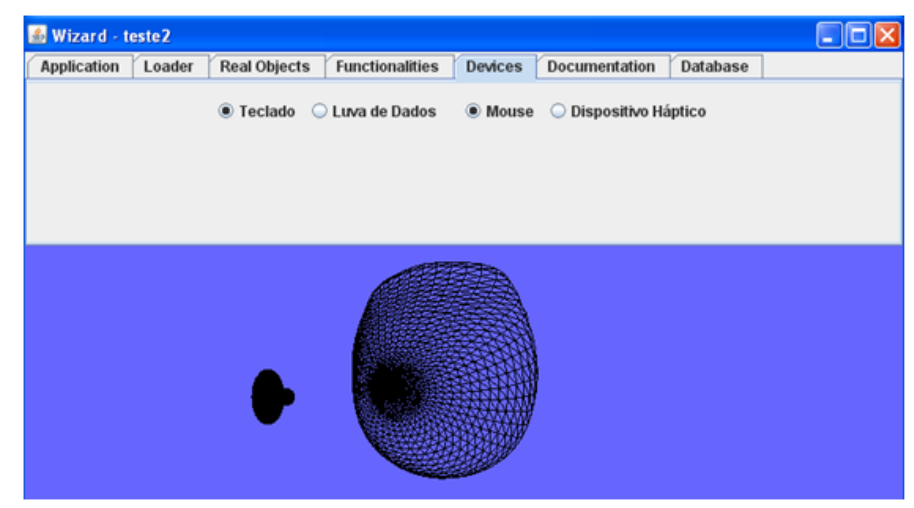

(b) Seleção de Dispositivos

Figura 4.9: ViMeTWizard: funcionalidades e dispositivos (Oliveira e Nunes, 2010).

equipamento háptico como dispositivos não convencionais. O diagrama da Figura 4.13 ilustra as possibilidades de interação com esses dispositivos, observando-se as combinações permitidas ao desenvolvedor.

O teclado é utilizado tanto para navegação quanto para seleção e manipulação de objetos no AV. Os demais dispositivos são utilizados para seleção e manipulação. Para manipular o órgão humano podem ser usados o teclado ou a luva de dados. O instrumento médico é manipulado pelo mouse ou dispositivo háptico. O controle do sistema é realizado automaticamente, visto que as operações de navegação e manipulação podem ser realizadas sem a interrupção da interação.

A inserção dos dispositivos convencionais foi implementada usando-se classes da API Java3D. Para os dispositivos não convencionais foram usados os drivers disponibilizados pelos fabricantes (implementados em linguagem C), fazendo-se a integração entre as linguagens por meio da API JNI (Java Native Interface), que permite a interoperação entre a aplicação escrita em Java e bibliotecas e programas desenvolvidos em outras linguagens, como C, C++ e Assembly, conforme detalhado em Corrêa et al. (2009) e Cornell e Horstmann (2003). Nas Figuras 4.14 e 4.15 são apresentados exemplos de interação com os dispositivos citados.

Atualmente o projeto do ViMeT envolve diversos alunos de Iniciação Científica, Mestrado e Doutorado. O objetivo é, em médio prazo, gerar aplicações com realismo que 


\section{CAPÍTULO 4. REALIDADE VIRTUAL EM TREINAMENTO MÉDICO}

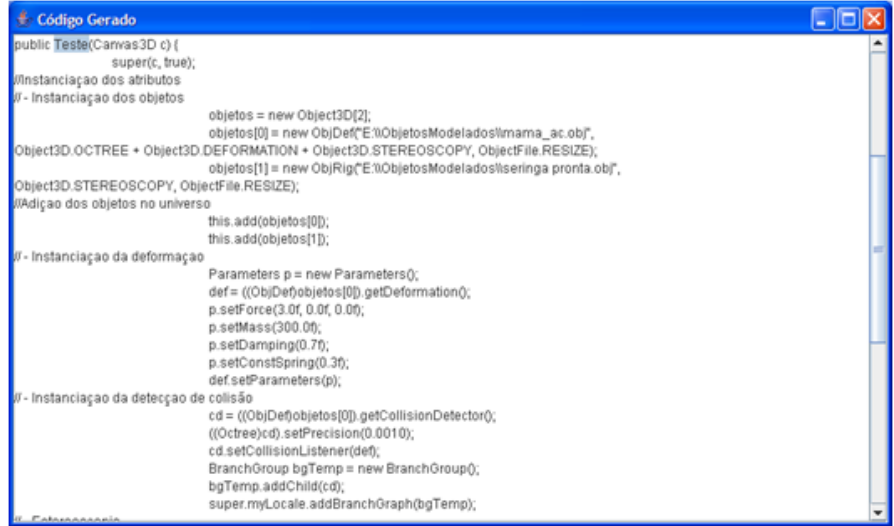

(a) Geração do código

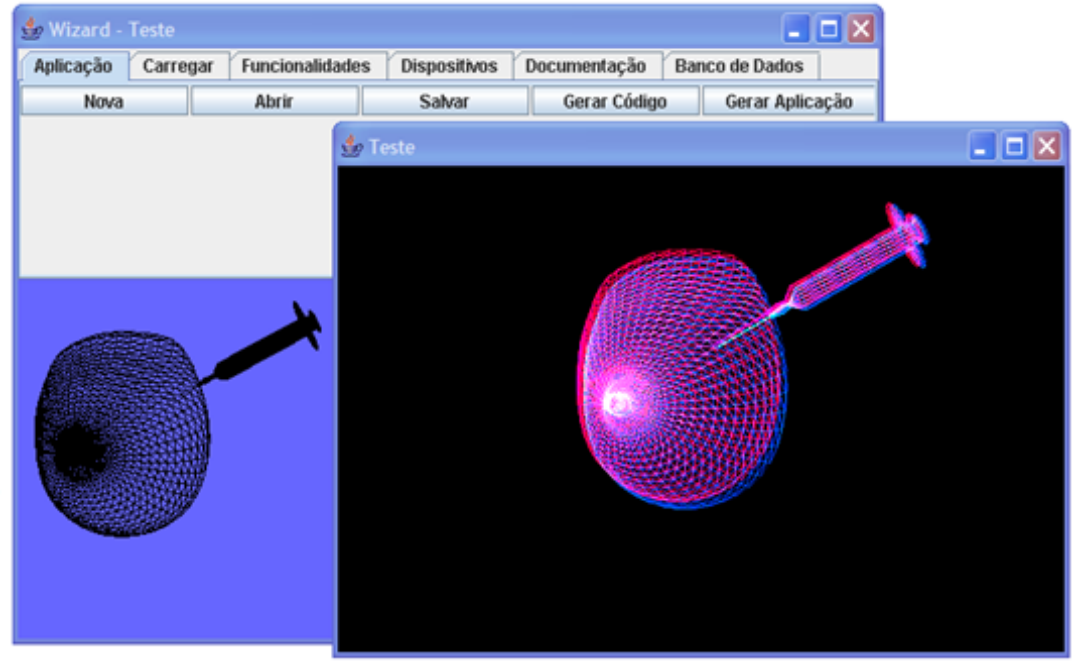

(b) Aplicação gerada

Figura 4.10: ViMeTWizard : geração de código e aplicação (Oliveira e Nunes, 2010).

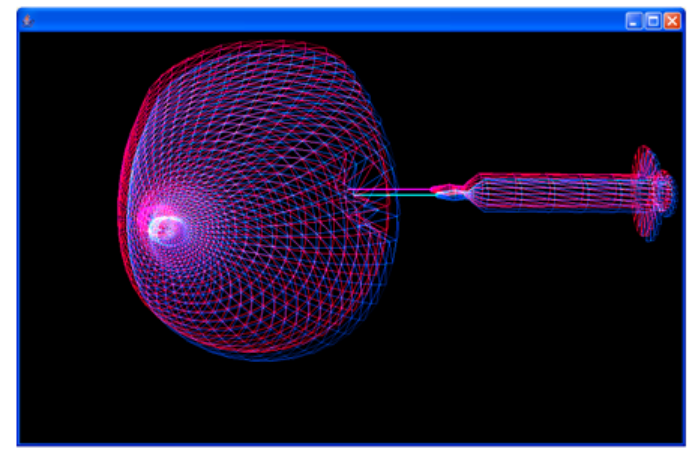

(a) Aplicação com anaglifos

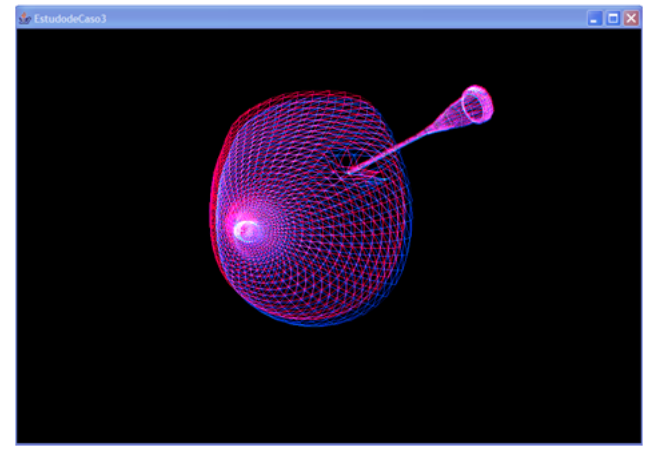

(b) Aplicação com nova modelagem de seringa

Figura 4.11: Aplicações geradas: punção de mama (Oliveira e Nunes, 2010).

possam ser efetivamente usadas na rotina da educação médica. Tal objetivo está con- 


\section{CAPÍTULO 4. REALIDADE VIRTUAL EM TREINAMENTO MÉDICO}

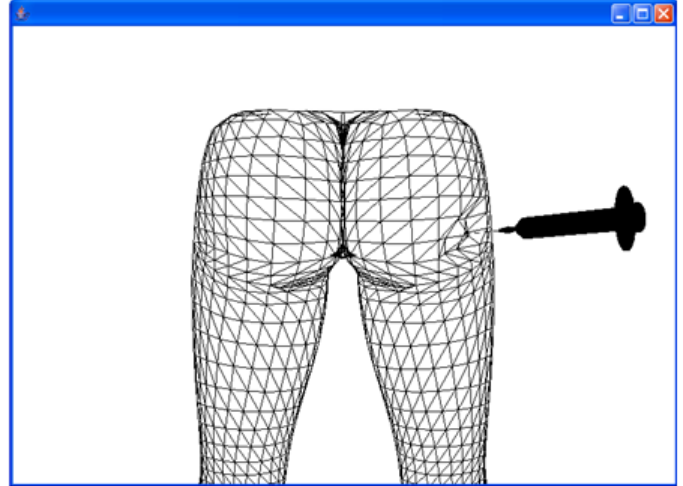

(a) Aplicação sem anaglifos

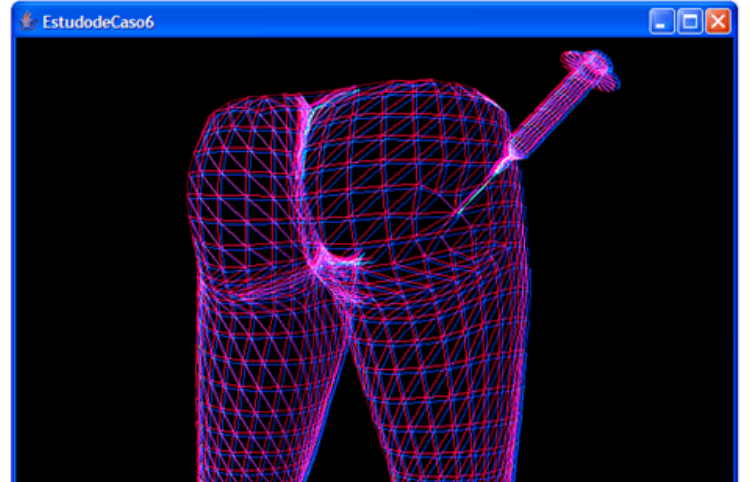

(b) Aplicação com anaglifos

Figura 4.12: Aplicações geradas: punção de nádegas (Oliveira e Nunes, 2010)

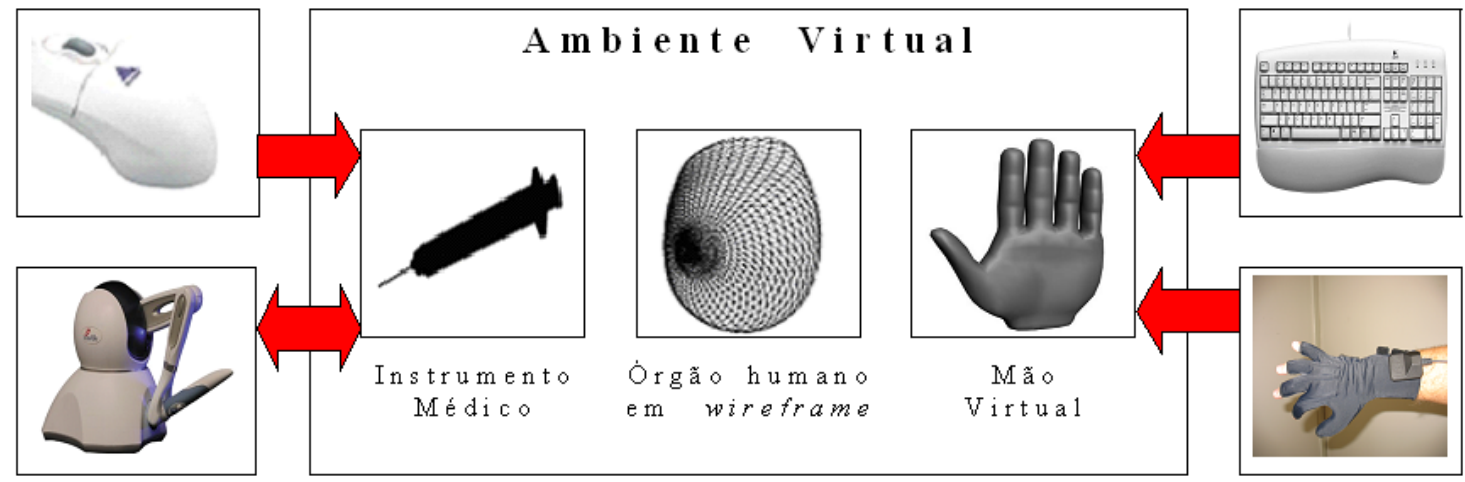

Figura 4.13: Interação da versão atual do ViMeT (Corrêa e Nunes, 2009).

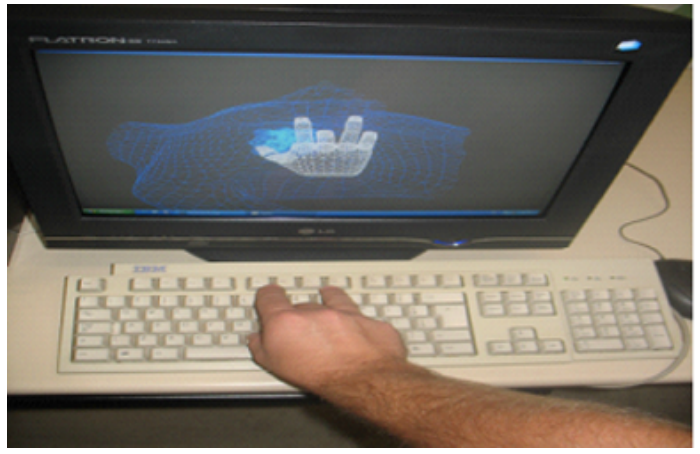

(a) Teclado

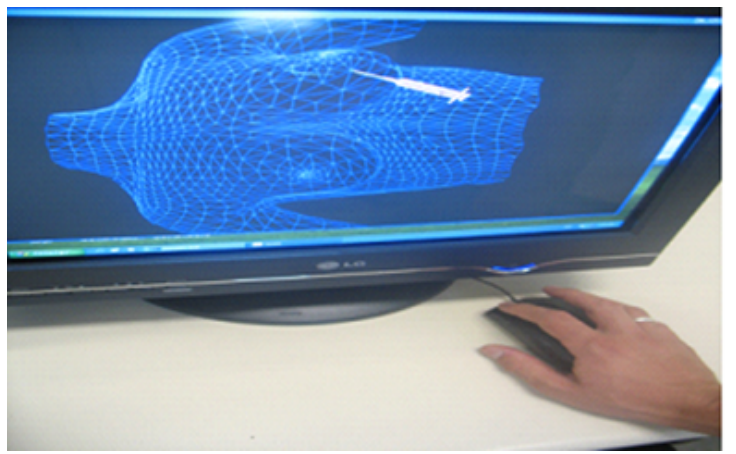

(b) Mouse

Figura 4.14: ViMeT: interação com dispositivos convencionais (Corrêa et al., 2009).

tido dentro da proposta de construir ambientes virtuais colaborativos no INCT-MACC (LNCC, 2011).

Entre as atividades em desenvolvimento estão: estudo da resistência dos tecidos do corpo humano para permitir deformação mais adequada, definição de novos métodos de de- 


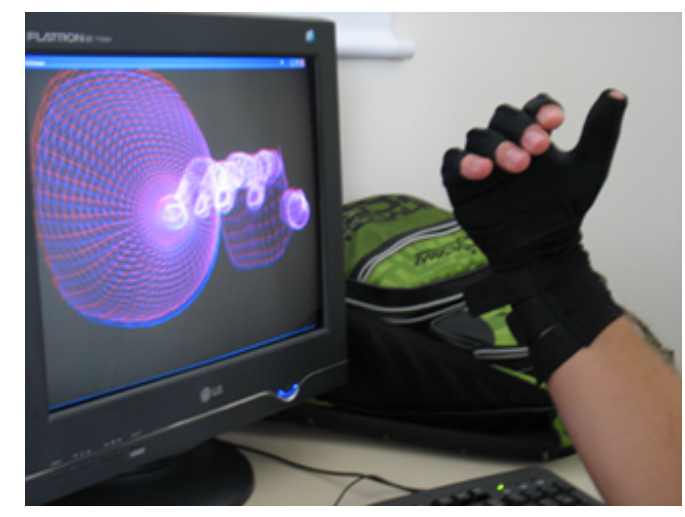

(a) Luva de dados

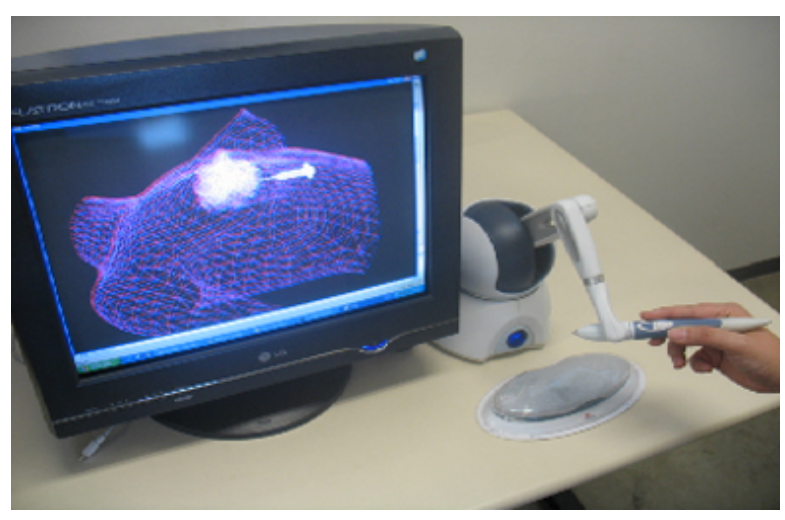

(b) Dispositivo háptico

Figura 4.15: ViMeT: dispositivos não convencionais (Corrêa et al., 2009).

tecção de colisão em tempo real, estudo e implementação de algoritmos em GPU ( Graphics Processing Unit) a fim de diminuir o tempo de processamento dos algoritmos, estudo de técnicas de iluminação para proporcionar realismo na visualização dos objetos, elaboração de jogos sérios (serious games), elaboração de métodos de avaliação para verificação do aprendizado de conteúdos e habilidades adquiridos pelo usuário durante o uso das ferramentas de treinamento e definição de critérios para teste de programas baseados em Grafo de Cena.

O desenvolvimento do framework ViMeT também envolve colaborações com a Escola Politécnica-USP, Instituto de Ciências Matemáticas e de Computação-USP, Faculdade de Economia, Administração e Contabilidade-USP, Universidade de Campinas, Universidade Federal da Paraíba e Universidade de Brasília. Entre as as principais publicações decorrentes deste projeto estão: Bezerra et al. (2009), Botega e Nunes (2005), Corrêa e Nunes (2009), Corrêa et al. (2008), Corrêa et al. (2009), , Kera e Nunes (2005), Kera et al. (2008), Nunes e Costa (2008b), Nunes et al. (2007a), Oliveira e Nunes (2007), Oliveira e Nunes (2010), Oliveira et al. (2006), Oliveira et al. (2007a) e Oliveira et al. (2007b). Salienta-se que o trabalho apresentado em Bezerra et al. (2009) recebeu o prêmio de melhor artigo na edição de 2009 do Workshop de Informática Médica (WIM), realizado no Congresso da Sociedade Brasileira de Computação.

\subsection{Geração de estudos de caso}

Na rotina médica real, cada paciente é único e a conduta em relação a um procedimento deve ser estabelecida de acordo com as características individuais do mesmo. Para que a efetividade de um treinamento virtual se consolide, é necessário evitar vícios em relação aos objetos de estudo, contemplando-se casos diferentes e com dificuldades variadas. A partir dessas constatações, foi verificado que o projeto $P u M a$ (seção 4.3) deveria ser incrementado 
no sentido de gerar casos variados a partir de dados provenientes de imagens reais. Assim, paralelamente ao desenvolvimento do framework ViMeT (seção 4.4), um estudo inicial sobre a geração de estudos de caso a partir de imagens médicas foi conduzido, permitindo obter malhas tridimensionais com base em medidas extraídas de imagens mamográficas.

De acordo com o exposto em Delfino (2007), inicialmente o sistema para geração de estudos de caso obtém as duas imagens das visões geralmente disponibilizadas no exame mamográfico: crânio-caudal (CC) e médio-lateral-oblíqua (MLO), conforme exemplificado na Figura 4.16. Essas imagens são submetidas a operações de pré-processamento, que preparam a imagem para a extração de características.

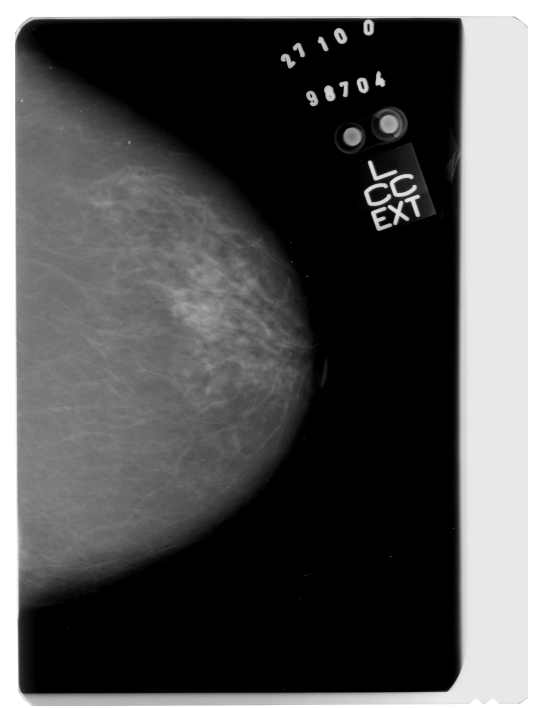

(a) Imagem CC.

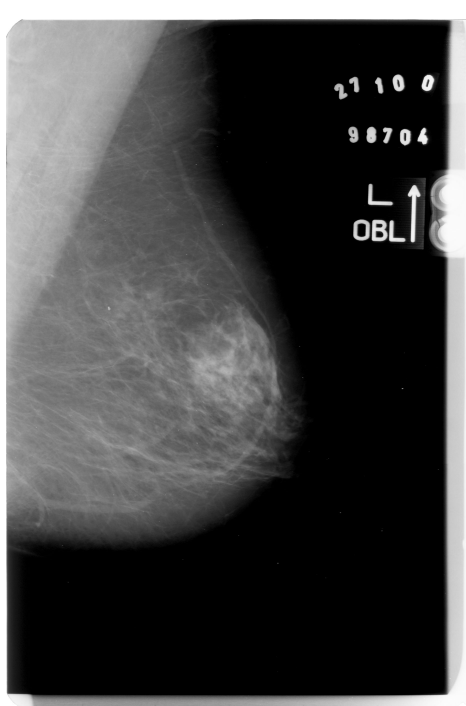

(b) Imagem MLO.

Figura 4.16: Imagens mamográficas para gerar estudos de caso (Delfino, 2007).

Após o pré-processamento, um algoritmo de segmentação usando uma técnica adaptada de crescimento de região é executado para separar a área da imagem referente à mama do fundo da mesma, resultando em imagens semelhantes às exemplificadas na Figura 4.17.

Uma vez obtidas as imagens segmentadas, passa-se à extração de medidas. Primeiramente, localizam-se os pontos superiores e inferiores da mama na imagem. Em seguida, executa-se o cálculo dos vértices internos, com base na distância entre o limite inferior e superior da mama - a quantidade de vértices desejados é definida pelo usuário e determina a precisão da malha a ser gerada. Na Figura 4.18 é ilustrado o funcionamento do algoritmo de extração de medidas aplicado nas imagens da Figura 4.17. No exemplo apresentado são extraídos 3 vértices em cada visão.

Depois de efetuados os cálculos para definir as posições dos vértices, é realizado o alinhamento entre as imagens das visões CC e MLO, tendo o local correspondente ao mamilo como ponto de partida do algoritmo. Ao final, são obtidas coordenadas $2 \mathrm{D}$ que 


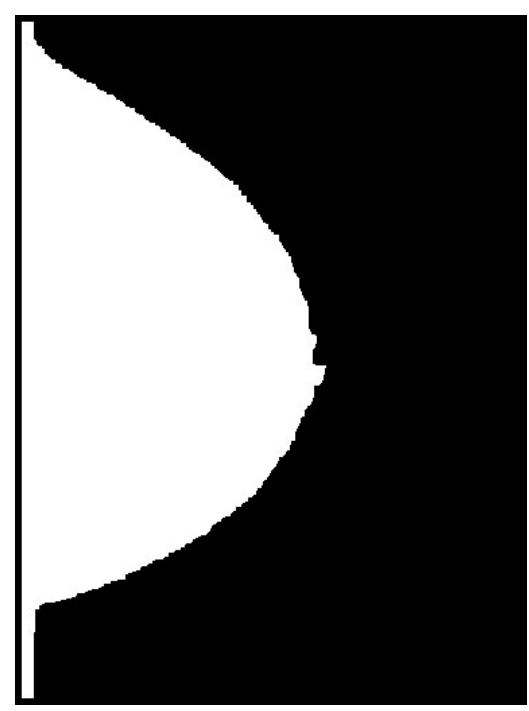

(a) Imagem CC.

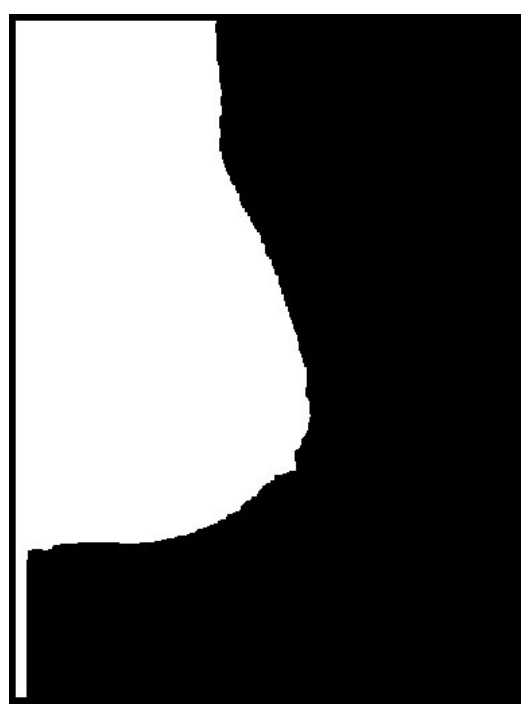

(b) Imagem MLO.

Figura 4.17: Imagens mamográficas após a segmentação (Delfino, 2007).

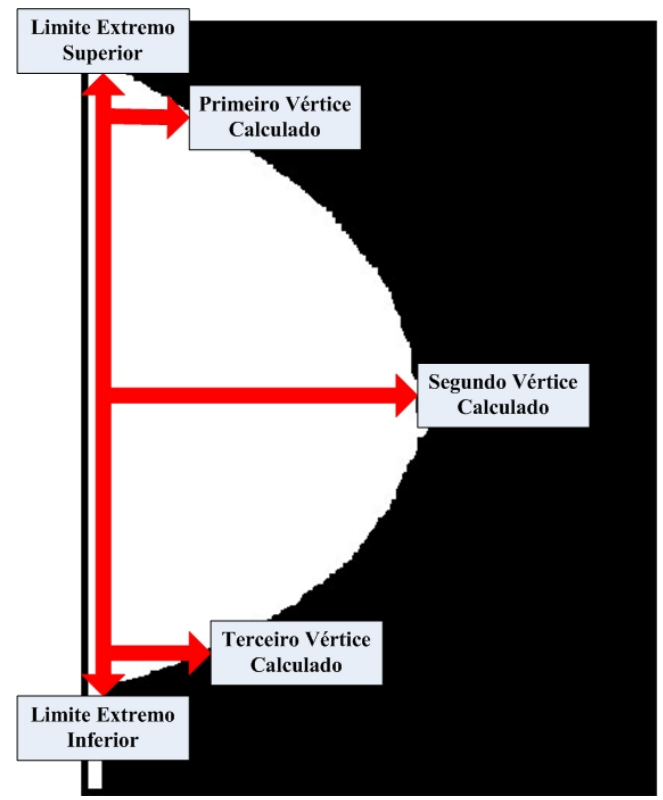

(a) Imagem CC.

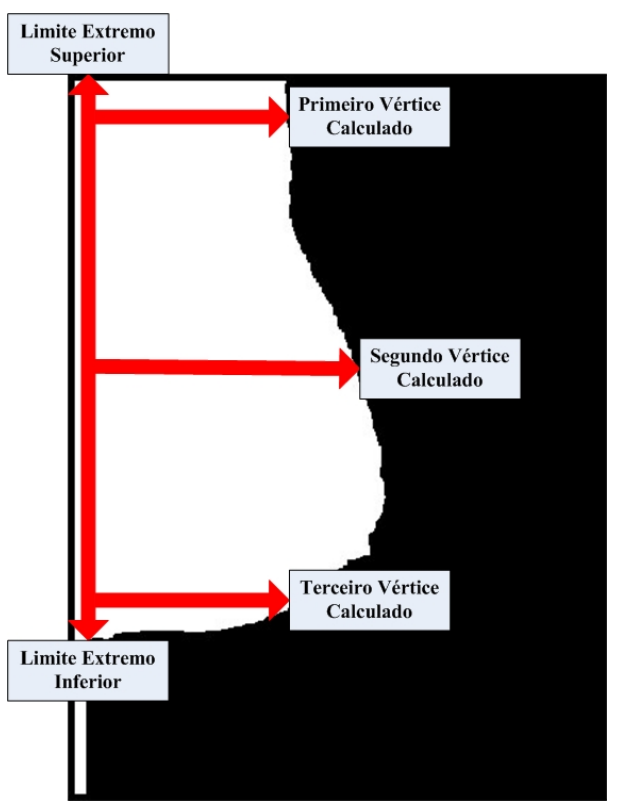

(b) Imagem MLO.

Figura 4.18: Posições de vértices adquiridos da imagem mamográfica (Delfino, 2007). 
necessitam ser convertidas para 3D, permitindo, assim, a construção da mama sintética 3D.

A conversão é executada aplicando-se as equações 4.1, 4.2 e 4.3, onde $p C C$ representa as coordenadas dos pixels da mama na visão CC formado pelo valor da abscissa $(x C C)$ e da ordenada $(y C C) ; p M L O$ corresponde às coordenadas dos pixels da mama na visão MLO composto pelo valor da abscissa $(x M L O)$ e da ordenada $(y M L O)$ e $p 3 D$ representa o mapeamento das coordenadas 2D em 3D. Esse mapeamento é aplicado a todos os pixels obtidos durante a fase de extração de medidas (Delfino, 2007).

Após a normalização dos valores obtidos, o resultado é armazenado em um arquivo no formato Object File, para posterior recuperação das coordenadas geradas. O formato Object File, popularmente conhecido como formato obj, é um padrão criado para o armazenamento de estruturas poligonais tridimensionais. Conforme explicado em Delfino (2007), dentre as operações existentes no padrão foram utilizados apenas os comandos $v$ e $f$, que representam, respectivamente, os vértices do modelo sintético 3D e a forma de ligação desses vértices para formar as faces do modelo.

$\mathrm{O}$ comando $v$ exige três parâmetros que, representam as coordenadas $(x, y, z)$ do vértice. A cada vez que a instrução $v$ é empregada, é criado um novo vértice e a ele é atribuído um índice, a fim de facilitar sua referência posterior na construção das faces. O comando $f$ recebe como entrada $n$ parâmetros que representam as ligações dos índices dos vértices gerados pelo comando $v$, onde $n$ é o total de vértices que a face possui (3 para faces triangulares, 4 para faces com o formato quadrado, 5 para faces no formato de pentaedro, e assim sucessivamente) (Delfino, 2007). A Figura 4.19 apresenta o código gerado a partir das coordenadas obtidas após a normalização.

$$
\begin{aligned}
p C C & =(x C C, y C C) \\
p M L O & =(x M L O, y M L O) \\
p 3 D & =(x C C, y M L O, y C C)
\end{aligned}
$$

A geração do nódulo sintético tridimensional segue passos semelhantes aos descritos para a geração da malha que representa a mama. Nesse caso, porém, o nódulo é demarcado previamente por um especialista, conforme exemplo disponibilizado na Figura 4.20.

Uma vez gerados os arquivos no formato $o b j$, estes são disponibilizados no ambiente de treinamento. Na Figura 4.21 é mostrado um exemplo da importação de um arquivo no formato .obj para o AV que contém a mama e na Figura 4.22 é ilustrado um exemplo que contém o nódulo. 
\#v x y z
v 0.0134483396749214350 .011401580444834320 .01117225435110524
v 0.1911585425220975550 .011401580444834320 .38432554967802024
v 0.0134483396749214350 .011401580444834321 .1306321403318504
v 0.024245828760664820 .39221436730230050 .01117225435110524
v 0.34463713738373570 .39221436730230050 .38432554967802024
v 0.024245828760664820 .39221436730230051 .1306321403318504
v 0.0023750603924990191 .1538399410172330 .01117225435110524
v 0.033759787007664631 .1538399410172330 .38432554967802024
v 0.0023750603924990191 .1538399410172331 .1306321403318504

(a) Geração dos índices. \#fv1 v2 v3 v4

f 1452

f 2563

f 4785

f 5896

(b) Geração das faces.

Figura 4.19: Código fonte para representar a mama no formato obj (Delfino, 2007).

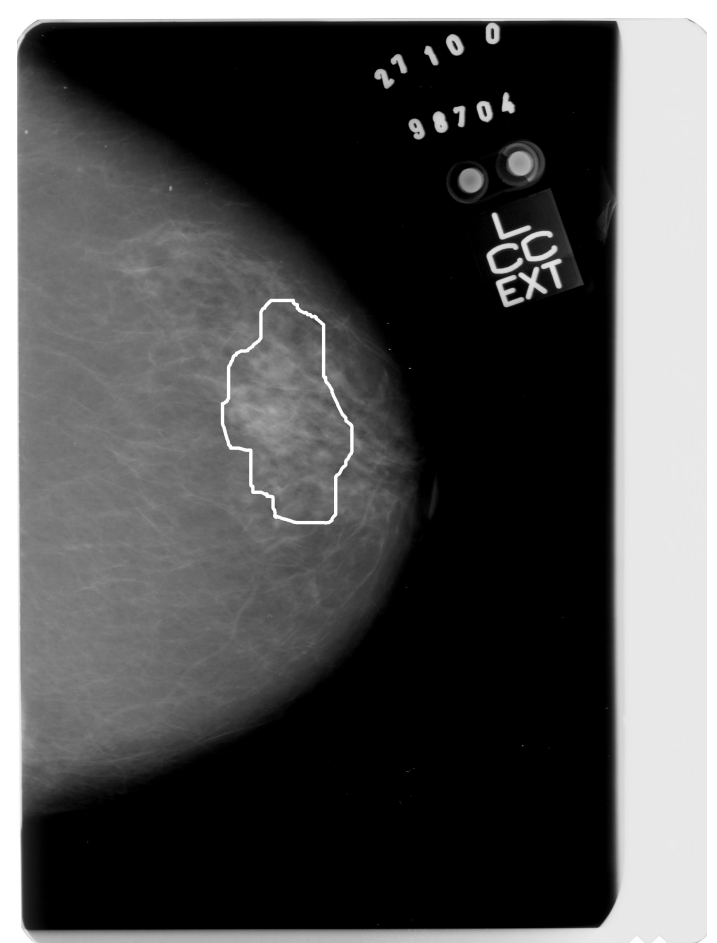

(a) Imagem CC.

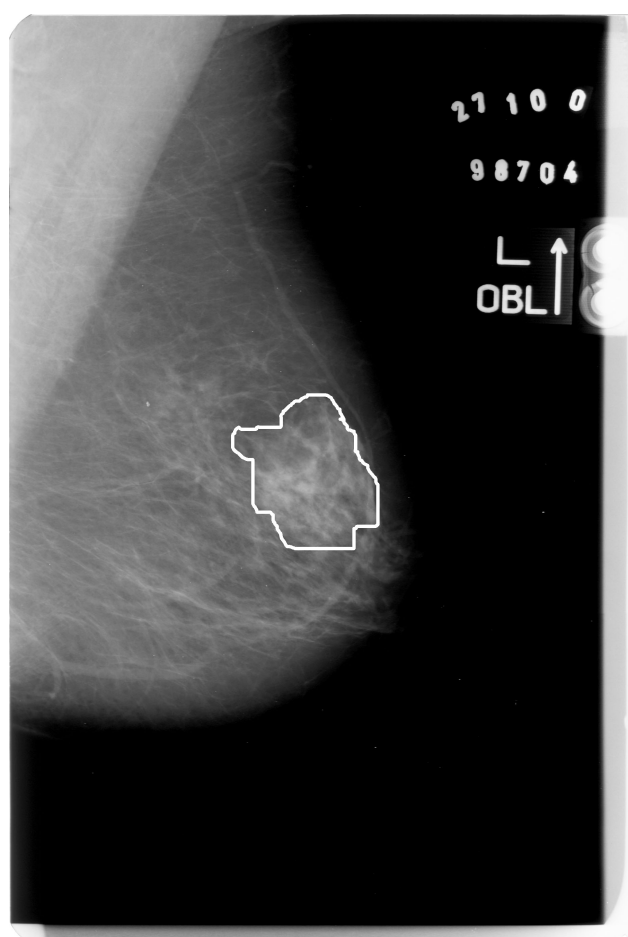

(b) Imagem MLO.

Figura 4.20: Imagem mamográfica com o nódulo demarcado (Delfino, 2007).

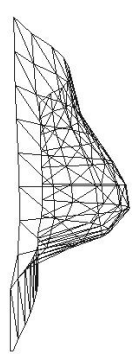

(a)

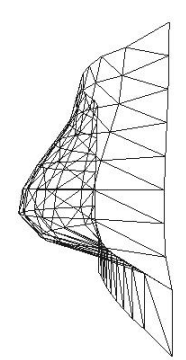

(b)

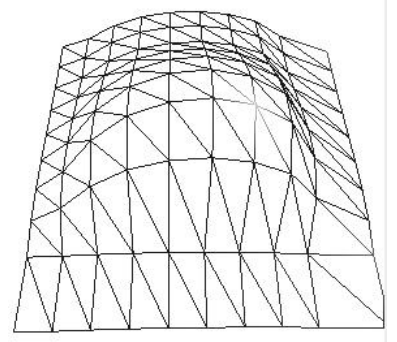

(c)

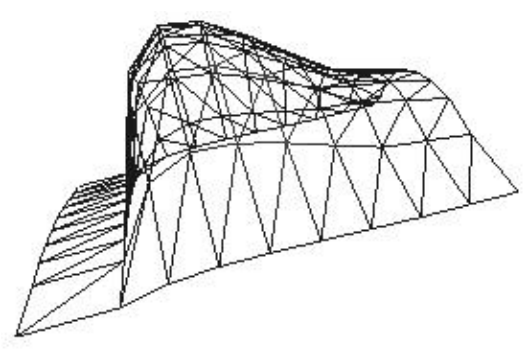

(d)

Figura 4.21: Modelos wireframe da mama (Delfino, 2007). 


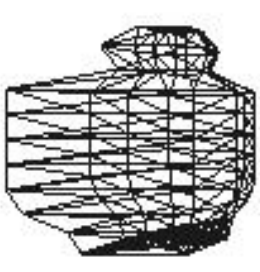

(a)

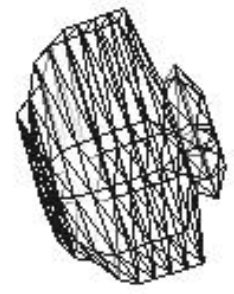

(b)

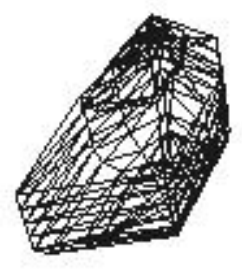

(c)

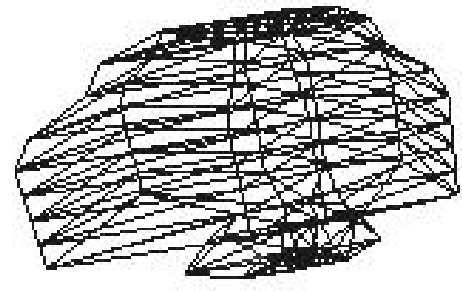

(d)

Figura 4.22: Modelos wireframe do nódulo (Delfino, 2007).

Um exemplo do AV com um estudo de caso gerado, no qual os objetos são cobertos por texturas é apresentado na Figura 4.23.

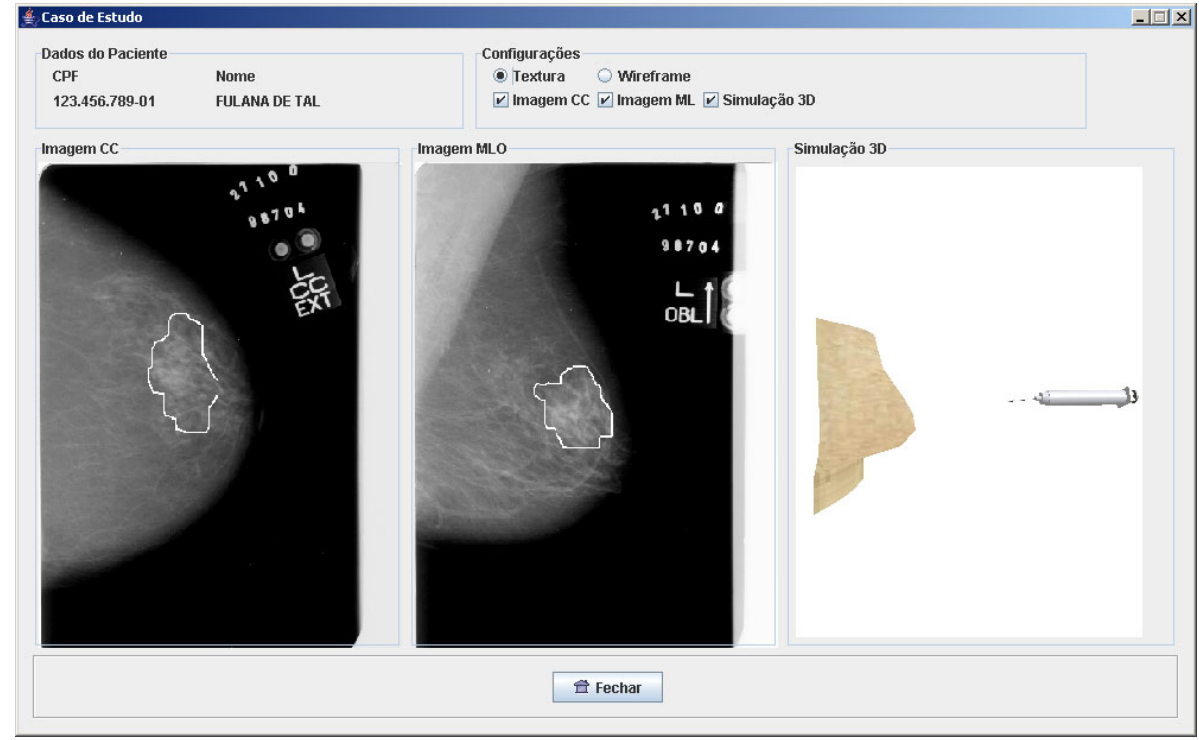

Figura 4.23: Ambiente Virtual para treinamento (Delfino, 2007).

Na Figura 4.24 é apresentado o mesmo estudo de caso da Figura 4.23, mas agora desconsiderando o uso de texturas.

A metodologia empregada neste projeto pode ser expandida para permitir a geração de malhas representativas de objetos 3D a partir de imagens de outras modalidades médicas que não geram seções transversais, considerando as mais variadas partes do corpo humano. Dessa forma, é possível produzir estudos de casos com diferentes níveis de dificuldades e correspondentes a imagens reais, favorecendo o aprendizado com ferramentas virtuais. As principais publicações resultantes deste projeto foram Delfino e Nunes (2006), Delfino e Nunes (2007a), Delfino e Nunes (2007b) e Delfino e Nunes (2009). 


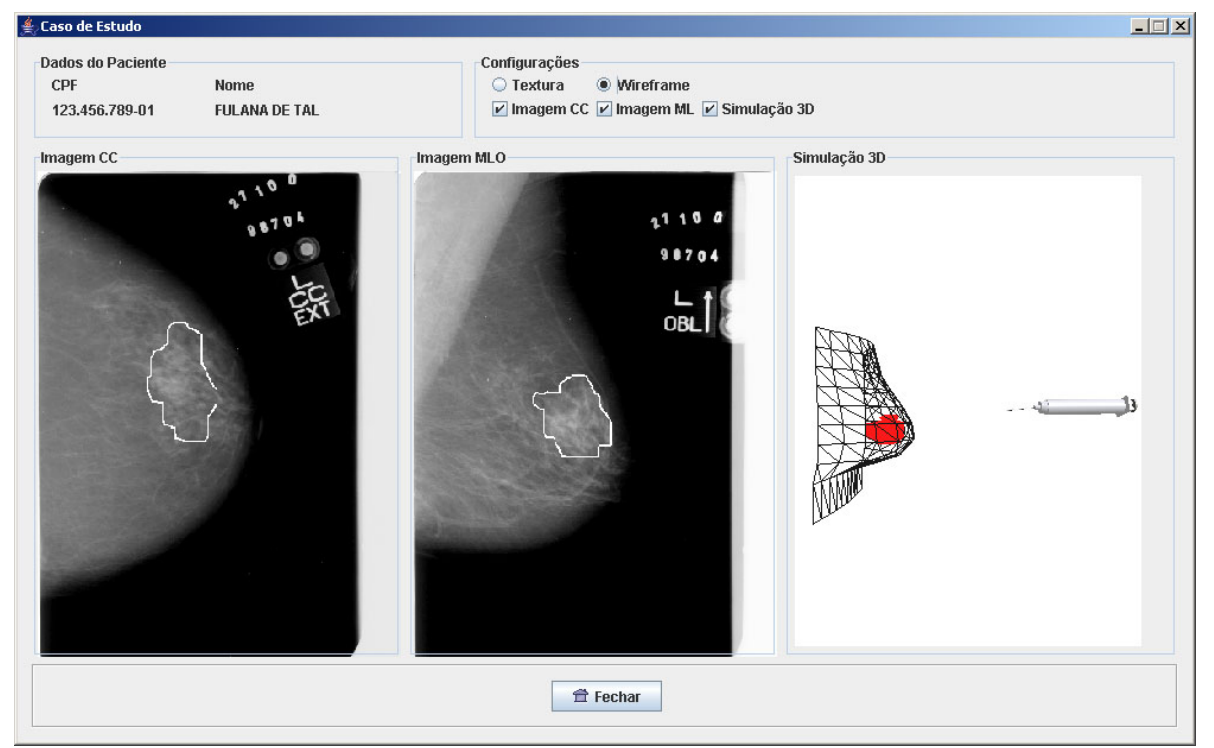

Figura 4.24: Ambiente Virtual para treinamento - modo wireframe (Delfino, 2007).

\subsection{Atlas virtuais}

Como já observado, há diversas categorias de aplicações quando se trata de treinamento usando RV na área de saúde. Uma das áreas bem exploradas é a criação de laboratórios virtuais, que permitem a diminuição de custos na educação em saúde à medida que diminuem a necessidade de criação e manutenção de laboratórios físicos. Um dos escopos de interesse neste contexto é o ensino de anatomia.

Os atlas convencionais bidimensionais para estudo de anatomia e fisiologia não permitem, em geral, uma visão integrada de órgãos e sistemas e são limitados em relação a proporcionar a percepção tridimensional do corpo humano. Apesar de apresentarem diferentes visões, na maioria dos casos, cabe ao leitor construir de forma imaginária a estrutura tridimensional real (Tori et al., 2009a). A esta dificuldade, acrescentam-se os altos custos de implantação e manutenção de laboratórios que, em muitos casos, podem limitar o acesso do estudante a estruturas reais, conforme analisaram Ma e Nickerson (2006).

Dentro das pesquisas realizadas pela autora neste contexto, destacam-se o Atlas Virtual da Mama e o projeto VIDA, apresentados a seguir.

\subsubsection{Atlas Virtual da Mama}

Com o objetivo de facilitar o estudo de anatomia e fisiopatologia do câncer de mama, a ferramenta apresentada em Ramos et al. (2005b) disponibiliza um atlas virtual que permite o acesso a uma base dados, fornecendo informações sobre as estruturas durante a navegação, além de possibilitar a visualização do crescimento de tumores malignos. 
O sistema é composto por dois módulos: Anatomia da Mama e Fisiopatologia do Câncer. O Módulo de Anatomia da Mama é o responsável por disponibilizar as estruturas 3D modeladas e as informações inerentes a elas, podendo executar, usando o mouse, operações de rotação e zoom. Por meio das setas do teclado é possível navegar através das estruturas mamárias, conforme pode ser observado na Figura 4.25, que ilustra a navegação interativa por um ducto lactífero. O usuário "caminha" no interior deste ducto e visualiza todo seu trajeto. Quando solicitado, o usuário tem acesso a informações sobre a estrutura acionada no momento (Figura 4.26).

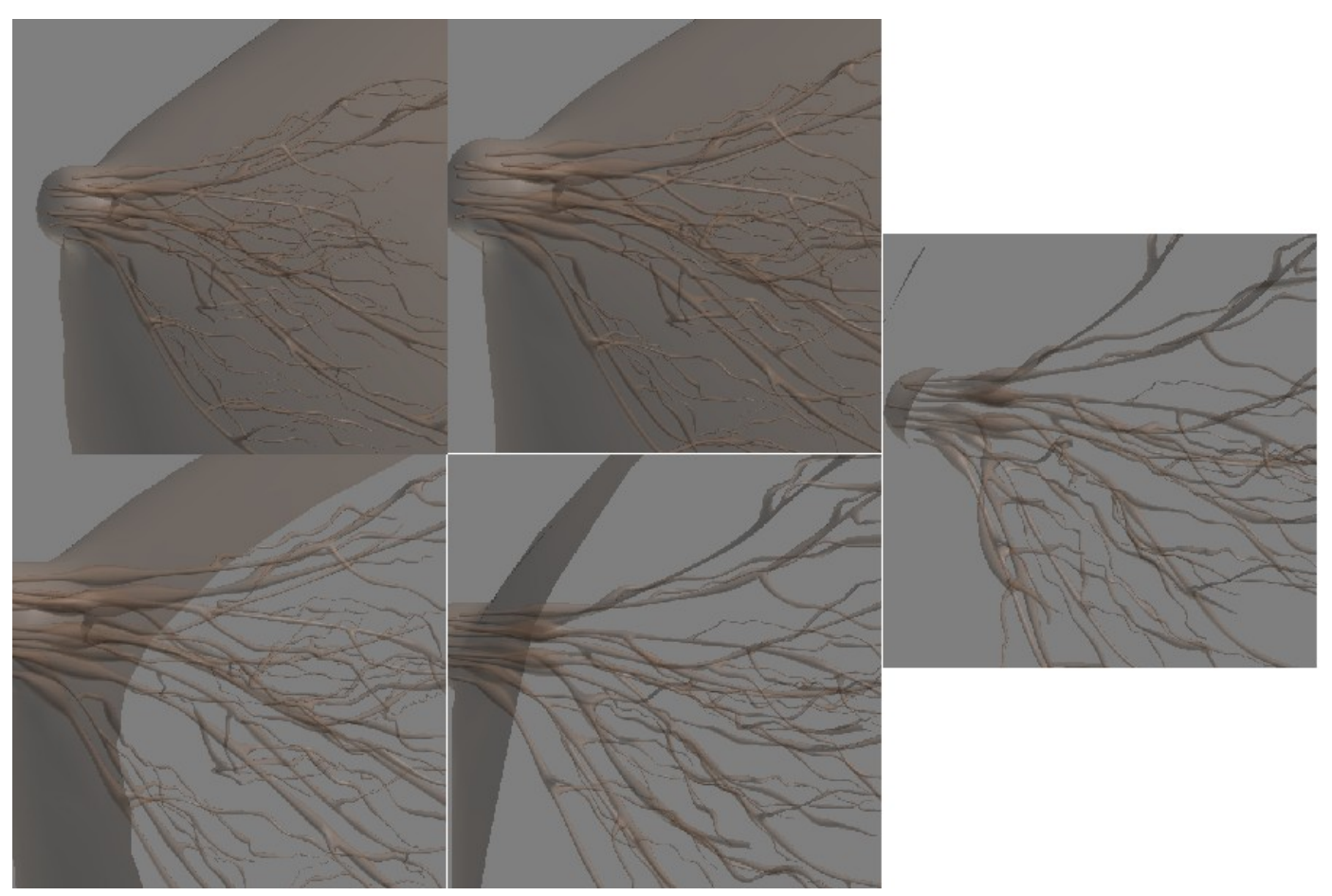

Figura 4.25: Exemplo de navegação no Atlas Virtual da Mama (Ramos et al., 2005b).

No Módulo de Fisiopatologia do Câncer, o usuário pode observar animações com o objetivo de conhecer como um tumor se desenvolve. Sendo conhecidas as estruturas nas quais o câncer de mama se desenvolve com maior frequência, como cita Halbe (2000), e os estágios de avanço da doença (DeVita, 2004), o usuário pode escolher, entre as opções de visualização do câncer, o quadrante da mama em que deseja observar o tumor se desenvolvendo, a estrutura mamária, o estágio de desenvolvimento da doença e o tipo de câncer. A Figura 4.27 ilustra o crescimento de um câncer em diversos estágios e na Figura 4.28 é apresentado um exemplo do desenvolvimento da doença em diferentes estruturas da mama. 


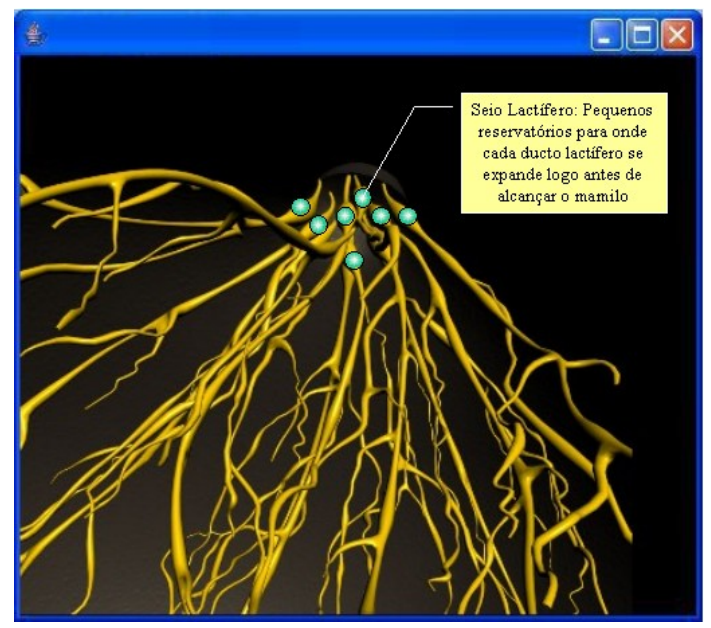

Figura 4.26: Informação exibida no Atlas Virtual da Mama (Ramos et al., 2005b).

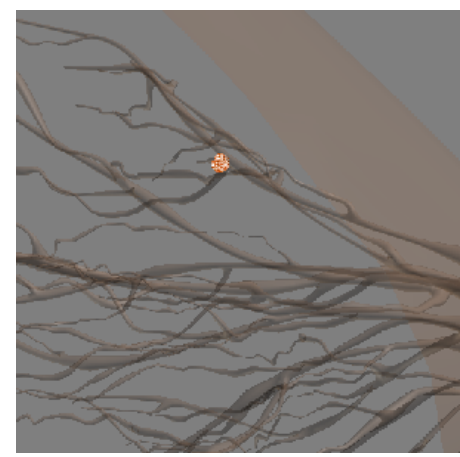

(a) Estágio I

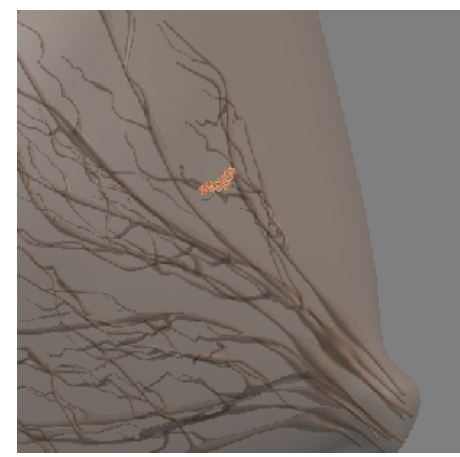

(b) Estágio II

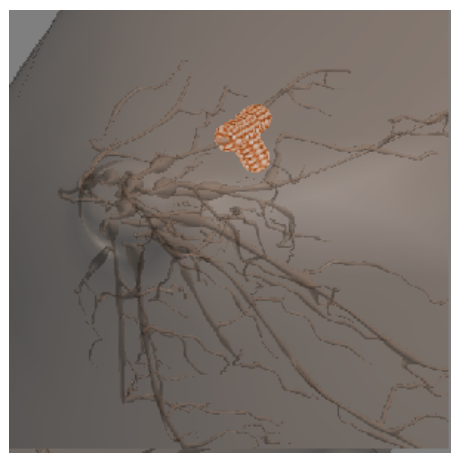

(c) Estágio III

Figura 4.27: Desenvolvimento de carcinoma (Ramos et al., 2005b).

\subsubsection{Projeto VIDA}

A ideia do projeto VIDA (Virtual and Interactive Distance-learning on Anatomy) é disponibilizar um AV de aprendizagem que forneça atlas anatômico virtual para treinamento de estudantes da área de saúde, que pode ser acessado a distância, via Internet, utilizando estereoscopia e interação direta ou por meio de dispositivos convencionais. A Figura 4.29 apresenta uma ilustração conceitual da manipulação dos elementos do atlas virtual, conforme percebido pelo aluno. Após selecionar a estrutura anatômica que irá manipular, o usuário vê uma projeção 3D à frente do monitor e poderá utilizar as próprias mãos para interagir com o modelo (Tori et al., 2009a).

No sistema é disponibilizada visualização estereoscópica, sendo que os parâmetros da projeção, como distância focal e paralaxe, são calibrados de forma que cada usuário tenha a sensação de estar visualizando a estrutura anatômica no ar, no espaço físico entre o seu corpo e o monitor (ou tela de projeção). 


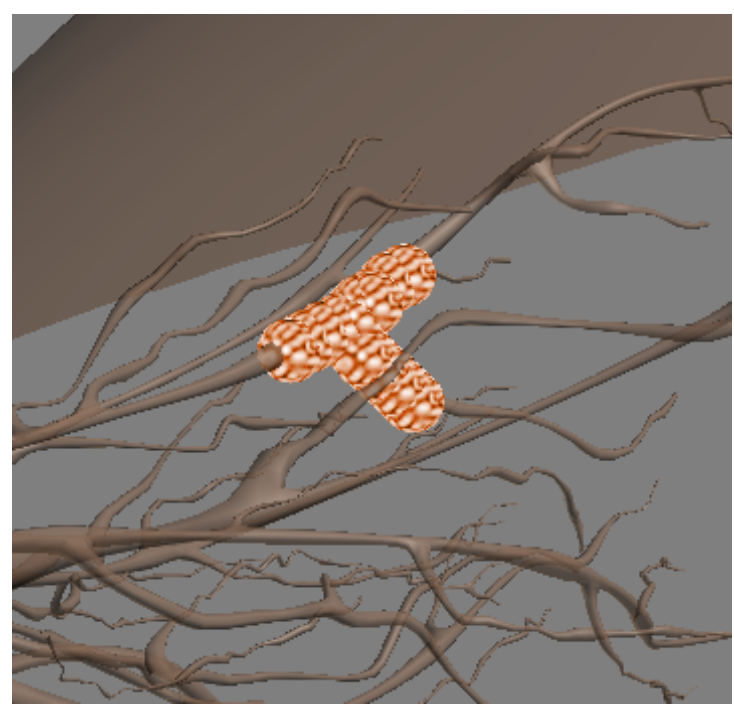

(a) Ductos Lactíferos

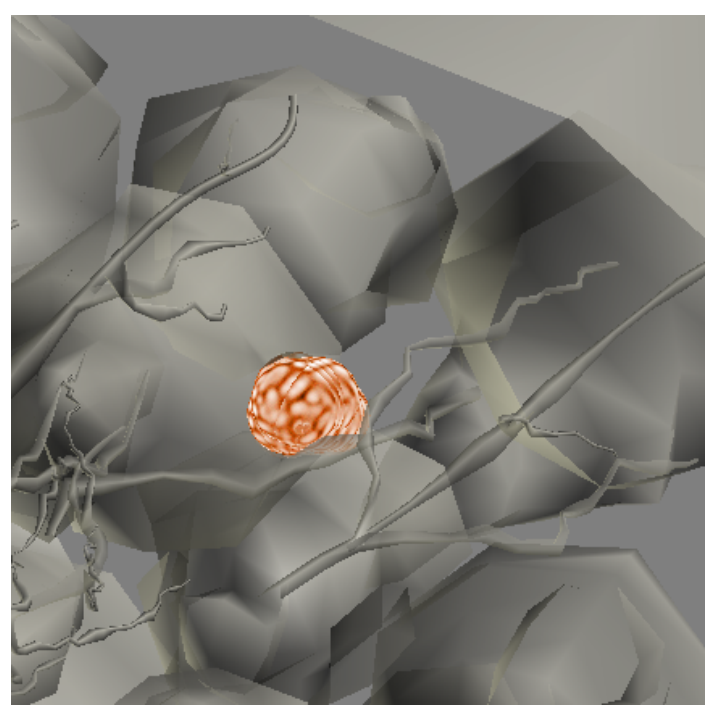

(b) Tecido Conjuntivo das Glândulas Mamárias

Figura 4.28: Câncer desenvolvendo-se em diferentes estruturas (Ramos et al., 2005b).

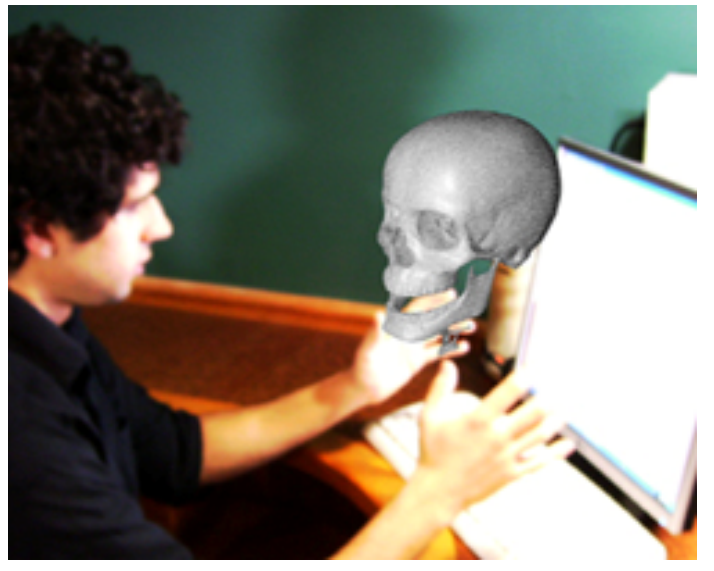

(a) Camada externa do modelo 3D

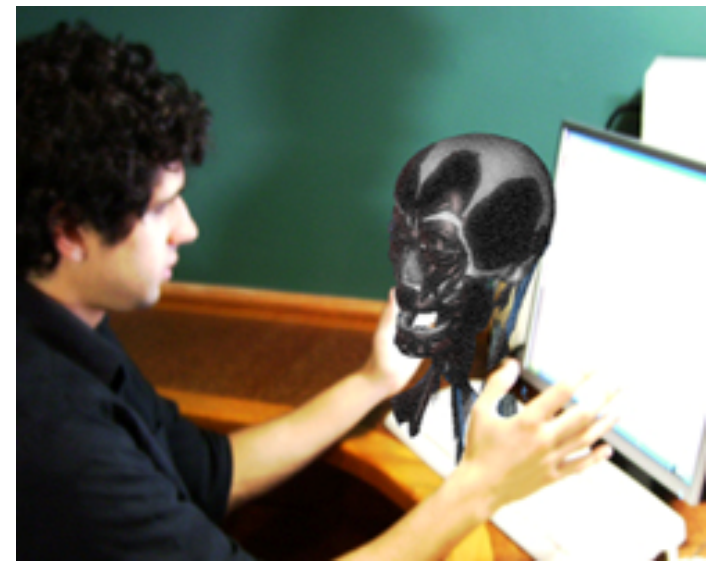

(b) Camada interna do modelo 3D

Figura 4.29: Interação direta do usuário com estruturas 3D (Tori et al., 2009a).

Conforme ilustrado na Figura 4.30, a arquitetura do sistema VIDA visa a permitir sua adaptação a realidades de ensino diferentes, podendo ser executado tanto em sistemas complexos e caros, como CAVEs, quanto em sistemas de baixo custo e na Internet.

O projeto está em desenvolvimento e atualmente a interação funciona com os dispositivos convencionais e parcialmente com o reconhecimento de gestos. Os módulos que compõem o processo de interação controlam a forma como o usuário interage com o sistema. Para manipular a estrutura anatômica o estudante pode utilizar as mãos, se uma webcam estiver disponível. Na versão atual, o sistema é capaz de rastrear as mãos do aprendiz, medindo a distância dessas ao objeto de estudo, provocando a substituição de objetos projetados e, assim, proporcionando o efeito de "raio-X", imprimindo a sensação 


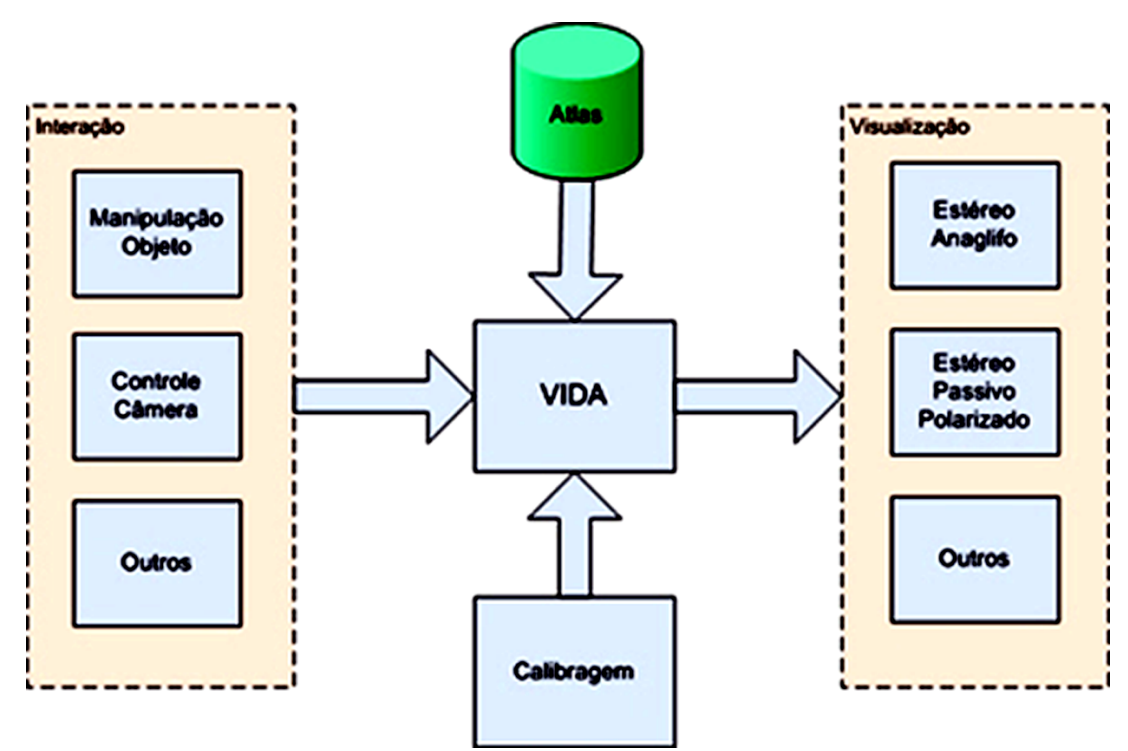

Figura 4.30: Arquitetura do Sistema VIDA (Tori et al., 2009a).

de estar acessando camadas mais internas da estrutura anatômica, conforme ilustrado na Figura 4.29.

Os módulos do grupo Visualização controlam a forma como o conteúdo é mostrado aos alunos, permitindo que diferentes técnicas possam ser utilizadas, dependendo do equipamento disponível. Por fim, o módulo de Calibração permite ao aluno modificar parâmetros tanto de interação como de visualização, "ajustando" o objeto virtual no espaço de forma a obter a sensação de imersão mais adequada às suas características.

Diferentemente do Atlas Virtual da Mama, o projeto VIDA é genérico para o ensino de anatomia, visando a gerar aplicações de quaisquer partes do corpo humano, bastando obter os modelos 3D necessários e configurar o sistema para exibi-los. A fim de facilitar essa construção de aplicações, uma interface gráfica é disponibilizada ao usuário, conforme ilustra a Figura 4.31.

Usando a interface apresentada, o usuário configura as propriedades da câmera, da visualização estereoscópica e da aparência do sistema. Também adiciona objetos a serem exibidos, estabelecendo características como o número da camada à qual cada estrutura ficará relacionada, posicionamento, orientação, escala, nomes das estruturas (que serão exibidos como etiquetas no AV) e textos explicativos que serão disponibilizados durante a execução do sistema. Esses parâmetros são gravados em um arquivo no formato $X M L$, posteriormente utilizado para configuração do atlas virtual quando o sistema é executado. Na Figura 4.32 é apresentada uma aplicação de atlas virtual para a área de Obstetrícia (Nunes et al., 2010).

As principais publicações geradas pelos resultados iniciais das pesquisas realizadas dentro do tema Atlas Virtuais foram: Nunes et al. (2010), Ramos et al. (2005b), Ramos et al. 
(2005a), Tori et al. (2009a) e Tori et al. (2009b) e Tori et al. (2010), sendo que o trabalho Tori et al. (2009a) recebeu o prêmio de melhor artigo na edição de 2009 do Workshop sobre Informática na Escola (WIE), realizada no Congresso da Sociedade Brasileira de Computação.

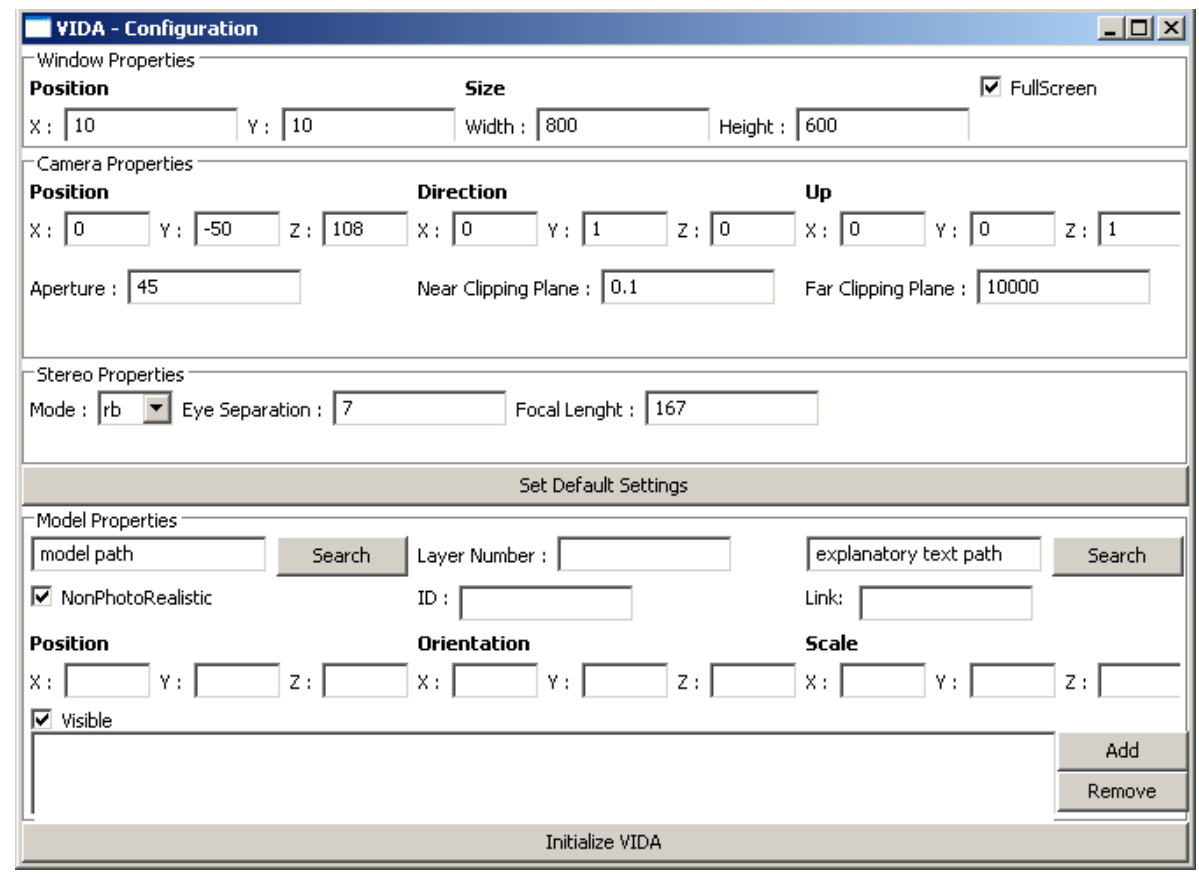

Figura 4.31: Interface gráfica para geração de aplicações.

\subsection{Jogos sérios}

Tradicionalmente os jogos digitais têm como principal objetivo o entretenimento. Nos últimos anos, fatores como o barateamento de tecnologia e a popularização de dispositivos móveis têm proporcionado acesso mais democrático a esse tipo de lazer.

Apesar dessa categoria de software ter surgido com a finalidade básica de entreter, o encantamento que proporciona a pessoas de todas as idades, mas principalmente a crianças e jovens, tem despertado a sua aplicação para finalidades adicionais, além do entretenimento. Em uma pesquisa com 100 estudantes da Universidade de São Paulo (Suzuki et al., 2009), foi verificado que $83 \%$ haviam jogado no último ano e mais da metade $(51,8 \%)$ jogavam de uma a três horas por sessão. Felmer et al. (2008) conduziram uma pesquisa para aferir a aprendizagem implícita em usuários de jogos eletrônicos e apontaram que jogadores intensivos e moderados apresentaram facilidades para captar as regularidades implícitas ou presentes de forma subliminar nos jogos, indicando o potencial de jogos eletrônicos como veículo de aprendizado (Machado et al., 2010). 


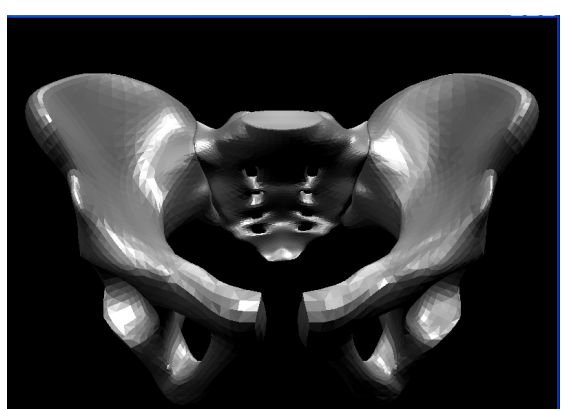

(a) Modelo original

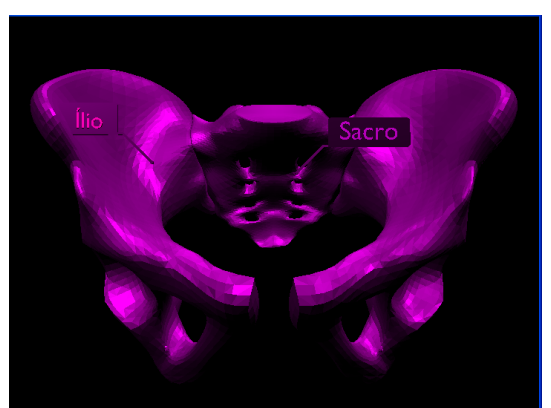

(b) Modelo com etiquetas

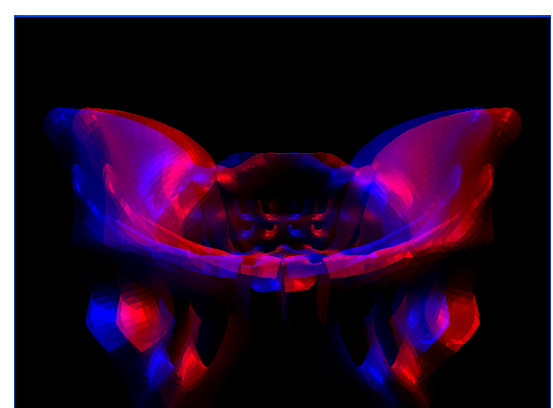

(c) Modelo em anaglifos
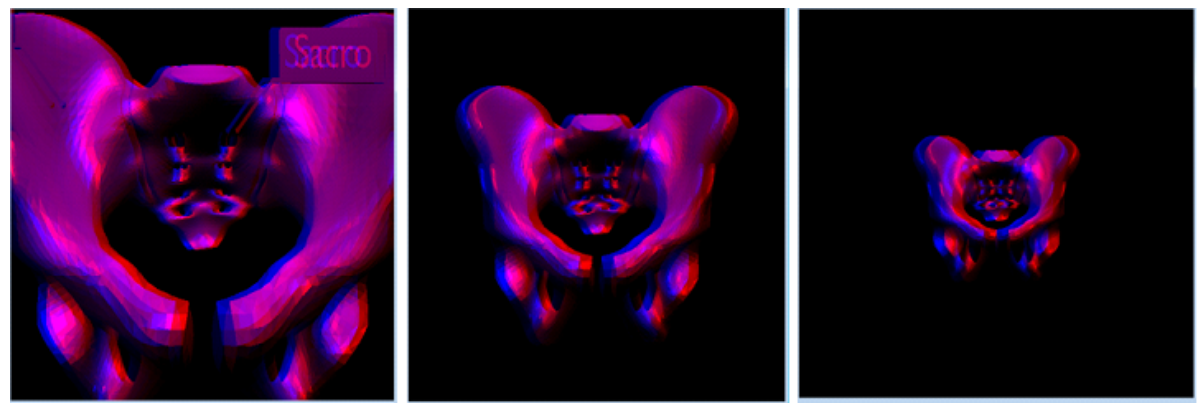

(d) Operação de escala
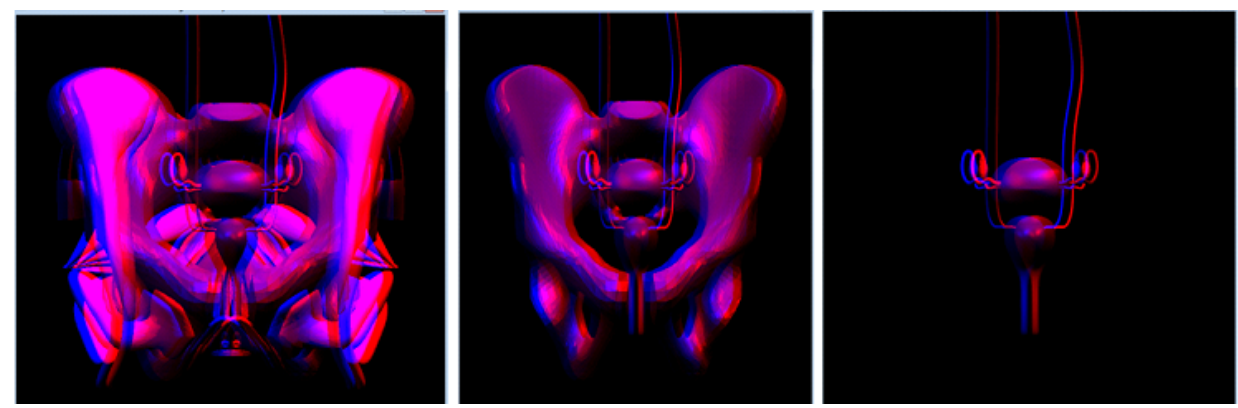

(e) Navegação simulando efeito de "raio-x"

Figura 4.32: Atlas virtual para área de Obstetrícia (Nunes et al., 2010).

Entre as novas funções atribuídas aos jogos eletrônicos está a de ensinar algo específico, seja por meio da transmissão de um conteúdo ou da possibilidade de exercitar alguma habilidade. A esses jogos com propósito específico, dá-se o nome de serious games ou, em tradução literal, jogos sérios. Apesar de não haver uma definição precisa sobre o 
termo serious games, essa classe de jogos visa principalmente a simulação de situações práticas do dia-a-dia, com o objetivo de proporcionar o treinamento de profissionais, situações críticas em empresas, conscientização para crianças, jovens e adultos e mesmo para situações corriqueiras, como escolher os opcionais e a cor de um carro (Zyda, 2005).

Conforme afirmado por Machado et al. (2010), um dos setores que tem se beneficiado dos jogos sérios é a Medicina. As dificuldades encontradas na obtenção de materiais de laboratório, validação de produtos e treinamento de pessoal tornam tais jogos um importante aliado do ensino na área médica, podendo beneficiar tanto estudantes quanto profissionais. A reprodução de situações cotidianas de forma realista é um requisito para que um jogo sério seja adequado para a educação em saúde. Por isso, a tecnologia de RV torna-se uma aliada a esta inovação no processo de aprendizagem.

Os desafios, níveis variados de dificuldades e a inteligência que aguça a curiosidade do jogador, presentes nos jogos sérios, podem incrementar a motivação para o aprendizado, contribuindo para a assimilação de conteúdos e práticas. De acordo com Machado et al. (2010), o desenvolvimento de um jogo sério para a educação em saúde usando RV é bastante semelhante ao desenvolvimento de qualquer outra aplicação de RV para treinamento em saúde. No entanto, o planejamento do jogo exige fases adicionais como a definição do roteiro, a conceituação artística e a jogabilidade (regras e desafios). Além desses, um aspecto que deve ser bem planejado é inteligência do jogo. Especialmente em jogos sérios, deve-se garantir que, ao final, o aprendiz tenha atingido o objetivo do jogo, podendo, para isso, ter percorrido caminhos variados.

De acordo com o descrito na seção 4.4, o estágio atual do framework ViMeT permite gerar aplicações semiprontas para simular exames de biópsia. Por si só as aplicações resultantes já poderiam contribuir com a educação médica. Porém, acrescentar um aspecto de jogabilidade ao treinamento pode torná-lo mais motivador e desafiador. Assim, um estudo em andamento está transformando uma aplicação gerada pelo ViMeT em um jogo sério.

Inicialmente foram estudados os casos possíveis de treinamento e os aspectos de jogabilidade possíveis de serem utilizados. Optou-se por acrescentar três aspectos principais: pontuação, tempo limite e fases com diferentes níveis de dificuldade. O objetivo final é atingir um nódulo no interior do órgão humano dentro de um tempo limite. Para isso, o jogador pode executar caminhos variados com o dispositivo de interação, ganhando pontos à medida que se aproxima do nódulo e perdendo-os quando se afasta. O local em que o aprendiz perfurou o órgão humano, assim como a distância entre o local perfurado e o local correto também contribuem com a pontuação. Na Figura 4.33 é apresentada a interface do jogo com a pontuação obtida pelo jogador. 


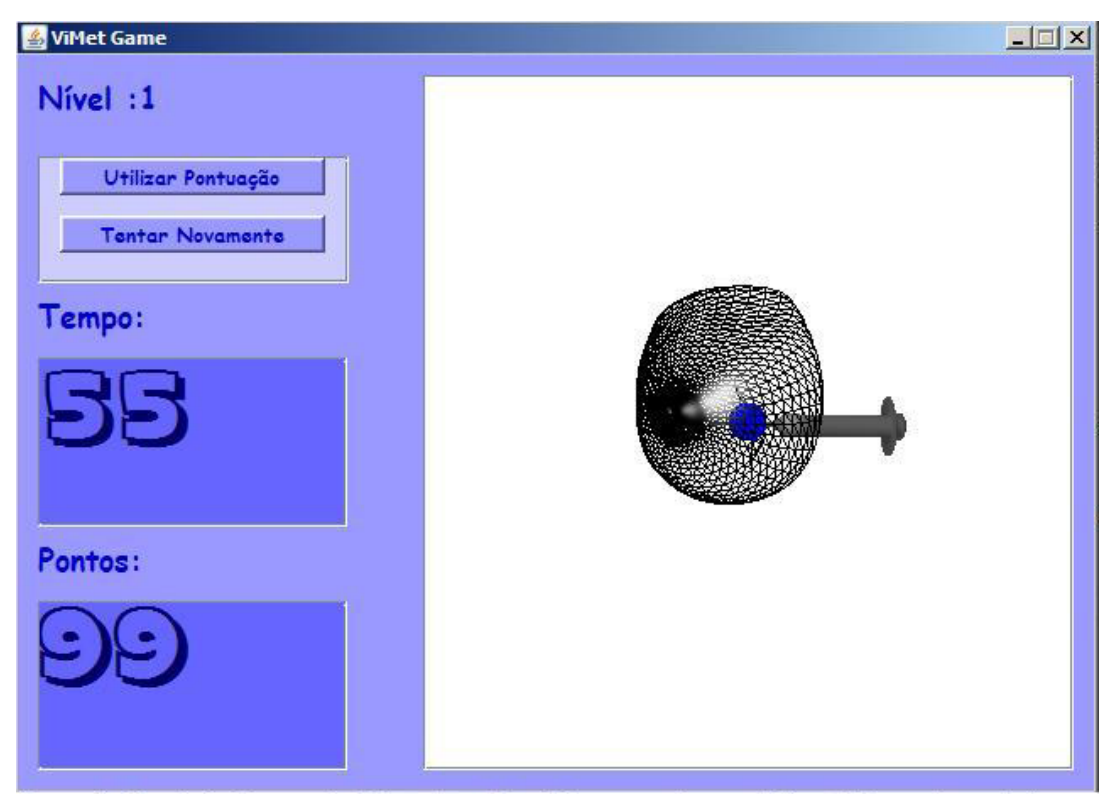

Figura 4.33: Interface inicial do jogo com pontuação e tempo.

No jogo são previstas 10 fases, sendo que em cada uma delas aumenta-se um aspecto de dificuldade (nódulo menor, forma ou localização do nódulo, uso de textura para "esconder" o nódulo, por exemplo). Para que o jogador possa mudar de fase, deve responder a uma pergunta de múltipla escolha sobre a teoria do exame de biópsia (Figura 4.34).

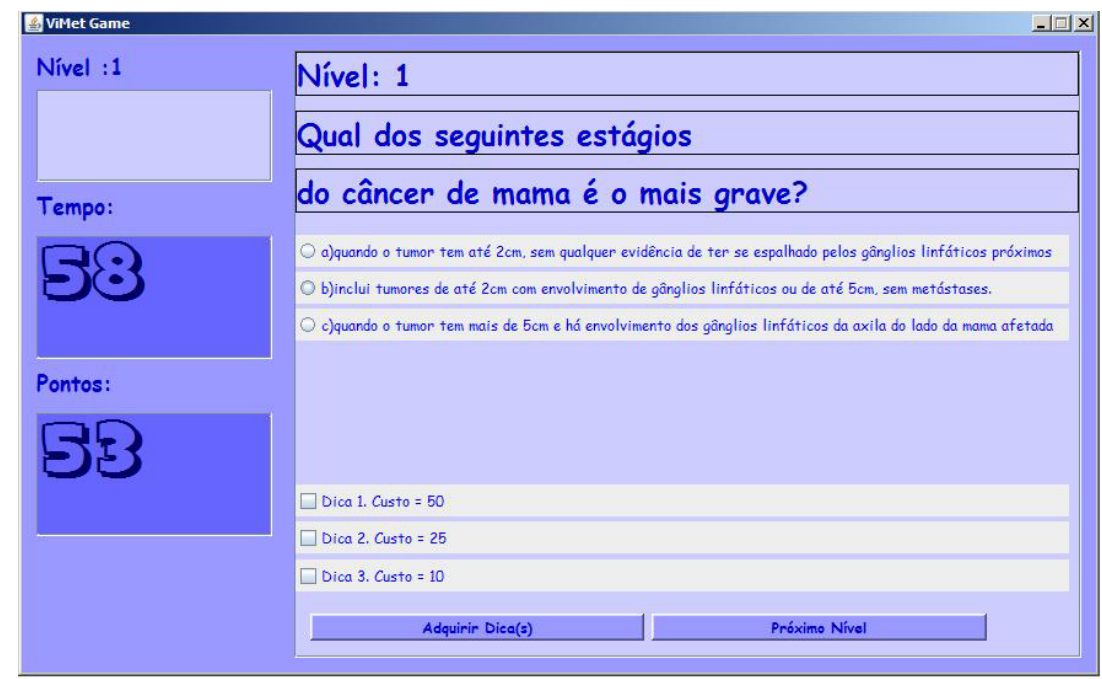

Figura 4.34: Utilização de perguntas para mudar de fase.

Com a definição de que a jogabilidade deveria incluir questões conceituais e exigir domínio da habilidade motora para executar o procedimento, pretende-se, ao mesmo tempo, que o aprendiz consiga dominar tanto os aspectos teóricos quanto os práticos da tarefa. Após finalizado o jogo, avaliações com professores e alunos da área deverão ser conduzidas, de forma a verificar a contribuição real que o software pode trazer ao aprendizado. 


\subsection{Considerações finais}

Os trabalhos de pesquisa apresentados neste capítulo foram conduzidos de forma incremental. Como mencionado, as pesquisas foram iniciadas em uma época em que poucos grupos no Brasil tinham a RV e, mais especificamente, as aplicações em saúde usando RV como objeto de pesquisa. Dessa forma, mesmo sem grandes possibilidades de intercâmbios de experiência no país, foi possível estudar características das tecnologias, opções disponíveis e objetos de pesquisa pouco explorados. Visando ao uso efetivo dos resultados obtidos e ao aumento da produtividade no desenvolvimento de ferramentas, mesmo em médio ou longo prazo, procurou-se adotar soluções tecnológicas de baixo custo e que permitissem reuso de código.

Outros projetos dentro deste contexto foram conduzidos ou iniciados no mesmo período, mas os aqui apresentados cobrem de forma geral os assuntos de pesquisa abordados, optando-se por não mencionar trabalhos que não incrementassem tópicos para a discussão que se pretende tecer. Ao longo do tempo, o processo de desenvolvimento e os resultados obtidos permitiram conduzir reflexões sobre os assuntos abordados, levando a elaborar a lista de requisitos apresentada no início do capítulo.

Como foi possível verificar, as diversas vertentes do processamento gráfico $2 \mathrm{D}$ e $3 \mathrm{D}$ podem se completar para explorar objetos de interesse de pesquisa, como é o caso da junção de processamento de imagens com técnicas de interação para, por exemplo, gerar casos diversos para treinamento de procedimentos. Outros exemplos dessa junção serão abordados no próximo capítulo.

A parceria com profissionais da área de saúde, principalmente com docentes e alunos da Faculdade de Medicina de Marília (Famema), permitiu avaliar algumas ferramentas desenvolvidas, detectando falhas durante a sua concepção e resultando na reestruturação de diversos conceitos. Os trabalhos aqui apresentados também forneceram embasamento para identificar espaços de pesquisa ainda não preenchidos na área, os quais geram oportunidades de temas que merecem ser explorados. Algumas reflexões sobre a avaliação com profissionais da saúde, assim como desafios e oportunidades, serão abordados no capítulo 6 . 


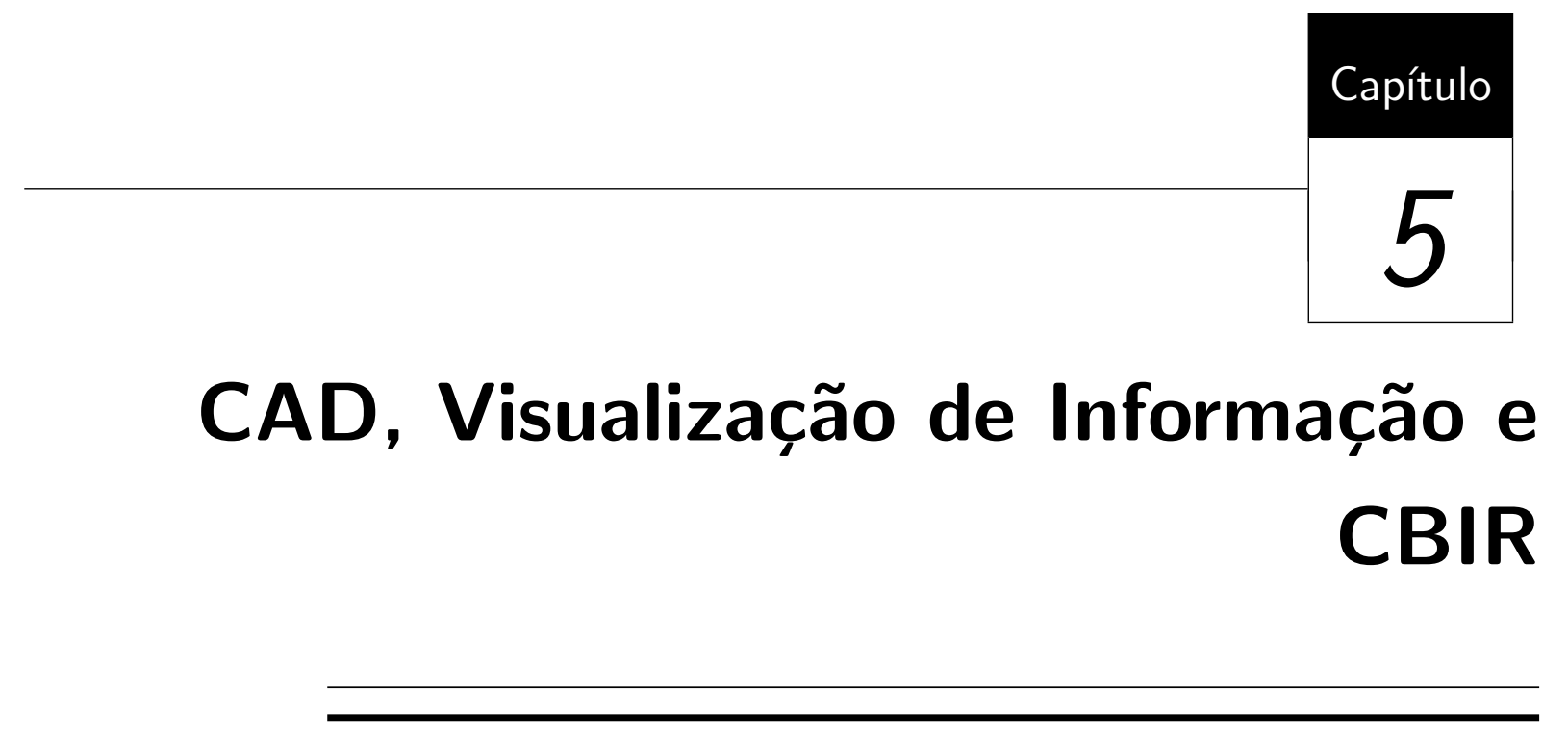

Nos capítulos 2 e 3, respectivamente, foram apresentados conceitos e aplicações de técnicas computacionais que, em geral, não foram retomados nos trabalhos apresentados no capítulo 4, principalmente relacionadas a Processamento de Imagens.

O objetivo deste capítulo é apresentar as pesquisas desenvolvidas conduzidas pela autora e sua equipe que não se enquadram exatamente em ferramentas de treinamento virtual, mas que usam conceitos de PI e RV nas suas implementações, ora considerados separadamente, ora considerados em conjunto. Alguns dos objetos de pesquisam extrapolam a área de saúde.

Desse conjunto de assuntos fazem parte os sistemas de auxílio ao diagnóstico, ferramentas para Visualização de Informação, trabalhos na área de CBIR e, por fim, um framework que usa conceitos de CBIR para teste de programas com saídas gráficas. As apresentações a seguir visam a tecer um panorama geral das técnicas e ferramentas desenvolvidas. Os detalhes de concepção, implementação e validação são disponibilizados nas referências citadas. 


\subsection{Auxílio ao diagnóstico}

Sistemas de CAD são sistemas computacionais, muitas vezes acoplados a equipamentos médicos, com a finalidade de auxiliar na tomada de decisão a respeito de um diagnóstico. Aplicações com finalidades diversas têm sido desenvolvidas por vários grupos de pesquisas, visando a auxiliar na composição de diagnósticos como uma forma de contribuir para a detecção precoce de doenças (Nunes, 2006). Como definido na seção 3.1, o objetivo de um sistema de CAD é oferecer uma segunda opinião a respeito da existência de uma anomalia.

O desenvolvimento desses sistemas exige primeiramente um conhecimento aprofundado sobre as imagens que serão utilizadas e a parte do corpo humano sob estudo. Além disso, quando se tratar de detecção de patologias, deve-se ainda conhecer as características da anomalia procurada e suas representações na imagem. Para tal, é necessário dominar os fundamentos de PI, a fim de desenvolver técnicas específicas para alcançar os requisitos do sistema.

Com o objetivo de verificar o desenvolvimento fetal e visualizar possíveis anomalias, técnicas de PI foram utilizadas para extrair medidas de imagens fetais provenientes de Ultrassonografia, a fim de compará-las com as medidas esperadas, considerando-se o estágio de desenvolvimento do feto. Em seguida, essas medidas foram utilizadas em um sistema de RV para permitir a comparação visual entre um feto com as medidas obtidas e um feto considerado normal. Na Figura 5.1 é apresentada a estrutura geral do sistema.

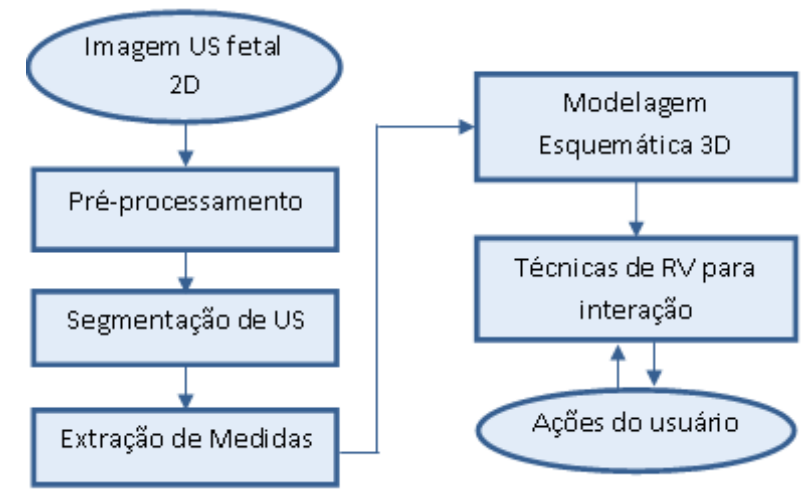

Figura 5.1: Estrutura do sistema de visualização de estruturas fetais (Luz, 2004).

Na etapa de pré-processamento das imagens, primeiramente é empregada a técnica de equalização para realçar o contraste global da imagem. Em seguida, é aplicada uma técnica de Splitting ${ }^{1}$ para aumentar o contraste das estruturas de interesse. As imagens resultantes são submetidas a um procedimento de limiarização com o objetivo de eliminar

\footnotetext{
${ }^{1}$ A técnica de Splitting visa a aumentar o contraste de uma imagem com base no seu histograma, dividindo os pixels em dois grupos distintos de níveis de cinza. Desta forma, os pixels com valores menores da imagem (cores escuras) são diminuídos ainda mais e aqueles com valores altos (pixels claros) tornam-se ainda mais claros.
} 
estruturas que possam ser identificadas como ruídos. Por último, é executada uma técnica de crescimento de região adaptada ao problema abordado, gerando a imagem final da etapa de pré-processamento. Na Figura 5.2 são exemplificadas imagens resultantes das fases citadas.

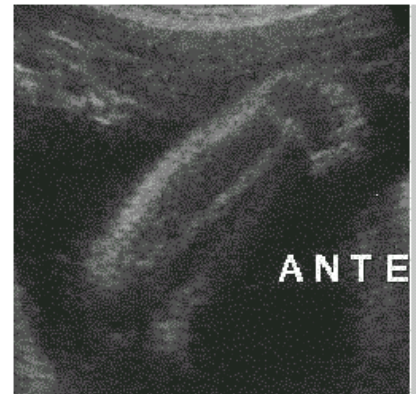

(a) Imagem original

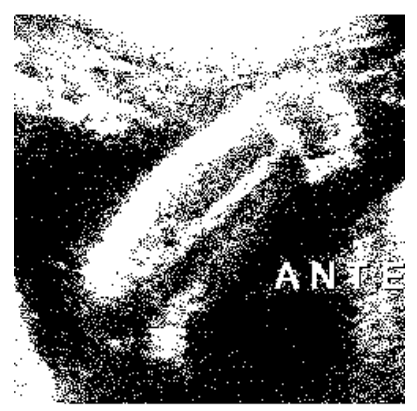

(d) Após limiarização

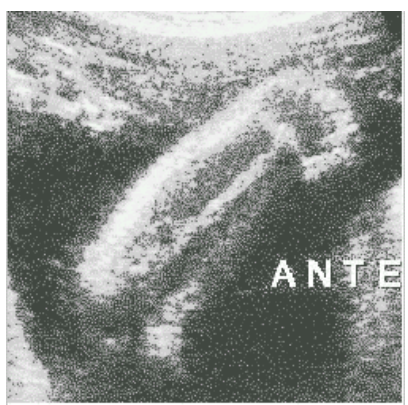

(b) Após equalização

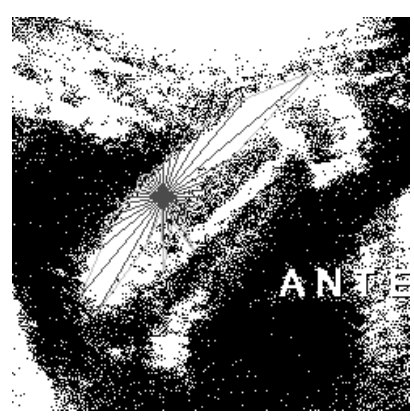

(e) Crescimento de região

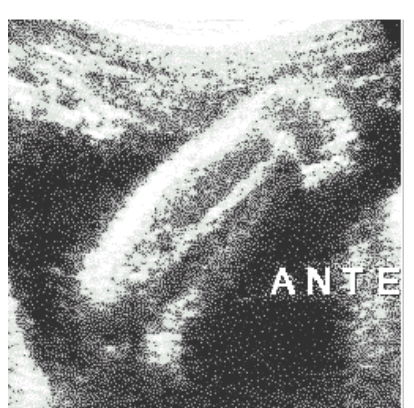

(c) Após splitting

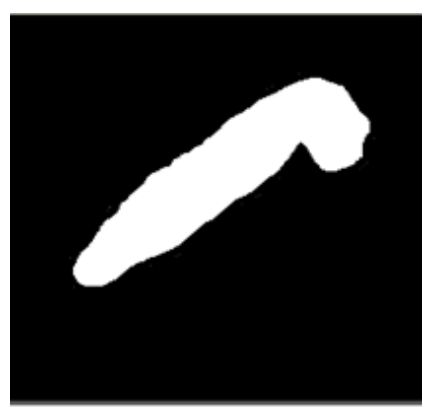

(f) Imagem resultante

Figura 5.2: Processamento para extração de medidas de imagens 2D de US (Luz, 2004).

Na etapa de segmentação, a técnica de crescimento de região "lança" raios a partir de um pixel semente até encontrar a borda da estrutura. Em seguida, os pontos encontrados na borda são ligados e a área da imagem considerada como não pertencente à estrutura de interesse é eliminada para que possa ser feita a extração das medidas.

Para criar o AV, as medidas extraídas são fornecidas ao sistema, que gera o código (em $V R M L)$, responsável por produzir os objetos para visualização. O sistema disponibiliza também a visualização da mesma estrutura com medidas consideradas corretas, fornecida por um especialista, a fim de auxiliar na identificação de eventuais problemas. Esse processo é ilustrado na Figura 5.3.

O AV permite visualizar cada estrutura separadamente (Figura 5.3) ou o feto como um todo, conforme pode ser conferido na interface exibida na Figura 5.4.

Também é possível visualizar fetos com algumas malformações previstas no sistema e interagir com o AV, executando operações de translação, rotação e zoom, conforme exemplificado na Figura 5.5. 


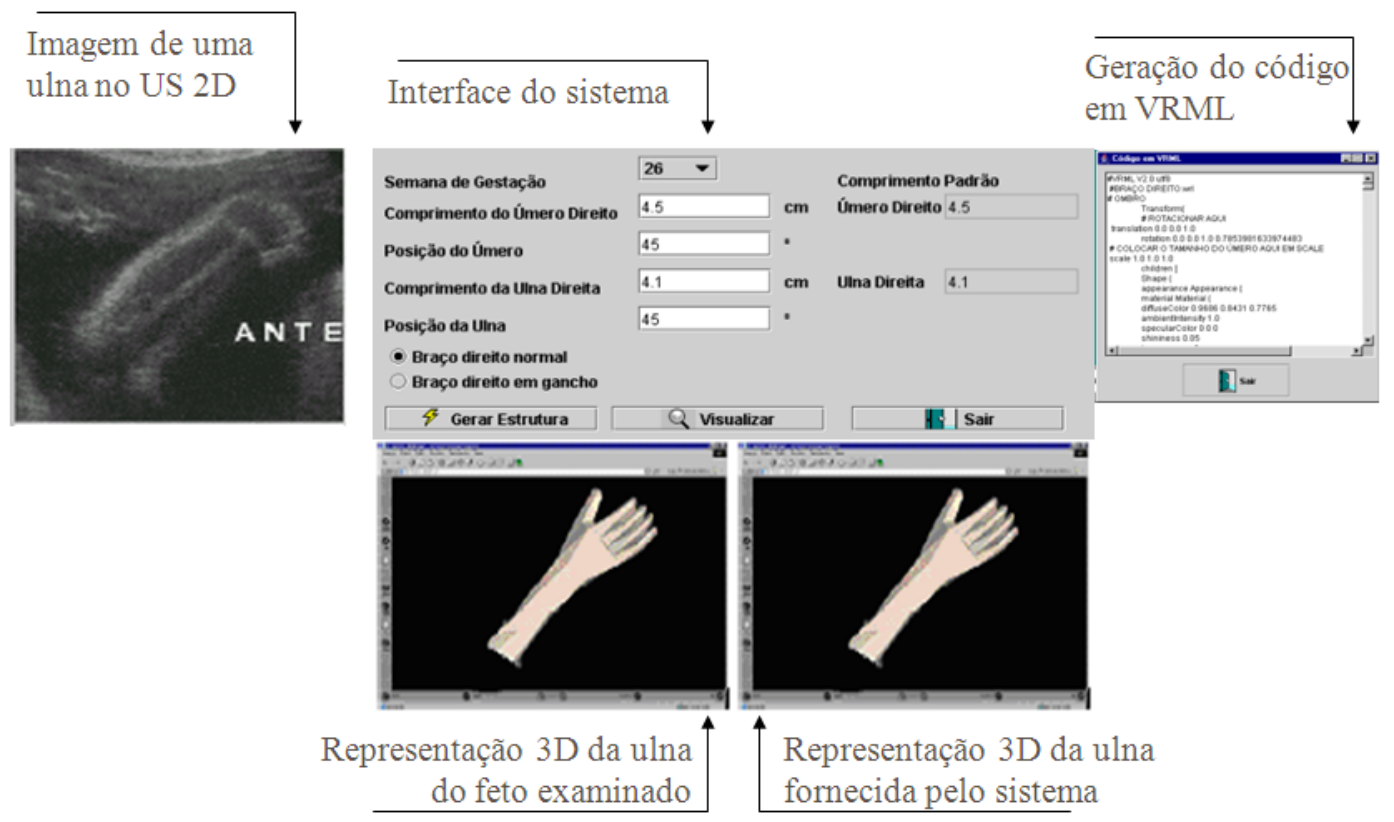

Figura 5.3: Fluxo de processamento para gerar o Ambiente Virtual (Hermosilla, 2004).

\begin{tabular}{|c|c|c|c|c|}
\hline Semana de Gestação & $26-$ & & & \\
\hline Circunferência Craniana & 29 & \multicolumn{2}{|c|}{ Diàmetro Biparietal } & 21.9 \\
\hline Estatura do Feto & 34.0 & \multicolumn{2}{|c|}{ Posição do Tronco } & 0 \\
\hline Comprimento Cabeça-Nádega & 23.0 & \multicolumn{2}{|c|}{ Posicão do Úmero Direito } & 45 \\
\hline Comprimento do Úmero Direito & 4.5 & \multicolumn{2}{|c|}{ Posição da Ulna Direita } & 45 \\
\hline Comprimento da Ulna Direita & 4.1 & \multicolumn{3}{|c|}{ Posição do Úmero Esquerdo } \\
\hline Comprimento do Úmero Esquerdo & 4 & \multicolumn{2}{|c|}{ Posição da Ulna Esquerda } & 90 \\
\hline Comprimento da Ulina Esquerda & 3 & \multicolumn{2}{|c|}{ Posição do Fêmur Direito } & 45 \\
\hline Comprimento do Fêmur Direito & 3.5 & \multicolumn{2}{|c|}{ Posição da Tíbia Direitta } & 90.0 \\
\hline Comprimento da Tibia Direita & 3 & \multicolumn{3}{|c|}{ Posição do Fêmur Esquerdo 45} \\
\hline Comprimento do Fêmur Esquerdo & 4.9 & \multicolumn{2}{|c|}{ Posiçð̃o da Tíbia Esquerda } & 45.0 \\
\hline Comprimento da Tíbia Esquerda & 4.3 & \multirow{2}{*}{\multicolumn{2}{|c|}{$\begin{array}{l}\text { - Pernas normais } \\
\text { Pernas em gancho } \\
\text { Pernas em x }\end{array}$}} & \\
\hline $\begin{array}{l}\text { Braços normais } \\
\text { Braços em gancho }\end{array}$ & & & & \\
\hline Sair & Gerar E & rutura & Q visualizo & ar Feto \\
\hline
\end{tabular}

Figura 5.4: Interface que recebe medidas para gerar estruturas 3D (Hermosilla, 2004). 
As principais publicações resultantes deste projeto foram: Hermosilla et al. (2004b), Hermosilla et al. (2004a), Hermosilla e Nunes (2004) Hermosilla e Nunes (2007).

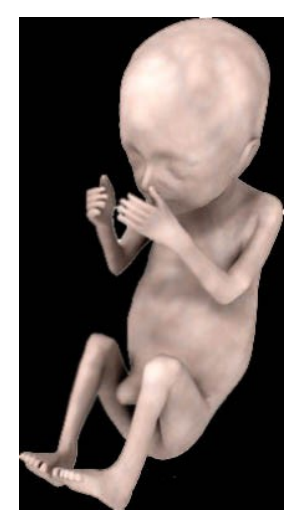

(a) Representação (b) de feto

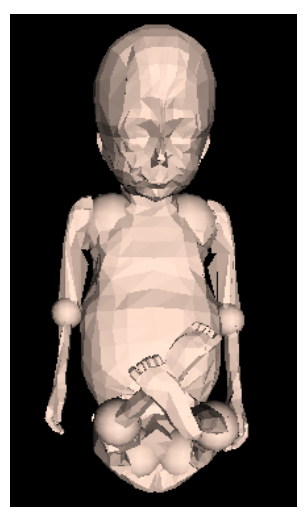

(b) Malformação pernas em "gancho"

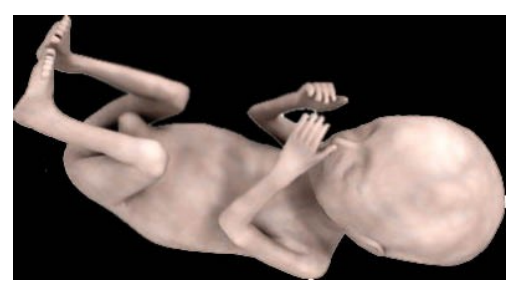

(c) Operação de rotação

Figura 5.5: Exemplos de visualização de feto (Hermosilla, 2004).

\subsection{Visualização de Informação}

O termo Visualização de Informação (VI) é atribuído a métodos que permitem a extração e a exibição de informações relevantes a partir de complexos conjuntos de dados, usando técnicas de CG, PI e RV. Conforme salientam Card et al. (1999), a visualização de dados e informações procura reunir o poder da percepção visual humana com o poder de processamento do computador para que um conjunto de dados possa ser analisado e compreendido rapidamente. Os pesquisadores afirmam, ainda, que pode-se conceituar VI como o uso de representação visual, interativa e com suporte computacional de dados abstratos para ampliar a cognição, ou seja, "usar a visualização para pensar".

Para transformar dados em estruturas visuais, a VI utiliza técnicas que mapeiam os dados em metáforas. A metáfora é uma figura de linguagem que transfere um termo para uma esfera de significado que não é a sua, com a finalidade de estabelecer representação do mundo por meio de analogias. O tratamento dessa visualização por muitas vezes não é simples, devido principalmente à natureza de alta dimensionalidade dos dados. Além disso, a metáfora utilizada no processo de VI em uma determinada aplicação deve ser definida a partir do domínio da aplicação e das características dos usuários finais da ferramenta (Santos, 2010). Para cada metáfora escolhida podem existir uma ou mais técnicas de VI a serem aplicadas.

As pesquisas conduzidas nesta área têm o objetivo principal de verificar como a RV pode contribuir para que informações possam ser visualizadas e rapidamente compreen- 
didas. Inicialmente, foi considerada uma base de imagens de dados médicos, evoluindo-se depois para considerar bases de dados quaisquer, como apresentado nas próximas seções.

\subsubsection{Ferramenta VRVis}

Como estudo de caso inicial, foi considerada uma base de dados médicos com grande volume de informações, responsável por armazenar dados de pacientes, exames e estruturas de interesse encontradas em imagens mamográficas a fim de auxiliar na detecção precoce do câncer de mama, por meio do uso de sistemas de auxílio ao diagnóstico (Nunes et al., 2003). A ferramenta resultante (VRVis - Virtual Reality Visualization) gera uma cena $3 \mathrm{D}$ que representa dinamicamente resultados de uma consulta realizada a partir da base de dados mencionada. Na Figura 5.6 é apresentada a estrutura geral da ferramenta implementada.

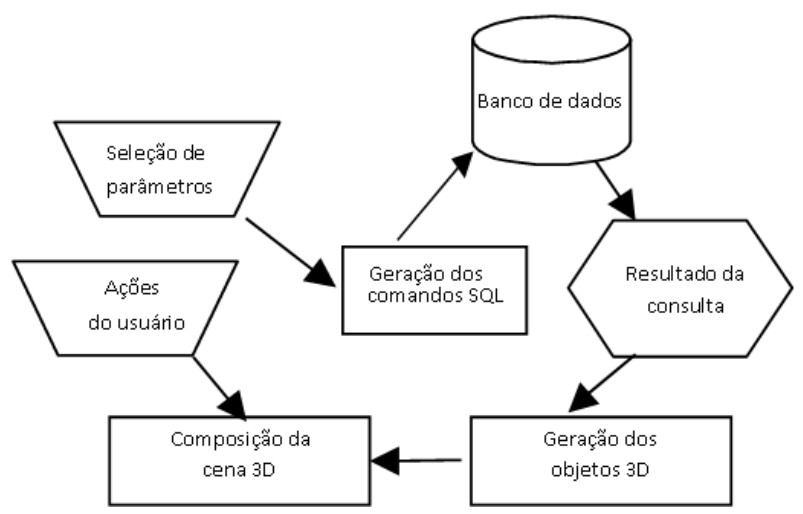

Figura 5.6: Estrutura da ferramenta VRVis (Berti, 2004).

A partir do modelo de dados elaborado para armazenar os dados da base de imagens em um SGBD, foram definidas as consultas mais relevantes para a condução das pesquisas. Nesta fase foram determinados os atributos, filtros e resultados esperados para as requisições possíveis. Na Figura 5.7 é exibida a interface de seleção de parâmetros para consulta da ferramenta VRVis.

Conforme detalhado em Berti (2004), uma vez definidos os parâmetros de consulta, é construída uma query, usando o comando Select da linguagem SQL (Structure Query Language) da seguinte forma: a partir dos parâmetros definidos pelo usuário, selecionam-se todas as ocorrências da base de imagens que atendam a pelo menos um parâmetro. À medida que um registro atende a mais de um critério de busca, o seu grau de relevância é incrementado. Assim, é possível identificar visualmente, na cena 3D, o quanto cada registro é relevante para os critérios estabelecidos pelo usuário. Os resultados são armazenados para serem recuperados no momento de exibição da cena.

Em seguida, foram definidas as representações dos atributos selecionados nas consultas. Foram construídas duas representações gráficas, usando metáforas do mundo real: uma 


\begin{tabular}{|c|c|c|}
\hline$\Leftrightarrow \mathrm{VR}$ is & & $=\square x$ \\
\hline Idade do Paciente & Reposição Hormonal & \\
\hline Menos de 30 anos & ГNẫo & \\
\hline $30-35$ anos & ГSim & \\
\hline $35-40$ anos & Bi-Rads & \\
\hline $40-45$ anos & Classificação 1 & \\
\hline $45-50$ anos & $\bigcirc$ Classificaçã̃o 2 & \\
\hline$\bigcirc$ Mais de 50 anos & $\bigcirc$ Classificaçã̃o 3 & \\
\hline & Classificaçã̃o 4 & \\
\hline & Classificação 5 & \\
\hline Cancer na Família & Classificaçã̃o 6 & \\
\hline Não & Tipo Achado & \\
\hline Sim & $\bigcirc$ Microcalcificaçẫo & \\
\hline Nódulo Palpável & Nódulo & \\
\hline ГNẫo & Calcificaçẫo & \\
\hline ГSim & & \\
\hline Uso Contraceptivo & Filtrar & \\
\hline ГNẫo & & \\
\hline ГSim & & \\
\hline
\end{tabular}

Figura 5.7: Ferramenta VRVis - seleção de parâmetros para consultas (Berti, 2004).

árvore e uma pirâmide. As folhas da árvore representam cada registro resultante da consulta ao BD, tendo sido usadas cores para diferenciar a relevância dos dados. Para a pirâmide, foram utilizados triângulos em ordem decrescente para representar o grau de relevância de cada registro. A ferramenta mostra os resultados obtidos em uma versão textual e permite ao usuário selecionar a metáfora para visualização da cena, usando a interface mostrada na Figura 5.8.

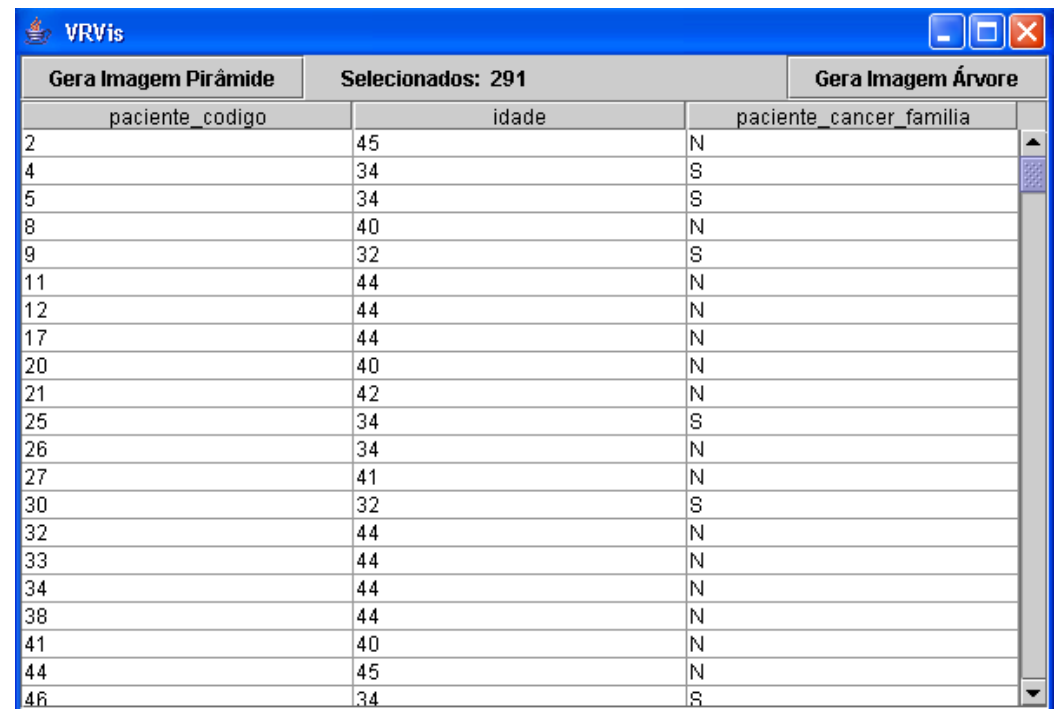

Figura 5.8: Resultado textual de uma consulta e seleção de metáfora (Berti, 2004).

A cena 3D gerada torna possível a interação do usuário com o AV, usando dispositivos convencionais (mouse e teclado) para executar movimentos de translação, rotação e seleção dos objetos. Na Figura 5.9(a) é apresentada a cena gerada com a legenda de cores e graus 
de relevância do resultado da pesquisa, usando a metáfora de árvore. Um exemplo usando a metáfora de pirâmide é apresentado na Figura 5.9(b).

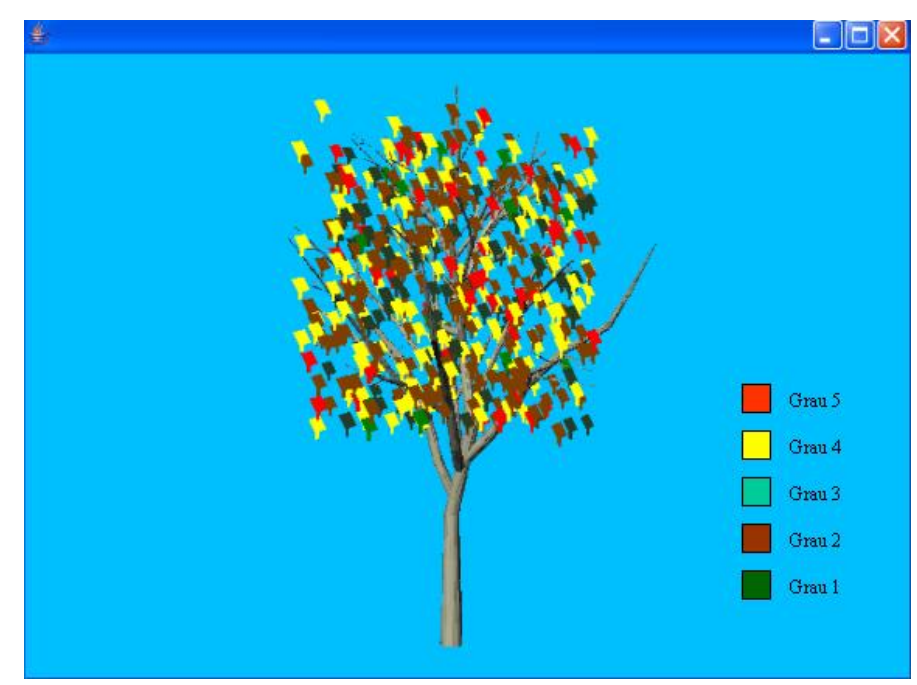

(a) Metáfora de árvore

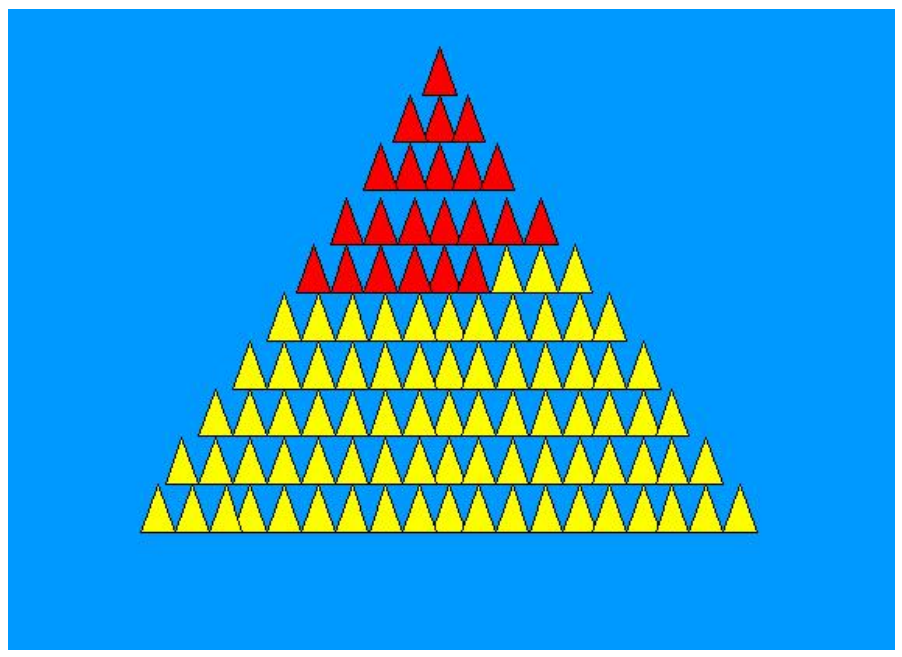

(b) Metáfora de pirâmide

Figura 5.9: Visualização do resultado de consultas com metáforas (Berti, 2004).

De acordo com o discutido em Berti (2004), os resultados exibidos de forma gráfica fornecem ao usuário uma visão geral de como sua base de dados se comporta, podendo compreender a composição dos seus dados. É possível visualizar qual grupo atende aos parâmetros definidos e, dentro deste grupo, acessar cada registro individualmente, selecionando-se uma folha da árvore ou um triângulo da pirâmide. Na Figura 5.10 é exibido um exemplo de acesso aos dados do registro a partir da interação do usuário, utilizando a metáfora de árvore. 


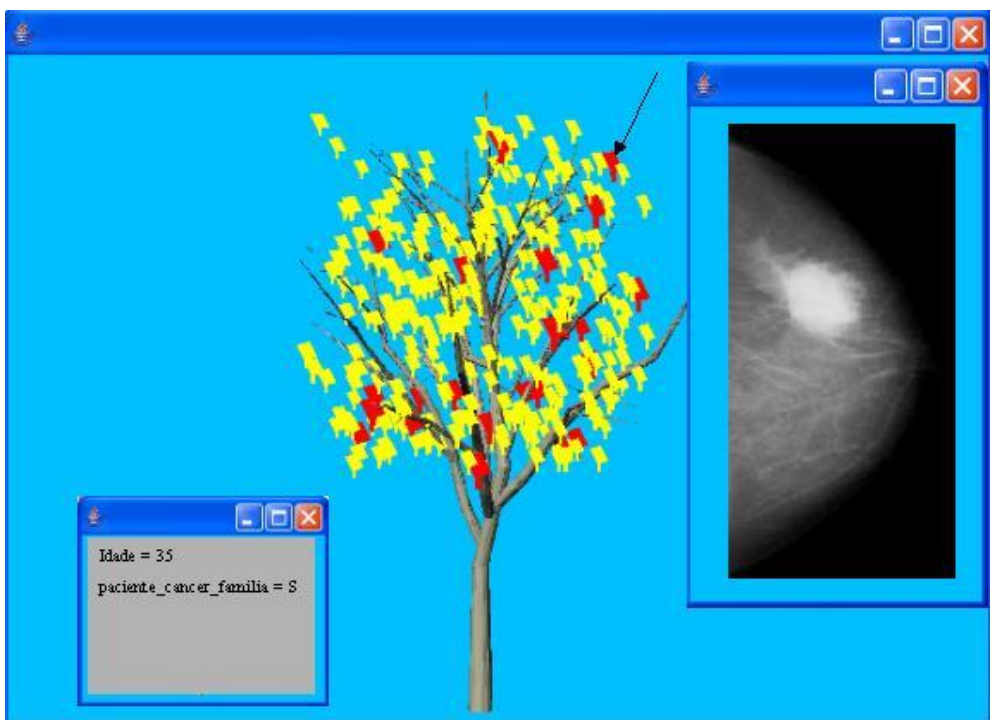

Figura 5.10: Acesso aos dados de um registro com ferramenta VRVis (Berti, 2004).

\subsubsection{Ferramenta VRVis Manager}

Como evolução do trabalho citado na seção 5.2.1, a ferramenta VRVis Manager tem como objetivo expandir a abrangência da ferramenta VRVis em relação aos SGBDs suportados e à flexibilidade para a criação de filtros. Além disso, há possibilidade de seleção de imagens a serem usadas como metáforas, de acordo com o conjunto de dados a ser representado, além de permitir o reaproveitamento de pesquisas já realizadas e armazenadas em um arquivo de histórico. Na Figura 5.11 é disponibilizado o diagrama com a estrutura de módulos da ferramenta.

Para possibilitar que o usuário utilize uma imagem como metáfora, o módulo de criação de Metáforas disponibiliza a interface apresentada na Figura 5.12. Conforme detalhado em Santos (2010), à imagem de uma metáfora podem ser atribuídos: nome, características de melhor representação para visualização da mesma em uma cena (podendo ser pela cor ou tamanho) e melhor tipo de dado para representação. É possível, ainda, padronizar a imagem como sendo base ou item de grupo. A característica de base de grupo permite que uma imagem possa representar múltiplas informações, podendo ser vinculada a ela até quatro outras informações (itens de grupo). Tal funcionalidade facilita a visualização de seleções que utilizam agrupamentos (cláusula group by do comando Select da linguagem $S Q L)$.

Como a ferramenta visa a oferecer visualização para quaisquer bancos de dados, a interface apresentada na Figura 5.13 oferece ao usuário a possibilidade de escolha de um SGBD entre quatro tipos oferecidos: MySQL, PostGreSQL, FireBird e Oracle. Em seguida, o usuário deve indicar a localização do BD, o nome e a senha do usuário. Com essas informações o sistema localiza o BD, executa a conexão com o SGBD e analisa os metadados da estrutura encontrada. 


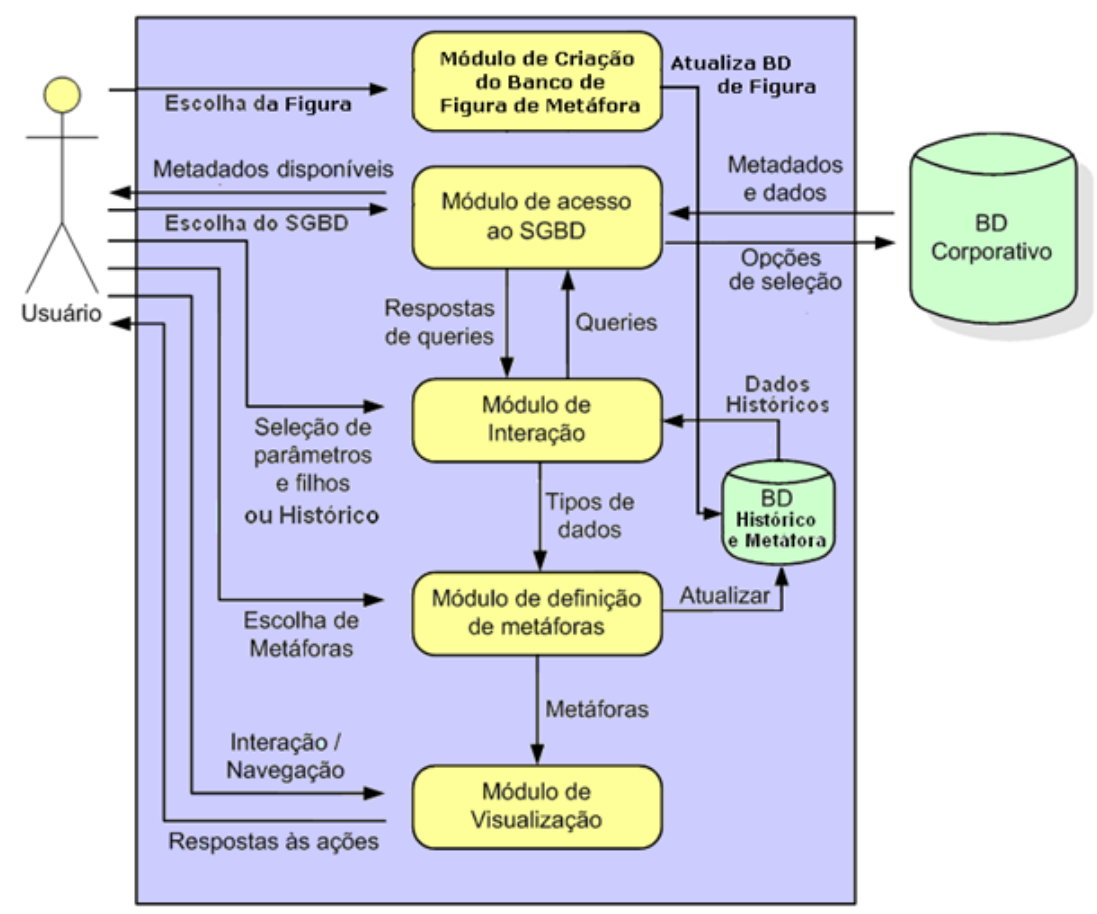

Figura 5.11: Estrutura da Ferramenta VRVis Manager (Santos, 2010).

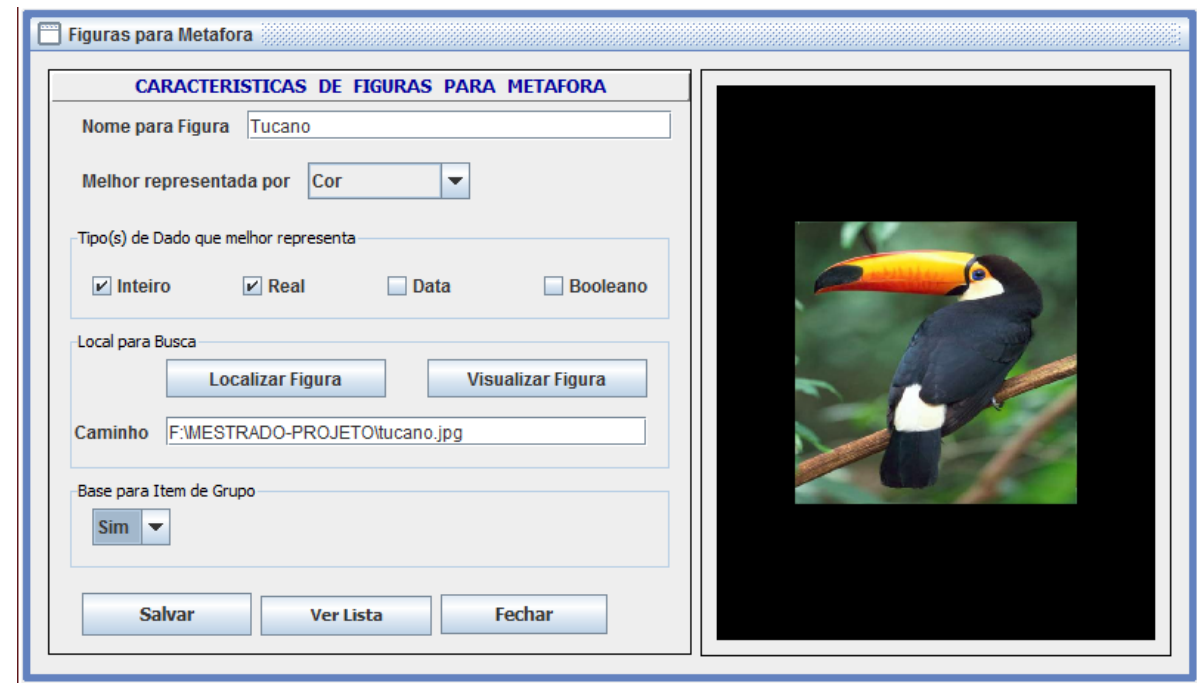

Figura 5.12: Seleção e armazenamento de imagem para metáfora (Santos, 2010). 


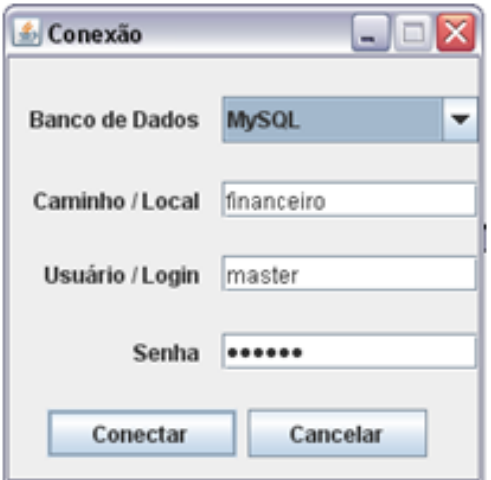

Figura 5.13: Interface para conexão com SGBD - VRVis Manager (Santos, 2010).

O módulo de Interação possibilita a criação de uma nova consulta ou a recuperação de uma pesquisa já realizada e armazenada como histórico no BD. Conforme explicado em Santos (2010), a opção por uma nova consulta disponibiliza uma lista com as tabelas encontradas durante a análise dos metadados e solicita ao usuário informar a tabela que deverá figurar como principal na composição da consulta (Figura 5.14). A tabela escolhida é exibida na cena 3D juntamente com as tabelas com as quais possui há algum tipo de relacionamento.

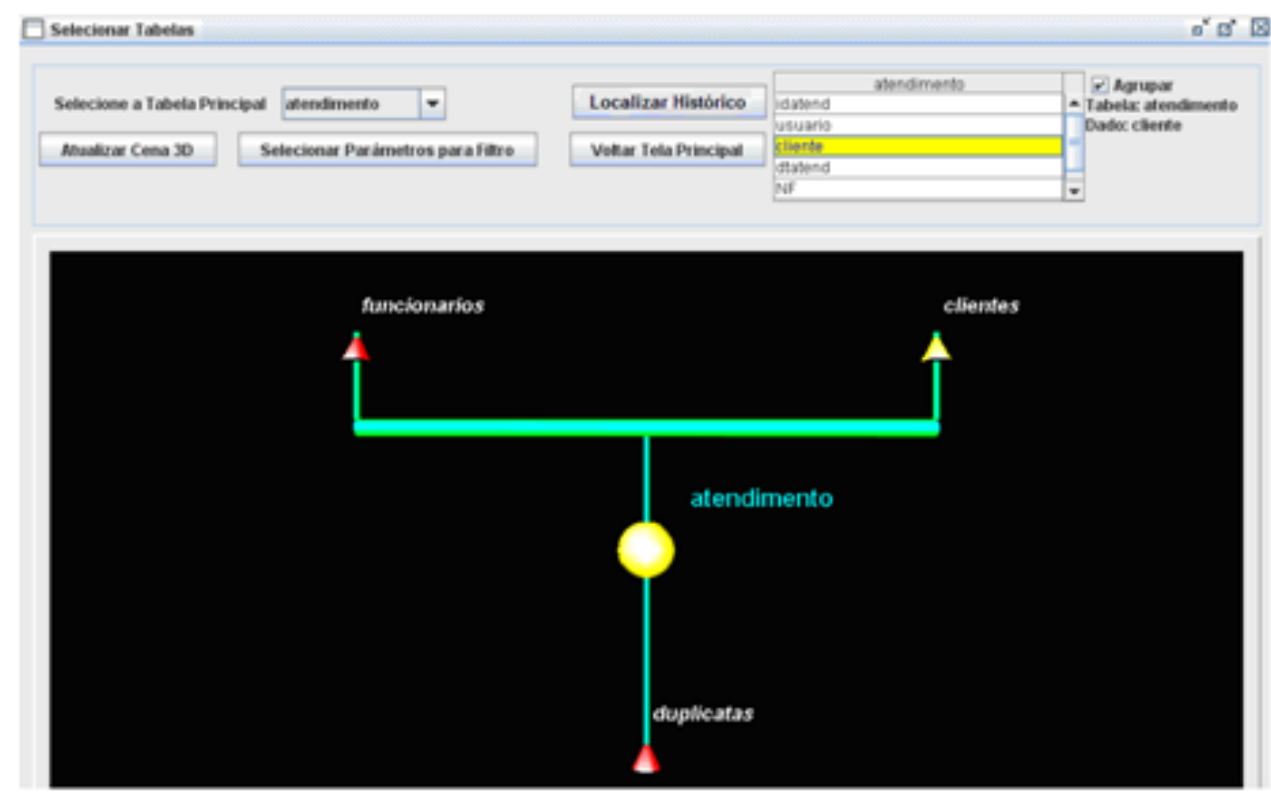

Figura 5.14: Seleção da tabela principal e visão dos relacionamentos (Santos, 2010).

Após a seleção das tabelas, o módulo de definição de metáforas permite a seleção de parâmetros para a montagem da cena final de visualização. De acordo com a interface observada na Figura 5.15, é possível selecionar parâmetros para visualização, totalização de dados (somente quando habilitada a opção de agrupamento) e filtragem de dados (permite a definição de valores para selecionar registros que atendam determinadas condições). 


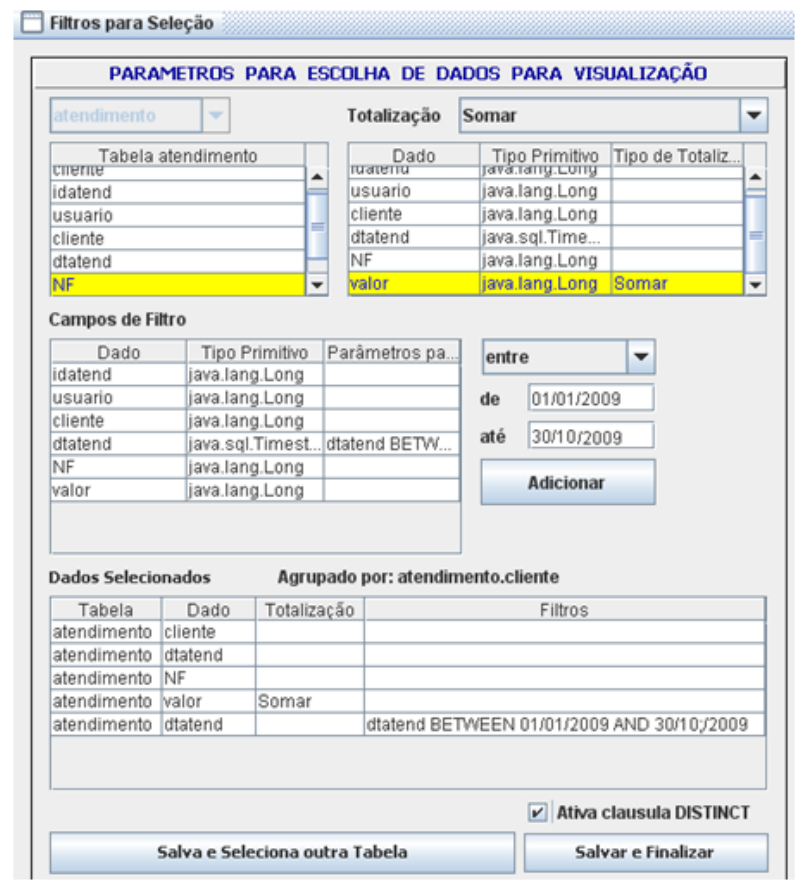

Figura 5.15: Seleção de dados e parâmetros para compor cena 3D (Santos, 2010).

Uma vez concluída esta etapa, o sistema disponibiliza ao usuário a relação de atributos que poderão ser selecionados para a criação da metáfora (Figura 5.16). Esta escolha deve ser feita com a seleção de cada dado a ser representado na cena final. Para cada dado selecionado, há três opções de representação: objeto armazenado no BD de metáforas (Figura 5.12), escolha de uma forma geométrica pré-definida (esfera, cilindro, cone ou cubo) ou escolha de um objeto de forma geométrica com textura.

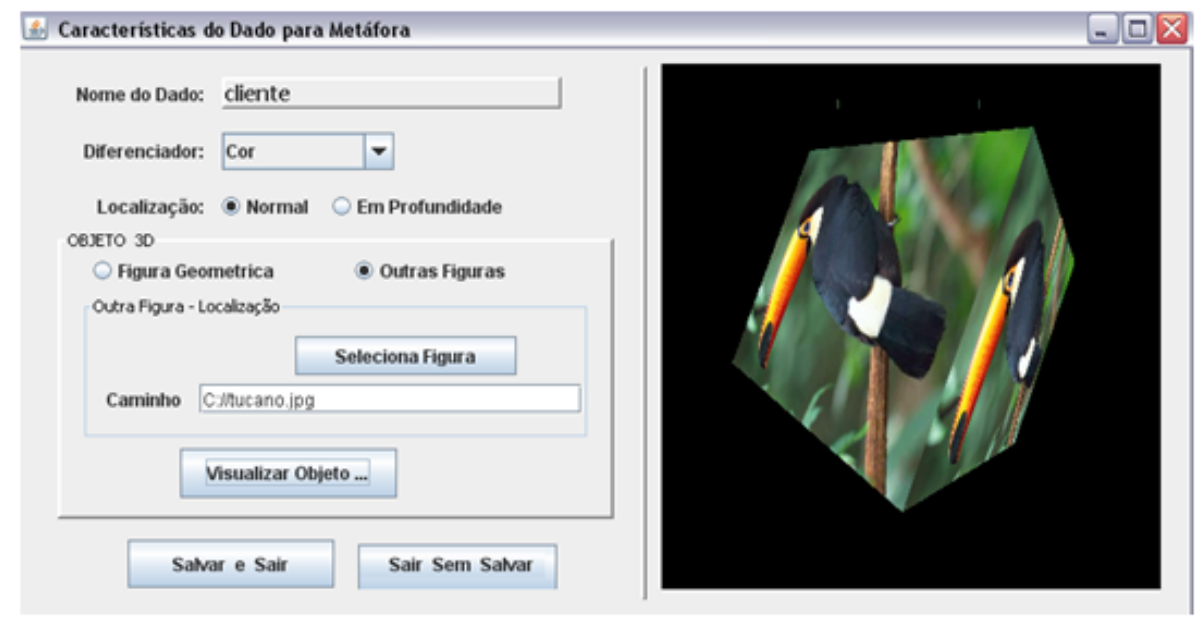

Figura 5.16: Escolha de atributos para criação de metáfora (Santos, 2010).

Uma vez definidos os atributos para consulta e suas respectivas metáforas, o módulo de Visualização apresenta a cena final e permite interação com a mesma. Um exemplo de cena gerada é apresentado na Figura 5.17, que exibe o resultado de uma pesquisa feita 
em um Sistema de Contas a Receber (SCR) de uma imobiliária com dados armazenados em um SGBD PostGreSQL. O BD contém registros relacionados a clientes, atendimentos aos clientes, funcionários que executam os atendimentos e duplicatas geradas a partir dos atendimentos. Na cena apresentada, o objeto "casa" que compõe a metáfora representa o número de locações e vendas de imóveis registrados no BD, e o objeto "cifrão" identifica as movimentações que estão com pagamento em atraso, conforme o número de duplicatas encontrado na pesquisa. Destaca-se, ainda, a seleção de um dos objetos para visualização de seus dados particulares.

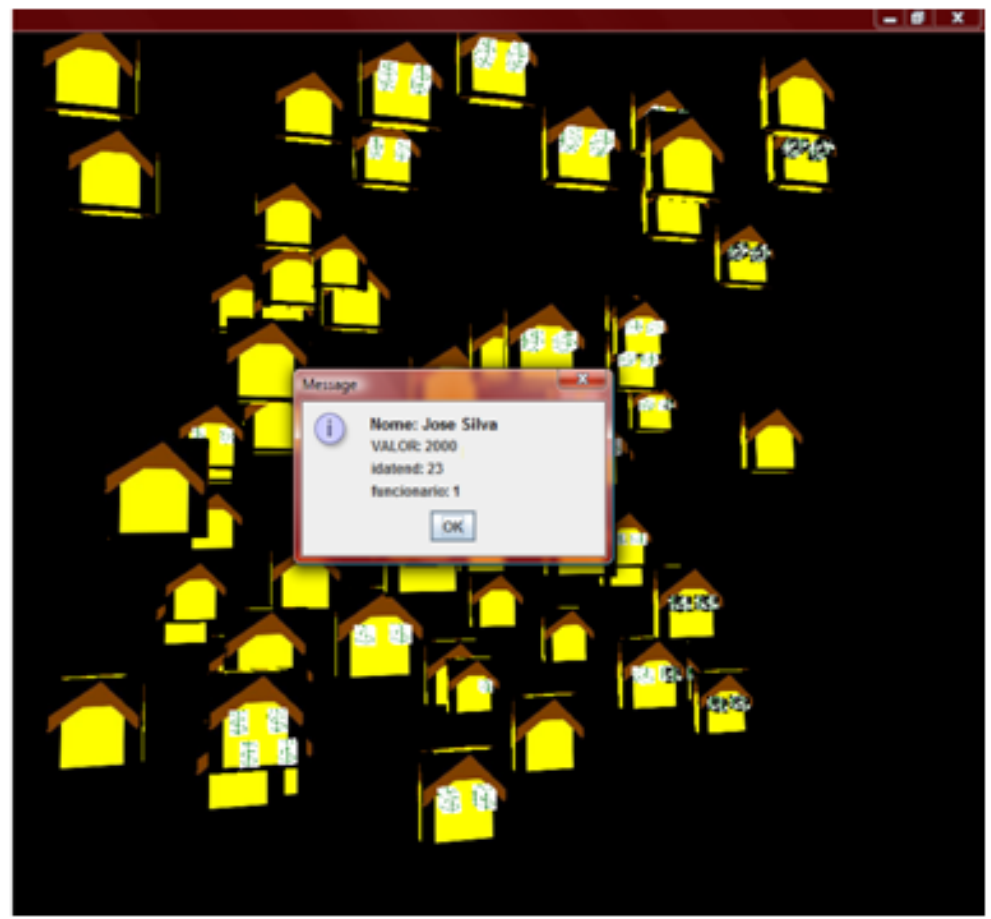

Figura 5.17: Cena 3D resultante de uma consulta (Santos, 2010).

Outro exemplo de cena gerada com a ferramenta é apresentado na Figura 5.18. Consiste no resultado de uma consulta a um Sistema de Gerenciamento Escolar (SGE) com dados armazenados em um SGBD MySQL, contendo registros relacionados a alunos, disciplinas, turmas, notas e faltas dos alunos nas disciplinas. A cena apresenta o resultado do filtro das turmas de alunos cadastrados, com a finalidade de visualizar a composição das turmas considerando o sexo dos alunos. As turmas são representadas pelos cubos, alunos do sexo masculino por bonecos de cor azul e alunos do sexo feminino por bonecos de cor laranja.

A ferramenta VRVis Manager foi avaliada por usuários de diversas categorias como funcionários com cargos administrativos, gerentes e alunos de cursos da área de Computação. Apesar de dificuldades relatadas em relação ao uso de ambientes 3D, houve avaliação positiva indicando um caminho para que esse tipo de ferramenta possa ser incluído como 


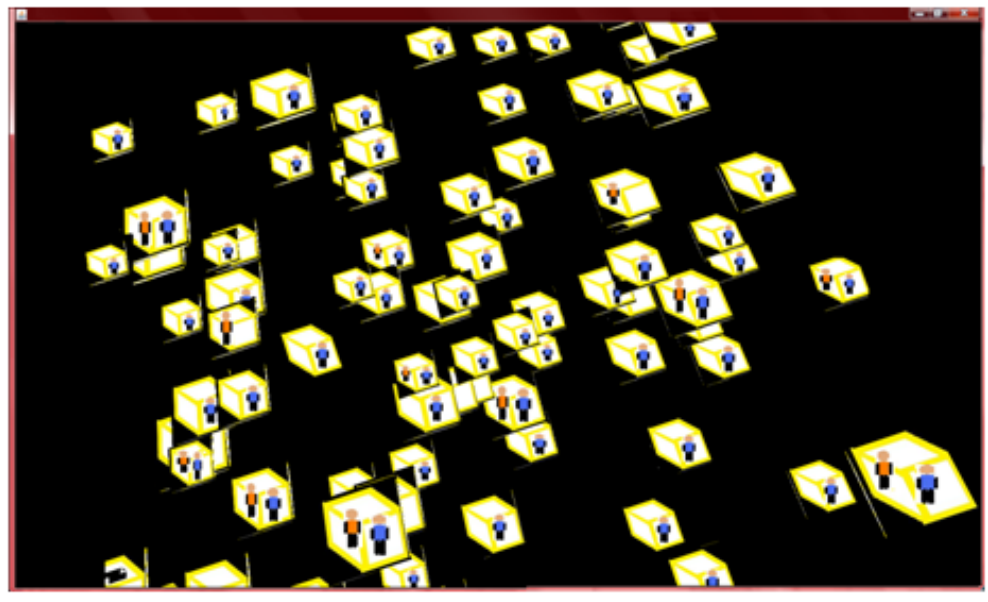

Figura 5.18: Cena 3D resultante de uma consulta (Santos, 2010).

auxiliar no processo de tomada de decisão de diversas áreas. Alguns pontos passíveis de melhorias foram identificados, que constituem oportunidades de pesquisa a serem retomadas no capítulo 6. Decorrentes deste projeto foram publicados os trabalhos Berti et al. (2004), Berti e Nunes (2005) e Santos et al. (2008).

\subsection{Recuperação de Imagens Baseada em Conteúdo}

$\mathrm{Na}$ área de CBIR, as pesquisas têm explorado o desenvolvimento de extratores para categorias específicas de imagens, análise do comportamento de funções de similaridade e, mais recentemente, a elaboração de um framework denominado O-FIm (Oracle for Images) com o objetivo de aplicar os conceitos de CBIR para teste de software com saídas gráficas, como detalhado nas seções a seguir.

\subsubsection{Imagens mamográficas}

O início da pesquisa na área de CBIR teve como objeto de estudos as imagens mamográficas, considerando a conhecimento acumulado a respeito dessas imagens a partir de pesquisas anteriormente desenvolvidas.

Foram utilizadas imagens de um BD desenvolvido pelo LAPIMO (Laboratório de Processamento de Imagens Médicas e Odontológicas, da EESC/USP) ${ }^{2}$. A composição do BD procurou obter a maior quantidade possível de mamogramas, de forma a incluir imagens provenientes de diferentes hospitais com os quais o LAPIMO mantém convênio de colaboração: Hospital das Clínicas da Faculdade de Medicina de Ribeirão Preto (HCFMRP-USP), Santa Casa de Misericórdia de São Carlos, Hospital São Paulo (EPM/UNIFESP), Hospital Pérola Byington (São Paulo), Clínica Segalla (Bauru-SP),

\footnotetext{
${ }^{2}$ http:/ /lapimo.sel.eesc.usp.br/bancoweb/
} 
Hospital Amaral Carvalho (Jaú-SP) e Hospital das Clínicas da Faculdade de Medicina da UNESP (Botucatu-SP). No processo de digitalização das imagens foram utilizados dois equipamentos a laser, ambos da marca Lumisys (Lumiscan 50 e Lumiscan 75) e que, segundo o fabricante, possibilitam obter imagens com até 12 bits de resolução de contraste (4096 níveis de cinza).

Após eliminar o fundo das imagens mamográficas com um algoritmo de segmentação (Santos, 2006), foi desenvolvido um modelo de dados simples, seguindo o paradigma relacional, para que as características extraídas pudessem ser armazenadas e recuperadas adequadamente, conforme pode ser verificado na Figura 5.19.

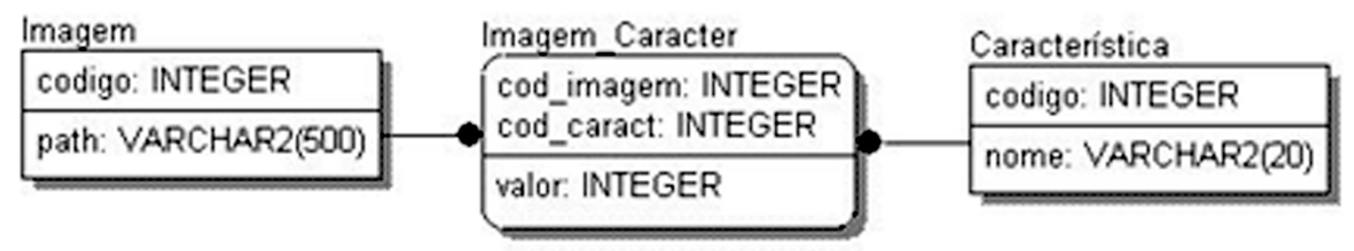

Figura 5.19: Diagrama Entidade-Relacionamento do sistema de CBIR (Santos, 2006).

Em seguida foram desenvolvidos seis extratores, cujas descrições estão disponibilizadas na Tabela 5.1.

Tabela 5.1: Extratores para recuperação de imagens mamográficas (Santos, 2006).

\begin{tabular}{|l|l|}
\hline Extrator & Descrição \\
\hline Área & $\begin{array}{l}\text { Média dos valores dos pixels da imagem dividida pelo maior valor } \\
\text { da escala de cinza }\end{array}$ \\
\hline Densidade & $\begin{array}{l}\text { Soma dos pixels da área pertencente à mama dividida pela quan- } \\
\text { tidade total de pixels da imagem }\end{array}$ \\
\hline Forma & $\begin{array}{l}\text { Relação entre quantidade de pixels do eixo y e a maior quanti- } \\
\text { dade de pixels no eixo } x \text { (quantidade de pixels é encontrada a } \\
\text { partir do centro da mama) }\end{array}$ \\
\hline Entropia & Grau de desordem dos pixels da imagem \\
\hline $\begin{array}{l}\text { Segundo Momento } \\
\text { Angular }\end{array}$ & Nível de homogeneidade da imagem \\
\hline Contraste & Variação entre níveis de cinza da imagem \\
\hline
\end{tabular}

Os três primeiros extratores são autoexplicativos e bem simples de implementar. Os demais referem-se a características de textura, sendo apresentados com mais detalhes a seguir.

Os extratores de textura foram implementados a partir do cálculo da matriz de coocorrência da imagem. Conforme definem Azevedo-Marques et al. (2002) e Ferrero et al. (2006), a matriz de coocorrência corresponde à frequência de um nível de cinza na imagem $A$ considerando uma distância em uma determinada direção. A posição $p(i, j)$ indica a 
frequência de ocorrência de um particular par de nível de cinza $i$ e $j$, obtido a partir de uma distância e de um ângulo (direção). Como exemplo, considerando a distância igual a 1 e o ângulo igual a 0 , a posição $(0,1)$ da matriz de coocorrência é incrementada em uma unidade caso o valor do elemento à esquerda ou à direita de um pixel de valor 0 seja igual a 1.

O grande problema no cálculo dessa matriz é a sua alta dimensionalidade. A implementação considerando precisamente a definição resultaria em uma matriz quadrada de ordem igual à quantidade de níveis de cinza da imagem. Como as imagens utilizadas nesta pesquisa foram armazenadas com 16 bits de resolução de contraste (65536 níveis de cinza), torna-se inviável computacionalmente a construção da referida matriz com a dimensão ideal. Para minimizar esta questão, foi encontrado o intervalo de níveis de cinza efetivamente utilizado nas imagens, constatando-se um máximo de 3600 níveis e conduzidas algumas adaptações para que o algoritmo se tornasse viável (Santos, 2006).

A partir da matriz de coocorrência obtida, foram calculados os extratores Entropia, Segundo Momento Angular e Contraste, conforme mostram as equações 5.1, 5.2 e 5.3, sendo que nesta última, $N_{g}$ é a quantidade de níveis de cinza da imagem.

$$
\begin{gathered}
\text { Entropia }=-\sum_{i} \sum_{j} p(i, j) \log (p(i, j)) \\
\text { Segundo Momento Angular }=\sum_{i} \sum_{j} p(i, j)^{2} \\
\text { Contraste }=\sum_{n=0}^{N_{g}-1} n^{2}\left\{\sum_{i} \sum_{j} p(i, j), \text { se }|i-j|=n\right\}
\end{gathered}
$$

Os extratores foram calculados para todas as imagens e armazenados no BD cujo modelo foi anteriormente apresentado. Em seguida foi disponibilizada uma interface para que o usuário pudesse definir a imagem de referência e os parâmetros para a consulta, conforme ilustrado na Figura 5.20. Para isso foram criadas caixas de seleção de cada uma das características do banco (parte A da Figura), e uma lista com todas as imagens do banco para a seleção da imagem de referência. Quando a imagem é selecionada, sua visualização é automaticamente disponibilizada abaixo da lista de seleção (parte B da Figura). É permitido, ainda, que o usuário determine quantas imagens deseja recuperar. Quando a consulta é confirmada, são exibidas as imagens mais similares à imagem de consulta segundo as características selecionadas (parte C da Figura). A recuperação é efetivada comparando-se os vetores das características selecionadas pelo usuário, utilizando o resultado da Distância Euclidiana (Equação 2.6) como métrica de similaridade. 


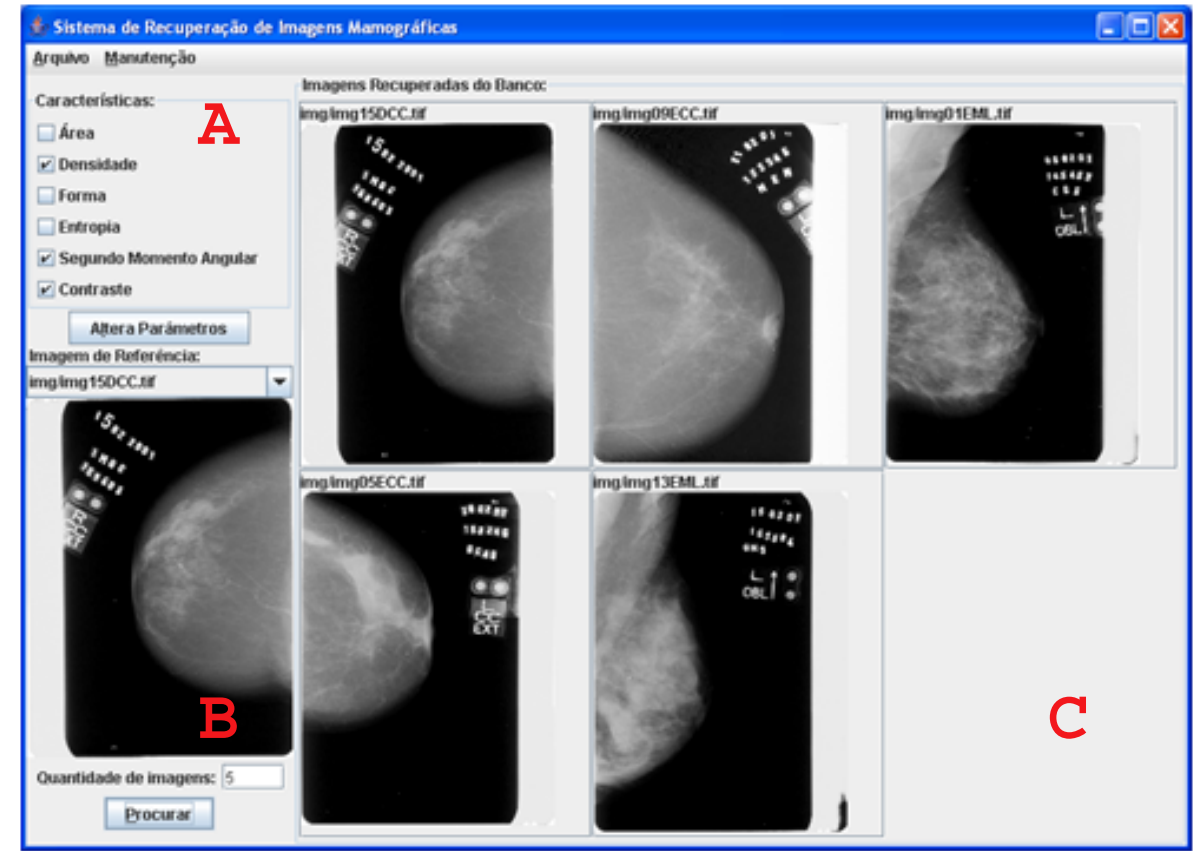

Figura 5.20: Interface para recuperação de imagens (Santos, 2006).

A ideia inicial deste trabalho foi explorar a área de CBIR dentro de um domínio já conhecido. Curvas de precisão e revocação (Baeza-Yates e Ribeiro-Neto, 1999) foram empregadas para avaliar os resultados obtidos, tornando possível perceber a variação da sensibilidade do sistema em relação às características relacionadas, conforme descrito em Santos et al. (2007b).

\subsubsection{Imagens de faces humanas}

Semelhante ao projeto apresentado na seção anterior, o sistema de recuperação baseada em conteúdo para imagens faciais, apresentado em Bergamasco (2010), executa a recuperação de imagens similares a partir de uma imagem modelo, permitindo que sejam selecionadas as características a serem utilizadas na busca, dentre várias disponibilizadas. Porém, um diferencial deste trabalho é utilizar a lógica Fuzzy para melhorar a resposta do sistema.

O desenvolvimento do sistema foi estruturado em 3 módulos: CBIR, Realimentação por Relevância e Fuzzy.

No módulo CBIR, inicialmente foi definida uma base de imagens adequada para a finalidade do sistema, tendo sido empregado um cenário controlado, com fotografias de rostos de homens e mulheres de diferentes raças na fase adulta, disponibilizado pela Universidade de Essex (Essex University, 2010).

Em seguida, conduziu-se a escolha e a implementação de algoritmos para a extração de características. Foram elaborados 17 extratores contemplando aspectos de cor, textura e forma, relacionados nas Tabelas 5.2, 5.3 e 5.4. 
Os extratores foram calculados e devidamente armazenados para todas as imagens presentes no BD. Foi também implementada a Distância Euclidiana (Equação 2.6) como função de similaridade.

Em linhas gerais, a lógica Fuzzy é uma proposta que procura atender o aspecto vago deixado pela teoria clássica dos conjuntos em relação a informações com dados imprecisos e incertos (Sandri e Correa, 1999). É bem sucedida em sistemas de controle de processos e decisões, denominados de sistemas fuzzy. Conforme mostrado na Figura 5.21, tais sistemas são compostos por três processos base: fuzzyficação, inferência e defuzzyficação.

O módulo Fuzzy do sistema implementado está diretamente relacionado com o Módulo de Realimentação por Relevância, descrito mais adiante. No módulo Fuzzy o objetivo é interpretar cada nota dada pelo usuário às imagens retornadas, a fim de identificá-las como coerentes ou não com a imagem modelo. Essas notas são atribuídas de forma iterativa com o objetivo que o algoritmo "aprenda", durante o treinamento, a identificar imagens mais relevantes a cada nova iteração. As notas indicam relevância baixa, média ou alta e são definidas regras para que o sistema refaça a busca por imagens relevantes.

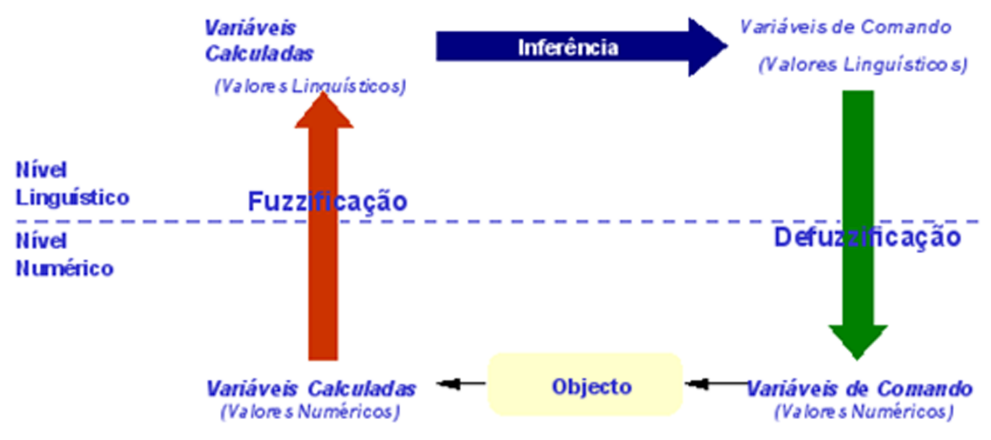

Figura 5.21: Esquema lógico de um sistema Fuzzy (Junges, 2006).

Conforme citado em Marques (2006), a técnica de realimentação por relevância tem dois objetivos principais: (1) reduzir o gap semântico entre a análise visual de alto nível feita pelo usuário e a análise de baixo nível feita por meio dos extratores e funções de similaridade e (2) reduzir a subjetividade da percepção humana, uma vez que diferentes usuários podem ter diferentes percepções de relevância para a mesma imagem. O usuário participa ativamente deste processo, categorizando as imagens resultantes em relevantes ou não relevantes, fazendo com que o algoritmo "aprenda" quais propriedades visuais são melhores para aquela determinada consulta. O aprendizado ocorre atribuindo-se pesos que são acrescidos nos vetores de características como um todo ou em cada uma das componentes desse vetor.

No Módulo de Realimentação por Relevância foi construída uma interface que permite ao usuário escolher a imagem modelo para, em seguida, o sistema apresentar as cinco imagens mais parecidas, conforme exemplificado na Figura 5.22. 
Tabela 5.2: Extratores de cor para imagens faciais (Bergamasco, 2010).

\begin{tabular}{|c|c|}
\hline Extrator & Descrição \\
\hline $\begin{array}{l}\text { Média do Histo- } \\
\text { grama em Nivel de } \\
\text { Cinza }\end{array}$ & $\begin{array}{l}\text { Calcula através do histograma, a média da frequência dos pi- } \\
\text { xels. Objetivo: obter uma informação relativa ao tom da imagem } \\
\text { (mais clara ou mais escura) }\end{array}$ \\
\hline $\begin{array}{l}\text { Média do Histo- } \\
\text { grama em RGB }\end{array}$ & $\begin{array}{l}\text { Calcula através do histograma, a média da frequência dos pi- } \\
\text { xels. Objetivo: obter uma informação relativa ao tom da imagem } \\
\text { (mais clara ou mais escura) }\end{array}$ \\
\hline $\begin{array}{l}\text { Desvio Padrão do } \\
\text { Histograma em Ní- } \\
\text { vel de Cinza }\end{array}$ & $\begin{array}{l}\text { Calcula através do histo } \\
\text { dos pixels. Objetivo: ob } \\
\text { em uma imagem (se houv }\end{array}$ \\
\hline $\begin{array}{ll}\text { Desvio Padrão do } \\
\text { Histograma em } \\
\text { RGB }\end{array}$ & $\begin{array}{l}\text { Calcula através do histograma, o desvio padrão da frequência } \\
\text { dos pixels. Objetivo: obter a informação da variação de cores } \\
\text { em uma imagem (se houve muita ou pouca variação) }\end{array}$ \\
\hline $\begin{array}{lr}\text { Obliquidade } & \text { do } \\
\text { Histograma } & \text { em } \\
\text { Nível de Cinza } & \\
\end{array}$ & $\begin{array}{l}\text { Calcula através do hist } \\
\text { dos pixels. Objetivo: ob } \\
\text { das cores }\end{array}$ \\
\hline $\begin{array}{lr}\text { Obliquidade } & \text { do } \\
\text { Histograma } & \text { em } \\
\text { RGB } & \\
\end{array}$ & $\begin{array}{l}\text { Calcula através do histog } \\
\text { dos pixels. Objetivo: obte } \\
\text { das cores }\end{array}$ \\
\hline $\begin{array}{l}\text { Média dos Pixels } \\
\text { em Nível de Cinza }\end{array}$ & $\begin{array}{l}\text { Calcula através da varred } \\
\text { suas cores. Objetivo: obt } \\
\text { imagem (mais clara ou me }\end{array}$ \\
\hline $\begin{array}{l}\text { Média dos Pixels } \\
\text { em RGB }\end{array}$ & $\begin{array}{l}\text { Calcula através da var } \\
\text { suas cores . Objetivo: } \\
\text { imagem (mais clara ou }\end{array}$ \\
\hline $\begin{array}{l}\text { Desvio Padrão dos } \\
\text { Pixels em Nível de } \\
\text { Cinza }\end{array}$ & $\begin{array}{l}\text { Calcula atr } \\
\text { drão de suc } \\
\text { de cores em }\end{array}$ \\
\hline $\begin{array}{l}\text { Desvio Padrão dos } \\
\text { Pixels em RGB }\end{array}$ & $\begin{array}{l}\text { Calcula através da varredura individual dos pixels, o desvio pa- } \\
\text { drão de suas cores. Objetivo: obter a informação da variação de } \\
\text { cores em uma imagem (se houve muita ou pouca variação) }\end{array}$ \\
\hline $\begin{array}{l}\text { Obliquidade dos } \\
\text { Pixels em Nível de } \\
\text { Cinza }\end{array}$ & $\begin{array}{l}\text { Calcula através da varredura individual dos pixels, o desvio pa- } \\
\text { drão de suas cores . Objetivo: obter a informação de quanto é a } \\
\text { variação das cores }\end{array}$ \\
\hline $\begin{array}{l}\text { Obliquidade dos } \\
\text { Pixels em RGB }\end{array}$ & $\begin{array}{l}\text { Calcula através da varredura individual dos pixels, o desvio pa- } \\
\text { drão de suas cores . Objetivo: obter a informação de quanto é a }\end{array}$ \\
\hline
\end{tabular}


Tabela 5.3: Extratores de textura para imagens faciais (Bergamasco, 2010).

\begin{tabular}{|l|l|}
\hline Extrator & Descrição \\
\hline Contraste & $\begin{array}{l}\text { Por meio da matriz de coocorrência, verifica a probabilidade de ocor- } \\
\text { rência de determinado padrão de cor. Com essa probabilidade é cal- } \\
\text { culado o contraste. Objetivo: determinar a variação de cores entre } \\
\text { pixels }\end{array}$ \\
\hline Entropia & $\begin{array}{l}\text { Por meio da matriz de coocorrência, usando os parâmetros de análise } \\
\text { dos pixels imediatamente vizinhos, verifica a probabilidade de ocorrên- } \\
\text { cia de determinado padrão de cor. Com essa probabilidade é calculada } \\
\text { a entropia. Objetivo: determinar a dispersão dos pixels }\end{array}$ \\
\hline
\end{tabular}

Tabela 5.4: Extratores de forma para imagens faciais (Bergamasco, 2010).

\begin{tabular}{|l|l|}
\hline Extrator & Descrição \\
\hline Escala & $\begin{array}{l}\text { Através dos momentos invariantes de Hu, calculados a partir do centro } \\
\text { de gravidade da imagem é possível calcular o grau de escala da imagem. } \\
\text { Objetivo: por meio do índice de escala, comparar duas imagens e ver } \\
\text { a diferença entre os tamanhos dos rostos }\end{array}$ \\
\hline Rotação & $\begin{array}{l}\text { Através dos momentos invariantes de Hu, calculados a partir do cen- } \\
\text { tro de gravidade da imagem é possível calcular o grau de rotação da } \\
\text { imagem. Objetivo: encontrar os eixos de inércia da imagem para com- } \\
\text { paração }\end{array}$ \\
\hline Translação & $\begin{array}{l}\text { Através dos momentos invariantes de Hu, calculados a partir do cen- } \\
\text { tro de gravidade da imagem é possível calcular o grau de translação } \\
\text { da imagem. Objetivo: encontrar os prolongamentos e orientações da } \\
\text { forma do rosto }\end{array}$ \\
\hline
\end{tabular}

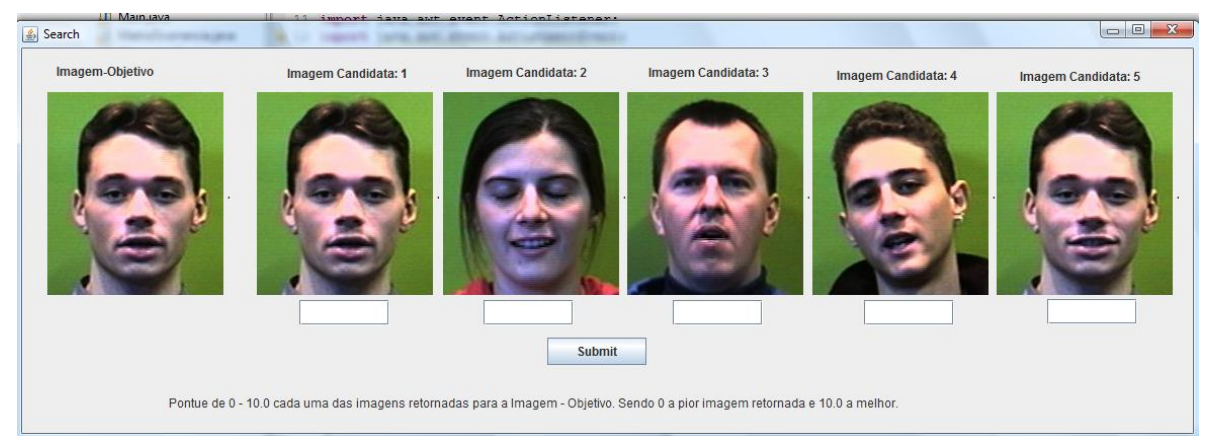

Figura 5.22: Interface para executar realimentação por relevância (Bergamasco, 2010). 
De acordo com o apresentado em Bergamasco (2010), a realimentação por relevância acontece quando, a partir da nota atribuída pelo usuário, o algoritmo identifica quais imagens pode descartar e quais deve usar como referência em uma próxima busca. A interação com o usuário termina somente quando ele julga que todas as imagens candidatas atendem a sua solicitação.

Em termos de implementação, o aprendizado ocorre fazendo-se a multiplicação do valor do peso encontrado na lógica Fuzzy pelo resultado obtido com a função de similaridade (neste caso, Distância Euclidiana), sendo que quanto maior o peso, menor será a relevância. Com essa multiplicação, o valor da distância tende a aumentar ou a permanecer igual. Se o valor aumentar significa que seu peso foi alto e, portanto, ocorre relevância baixa. Assim, possivelmente na próxima iteração essa mesma imagem não esteja entre as cinco menores distâncias e não retorne mais ao usuário. Na Figura 5.23 é apresentada a sequência de tarefas de interação do usuário com o sistema de reconhecimento facial.

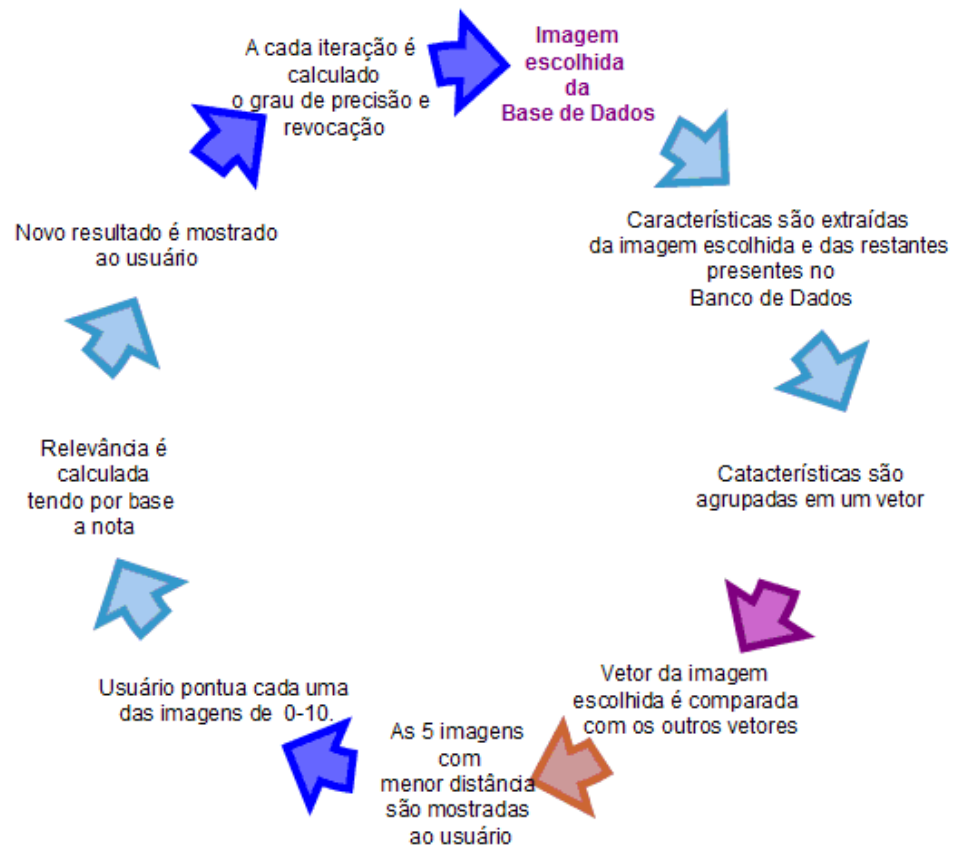

Figura 5.23: Interação do usuário com sistema (Bergamasco, 2010).

Vários estudos de caso foram conduzidos para verificar os algoritmos implementados, disponíveis em Bergamasco (2010). Na base de imagens utilizada há 40 rostos, sendo que cada um deles possui 5 imagens disponíveis, alterando-se apenas a expressão facial. Para exemplificar o funcionamento da realimentação por relevância usando a lógica Fuzzy, na Figura 5.24 é disponibilizado o resultado de duas iterações. Na Figura 5.24(a) a primeira imagem exibida é o modelo para a consulta. Após a atribuição de pesos pelo usuário, a segunda interação apresenta um resultado mais coerente, conforme pode ser conferido na Figura 5.24(b). 


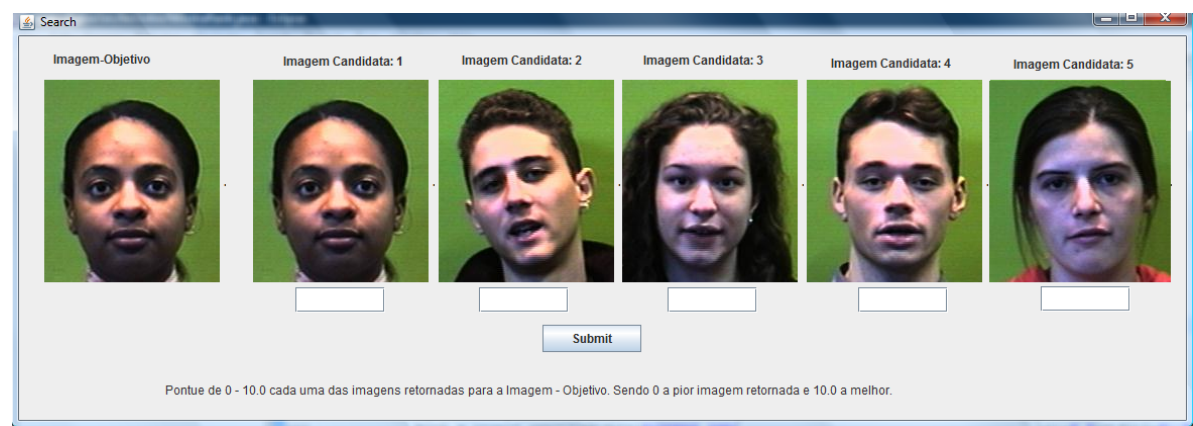

(a) Primeira iteração

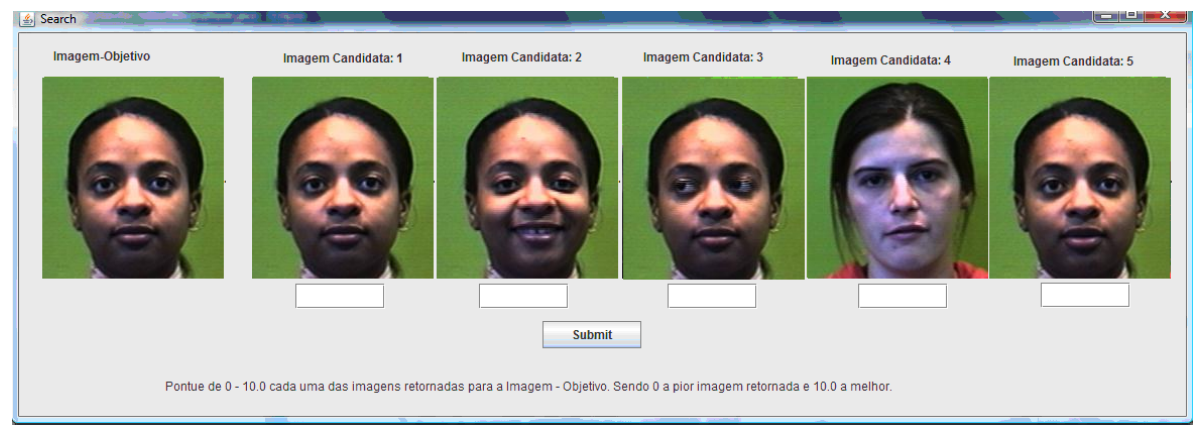

(b) Segunda iteração

Figura 5.24: Uso da lógica Fuzzy na realimentação por relevância (Bergamasco, 2010).

\subsubsection{Recuperação de imagens na Internet}

A Internet tornou-se nos últimos anos uma das grandes fontes de consulta para os mais variados tipos de interesse. Assim, uma investigação sobre a possibilidade do uso de CBIR para Internet pode contribuir para que no futuro as buscas não se limitem aos termos textuais atualmente utilizados.

Visando a contribuir dentro desse contexto, foi conduzida uma investigação sobre a possibilidade de recuperar imagens similares a uma determinada imagem de referência considerando pesquisas na Internet. Devido à impossibilidade de aplicar diretamente os recursos de CBIR em sites de busca, na primeira fase do sistema foi necessária a integração com sistemas de busca disponíveis que retornam imagens a partir de consultas textuais. Para isso foi utilizada a API Google Web Toolkit (GWT) (GWT, 2010), que realiza a integração com o sistema de buscas da Google.

De acordo com o esquema apresentado na Figura 5.25, o sistema apresenta uma interface com um campo para a consulta por palavra-chave. A partir da interface, é possível selecionar a imagem que será usada como foco de pesquisa dentre as retornadas, além da escolha das características que serão utilizadas durante a busca por similaridade.

Após exibir as imagens resultantes da integração com a API GWT, inicia-se a busca das imagens similares, solicitando ao usuário que selecione a imagem modelo e as características a serem usadas na busca, conforme esquema disponibilizado na Figura 5.26. 


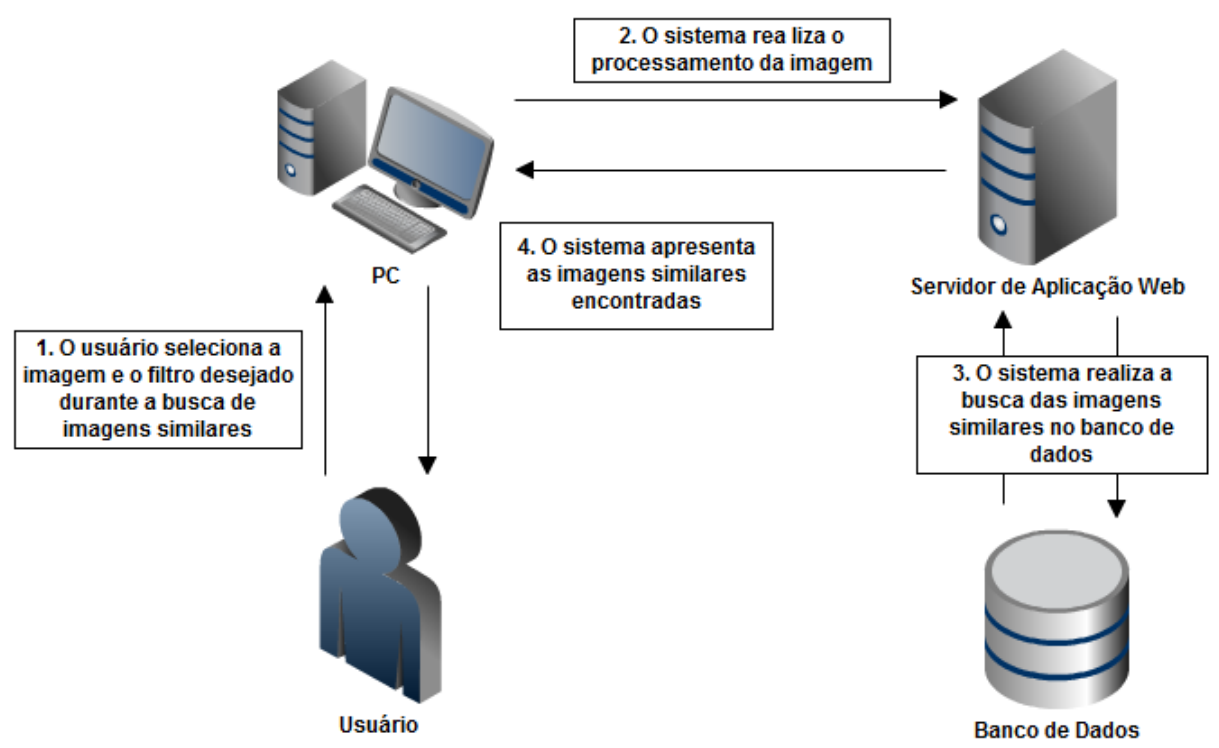

Figura 5.25: Fluxo para a busca de imagens na Internet (Moraes, 2010).

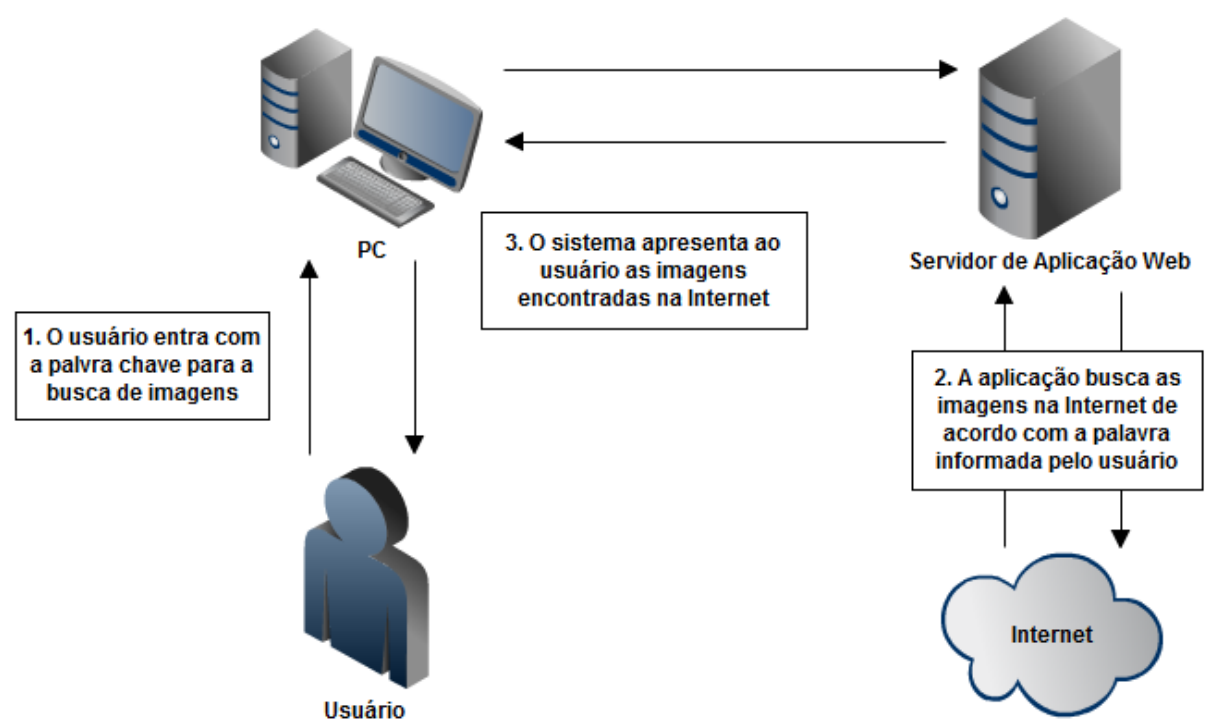

Figura 5.26: Fluxo para a busca de imagens similares (Moraes, 2010). 
Para a extração das características foram implementados os extratores de cor, textura e forma apresentados na Tabela 5.5.

Tabela 5.5: Extratores para recuperação de imagens na Internet (Moraes, 2010).

\begin{tabular}{|l|l|}
\hline Extrator & Descrição \\
\hline Cores Fracas & $\begin{array}{l}\text { Porcentagem de cores fracas da imagem obtida a partir do his- } \\
\text { tograma de cor }\end{array}$ \\
\hline Cores Médias & $\begin{array}{l}\text { Porcentagem de cores médias da imagem obtida a partir do his- } \\
\text { tograma de cor }\end{array}$ \\
\hline Cores Fortes & $\begin{array}{l}\text { Porcentagem de cores fortes da imagem obtida a partir do his- } \\
\text { tograma de cor }\end{array}$ \\
\hline $\begin{array}{l}\text { Razão Altura/Lar- } \\
\text { gura }\end{array}$ & Mede a razão entre a altura e a largura dos objetos da imagem \\
\hline $\begin{array}{l}\text { Transformação } \\
\text { Area-Ponto }\end{array}$ & Retorna quantidade de objetos de uma imagem \\
\hline Assinatura & Representação da fronteira dos objetos da imagem \\
\hline Contraste & Identifica diferenças entre os tons de cinza da imagem \\
\hline Entropia & Mede o grau de desordem dos pixels contidos na imagem \\
\hline $\begin{array}{l}\text { Segundo Momento } \\
\text { Angular }\end{array}$ & Mede a uniformidade de uma textura \\
\hline
\end{tabular}

De acordo com o detalhamento dos algoritmos, disponibilizado em Moraes (2010), os três primeiros extratores calculam porcentagens de pixels referentes, respectivamente, às partes inicial, do meio e final do histograma da imagem. A "razão altura/largura" encontra o menor retângulo que enquadra os objetos após ser executado um procedimento de deteç̧ão de borda e calcula a relação entre a altura e a largura desse objeto.

A "Transformação área-ponto" (Nishikawa et al., 1993) foi proposta inicialmente com o objetivo de transformar microcalcificações em um único pixel, para que se pudesse realizar a contagem de agrupamentos dessas estruturas em imagens mamográficas. Consiste em aplicar iterativamente uma máscara de tamanho 3 x 3 pixels na imagem, a partir do canto superior esquerdo. Para cada iteração, são contabilizados os pixels localizados sob a máscara que possuem nível de cinza superior ao do fundo da imagem. Se forem encontrados mais de dois pixels que atendam a essa condição, todos os pixels sob a máscara são ajustados para terem o mesmo valor do fundo da imagem, com exceção do pixel do canto inferior direito que é ajustado para ter o maior valor da escala de cinza. A máscara é então movida a cada dois pixels para a direita e para baixo, varrendo toda a imagem, conforme exemplificado na Figura 5.27. Especialmente para a aplicação de CBIR em questão, este extrator auxilia na identificação da quantidade de objetos não conectados na imagem.

A assinatura é uma representação unidimensional da borda de um objeto contido na imagem. Essa técnica obtém o gráfico da distância do centróide à borda em função de 

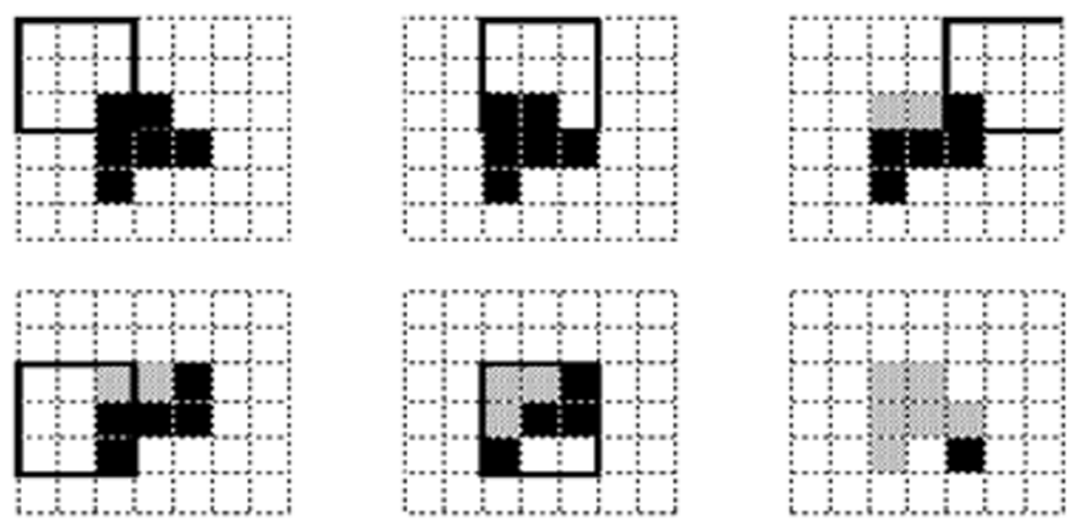

Figura 5.27: Funcionamento da técnica transformação área-ponto (Moraes, 2010).

um ângulo estabelecido. Para esse extrator, executa-se primeiro um algoritmo para obter os valores de distância do centróide à borda; em seguida, é calculado o desvio padrão das distâncias obtidas.

Por fim, os últimos extratores que visam a obter características de textura da imagem já foram abordados na seção 5.3.1.

Na Figura 5.28 é apresentada a interface do sistema. Conforme já mencionado, inicialmente é disponibilizado um campo para a pesquisa de imagens por palavra-chave (letra A na Figura). O sistema apresenta, então, uma interface com os extratores que podem ser selecionados para a pesquisa por conteúdo (letra B) e explicações sobre eles (letra C). O usuário pode escolher também a quantidade de imagens a serem retornadas (letra D). Após a pesquisa das imagens na Internet, são apresentadas as imagens retornadas para que se possa selecionar a imagem de referência para a consulta (letra E). Por fim, as imagens resultantes, considerando os parâmetros determinados, são disponibilizadas (letra G).

Assim como nos trabalhos anteriores, foram conduzidos diversos estudos de casos que confirmaram a grande variação dos resultados em função dos extratores selecionados. No entanto, a construção desse protótipo indicou que é possível executar buscas por conteúdo no contexto da Internet, abrindo caminho para o desenvolvimento de técnicas que possam mudar a forma de recuperar imagens ou outros dados multimídia na Web.

\subsubsection{Avaliação de funções de similaridade}

Em CBIR, tão importante quanto desenvolver componentes específicos para determinadas categorias de imagens, é avaliar a efetividade desses componentes, visto que a alteração de extratores e funções de similaridade pode resultar em recuperações de imagens diferentes.

Visando a oferecer uma contribuição nesse sentido, está em desenvolvimento um trabalho com o objetivo de implementar diferentes funções de similaridade e executar casos 


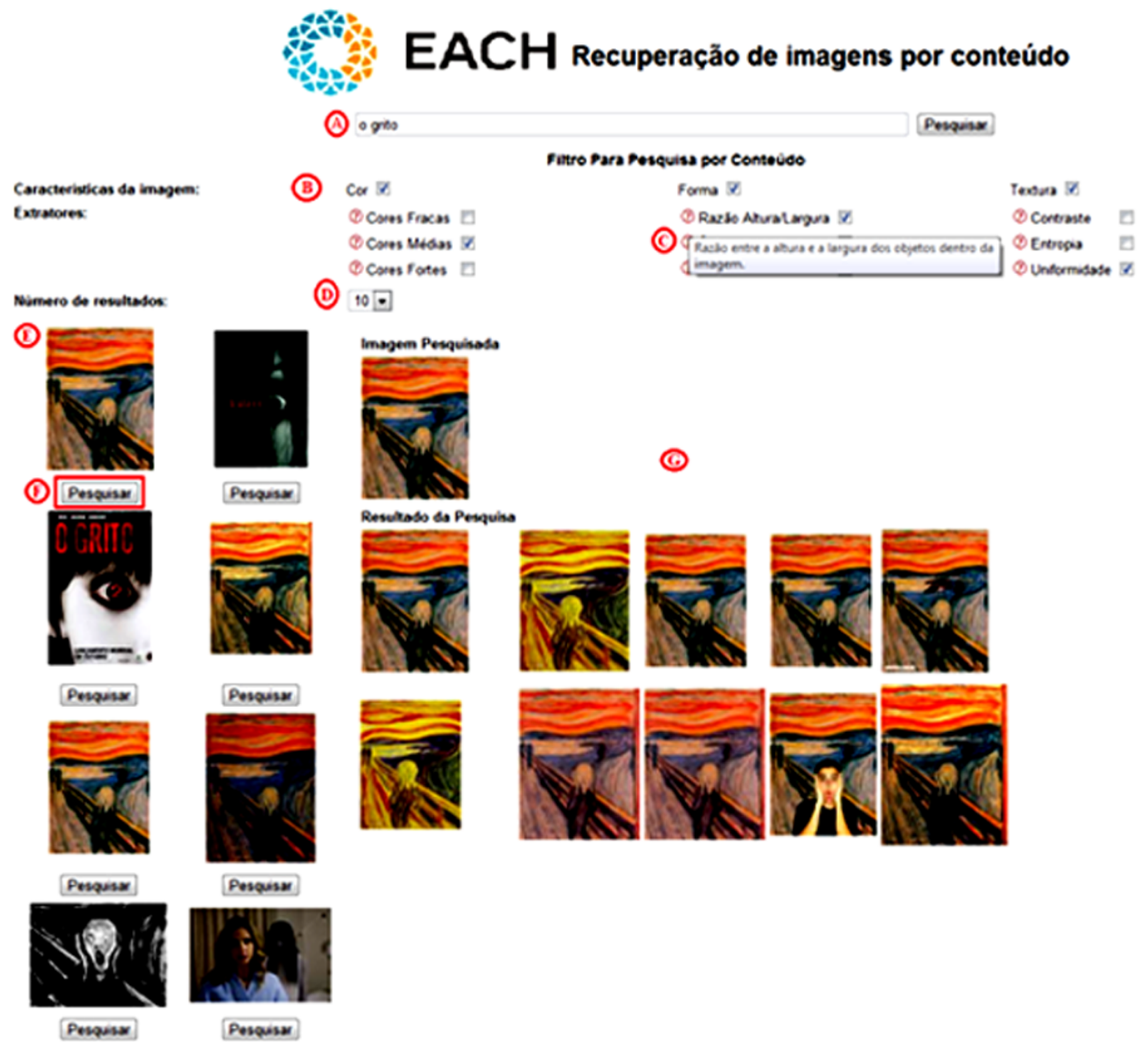

Figura 5.28: Interface para busca por conteúdo na Internet (Moraes, 2010). 
de teste para as mesmas, a fim de se verificar o quanto essas funções influenciam nos resultados de consultas de imagens por similaridade.

Inicialmente foi realizada uma revisão sistemática na literatura a fim de verificar as funções de similaridade usualmente utilizadas em CBIR (Gonçalves et al., 2010). A seguir são apresentadas breves descrições e o equacionamento das funções implementadas até o momento. Nas equações, $A$ e $B$ representam os vetores de características de duas imagens sendo comparadas e $n$ representa o número de atributos (extratores de características) utilizados para a realização das comparações. Mais detalhes, assim como as referências de onde foram extraídas as equação citadas, estão disponíveis em Gonçalves (2010).

Conforme descrito em Gonçalves (2010), a família de distâncias métricas Minkowski ou $L_{p}$ tem sua forma geral apresentada na Equação 5.4. Essas métricas podem ser influenciadas por qualquer característica que apresente grande variação entre os vetores que estão sendo comparados.

$$
\operatorname{Dis}_{L_{p}}(A, B)=\sqrt[p]{\sum_{i=0}^{n-1}\left|a_{i}-b_{i}\right|^{p}}
$$

Quando $p=1$, tem-se a distância Manhattan, apresentada na Equação 5.5. Quando $p=2$, tem-se a distância Euclidiana. Quando $p \rightarrow \infty$, é obtida a distância Chebychev (Equação 5.6).

$$
\begin{aligned}
\operatorname{Dis}_{L_{1}}(A, B) & =\sum_{i=0}^{n-1}\left|a_{i}-b_{i}\right| \\
\operatorname{Dis}_{L_{\infty}}(A, B) & =\max _{i=0}^{n-1}\left|a_{i}-b_{i}\right|
\end{aligned}
$$

A Distância Trigonométrica é calculada usando-se a Equação 5.7, mas várias considerações sobre seus parâmetros estão sendo analisadas, descritas em Gonçalves (2010).

$$
\operatorname{Dis}(A, B)=\sum_{i=0}^{n-1} \sin \left(\arctan \left(\left|a_{i}-b_{i}\right|\right)\right)
$$

A distância Hausdorff entre dois vetores $A$ e $B$ representa o menor valor $d$ tal que todo ponto de $A$ tem um ponto de $B$ dentro da distância $d$, e todo ponto de $B$ tem um ponto de $A$ dentro da distância $d$, sendo definida pela Equação 5.8.

$$
\operatorname{Dis}(A, B)=\max \left(\max _{a \in A}\left(\min _{b \in B}(|a-b|)\right), \max _{b \in B}\left(\min _{a \in A}(|b-a|)\right)\right)
$$

Na Equação 5.8, $\max _{a \in A}\left(\min _{b \in B}(|a-b|)\right)$ significa que, fixado um $a \in A$, deve-se obter a menor distância entre esse valor $a$ e algum valor $b \in B$. Feito isso, para cada $a \in A$, deve-se obter $d_{1}$, que é a maior dessas distâncias mínimas observadas para cada valor de $A$ 
com algum valor de $B$. O contrário ocorre com $\max _{b \in B}\left(\min _{a \in A}(|b-a|)\right)$. Nesse caso, obtém-se $d_{2}$ que é a maior distância observada no conjunto de distâncias mínimas entre cada valor de $B$ e algum valor de $A$. A distância de Hausdorff $d$ será o máximo entre $d_{1}$ e $d_{2}$.

A distância de Mahalanobis (Equação 5.9) é apropriada para casos onde existem diferenças significativas entre os dados dos vetores sendo comparados. Isso porque ressalta essa variabilidade através da matriz de covariância, agregando grupos de menor variação em contraposição aos de expressiva variabilidade (Paris, 2008). A covariância, em Teoria da Probabilidade e em Estatística, é uma medida que indica o quão fortemente duas variáveis aleatórias $X$ e $Y$, com respectivas médias $\mu_{X}$ e $\mu_{Y}$, estão relacionadas uma com a outra (Devore, 2006).

$$
\operatorname{Dis}(A, B)=\sqrt{(A-B)^{T} C^{-1}(A-B)}
$$

onde $C$ é a matriz de covariância calculada sobre os vetores de características das imagens.

Pretende-se aplicar as funções implementadas em diferentes categorias de imagens para que seja possível tecer reflexões sobre seus comportamentos. O primeiro estudo de caso definido visa a avaliar o comportamento de diferentes funções de similaridade em um processo de teste de software para um sistema de CAD, utilizando o framework O-FIm (apresentado na seção 5.4).

A aplicação previamente desenvolvida segmenta imagens mamográficas de forma automática (Nunes et al., 2007b). Desse modo, o objetivo é comparar os mamogramas segmentados (retornados pela aplicação) com mamogramas segmentados manualmente, que representam as saídas corretas esperadas para o sistema de CAD.

Para a condução do estudo de caso, foram segmentadas trinta imagens pelo sistema de CAD, compondo o conjunto de saídas a serem testadas. As mesmas imagens foram também segmentadas manualmente por duas pessoas $\left(P_{1}\right.$ e $\left.P_{2}\right)$, gerando, assim, dois conjuntos de imagens modelos a serem comparadas com as imagens em teste. A Figura 5.29 apresenta um exemplo de imagem mamográfica original e suas respectivas segmentações automática e manual.

Os três conjuntos gerados pelas segmentações são representados com as notações apresentadas nas equações 5.10, 5.11 e 5.12, respectivamente. Cada imagem segmentada pelo sistema de CAD (Test) será comparada às suas respectivas imagens segmentadas manualmente nos conjuntos de imagens modelos (ModelP1 e ModelP2). O objetivo é indicar se a aplicação sob teste segmenta corretamente as imagens mamográficas e o quanto as diferentes funções de similaridade exercem influência nos resultados.

$$
\text { Test }=\left\{t_{1}, t_{2}, t_{3} \ldots, t_{30}\right\}
$$




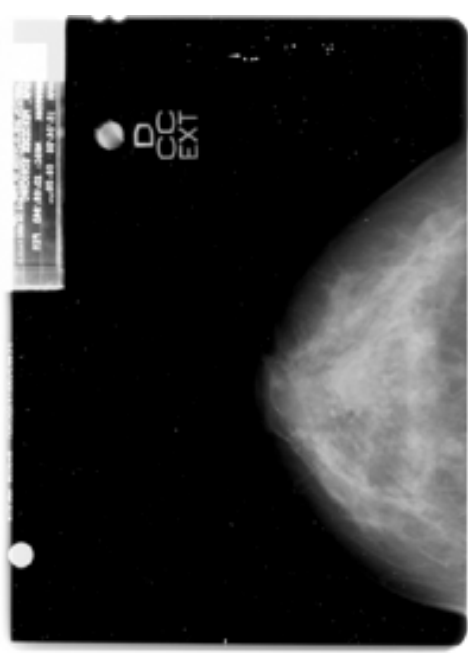

(a) Imagem original

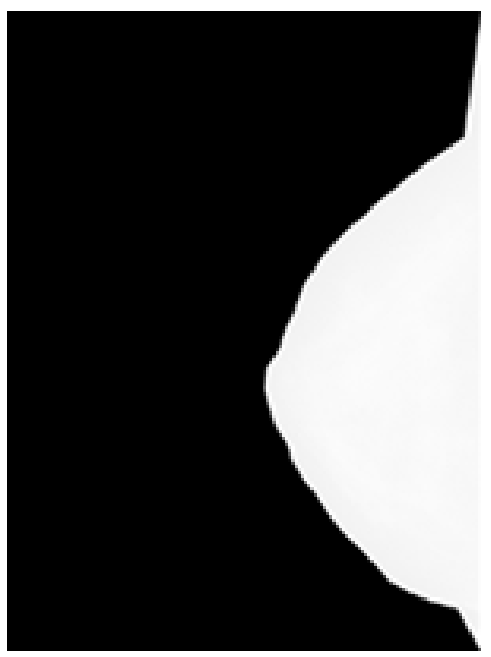

(b) Imagem segmentada pelo (c) Imagem segmentada manualCAD

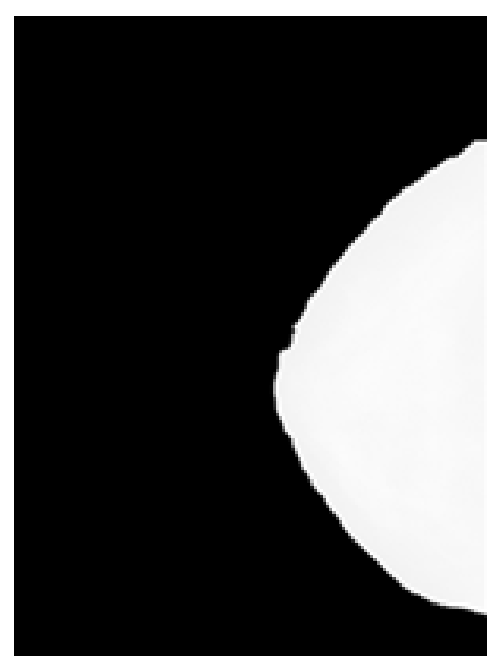
mente

Figura 5.29: Exemplo de imagens usadas no estudo de caso (Nunes et al., 2009a).

$$
\begin{aligned}
& \text { ModelP1 }=\left\{m P 1_{1}, m P 1_{2}, m P 1_{3} \ldots, m P 1_{30}\right\} \\
& \text { ModelP2 }=\left\{m P 2_{1}, m P 2_{2}, m P 2_{3} \ldots, m P 2_{30}\right\}
\end{aligned}
$$

Foram implementados três extratores de características (Nunes, Delamaro e Oliveira, 2009a):

- Área: contabiliza a quantidade de pixels que pertencem à região da mama. Como a imagem mamográfica é segmentada, a região que não pertence à mama é formada por pixels de valor zero. Para normalizar o valor da característica, divide-se o número de pixels pertencentes à região da mama pelo número total de pixels da imagem. Obtém-se, assim, um valor no intervalo $[0,1]$;

- Perímetro: contabiliza o número de pixels que pertencem à borda demarcada da mama. O valor obtido é dividido pelo perímetro total da imagem;

- Assinatura: o valor gerado por este extrator representa o formato do contorno da mama de acordo com a sua regularidade. Para tanto, o algoritmo localiza o centro da mama na última coluna da imagem, toma intervalos em graus, calculando a distância deste ponto de centro à borda da mama, e calcula o desvio padrão dos valores obtidos (para um círculo perfeito, esse valor seria igual a zero). O extrator retorna o desvio padrão obtido dividido pela maior medida calculada na etapa anterior.

Atualmente o estudo de caso citado está sendo finalizado e outros estão sendo definidos. Espera-se, ao final deste trabalho, tecer um perfil do comportamento de cada função de 
similaridade implementada, contribuindo, assim, para a implementação e uso de sistemas de CBIR.

\subsection{Framework O-FIm}

Muitas vezes, pesquisadores e desenvolvedores de software de áreas aplicadas negligenciam um ponto crucial da Engenharia de Software: a validação. Conforme é lembrado em Oliveira et al. (2009a), o uso de técnicas e critérios de teste de software adequados, durante todas as fases do processo de desenvolvimento, em geral, implica em aumentar o tempo e o custo do projeto. Todavia, pode haver uma economia significativa quando testes são aplicados de maneira automatizada e sistemática.

Um oráculo é um mecanismo utilizado para determinar se a execução ou comportamento de uma aplicação sob teste está correta ou não. Pode ser representado por especificações do software, ou simplesmente o conhecimento prévio do programador sobre o funcionamento e o comportamento do sistema testado (Howden e Eichhorst, 1978).

O framework O-Fim (Oracle for Images), descrito em Oliveira et al. (2009a), emprega conceitos de CBIR visando a automatização de oráculos para programas cuja saída é apresentada na forma de uma imagem, seja ela uma interface gráfica, seja qualquer imagem produzida pelo programa em teste. O conjunto de características que se deseja utilizar não é específico para um domínio ou um software dentro de um domínio. O framework visa a oferecer flexibilidade ao testador possibilitando que ele escolha as características a serem usadas na comparação de imagens, assim como a função de distância usada na busca. A partir dessas definições, deve ser possível configurar como as características devem ser comparadas (parametrização) e adicionar ou instalar novos extratores e funções de similaridade de maneira simples.

Na Figura 5.30 é ilustrada a maneira como o O-FIm foi concebido. Um testador configura seu descritor de oráculo (seleciona extratores, parâmetros e funções de similaridade), o parser reconhece quais extratores e parâmetros serão utilizados e o núcleo executa a instanciação das classes necessárias para o teste e realiza a comparação.

Para padronizar o funcionamento da ferramenta são usados conceitos de interface da linguagem Java, que descreve um conjunto de métodos que podem ser chamados em um objeto, porém não são fornecidas implementações concretas para tais métodos. Dessa forma, as interfaces constituem um protocolo que deve ser seguido por uma classe para que ela seja considerada um acessório O-FIm válido. Assim, é necessário que qualquer classe Java que represente extratores ou funções implemente as interfaces denominadas IExtractor, para extratores, e ISimilarity, para funções de similaridade, respectivamente. Nas Figuras 5.31 e 5.32 são apresentadas as interfaces citadas. 


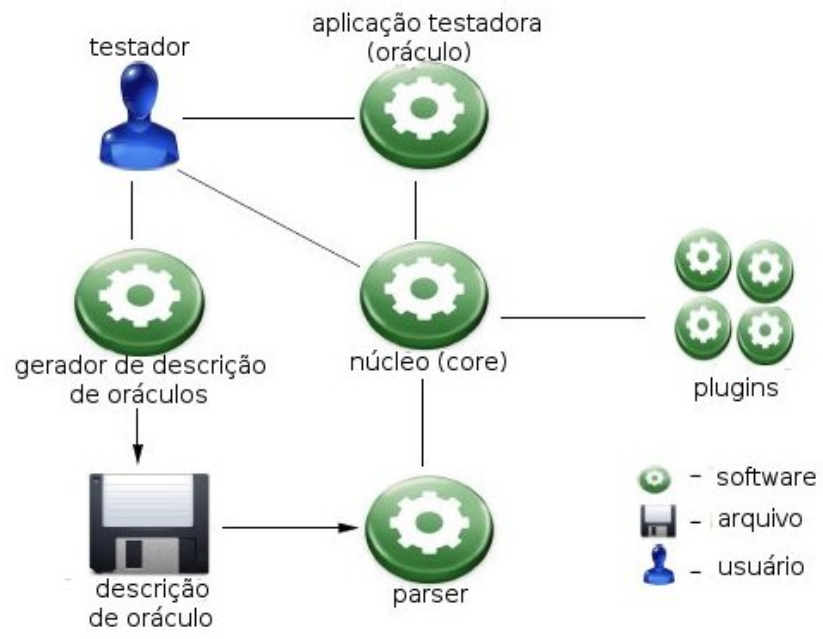

Figura 5.30: Arquitetura da Ferramenta O-FIm (Oliveira et al., 2009a).

De acordo com o explicado em Oliveira et al. (2009a), o núcleo do framework O-FIm permite que o testador instale e remova plugins e disponibiliza uma API a partir da qual o testador pode construir seus oráculos. A instalação de um extrator ou de uma função de similaridade nada mais é do que a realização de uma cópia do pacote principal das classes Java de tal extrator para um diretório de conhecimento da estrutura que administrará o ambiente.

Para instalar e remover plugins, o núcleo pode ser invocado diretamente na linha de comando. Por exemplo, para instalar um plugin pode-se executar:

java br.oraculos. Main install MyExtractor/home/icmc/extractor br.extractors. MyExtractor

Como pode ser conferido na Figura 5.30, o O-FIm depende de uma descrição textual feita em arquivo texto por meio da qual o usuário/testador pode exprimir suas especificações para um teste. Uma das funcionalidades da ferramenta é a geração, persistência e recuperação de tais arquivos. O reconhecimento e manuseio dos arquivos descritores são funções de um parser que funciona como um parametrizador. Tal parser, quando reconhece uma descrição, indica ao núcleo quais objetos e parâmetros serão usados pelo oráculo durante o teste.

Para facilitar a tarefa do usuário, uma interface gráfica no formato de uma ferramenta "wizard" foi implementada para que o testador possa verificar os plugins instalados e parametrizá-los de acordo com as suas necessidades (Figura 5.33).

Um exemplo de arquivo com a descrição necessária para execução de uma aplicação é apresentado na Figura 5.34.

O framework O-FIm tem sido utilizado para aplicações gerais de CBIR, além do escopo de oráculos automatizados para os quais foi concebido. Algumas linhas de pesquisa dentro 


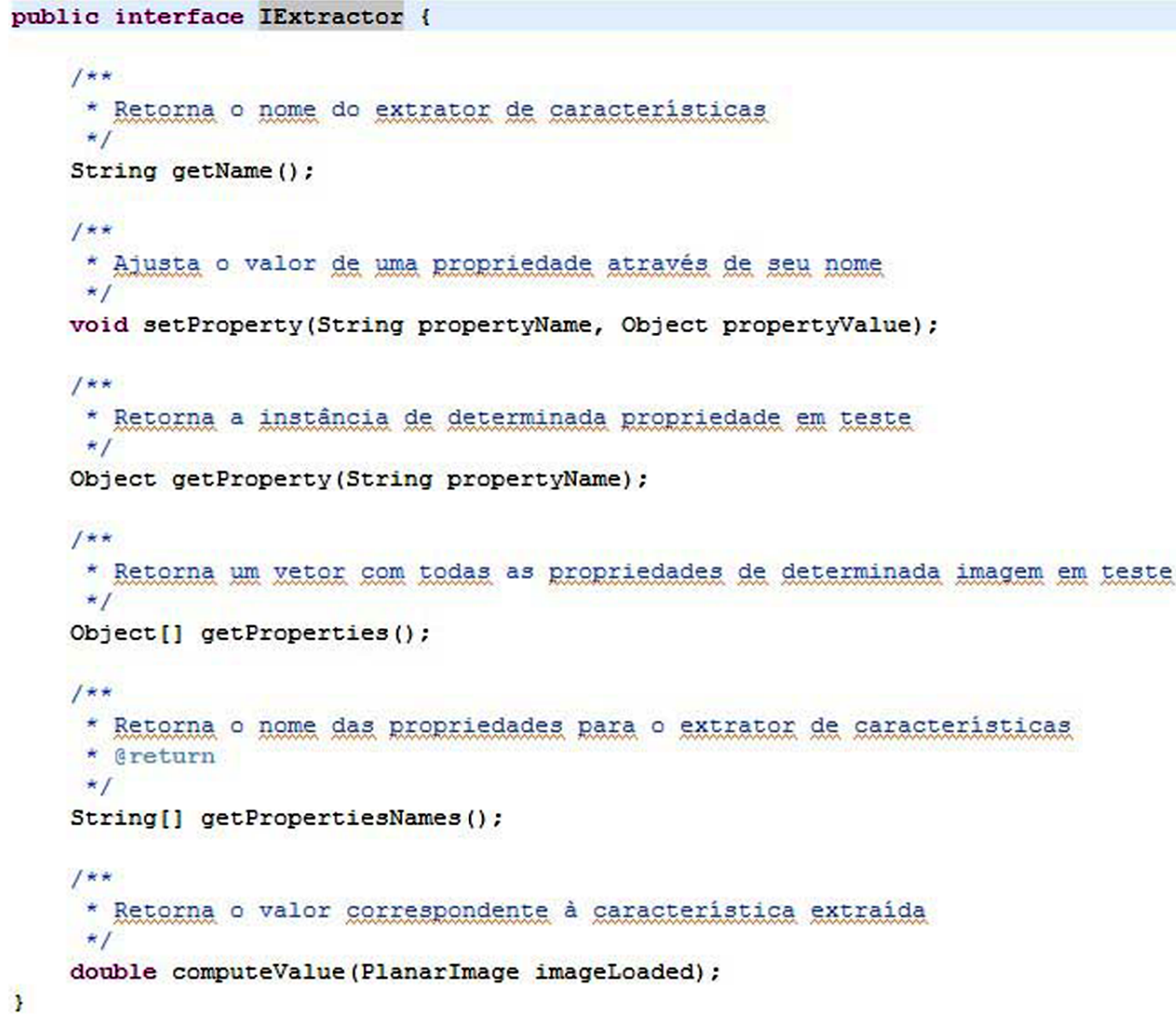

Figura 5.31: Interface IExtractor.

desse contexto estão sendo exploradas, como a disponibilização de um conjunto de funções de distância (seção 5.3.4) e a disponibilização de extratores que possam ser adaptados para domínios diversos.

A aplicação do framework O-FIm no estudo de caso mencionado na seção anterior e em outro estudo de caso relacionado a páginas exibidas em navegadores da Internet compôs um artigo em periódico aceito para publicação (Delamaro et al., 2011). Além disso, vários outros trabalhos foram publicados considerando o framework O-FIm e também os trabalhos anteriores na área de CBIR, sendo os principais: Gonçalves et al. (2010), Oliveira et al. (2008), Oliveira et al. (2009b), Oliveira et al. (2009a), Santos et al. (2007b), Santos et al. (2007a) e Nunes et al. (2009a).

A ferramenta está disponível no endereço http://ccsl.icmc.usp.br/drupal5/pt-br/ content/o-fim-oracle-images.

\subsection{Considerações finais}

O conteúdo apresentado neste capítulo teve o objetivo de abordar as pesquisas conduzidas envolvendo assuntos que extrapolam o escopo de treinamento médico explorado no capítulo anterior. Mesmo que, em alguns casos, a área de saúde não seja especificamente 


\section{CAPÍTULO 5. CAD, VISUALIZAÇÃO DE INFORMAÇÃO E CBIR}

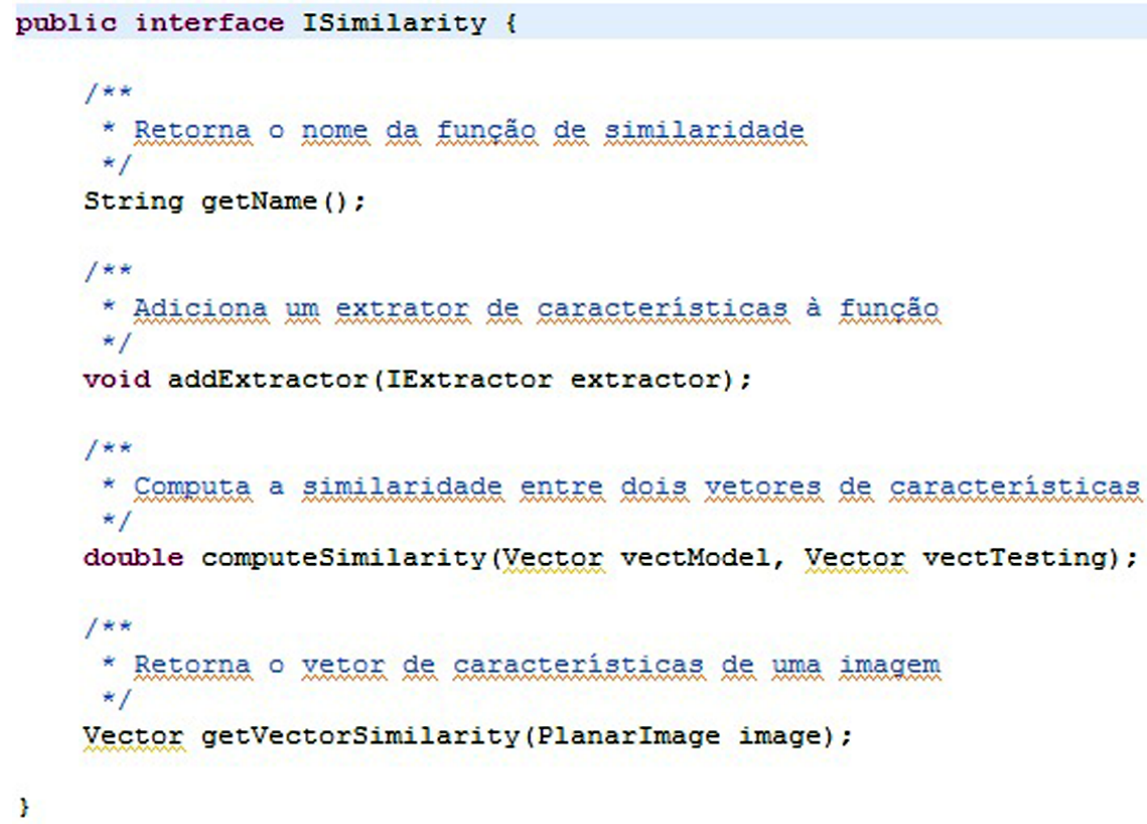

Figura 5.32: Interface ISimilarity.

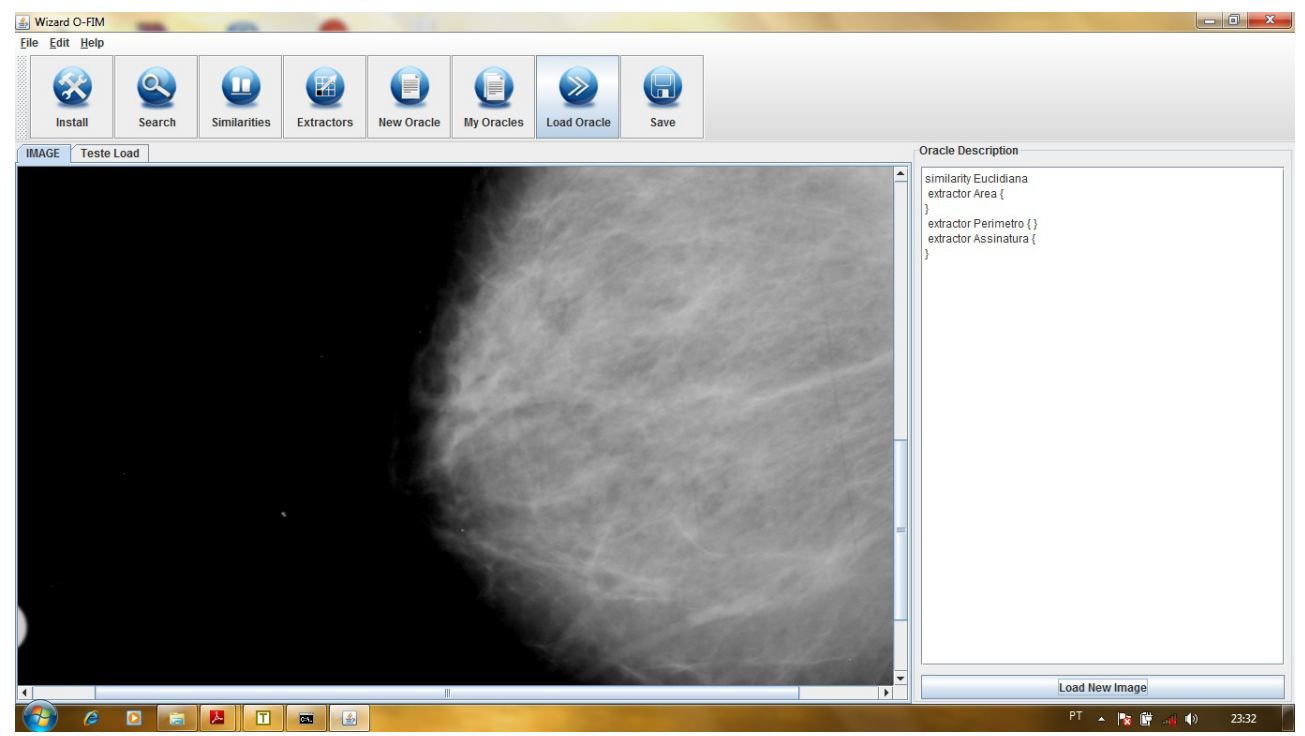

Figura 5.33: Interface gráfica do framework O-FIm.

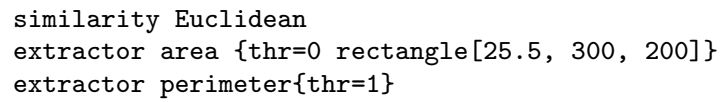

Figura 5.34: Arquivo para execução de aplicação usando O-FIm (Oliveira et al., 2009a). a área de aplicação, como nas Seções 5.2.2, 5.3.2, 5.3.3 e 5.4, sem dúvida as necessidades de profissionais dos mais diversos campos de saúde constituem um dos maiores objetos de interesse para aplicar as técnicas e ferramentas desenvolvidas. 
A condução das pesquisas apresentadas neste capítulo e no capítulo anterior gerou várias discussões e permitiu perceber o grande potencial de aplicação dos resultados obtidos. Por outro lado, uma série de desafios a serem vencidos também foram descobertos. Reflexões sobre tais desafios e formas de abordá-los constituem o assunto do próximo capítulo. 


\section{corane \\ 6 \\ Desafios e oportunidades}

Nos capítulos anteriores foram apresentadas técnicas que, em geral, compõem ferramentas usando principalmente Realidade Virtual e Processamento de Imagens no âmbito da saúde. Foi também, no capítulo 3, apresentado um panorama de pesquisas realizadas ao redor do mundo a fim de fornecer uma visão geral do estado da arte das aplicações na área de saúde dentro do escopo aqui abordado.

O estado da arte das pesquisas realizadas na área mostra que, em geral, há um espaço considerável entre os resultados obtidos no Brasil e aqueles citados por centros de pesquisa localizados principalmente nos Estados Unidos e em vários países da Europa. A forma como a pesquisa é desenvolvida nos países citados, juntamente com a origem do aporte de verbas para financiá-la, certamente constituem o principal motivo para tais diferenças, embora não seja o único.

Como forma de contribuir com a reflexão sobre o fomento e a valorização da pesquisa em geral, mas especialmente considerando as áreas contempladas neste documento, a seguir são apresentados alguns desafios a serem superados para, na sequência, verificar que tais desafios podem constituir importantes oportunidades para a pesquisa, inovação e desenvolvimento de produtos. 


\subsection{Desafios}

Todas as principais áreas abordadas apresentam desafios a serem vencidos. Tais desafios podem ser divididos em técnicos, econômicos e sociais, embora alguns deles possam se enquadrar em mais de uma categoria.

\subsubsection{Aspectos Técnicos}

Em relação aos aspectos técnicos que ainda constituem desafios a serem vencidos, é interessante citar que tanto as pesquisas em PI quanto em RV têm grande volume de dados a ser processado. Embora tenha havido significativo aumento do poder de processamento e armazenamento dos computadores nos últimos anos, este incremento foi acompanhado pelo crescimento da quantidade de dados digitais gerados que devem ser processados e armazenados. Por isso, ainda há muito o que se fazer.

Em especial, verifica-se que nem sempre as linguagens de programação oferecem recursos que permitam, de forma rápida, usufruir de máquinas multiprocessadas ou de processamento paralelo, permitindo construir algoritmos mais rápidos e otimizados. Quando as aplicações incluem características de RV, a questão se torna ainda mais crítica, visto que deve prever, adicionalmente, o processamento para a renderização dos objetos e comumente a inclusão de dispositivos não convencionais.

Um outro aspecto específico de RV aplicada em treinamento médico é a questão dos dispositivos utilizados nas simulações. A partir da avaliação de algumas aplicações de treinamento médico para simulação de exames de biópsia com profissionais da área (Corrêa et al., 2009), duas limitações em relação a esta questão foram percebidas: a dificuldade em correlacionar o virtual com o real e a inadequação dos dispositivos tangíveis.

Conforme já enfatizado em Nunes et al. (2009b), em relação à dificuldade que usuários apresentam para estabelecer uma correlação entre os objetos reais e virtuais (uma parte do corpo humano ou um instrumento médico, por exemplo), é importante salientar que no Brasil a educação médica ainda não tem uma cultura de utilização de ferramentas com objetos virtuais, motivo pelo qual a utilização de sistemas de RV e RA pode sofrer algum grau de dificuldade ou resistência.

Percebe-se que, mesmo com a expansão do oferecimento de artefatos 3D na sociedade, principalmente referente ao entretenimento (como ocorre no cinema e em jogos eletrônicos), a experiência com a visualização não tem sido a mesma em relação à manipulação dos objetos. Assim, estudantes e profissionais da área têm pouca ou nenhuma experiência com interação 3D e, por isso, sentem dificuldades por exemplo, de se localizar no AV e definir a ação que devem imprimir em um dispositivo para obter a reação desejada. Para minimizar essas dificuldades, profissionais avaliadores sugeriram a utilização de objetos 
físicos semelhantes àqueles utilizados no treinamento tradicional para que usuários possam mais facilmente estabelecer a correlação espacial com os objetos virtuais utilizados na simulação.

Ainda em relação a aplicações de treinamento virtual, observa-se a escassez de dispositivos tangíveis capazes de proporcionar a sensação tátil adequada e, ao mesmo, ser ergonomicamente semelhantes aos utilizados na prática dos procedimentos reais (Nunes et al., 2009b). Apesar de já existir uma gama de dispositivos hápticos comercialmente disponíveis, suas características, como a forma, o tamanho e o peso, muitas vezes não condizem com o necessário para simular com realismo os dispositivos reais. Acrescenta-se, ainda, o fato de que dispositivos hápticos capazes de simular múltiplos pontos de contato apresentam limitações nas aplicações de tempo real, tanto em relação ao custo quanto à utilização em sistemas que abordem múltiplas tarefas, como o caso dos sistemas de RV e RA. Por essa razão, a simulação do contato físico em ambientes virtuais para a saúde ainda é pouco realista e concentra-se em atividades em que um único ponto de contato é suficiente, como cortes (simulação de bisturis) e perfurações (simulação de agulhas). Além disso, o preço alto e o fato de não existirem dispositivos com tecnologia nacional contribuem para adicionar restrições às pesquisas da área.

Outra questão que merece destaque refere-se às tarefas colaborativas e cooperativas síncronas. No contexto das aplicações de RV para a saúde, ainda há sérias limitações devido à latência das redes atuais. Em atividades que exigem realismo, atrasos no tempo de resposta podem constituir um fator de risco se a aplicação envolver um paciente real. No melhor caso, prejudica a motivação dos envolvidos na tarefa colaborativa. As consequências dessa questão são a ausência de sistemas imersivos de tempo real para cirurgias comandadas exclusivamente a distância e a escassez de sistemas de treinamento colaborativos.

Dessa forma, o realismo das aplicações de RV para saúde ainda é um grande entrave para que haja uma efetiva transferência de tecnologia dos centros de pesquisa para a indústria. Conforme abordado no capítulo 4, alguns requisitos devem ser preenchidos para que tais ferramentas simulem com propriedade procedimentos da área de saúde. As limitações técnicas ainda hoje existentes dificultam a criação de ferramentas que proporcionem realismo contemplando os requisitos necessários. O realismo pode ser menos necessário em algumas aplicações de RV para saúde, como, por exemplo, atlas virtuais e jogos. No entanto, aplicações como simulações, treinamento e terapia podem ter seus resultados comprometidos se este aspecto não for contemplado.

As aplicações que utilizam predominantemente técnicas de Processamento de Imagens também têm seus desafios técnicos a serem vencidos. Além do volume de dados a ser processado e armazenado, já citado no início desta seção, a variabilidade de formatos 
e a resolução cada vez mais alta das imagens a serem processadas constituem grandes obstáculos nas duas áreas abordadas neste documento: CAD e CBIR.

Em relação aos formatos disponíveis de imagens, a área de saúde tem discutido padrões que incluem protocolos de comunicação e formatos de imagem, como é o caso do DICOM (Digital Imaging and Communications in Medicine) (Nema, 2011). A proposta da Association of Electrical and Medical Imaging Equipment Manufacturers é que equipamentos e sistemas da área médica utilizem uma padronização nas suas rotinas de aquisição e armazenamento de imagens. No entanto, a falta de profissionais com o domínio técnico de tais padrões, a obsolescência de equipamentos disponíveis nos ambientes de pesquisa, os quais não contemplam esses padrões, e a distância existente, no Brasil, entre a pesquisa acadêmica e a indústria dificultam o desenvolvimento de projetos em conjunto que se comuniquem adequadamente.

Em CAD, as consequências imediatas das questões citadas são a dificuldade de proporcionar o reuso de código e a falta de métodos objetivos para avaliação dos sistemas desenvolvidos.

Dando enfoque ao reuso de código, conforme foi esboçado no capítulo 3, verifica-se, no país, a existência de vários grupos de pesquisa trabalhando em torno do mesmo tema, muitas vezes sem colaborações. Frequentemente, superados os aspectos sociais envolvidos, as tentativas de colaboração - as quais poderiam produzir resultados mais rápidos e efetivos - esbarram nas questões de concepção, formatos, linguagens de programação e pacotes de software utilizados no desenvolvimento de técnicas, causando retrabalho relacionado principalmente à implementação. É certo que tal desafio já vem sendo trabalhado por vários fabricantes de pacotes de software que fornecem bibliotecas com componentes genéricos de PI. No entanto, como já abordado no capítulo 2, o desenvolvimento de sistemas de CAD exige conhecimento da imagem médica sob processamento, do objetivo do sistema e do órgão humano sob avaliação, fazendo com que técnicas genéricas tenham que ser adaptadas a cada problema.

Referente à avaliação dos sistemas desenvolvidos, é comum na literatura de CAD encontrar resultados os mais variados possíveis, dependendo dos dados de entrada. A maioria dos pesquisadores dessa área utiliza a Curva ROC (Receiver Operating Characteristic) ou alguma adaptação dela para avaliar seus sistemas (Nishikawa et al., 1994). E, por si só, o instrumento é adequado. O problema é que o resultado pode apresentar grande variação em função dos casos escolhidos para a condução da avaliação. O ideal poderia ser, então, que se empregassem os mesmos casos para avaliar e comparar diferentes sistemas. No entanto, tecnicamente esbarra-se na questão de formatos e padrões, remetendo ao início da discussão em relação a este tópico. 
As consequências para CBIR são parecidas com as discutidas nos parágrafos anteriores. Também percebe-se vários grupos de pesquisa explorando objetos afins, sem muitas colaborações e com retrabalho. Aqui, acrescenta-se o fato de que extratores e funções de similaridade podem ser mais simples de compartilhar, dependendo do objeto de estudos. Também em relação à avaliação de sistemas de CBIR, pode haver grande variação em função da base de imagens utilizada. Como mencionado no capítulo 5, as curvas de precisão e revocação são muito empregadas na avaliação desses sistemas, mas a comparação entre sistemas distintos desenvolvidos para a mesma finalidade fica prejudicada se não houver uma base de imagens em comum. Verifica-se, entretanto, que nesta área há mais facilidade e mais iniciativas de disponibilização de bases de imagens gratuitamente, como, por exemplo, a citada na seção 5.3.2.

Finalmente, é interessante abordar a frequente ausência de uso de técnicas e métodos de Engenharia de Software (ES) no desenvolvimento de pesquisas nesta área de processamento gráfico para a saúde. Na ânsia de desenvolver técnicas inovadoras para solucionar problemas, muitas vezes os pesquisadores negligenciam princípios úteis e bem estabelecidos, provenientes da ES, principalmente em relação a análise de requisitos, controle de versões, documentação e validação. A consequência deste fato é a dificuldade encontrada posteriormente para gerenciar projetos de maior porte, agregar novos pesquisadores ao projeto, compartilhar experiências e, enfim, contribuir para a transferência de tecnologia para a indústria.

\subsubsection{Aspectos Econômicos}

Nesta seção são considerados como desafios econômicos aqueles que limitam o desenvolvimento da pesquisa devido a algum fator financeiro.

De amplo conhecimento dos pesquisadores de quaisquer áreas, no Brasil as restrições econômicas atrasam, limitam e até mesmo causam o descontinuidade de projetos. Conforme já explorado em Nunes et al. (2009b), as verbas para pesquisa no Brasil são predominantemente provenientes de órgãos governamentais, com pouca participação da iniciativa privada. E a demanda cresce a cada dia. Assim, muitas pesquisas iniciadas são interrompidas ou têm seu ritmo reduzido quando tais verbas se esvaem.

Nos últimos anos o investimento em pesquisa no Brasil não acompanhou a evolução do Produto Interno Bruto (PIB), o que indica que o setor não tem recebido a atenção necessária para propiciar um real desenvolvimento ao país, conforme analisado no relatório produzido em 2010 pela Unesco (Organização das Nações Unidas para a educação, a ciência e a cultura) sobre a situação da ciência ao redor do mundo (Unesco, 2010). Outra observação importante nesse relatório é que no período de 2002 a 2007 a quantidade de pesquisadores no Brasil cresceu de 71,8 mil para 122,8 mil. No entanto, o investimento em 
pesquisa não acompanhou tal crescimento, sendo que a taxa de investimento em pesquisa caiu de US\$181,4 mil por pesquisador, em 2002, para US\$162,1 mil em 2007. Considerando este contexto, encontra-se um dos obstáculos que culminam na lentidão para o desenvolvimento de pesquisas e obtenção de resultados significativos.

Quando discute-se pesquisa em RV, adicionalmente existem dificuldades em relação à aquisição de dispositivos não convencionais, principalmente destinados à visualização 3D e interação com retorno háptico, que na sua totalidade são importados. As pesquisas em RV no Brasil dedicam-se majoritariamente a contribuições na área de software, sendo praticamente nula a participação do país em pesquisas na área de dispositivos. O custo alto de dispositivos contribui, também, para dificultar a transferência de tecnologia para o setor produtivo, principalmente se o destino, em se tratando da área de saúde, referir-se a hospitais, escolas ou outros órgãos públicos.

Por fim, um desafio que vem sendo diminuído nos últimos anos, mas que ainda não foi totalmente superado, é o custo de desenvolvimento de software. Várias bibliotecas e linguagens têm sido disponibilizadas gratuitamente, tanto para PI quanto para RV. No capítulo 4 foram apresentadas algumas tecnologias de software no campo de RV, genéricas ou específicas para a construção de projetos na área de saúde, permitindo gerar ferramentas com baixo custo. Ainda que os pacotes de software sejam limitados ou demasiadamente específicos, os próprios pesquisadores têm oferecido muitas contribuições em formas de frameworks, bibliotecas e componentes, auxiliando na superação deste desafio. Embora no Brasil seja perceptível um cenário favorável em relação a essa questão, a disponibilização de pacotes gratuitos ainda é um desafio que merece atenção dos pesquisadores.

\subsubsection{Aspectos Sociais}

Como aspectos sociais estão sendo considerados os desafios referentes principalmente ao ser humano e como as pesquisas são conduzidas por esses. Apesar das considerações a seguir terem sido tecidas em relação ao contexto delimitado neste documento, várias delas são aplicáveis a pesquisas em quaisquer áreas de conhecimento.

Primeiramente, é interessante citar o desafio relacionado à forma como as pessoas se envolvem e desenvolvem pesquisa no Brasil, diretamente relacionado ao exposto na seção anterior. Quase a totalidade de pesquisas brasileiras é realizada em universidades, envolvendo temporariamente alunos de graduação e pós-graduação, que se desvinculam das mesmas ao terminarem seus cursos. Este fato provoca descontinuidade no desenvolvimento de muitos projetos, ao contrário do que acontece em países mais desenvolvidos, que possuem centros de pesquisas dedicados a assuntos diversos, muitos deles mantidos pela iniciativa privada e com um efetivo de recursos humanos constante. 
Ainda relacionada com este assunto, está a dificuldade no estabelecimento de colaborações entre grupos. Apesar de haver esforços pessoais, muitas vezes a distância física, as dificuldades de comunicação e a condução de projetos já iniciados não favorecem o estabelecimento de colaborações entre equipes que pesquisam assuntos afins. Uma iniciativa que tem contribuído para superar esses obstáculos é a criação dos Institutos Nacionais de Ciência e Tecnologia (INCTs) (CNPq, 2011), que congregam pesquisadores do país todo em redes de colaborações nas diversas áreas do conhecimento. Dentro da área de pesquisa aqui exploradas destaca-se o INCT-MACC (Medicina Assistida por Computação Científica) (LNCC, 2011).

Para completar a reflexão em torno de como se faz pesquisa, de grande influência é a forma como os pesquisadores são avaliados. Estabelecer métricas de avaliação é um desafio constante em todos os segmentos. No Brasil, nos últimos anos tem-se valorizado quase que exclusivamente artigos publicados em detrimento de outros aspectos como formação de recursos humanos, disseminação do conhecimento, transferência de tecnologia e desenvolvimento de produtos que culminem, por exemplo, em patentes. Embora a publicação em periódicos seja uma ação necessária para a boa colocação do país no cenário mundial de pesquisa, tem-se criado uma cultura de "desenvolver projetos que resultem em publicações" no lugar de se "desenvolver projetos que solucionem problemas e tragam desenvolvimento ao país". Superar esse desafio está muito além do escopo deste trabalho, visto que exige um amadurecimento na cultura de pesquisa do país e suas políticas.

Um aspecto limitante especificamente relacionado a pesquisas de tecnologias aplicadas à saúde, é a lentidão com que ocorrem mudanças na forma de aprendizagem na educação em saúde. Os aprendizes das mais diversas áreas tendem a transportar a prática aprendida durante seus cursos para a atuação profissional. Atualmente, no Brasil ainda é exíguo o uso de ferramentas computacionais no diagnóstico e treinamento em saúde e para mudar esta realidade é necessária a intervenção de equipes multi e interdisciplinares.

A multidisciplinaridade está relacionada ao uso de conceitos de uma área para auxiliar outras áreas, que não necessariamente precisam beneficiar a primeira e sem a obrigatoriedade de integração de conceitos (Menezes e Santos, 2011). Por outro lado, a interdisciplinaridade apresenta-se quando técnicas e metodologias de uma área, aliadas a outras áreas, resultam em benefícios a ambas, implicando em relação de reciprocidade e de mutualidade frente aos problemas do ensino e da pesquisa (Gattás e Furegato, 2006).

Tanto a inter quanto a multidisciplinaridade exigem que profissionais diversos integrem equipes de pesquisa e desenvolvimento, favorecendo a reunião de conhecimentos. No entanto, a formação de tais equipes requer, antes de tudo, um esforço adicional no estabelecimento de uma linguagem comum, que permita a comunicação entre pessoas com diferentes formações a fim de se atingir o objetivo almejado. 
Finalmente, mas não menos importantes, estão as questões relacionadas à ética. Conforme afirmado em Nunes et al. (2009b), o avanço dos preceitos de bioética tem gerado impactos em vários domínios das ciências da saúde e perpassa, de maneira incisiva, o uso das novas tecnologias nesta área. Nesse sentido, a utilização e a construção de artefatos tecnológicos devem receber especial atenção de maneira a não colocar em risco a saúde de seus usuários.

Alguns importantes órgãos de pesquisa tecnológica estão sensíveis a este tema. O IEEE (IEEE, 2011) e a ACM (ACM, 2011) possuem códigos de ética que contemplam aspectos relacionados à conduta profissional, ao desenvolvimento e uso das tecnologias e seus impactos na qualidade de vida das pessoas. Tais códigos destacam a necessidade de entendimento da tecnologia de maneira a reconhecer possíveis consequências negativas em relação à segurança, saúde e bem-estar público.

Nos casos específicos de CAD e CBIR, é dever ético garantir que validações sejam conduzidas de forma metódica e transparente a fim de que os resultados apresentados sejam, de fato, condizentes com o funcionamento do software.

No caso da tecnologia de RV, existem diversos fatores que podem influenciar na geração de problemas, sendo que alguns são associados aos aspectos técnicos de equipamentos e à construção do AV, enquanto outros são inerentes ao próprio usuário. Logo, precauções especiais devem ser tomadas para assegurar a segurança e o bem-estar de pacientes em ambiente virtuais 3D. Antes de expor os pacientes a esses ambientes, é fundamental que sejam verificadas suas características individuais, assegurando que eles não estejam sofrendo de problemas de saúde ou apresentem outros fatores (como estar alcoolizados ou sob efeitos de medicamentos que afetem as funções visuais ou perceptivas) que possam impedir o uso de tais sistemas.

\subsection{Oportunidades}

Se por um lado os desafios impõem limites atuais às pesquisas, por outro, imaginar uma forma de transpô-los, planejando o futuro, pode esboçar uma série de oportunidades de pesquisa e desenvolvimento.

Provavelmente são os desafios de ordem técnica os que mais proporcionam oportunidades de pesquisa, especialmente na área de Ciência da Computação. Porém, os aspectos de ordem social também podem conduzir a pesquisas de caráter multidisciplinar e aqueles relacionados a questões econômicas podem ser indiretamente minimizados a partir do momento em que outros desafios são superados, como acontece com a questão de desenvolvimento de hardware mais adequado a aplicações de RV. Não serão citadas sugestões a 
respeito de políticas de ordem econômica por entender-se que não constituem tópicos de pesquisa no contexto abordado neste trabalho.

A fim de organizar as discussões, em linhas gerais são apresentados os seguintes aspectos: grande volume de dados, reutilização de código, dispositivos de interação, aplicações colaborativas, metodologias de avaliação, criação de bases de imagens, geração de estudos de caso para treinamento médico, biblioteca de extratores para CBIR, técnicas inteligentes para visualização de dados, interfaces naturais e metodologias para transferência de tecnologia.

Em primeiro lugar, destaca-se que o grande volume de dados envolvidos nas áreas citadas abre espaço para que algoritmos mais eficazes sejam desenvolvidos com a finalidade de permitir o processamento e o armazenamento de imagens médicas de forma eficiente e sem perda de dados, requisito básico para que possam ser usadas para auxílio ao diagnóstico. Da mesma forma, desenvolver pacotes de software que permitam aos sistemas aproveitar o poder de máquinas multiprocessadas também constitui um tópico de interesse para a área de processamento gráfico aplicado em saúde.

Dentre esses pacotes de software, incluem-se também aqueles específicos para certos domínios de conhecimento, permitindo o desenvolvimento mais rápido de aplicações por meio de reutilização de código. Relacionado a esse contexto, é também necessária a criação de bibliotecas de objetos sintéticos tridimensionais com realismo para uso viável nas aplicações de RV. A viabilidade citada aqui inclui tanto a questão de custo quanto a questão de otimização técnica, isto é, objetos e software que sejam criados de forma a proporcionar a precisão e o tempo de resposta adequados às aplicações em saúde.

Mais relacionada com áreas da Engenharia, a resposta à lacuna de dispositivos de RV adequados a aplicações de saúde também constitui um ponto importante a ser explorado. Enfatiza-se aqui o desenvolvimento de hardware, com o objetivo de simular equipamentos utilizados no mundo real de forma mais realista, ergonômica e precisa. O software básico relacionado ao hardware também se apresenta como uma área desafiadora, pois precisa ser portável para as necessidades das aplicações.

$\mathrm{Na}$ área de redes de computadores, pesquisas para facilitar o desenvolvimento de aplicações colaborativas em tempo real igualmente compõem oportunidades relacionadas à Computação aplicada à saúde. Além das aplicações de RV citadas como desafio na seção anterior, as pesquisas na área de Telemedicina, que têm o objetivo de fazer com que imagens possam chegar íntegras e rapidamente a um especialista, também são exemplos de aplicações que se beneficiariam de resultados obtidos na área de redes.

Outro ponto ainda pouco explorado diz respeito, principalmente na área de RV, à criação de metodologias de avaliação das técnicas e ferramentas desenvolvidas, que ainda é incipiente. Para que as aplicações possam ser efetivamente incluídas na rotina dos profis- 
sionais da saúde, métodos eficientes de avaliação são necessários para medir a adequação das ferramentas aos requisitos estabelecidos, à necessidade técnica e ao aprendizado do usuário, garantindo, assim, a exequibilidade e a assertividade das ferramentas. Nesse sentido, muito tem-se a aprender com a área de saúde, na qual os métodos de avaliação, já considerando os aspectos éticos que possam estar envolvidos, são bem estabelecidos e obrigatoriamente fazem parte do planejamento da pesquisa. Dificilmente uma pesquisa em saúde é aprovada pelo Comitê de Ética sem que tais métodos estejam devidamente esclarecidos e adequados.

Ainda considerando a questão de avaliação, o uso da RV para fins de treinamento na área de saúde evidencia a necessidade de rastrear as ações do usuário, identificando falhas, dificuldade e acertos que permitam observar seu desempenho e seu progresso ao longo do treinamento. Atualmente, a pesquisa de formas de avaliação online e de avaliação continuada de usuários em ambientes virtuais é uma importante área que permitirá, no futuro, utilizar, de forma mais abrangente, os sistemas de RV como ferramentas efetivas de treinamento no campo da saúde (Machado e Moraes, 2009).

Essa área de avaliação relacionada especificamente a CBIR e CAD ainda constitui uma lacuna principalmente quanto deseja-se comparar sistemas distintos construídos para a mesma finalidade, como discutido na seção anterior. Assim, a criação de bases de imagens, com formatos não proprietários, com grande volume de casos variados, laudos médicos e dados precisos a respeito de estruturas de interesse é uma necessidade premente na fase de validação desses sistemas, compondo um rol de pesquisas a serem exploradas.

Já foi citado neste trabalho o quanto fatores subjetivos podem influenciar os diagnósticos e o auxílio que CADs podem oferecer para diminuir tal subjetividade. Assim, unindo os conceitos de CAD aos de CBIR, um objeto de pesquisa bastante complexo e que merece exploração mais aprofundada é incluir nessas bases de imagens casos clínicos documentados que permitam a recuperação por conteúdo com o objetivo de auxiliar na composição de diagnósticos. Dessa forma, profissionais poderiam encontrar casos parecidos a um caso representado por uma imagem modelo e sobre o qual tem-se incerteza do diagnóstico.

A geração de estudos de caso é outra oportunidade relacionada à necessidade de realismo das aplicações de treinamento médico, mas também útil a aplicações de RV que visam a auxiliar no planejamento de procedimentos considerando características individuais dos pacientes. Integrando-se técnicas de PI, CG e RV, é possível gerar e manipular objetos 3D, conforme exemplificado na seção 4.5. Da mesma forma, a geração de imagens sintéticas bidimensionais incluindo estruturas de interesse pode ser uma alternativa para compor as bases de imagens citadas no parágrafo anterior. 
Nesse contexto também seria de grande interesse o desenvolvimento de técnicas inteligentes que possam sugerir casos aleatórios para as sessões de treinamento virtual considerando o perfil e a trajetória percorrida pelo usuário durante a execução do sistema. Essas técnicas poderiam ser aplicadas em jogos sérios, favorecendo a motivação para o aprendizado e garantindo o alcance do objetivo final do jogo, independentemente do caminho percorrido pelo jogador/aprendiz.

Ainda considerando aspectos técnicos, outro tópico a ser explorado é o emprego de interfaces naturais, inerentes ao ser humano, como gesto, voz e movimentos do corpo para a interação com AVs. Essa linha possível de oportunidades de pesquisa também exige a integração de técnicas de PI e RV.

Especificamente na área de CBIR, há alguns objetos pouco explorados que podem resultar em bons temas de pesquisa e desenvolvimento. A maioria das aplicações citadas na literatura de CBIR direcionadas à área de saúde dedica-se a encontrar em uma base de imagens, aquelas que são semelhantes à imagem modelo. No entanto, ampliar o uso deste conceito poderia ser bastante útil no sentido de efetivamente tornar os resultados dessas pesquisas úteis para os profissionais de saúde.

Um exemplo de ponto oportuno para exploração nesse âmbito seria a disponibilização de bibliotecas de extratores específicos para imagens provenientes de modalidades médicas (por exemplo, CT, US e RMN).

Métodos inteligentes que pudessem sugerir os melhores extratores após analisar um pequeno grupo de imagens também poderiam contribuir para favorecer a transferência de tecnologia para o setor produtivo. Além disso, explorar as estruturas de SGBDs e propor formas de incluir conceitos de CBIR para a recuperação de informação é um tópico, já citado por Guliato et al. (2009), que pode também favorecer a disseminação desses conceitos e sua inclusão nas rotinas profissionais.

A tema de Visualização de Informação utilizando RV também conduz a oportunidades de pesquisa pouco exploradas na literatura. Entre eles estão a definição automática de metáforas e o desenvolvimento de técnicas para disponibilização de objetos de forma otimizada na cena 3D, contribuindo para facilitar a visualização de acordo com a quantidade de dados retornados da consulta. Também em relação a este assunto técnicas de avaliação poderiam ser interessantes para definir métricas que pudessem indicar o nível de efetividade no sistema. Um estudo inicial utilizando técnicas provenientes da área de usabilidade foi apresentado em Santos (2010).

Em relação aos aspectos sociais, é nítido que muitos dos desafios não podem ser superados apenas com iniciativas individuais dos pesquisadores e, portanto, não constituam exatamente oportunidades de pesquisa. No entanto, algumas discussões em relação à postura frente a esses desafios merecem destaque. 
Inicialmente, é interessante citar a questão das colaborações entre grupos. Nota-se que esta já uma realidade que vem sofrendo mudanças no país, mas é necessário que haja continuidade neste esforço a fim de que resultados mais efetivos sejam obtidos. Uma das formas de incrementar tais colaborações é a continuidade do lançamento de editais de fomento à pesquisa que exijam parcerias, principalmente aqueles que contemplam o trabalho conjunto entre grupos consolidados e grupos emergentes.

Também não somente relacionada ao esforço dos grupos de pesquisa, mas principalmente de responsabilidade dos órgãos decisores, está a questão da avaliação dos pesquisadores, citada anteriormente como um desafio. Independentemente de avaliação, é necessário que os grupos continuem se preocupando com ítens como formação de recursos humanos com alta qualidade, registro de patentes e transferência de tecnologia. A pesquisa considerando esses aspectos pode proporcionar efetivamente o desenvolvimento do país nos seus mais diversos setores.

Especificamente em relação à pesquisa visando ao desenvolvimento de tecnologias aplicadas à saúde e sua inclusão efetiva na rotina dos profissionais de saúde, é importante aqui estreitar as relações com esses profissionais, compondo equipes multidisciplinares de pesquisa, a fim que de que as soluções sejam, de fato, adequadas às suas necessidades. Dessa forma, os pesquisadores de Computação podem efetivamente aproveitar as oportunidades reais que as demandas das diversas áreas de saúde proporcionam para pesquisa e desenvolvimento.

Outra questão relacionada aos aspectos sociais e que pode constituir uma oportunidade de reflexão social é a composição e a divulgação efetiva de um código de ética. Como citado, instituições internacionais como o IEEE e a ACM já disponibilizam códigos que podem ser seguidos pela área de Computação. A SBC planeja compor um Código de Ética para os profissionais da área de Computação e Informática ${ }^{1}$. É importante que a comunidade participe fazendo com que esta oportunidade reflita o amadurecimento dos pesquisadores brasileiros em relação também a esse aspecto.

Finalmente, uma oportunidade a ser explorada, relacionada a todos os tópicos abordados neste documento é o desenvolvimento de metodologias que favoreçam a transferência de tecnologia, o uso dos resultados das pesquisas para o bem comum e, particularmente, a inclusão de ferramentas computacionais na educação dos profissionais de saúde.

\footnotetext{
${ }^{1}$ http://www.sbc.org.br/index.php?option $=$ com $\_$content\&view $=$article\&id $=82$
} 


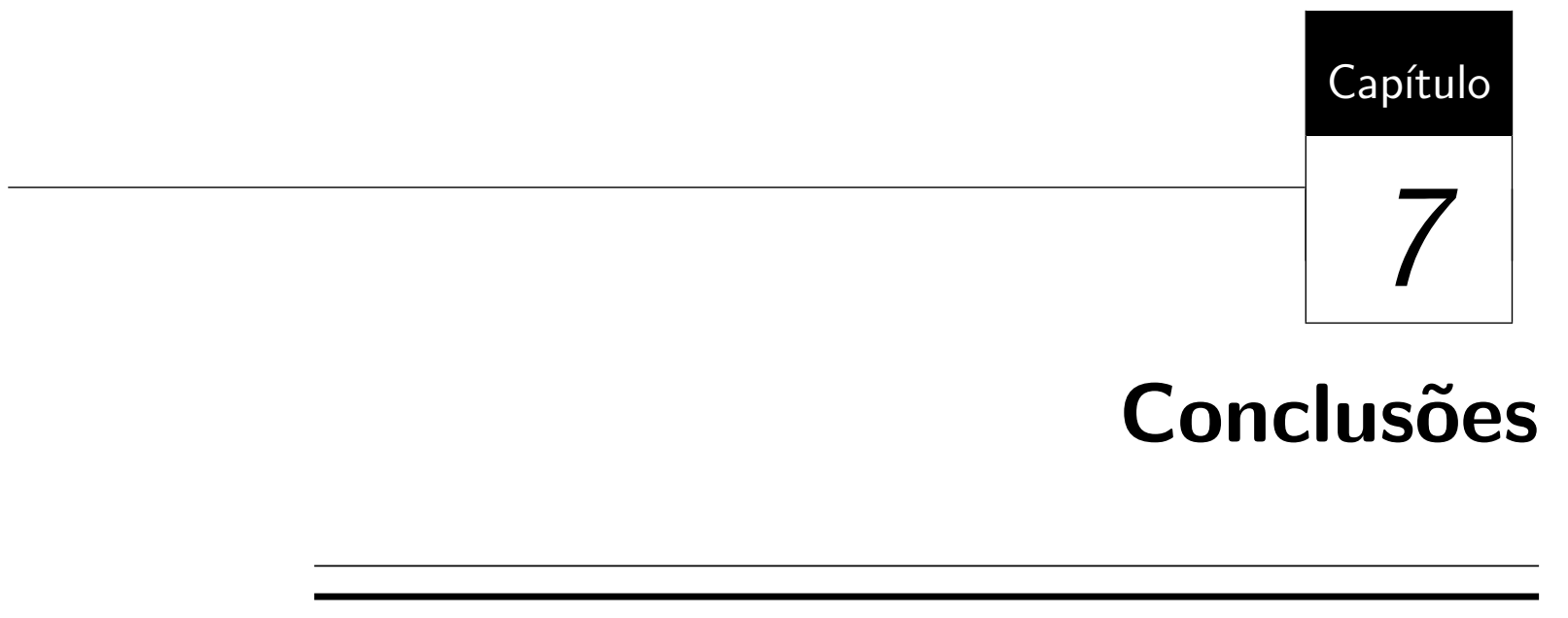

O objetivo do presente documento foi apresentar de forma sistematizada as pesquisas da autora e sua equipe na área de Computação aplicada à saúde, utilizando técnicas e ferramentas de Processamento de Imagens e Realidade Virtual. Com esta visão geral, foram discutidos requisitos, desafios e oportunidades.

Algumas considerações esboçadas ao longo do documento são aqui destacadas, como forma de concluir a reflexão apresentada principalmente no capítulo 6 .

No capítulo 2 foram apresentados aspectos conceituais a respeito das especialidades computacionais contempladas nas pesquisas realizadas. A primeira consideração a se destacar é que o desenvolvimento de técnicas computacionais para a área de saúde vai muito além do emprego de técnicas clássicas. Para se atingir objetivos específicos, é necessário um conhecimento profundo da área de aplicação, contemplando a formação da imagem médica, quando for o caso; as características da anomalia a ser detectada ou do procedimento a ser simulado e as características do órgão humano que constitui o objeto de pesquisa. De posse de tal conhecimento, as técnicas desenvolvidas devem ser específicas para solucionar o problema abordado.

Os trabalhos citados no capítulo 3 permitem perceber que o estado da arte atual das pesquisas conduzidas no Brasil, na sua maioria ainda está aquém daquelas desenvolvidas em centros de pesquisa ao redor do mundo. No capítulo 6 foram esboçados alguns desafios a serem superados que explicam, em partes, tais diferenças. A despeito de tais desafios, o Brasil apresentou um crescimento superior a $110 \%$ em seis anos na quantidade de artigos 
publicados em periódicos indexados, considerando o período de 2002 a 2008, fazendo com que a participação do país nas publicações mundiais crescesse um ponto percentual (de 1,7\% em 2002 para 2,7\% em 2008) (Unesco, 2010).

Entretanto, analisando os dados apresentados em Unesco (2010), percebe-se que a contribuição da área de Engenharia e Tecnologia ainda é pequena quando comparada a outras áreas como Biologia e Medicina (as duas maiores considerando o total de publicações). A partir dessa breve análise, duas conclusões podem ser tecidas: (1) de forma geral, os resultados da área de Engenharia e Tecnologia ainda precisam ser mais expressivos em relação a contribuições científicas e (2) uma vez que discute-se aqui a aplicação de tecnologias em saúde e que esta última área tem uma das maiores participações em resultados científicos, é possível deduzir que pesquisas interdisciplinares, que tragam benefícios para ambas as áreas, podem, também, contribuir para que a participação da área de Engenharia e Tecnologia seja mais significativa, em relação à publicação em periódicos indexados, no contexto mundial.

Uma vez citadas as pesquisas interdisciplinares, cabe aqui refletir e concluir sobre as dificuldades de compreensão, muitas vezes por parte dos pares, a respeito de pesquisa aplicada nas áreas de Computação e Engenharia. Apesar desse quadro estar mudando no Brasil (percebido principalmente pelo lançamento - por parte dos órgãos de fomento de pesquisa - de editais que contemplam objetos interdisciplinares), a falta de formação interdisciplinar da comunidade acadêmica, muitas vezes leva a avaliações inadequadas de projetos e artigos submetidos para publicação.

De fato, quando unem-se áreas de conhecimento para solução de problemas de pesquisa mais abrangentes, é comum elaborar-se a pergunta: qual é a contribuição científica para cada uma das áreas envolvidas? Especificamente dentro do escopo deste trabalho, ousa-se perguntar: o que é uma pesquisa válida na área de Computação em saúde? Conforme discutido em Wainer et al. (2006), este conceito ainda está em construção e os temas interdisciplinares de pesquisa nesta área acabam por reaproveitar métodos e técnicas provenientes das duas áreas.

Por ora, neste trabalho arriscamos adotar simplesmente que a pesquisa válida na área interdisciplinar de Computação em saúde é aquela que traz contribuições tanto para a área de Computação quanto para a área de saúde contemplada. Com essa definição como diretriz, torna-se mais fácil elaborar e avaliar projetos e publicações neste campo interdisciplinar.

Como consequência do discutido, tem-se que uma contribuição na área de Computação é aquela que proporciona desenvolvimento à própria área, ou seja, quando cria-se, por exemplo, uma nova técnica de realce em PI ou de interação em RV para resolver um problema da área de saúde, contribui-se com o desenvolvimento das respectivas subáreas 
da Computação à medida que tais técnicas podem ter seu uso expandido para outros domínios de aplicação.

Sendo assim, identificamos que as principais contribuições dos trabalhos conduzidos pela autora e apresentados neste documento referem-se ao desenvolvimento de técnicas de realce de contraste e segmentação de imagens, detecção de colisão em AVs e suas consequentes deformações, definição de mecanismos para Visualização de Informação, além da construção de ferramentas de forma automatizada, com baixo custo, por meio de reuso de componentes de software.

Um grande desafio a ser enfrentado como continuidade das pesquisas aqui apresentadas é fazer com que os resultados obtidos sejam efetivamente empregados na rotina dos profissionais de saúde. Para isso, é necessário que profissionais da área de aplicação façam parte da equipe de pesquisa - o que já vem ocorrendo em vários casos - e que as aplicações atinjam níveis satisfatórios de eficiência. Em aplicações de CAD e CBIR, níveis satisfatórios significam ter resultados corretos com diferentes bases de imagens, como discutido no capítulo 6. Para aplicações de RV, principalmente aquelas relacionadas a treinamento e simulação, o significado de eficiência está diretamente relacionado ao realismo na visualização e na interação.

A partir dessas considerações, é possível enfatizar que a continuidade das pesquisas aqui apresentadas visa a contribuir efetivamente com:

- agilização no desenvolvimento de ferramentas computacionais para a área de saúde por meio de reuso de software;

- inovação tecnológica e na educação em saúde do país, visto que ainda é rara a inclusão de ferramentas virtuais desenvolvidas no Brasil;

- possibilidade de diminuição de custo a partir da aplicação real de ferramentas construídas na educação em saúde.

É importante destacar que o trabalho desenvolvido vem repercutindo na comunidade, o que pode ser comprovado observando-se alguns pontos do currículo da autora:

- obtenção de recursos de órgãos financiadores (principalmente CNPq e Fapesp), por meio de projetos de pesquisa e bolsas para alunos;

- obtenção de Bolsa de Produtividade em Pesquisa (CNPq) no período de 2005 a 2013

- publicações de resultados obtidos em periódicos e conferências da área;

- participação ativa em diversos comitês de programas e comitê de revisores de conferências nacionais e internacionais; 
- participação no corpo editorial da recém-lançada revista $S B C$ Journal on $3 D$ Interactive Systems;

- participação como consultora ad hoc de vários órgãos de fomento e programas de pesquisa de várias instituições;

- contribuição na formação de recursos humanos levando à nucleação de grupos de pesquisa em instituições do país;

- participação ativa na Comissão Especial de Realidade Virtual da SBC;

- coordenação da Comissão Especial de Computação Aplicada à Saúde da SBC, tendo participado da mesma desde sua criação;

- coordenação de Laboratório de Pesquisa Associado dentro do INCT-MACC, contribuindo para o estabelecimento de colaborações entre vários grupos de pesquisa na área.

Conclui-se, portanto, que trabalhos nessas linhas fazem com que as áreas se complementem em termos de pesquisa: a Computação auxilia na elaboração de soluções para a área de saúde, ao mesmo tempo que se desenvolve por meio da proposta de técnicas inovadoras. A área de saúde se beneficia das técnicas computacionais, ao mesmo tempo que propõe novos desafios a serem vencidos. 


\section{Referências Bibliográficas}

Ackerman, M. The Visible Human Project: a resource for education. Journal of Digital Imaging, v. 74, n. 6, p. 667-670, 1999.

ACM ACM Code of Ethics and Professional Conduct. [On-line].

Disponível em http://www.acm.org/constitution/code.html (Acessado em January, 25, 2011)

Acton, S.; Soliz, P.; Russell, S.; Pattichis, M. Content based image retrieval: The foundation for future case-based and evidence-based ophthalmology. In: Multimedia and Expo, 2008 IEEE International Conference on, 2008, p. 541-544.

Alberio, M. V.; Oliveira, J. C. Acontece-cardio: um ambiente colaborativo para treinamento em cirurgia cardíaca. In: Proceedings of Symposium on Virtual Reality, Belém (PA): Sociedade Brasileira de Computação, 2006, p. 397-408.

Ames, A. L.; Nadeau, D. R.; Moreland, J. L. The VRML 2.0 Sourcebook. John Wiley \& Sons, New York, 1997.

Andaló, F.; Miranda, P.; Torres, R.; Falcão, A. Shape feature extraction and description based on tensor scale. Pattern Recognition, v. 43, p. 26-36, 2010.

Antonelli, M.; Lazzerini, B.; Marcelloni, F. Segmentation and reconstruction of the lung volume in CT images. In: SAC '05: Proceedings of the 2005 ACM Symposium on Applied Computing, New York, NY, USA: ACM, 2005, p. 255-259.

ARToolKit Artoolkit Home Page. [On-line].

Disponível em http://www.hitl.washington.edu/artoolkit/ (Acessado em January, 20, 2011) 
Aukstakalnis, S.; Blatner, D. Silicon Mirage - The Art and Science of Virtual Reality. Berkeley, CA, Peachpit Press, 1992.

Azevedo-Marques, P. M.; Honda, M. H.; Rodrigues, J. A. H.; Santos, R. R.; Traina, A. J. M.; Traina Jr., C.; Bueno, J. M. Recuperação de imagem baseada em conteúdo: uso de atributos de textura para caracterização de microcalcificações mamográficas. Radiologia Brasileira, v. 35, p. 93-98, 2002.

Azuma, R. T. A Survey of Augmented Reality. Presence: Teleoperators and Virtual Environments, v. 6, n. 4, p. 355-385, 1997.

Azzarelli, A.; Guzzon, A.; Pilotti, S.; Quaglinodo, V.; Bono, A.; Pietro, S. D. Accuracy of breast cancer diagnosis by physical, radiologic and cytologic combined examinations. Tumori, v. 6, n. 9, p. 137-141, 1983.

Bacon, J.; Tardella, N.; Pratt, J.; Hu, J.; English, J. The Surgical Simulation and Training Markup Language (SSTML): An XML-Based Language for Medical Simulation. Studies in Health Technologies and Informatics, v. 119, p. 37-42, 2006.

Baeza-Yates, R.; Ribeiro-Neto, B. Modern information retrieval. Addison Wesley Longman, 1999.

Balaniuk, R.; Costa, I. F.; Melo, J. Cosmetic breast surgery simulation. In: Proceedings of Symposium on Virtual Reality, Belém (PA): Sociedade Brasileira de Computação, 2006.

Ballard, D. H.; Brown, C. M. Computer vision. Englewood Cliffs, New Jersey: Prentice-Hall Inc, 1982.

Baños, R. M.; Botella, C.; Garcia-Palacios, A.; Villa, H.; Perpiña, C.; Alcañiz, M. Presence and reality judgment in virtual environments: A unitary construct? CyberPsychology \& Behaviour, v. 3, n. 3, p. 327-335, 2000.

Barione, M. C. N.; Razente, H. L.; Traina, A. J. M.; Traina Jr, C. Accelerating k-medoid based Algorithms through the Utilization of Metric Access Methods. Journal of Systems and Software, v. 81, p. 343-355, 2008.

Bastos, T. A.; Silva, R. J. M.; Raposo, A. B.; Gattas, M. ViRAL: Um Framework para o desenvolvimento de aplicações de Realidade Virtual. In: SBC, ed. Proceedings of VII Symposium on Virtual Reality, São Paulo, 2004, p. 51-62.

Bergamasco, L. C. C. Recuperação de imagens por conteúdo utilizando Lógica Fuzzy - um estudo de caso sobre imagens faciais. Trabalho de Conclusão de Curso (Bacharelado 
em Sistemas de Informação), Escola de Artes, Ciências e Humanidades - Universidade de São Paulo, São Paulo (SP), 2010.

Berti, C. B. VRVis: Ferramenta de Realidade Virtual para Visualização de Informações. Dissertação de Mestrado, Centro Universitário Eurípides de Marília, Marília(SP), 2004.

Berti, C. B.; Nunes, F. L. S. Visualização de informações de bases de imagens médicas utilizando realidade virtual. In: Anais do V Workshop de Imagens Médicas (WIM), Porto Alegre (RS), 2005.

Berti, C. B.; Nunes, F. L. S.; Sementille, A. C.; Brega, J. R. F.; Rodello, I.; Takashi, R. Information visualization: Using virtual reality techniques in the three-dimensional representation of data from a medical images database. In: Proceedings of the 2004 ACM SIGGRAPH international conference on Virtual Reality continuum and its applications in industry, New York, NY, USA: ACM, 2004, p. 152-154 (VRCAI '04, v.1).

Bertrand, J.; Babu, S. V.; Polgreen, P.; Segre, A. Virtual agents based simulation for training healthcare workers in hand hygiene procedures. In: Proceedings of the 10th international conference on Intelligent virtual agents, Berlin, Heidelberg: Springer-Verlag, 2010, p. 125-131 (IVA 10, v.1).

Bezerra, A.; Nunes, F. L. S.; Corrêa, C. G. Avaliação de uma luva de dados em um sistema virtual para aplicações de treinamento médico. In: Anais do WIM2009 IX Workshop de Informática Médica / XXIX Congresso da Sociedade Brasileira de Computação, 2009.

Böhm, C.; Berchtold, S.; Keim, D. A. Searching in high-dimensional spaces: Index structures for improving the performance of multimedia databases. ACM Comput. Surv., v. 33, n. 3, p. 322-373, 2001.

Botega, L. C. Implementação de estereoscopia de baixo custo para aplicações em ferramentas de realidade virtual para treinamento médico. Trabalho de Conclusão de Curso (Bacharelado em Ciência da Computação), Centro Universitário Eurípides de Marília, Marília(SP), 2005.

Botega, L. C.; Nunes, F. L. S. Implementação de estereoscopia de baixo custo para aplicações em ferramentas de realidade virtual para treinamento médico. In: Proceedings of In: XVIII Brazilian Symposium on Computer Graphics and Image Processing (SIBGRAPI) - Workshop de Trabalhos de Iniciação Científica em Computação Gráfica e Processamento de Imagens (WICCGPI), 2005. 
Burdea, G.; Coiffet, P. Virtual Reality Technology. Inc.: New York, USA: John Wiley \& Sons, 1994.

Burdea, G. C.; Coiffet, P. Virtual Reality Technology. Comput. Animat. Virtual Worlds, v. 16, n. 5, p. 559-560, 2003.

Burkhard, W. A.; Keller, R. M. Some approaches to best-match file searching. Commun. $A C M$, v. 16, n. 4, p. 230-236, 1973.

Calonego Jr, N.; Garcia, M. B.; Meiguins, B.; Valerio-Netto, A.; Caterino, P. Modelagem e Programação de Ambientes Virtuais Interativos, cáp. 1. 1a. ed Editora Mania de Livro, p. 95-105, 2004.

Campadelli, P.; Casiraghi, E.; Valentini, G. Lung nodules detection and classification. In: Image Processing, 2005. ICIP 2005. IEEE International Conference on, 2005, p. I - 1117-20.

Card, S. K.; Mackinlay, J.; Shneiderman, B. Information visualization: Using vision to think. 1st ed. Academic Press, San Diego, 1999.

Cardoso, L. S.; Costa, R. M. E. M.; Piovesana Neto, A.; Carvalho, J.; Ferreira, H.; Lopes, M.; Crispim, A.; Pena, L.; Araújo, K. Utilização de Ambientes Virtuais na Reabilitação de Pacientes com Lesão Cerebral por AVC e TCE. In: Anais do X Congresso Brasileiro de Informática em Saúde, Florianópolis, SC, 2006, p. 1406-1410.

Chaudhry, M.; Ashraf, R.; Jafri, M.; Akbar, M. Computer aided diagnosis of skin carcinomas based on textural characteristics. In: Machine Vision, 200\%. ICMV 200\%. International Conference on, 2007, p. 125-128.

Choi, K. S.; Sun, H.; Heng, P. A.; Cheng, J. C. Y. A scalable force propagation approach for web-based deformable simulation of soft tissues. In: Proceedings of the seventh international conference on 3D Web technology, New York, NY, USA: ACM, 2002, p. 185-193 (Web3D'02, v.1).

Ciaccia, P.; Patella, M.; Zezula, P. M-tree: An Efficient Access Method for Similarity Search in Metric Spaces. In: VLDB '9\%: Proceedings of the 23rd International Conference on Very Large Data Bases, San Francisco, CA, USA: Morgan Kaufmann Publishers Inc., 1997, p. 426-435.

CNPq INCT. [On-line].

Disponível em <http://www. cnpq.br/programas/inct/_apresentacao/index.html> (Acessado em January, 25, 2011) 
Cornell, G.; Horstmann, C. S. $\quad$ Native Methods - Core Java 2 - Advanced Features, v. 2. Pearson Education of Brazil, 2003.

Corrêa, C. G.; Nunes, F. L. S. Interação com dispositivos convencionais e não convencionais utilizando integração entre linguagens de programação. In: SBC, ed. Abordagens Práticas de Realidade Virtual e Aumentada, Porto Alegre, RS: XI Symposium on Virtual and Augmented Reality, 2009, p. 61-103.

Corrêa, C. G.; Nunes, F. L. S.; Bezerra, A. Implementação de interação em sistemas virtuais para simulação de exame de biópsia. In: Proceedings of WIM 2008 - Workshop de Informática Médica - XXVIII Congresso da SBC, Belém, PA, 2008, p. 91-100.

Corrêa, C. G.; Nunes, F. L. S.; Bezerra, A.; Carvalho, J. P. Evaluation of VR medical training applications under the focus of professionals of the health area. In: SAC '09: Proceedings of the 2009 ACM symposium on Applied Computing, New York, NY, USA: ACM, 2009, p. 821-825.

Cote, M.; Boulay, J.-A.; Ozell, B.; Labelle, H.; Aubin, C.-E. Virtual reality simulator for scoliosis surgery training: Transatlantic collaborative tests. In: Haptic Audio visual Environments and Games, 2008. HAVE 2008. IEEE International Workshop on, 2008, p. $1-6$.

Cunha, I. L. L.; Monteiro, B. S.; Moraes, R. M.; Machado, L. S. Anatomi 3D: Um atlas digital baseado em Realidade Virtual para ensino de Medicina. In: Proceedings of Symposium on Virtual Reality, Belém (PA): Sociedade Brasileira de Computação, 2006, p. 3-14.

Datta, R.; Joshi, D.; Li, J.; Wang, J. Z. Image retrieval: Ideas, influences, and trends of the new age. ACM Comput. Surv., v. 40, n. 2, p. 1-60, 2008.

Delamaro, M. E.; Nunes, F. L. S.; Oliveira, R. A. Using concepts of content-based image retrieval to implement graphical testing oracles. Software Testing, Verification ES Reliability aceitoparapublicao, 2011.

Delfino, S. R. Geração de Estudos de Caso para Treinamento Médico Virtual a partir de Técnicas de Processamento de Imagens e Realidade Virtual. Dissertação de Mestrado, Centro Universitário Eurípides de Marília, Marília(SP), 2007.

Delfino, S. R.; Nunes, F. L. S. Estudo Comparativo entre Algoritmos de Segmentação para simulação tridimensional de imagens mamográficas. In: Anais do II Workshop de Visão Computacional, São Carlos (SP), 2006. 
Delfino, S. R.; Nunes, F. L. S. Extração de Medidas de Imagens Mamográficas para Geração de Ambientes Virtuais. In: Proceedings of XXXIII Conferencia Latinoamericana de Informática, San José, Costa Rica, 2007a, p. 15-23.

Delfino, S. R.; Nunes, F. L. S. Punção de mama virtual: um módulo para geração de casos para estudo. In: Anais do VII Worshop de Informática Médica, Porto de Galinhas (PE): Sociedade Brasileira de Computação, 2007b, p. 146-155.

Delfino, S. R.; Nunes, F. L. S. Geração de estudos de casos para treinamento médico virtual a partir de técnicas de realidade virtual e processamento de imagens. In: Anais do WIM2009 - IX Workshop de Informática Médica / XXIX Congresso da Sociedade Brasileira de Computação, Bento Gonçalves (RS), 2009.

Delingette, H.; Ayache, N. Hepatic surgery simulation. Commun. ACM, v. 48, n. 2, p. 31-36, 2005.

Demir, C.; Gultekin, S. H.; Yener, B. Learning the topological properties of brain tumors. IEEE/ACM Trans. Comput. Biol. Bioinformatics, v. 2, n. 3, p. 262-270, 2005.

Deutsch, J.; Lewis, J.; Burdea, G. Virtual reality-integrated telerehabilitation system: Patient and technical performance. In: Virtual Rehabilitation, 2006 International Workshop on, 2006, p. 140-144.

DeVita, V. Cancer - Principles and Practice of Oncology. 7th ed. Lippincott-Raven, 2004.

Devore, J. L. Probabilidade e Estatística para Engenharia e Ciências. 6a. ed. São Paulo: Pioneira Thomson Learning, 2006.

Dimitrova, M.; Roumenin, C.; Lozanova, S.; Lahchev, L.; Rotger, D.; Radeva, P. An interface system based on multimodal principle for cardiological diagnosis assistance. In: CompSysTech '07: Proceedings of the 2007 international conference on Computer systems and technologies, New York, NY, USA: ACM, 2007, p. 1-6.

Doi, K. Diagnostic imaging over the last 50 years: research and development in medical imaging science and technology. Physics in Medicine and Biology, v. 51, n. 13, p. R5-R27, 2006.

Disponível em http://stacks . iop.org/0031-9155/51/i=13/a=R02 (Acessado em January, 30, 2011)

Doi, K. Computer-aided diagnosis in medical imaging: Historical review, current status and future potential. Computerized Medical Imaging and Graphics, v. 31(4-5), p. 191-211, 2007. 
Dorileo, E. A. G.; Frade, M. A. C.; Roselino, A. M. F.; Rangayyan, R. M.; Azevedo-Marques, P. M. Color image processing and content-based image retrieval techniques for the analysis of dermatological lesions. In: Engineering in Medicine and Biology Society, 2008. EMBS 2008. 30th Annual International Conference of the IEEE, 2008, p. 1230-1233.

Dube, S.; El-Saden, S.; Cloughesy, T.; Sinha, U. Content Based Image Retrieval for MR Image Studies of Brain Tumors. In: Engineering in Medicine and Biology Society, 2006. EMBS '06. 28th Annual International Conference of the IEEE, 2006, p. $3337-3340$.

Duque, J. J.; Sturzbecher, M. J.; Araujo, D. B.; Felipe, J. C. A New Method for Detection of Active Brain Regions with Event-Related fMRI Time Series Analysis. Computer Graphics and Image Processing, Brazilian Symposium on, v. 0, p. 329-334, 2007.

Durlack, N.; Mavor, A. Virtual Reality - Scientific and Technological Challenges. Washington: National Academy Press, 1995.

El-Naqa, I.; Yang, Y.; Galatsanos, N.; Nishikawa, R.; Wernick, M. A similarity learning approach to content-based image retrieval: application to digital mammography. Medical Imaging, IEEE Transactions on, v. 23, n. 10, p. 1233-1244, 2004.

Essex University Collection of facial images. [On-line].

Disponível em http://www.face-rec.org (Acessado em December, 15, 2010)

Estabridis, K.; Figueiredo, R. J. P. Automatic Detection and Diagnosis of Diabetic Retinopathy. In: Image Processing, 200\%. ICIP 200\%. IEEE International Conference on, 2007, p. II-445-II-448.

Fang, J.; Fang, S.; Huang, J.; Tuceryan, M. Digital geometry image analysis for medical diagnosis. In: SAC '06: Proceedings of the 2006 ACM symposium on Applied computing, New York, NY, USA: ACM, 2006, p. 217-221.

Favretto, F.; Bergo, F.; Falcao, A. A Fast and Automatic Method for 3D Rigid Registration of MR Images of the Human Brain. In: Computer Graphics and Image Processing, 2008. SIBGRAPI'08. XXI Brazilian Symposium on, 2008, p. 121-128.

Felipe, J. C.; Ribeiro, M. X.; Sousa, E. P. M.; Traina, A. J. M.; Traina Jr., C. Effective shape-based retrieval and classification of mammograms. In: SAC '06: Proceedings of the 2006 ACM symposium on Applied computing, New York, NY, USA: ACM, 2006, p. 250-255. 
Felipe, J. C.; Traina, A. J. M.; Traina Jr., C. A new family of distance functions for perceptual similarity retrieval of medical images. Journal of Digital Imaging, p. 1618-727X, 2008.

Felmer, L. R.; Boudon, P. A.; Filsecker, M. Aprendizaje implícito en usuarios intensivos de videojuegos. Paidéia (Ribeirão Preto), v. 18, p. 165-174, 2008.

Disponível em http://www.scielo.br/pdf/paideia/v18n39/v18n39a15.pdf (Acessado em January, 12, 2011)

Ferrero, C. A.; Lee, H. D.; Chung, W. F.; Coy, C. S. R.; Fagundes, J. J.; Góes, J. R. N. Seleção de características baseadas em textura para a identificação de anormalidades em imagens de colonoscopia. In: Anais do X Congresso Brasileiro de Informática em Saúde - CBIS'2006, Florianópolis, SC-Brazil, 2006.

Freitas, C. M. D. S.; Manssour, I. H.; Nedel, L. P.; Gavião, J. K.; Paim, M. T. C.; Maciel, A. Framework para Construção de Pacientes Virtuais: Uma aplicação em Laparoscopia Virtual. In: Proc. Symp. on Virtual Reality, Ribeirão Preto, SP, Brazil, 2003, p. 283-294.

Freitas Jr., R.; Freitas, M. E. D. C.; Moreira, M. A. R.; Souza, J. A. Punção aspirativa por agulha fina em lesões palpáveis da mama. Ginecol. Oncol., v. 4, p. 11-15, 1995.

Furuie, S. S.; Rebelo, M. S.; Moreno, R. A.; Santos, M.; Bertozzo, N.; Motta, G. H. M. B.; Pires, F.; Gutierrez, M. A. Managing Medical Images and Clinical Information: InCor's Experience. Information Technology in Biomedicine, IEEE Transactions on, v. 11, n. 1, p. 17-24, 2007.

Gaede, V.; Günther, O. Multidimensional access methods. ACM Comput. Surv., v. 30(2), p. 170-231, 1998.

Gallo, L.; De Pietro, G.; Coronato, A.; Marra, I. Toward a natural interface to virtual medical imaging environments. In: AVI '08: Proceedings of the working conference on Advanced visual interfaces, New York, NY, USA: ACM, 2008, p. 429-432.

Gattás, M. L. B.; Furegato, A. R. F. Interdisciplinaridade: uma contextualização. Acta Paulista de Enfermagem, v. 19, p. 323-327, 2006.

Gibson, S. F. F.; Mirtch, B. A survey of deformable modeling in computer graphics. Technical Report 1, Mitsubishi Electric Information Technology Center America, http://www.merl.com/people/frisken/deformationSurvey.pdf, 1997.

Gladlin, E. A Biomechanical Modeling of Soft Tissue and Facial Expressions for Craniofacial Surgery Planning. PhD Thesis, FUBerlin, 2003. 
Goh, K. Virtual reality applications in neurosurgery. In: Engineering in Medicine and Biology Society, 2005. IEEE-EMBS 2005. 27th Annual International Conference of the, 2005, p. 4171-4173.

Gomes, J.; Velho, L. Computação gráfica: Imagem. IMPA, 2002.

Gonçalves, V. M. Avaliação de Funções de Similaridade em Sistemas de CBIR - Relatório parcial apresentado à Fundação de Amparo à Pesquisa do Estado de São Paulo (Fapesp), referente à bolsa de Iniciação Científica vinculada ao processo de número 2010/01496-1. Relatório Técnico, Escola de Artes, Ciências e Humanidades - Universidade de São Paulo, 2010.

Gonçalves, V. M.; Nunes, F. L. S.; Delamaro, M. E. Avaliação de Funções de Similaridade em Sistemas de CBIR: uma Revisão Sistemática. In: Anais do VI Workshop de Visão Computacional (WVC 2010), Presidente Prudente - SP, Brasil: FCT-UNESP, 2010, p. 199-204.

Gonzalez, R. C.; Woods, R. E. Digital image processing. 3rd ed. Prentice Hall, 2007.

Guliato, D.; Carvalho, J.; Rangayyan, R.; Santiago, S. Feature Extraction from a Signature Based on the Turning Angle Function for the Classification of Breast Tumors. Journal of Digital Imaging, v. 21, n. 1, p. 129-144, 2008a.

Guliato, D.; Melo, E. V.; Rangayyan, R. M.; Soares, R. C. PostgreSQL-IE: An Image-handling Extension for PostgreSQL. Journal of Digital Imaging, v. 22, p. 149-165, 2009.

Guliato, D.; Rangayyan, R.; Carvalho, J.; Santiago, S. Polygonal Modeling of Contours of Breast Tumors With the Preservation of Spicules. Biomedical Engineering, IEEE Transactions on, v. 55, n. 1, p. 14-20, 2008b.

GWT Google Web Toolkit. [On-line].

Disponível em <http://code.google.com/intl/pt-BR/webtoolkit/> (Acessado em January, 3, 2011)

Hafner, J.; Sawhney, H.; Equitz, W.; Flickner, M.; Niblack, W. Efficient color histogram indexing for quadratic form distance functions. Pattern Analysis and Machine Intelligence, IEEE Transactions on, v. 17, n. 7, p. 729-736, 1995.

Halbe, H. W. Tratado de Ginecologia. 3a. ed. Editora Roca, São Paulo, SP, 2000.

Hand, C. Other Faces of Virtual Reality. In: First International Conference MHVR Lecture Notes in Computer Science, Moscow: Moscow: Ed. Springer, 1994, p. 107-116. 
Handolin, L.; Partio, E. K.; Arnala, I.; Pajarinen, J.; Pätiälä, H.; Rokkanen, P. The effect of low-intensity pulsed ultrasound on bone healing in SR-PLLA rod fixed experimental distal femur osteotomy in rat. J Mater Sci Mater Med, v. 18, n. 6, p. 1239-1245, 2007.

Hao, B.; Leung, C. K.-S.; Camorlinga, S.; Reed, M. H.; Bunge, M. K.; Wrogemann, J.; Higgins, R. J. A computer-aided change detection system for paediatric acute intracranial haemorrhage. In: C3S2E '08: Proceedings of the 2008 C3S2E conference, New York, NY, USA: ACM, 2008, p. 109-111.

Heng, P. A. Research and Applications of Virtual Medicine. In: Engineering in Medicine and Biology Society, 2005. IEEE-EMBS 2005. 27th Annual International Conference of the, 2005, p. 4160-4163.

Heng, P.-A.; Wong, T.-T.; Yang, R.; Chui, Y.-P.; Xie, Y. M.; Leung, K.-S.; Leung, P.-C. Intelligent inferencing and haptic simulation for chinese acupuncture learning and training. Information Technology in Biomedicine, IEEE Transactions on, v. 10, n. 1, p. 28-41, 2006.

Hennel, J. W.; Klinowski, J. Fundamentals of nuclear magnetic resonance. Essex England: Longman Scientific \& Technical, 1993.

Hermosilla, L. G. Ferramenta de realidade virtual para geração dinâmica de estruturas de feto. Dissertação de Mestrado, Centro Universitário Eurípides de Marília, São Paulo (SP), 2004.

Hermosilla, L. G.; Nunes, F. L. S. Modelagem dinâmica tridimensional de fetos utilizando técnicas de realidade virtual. In: Anais do III Congresso Latino-Americano de Engenharia Biomédica, João Pessoa, SP, 2004, p. 1591-1594.

Hermosilla, L. G.; Nunes, F. L. S. Geração e manipulação de feto do bióptipo brasileiro utilizando técnicas de Realidade Virtual. In: Anais do VII Worshop de Informática Médica, Porto de Galinhas (PE): Sociedade Brasileira de Computação, 2007, p. 106-115.

Hermosilla, L. G.; Nunes, F. L. S.; Rodello, I.; Sementille, A. C.; Brega, J. R. F. Geração dinâmica e manipulação de estruturas de feto utilizando realidade virtual não imersiva. In: SBC, ed. Proceedings of VII Symposium on Virtual Reality, São Paulo, 2004a, p. $195-206$.

Hermosilla, L. G.; Nunes, F. L. S.; Sementille, A. C.; Brega, J. R. F.; Rodello, I. A virtual reality system for dynamic generation of fetus structures from ultrasound images. In: Proceedings of the 2004 ACM SIGGRAPH international conference on Virtual Reality 
continuum and its applications in industry, New York, NY, USA: ACM, 2004b, p. 328-331 (VRCAI'O4, v.1).

Hirota, G.; Maheshwari, R.; Lin, M. C. Fast volume-preserving free form deformation using multi-level optimization. In: Proceedings of the fifth ACM symposium on Solid modeling and applications, New York, NY, USA: ACM, 1999, p. 234-245 (SMA 99, v.1).

Howden, W. E.; Eichhorst, P. Proving properties of programs from program traces. In: Press, I. C. S., ed. Tutorial: Software Testing and Validation Techniqus: E Miller and W.E. Howden, New York, 1978.

Hutchins, M.; Stevenson, D.; Gunn, C.; Krumpholz, A.; Pyman, B.; O’Leary, S. "I think i can see it now!": evidence of learning in video transcripts of a collaborative virtual reality surgical training trial. In: OZCHI '05: Proceedings of the 17th Australia conference on Computer-Human Interaction, Narrabundah, Australia, Australia: Computer-Human Interaction Special Interest Group (CHISIG) of Australia, 2005, p. 1-4.

IEEE IEEE Code of Ethics. [On-line].

Disponível em https ://www.ieee.org/about/ethics_code/DF_IEEE_MIG_MCT_80596 (Acessado em January, 25, 2011)

INCA Institulo Nacional do Câncer. [On-line].

Disponível em http://www.inca.org.br (Acessado em January, 15, 2011)

Jacobson, L. Realidade Virtual em Casa. Rio de Janeiro: Berkeley, 1994.

Johanson, M. Stereoscopic video transmission over the internet. In: Proceedings of the Second IEEE Workshop on Internet Applications (wiapp '01), Washington, DC, USA: IEEE Computer Society, 2001, p. 12-21 (WIAPP '01, v.1).

Johnsen, K.; Raij, A.; Stevens, A.; Lind, D. S.; Lok, B. The validity of a virtual human experience for interpersonal skills education. In: CHI 'O\%: Proceedings of the SIGCHI conference on Human factors in computing systems, New York, NY, USA: ACM, 2007, p. 1049-1058.

Johnson, R. E. Components, frameworks, patterns. SIGSOFT Softw. Eng. Notes, v. 22, p. 10-17, 1997.

Jung, Y.; Recker, R.; Olbrich, M.; Bockholt, U. Using X3D for medical training simulations. In: Web3D '08: Proceedings of the 13th international symposium on 3D web technology, New York, NY, USA: ACM, 2008, p. 43-51. 
Junges, L. C. D. Introdução a Lógica Fuzzy. [On-line].

Disponível em s2i.das.ufsc.br/tikiwiki/apresentacoes/logica-fuzzy.pdf (Acessado em January, 15, 2011)

Kanehira, R.; Shoda, A.; Yagihashi, M.; Narita, H.; Fujimoto, H. Development of an Acupuncture Training System Using Virtual Reality Technology. In: Fuzzy Systems and Knowledge Discovery, 2008. FSKD '08. Fifth International Conference on, 2008, p. $665-668$.

Keeve, E.; Jansen, T.; Krol, Z.; Ritter, L.; von Rymon-Lipinski, B.; Sader, R.; Zeilhofer, H.-F.; Zerfass, P. JULIUS - An Extendable Software Framework for Surgical Planning and Image-Guided Navigationg. Lecture Notes in Computer Science, Medical Image Computing and Computer-Assisted Intervention - MICCAI 2001, v. 2208/2010, p. 161-167, Book Medical Simulation, 2001.

Kera, M. Detecção de colisão utilizando hierarquias em ferramentas de realidade virtual para treinamento médico. Trabalho de Conclusão de Curso (Bacharelado em Ciência da Computação), Centro Universitário Eurípides de Marília, Marília(SP), 2005.

Kera, M.; Nunes, F. L. S. $\quad$ Detecção de colisão para treinamento médico virtual utilizando tecnologias gratuitas. In: Anais do 2o. Simpósio de Instrumentação e Imagens Médicas, 2005.

Kera, M.; Nunes, F. L. S.; Pedrini, H. Detecção de Colisão de Objetos em Ambientes Virtuais para Treinamento Médico Utilizando JOGL. In: Anais do WRVA 2008 - 50. Workshop de Realidade Virtual e Aumentada, 2008.

Kilgard, M. J. OpenGL Programming for the $X$ Window System. $\quad 4$ th ed. Addison-Wesley, Massachusetts, 1997.

Kirner, C.; Siscoutto, R. A. Realidade Virtual e Aumentada - Conceitos, Projetos e Aplicações. In: Fundamentos de Realidade Virtual e Aumentada, Editora SBC, p. 2-21, 2007.

Kirner, K.; Tori, R. Introdução à Realidade Virtual, Realidade Misturada e Hiper-realidade. In: Realidade Virtual: Conceitos, Tecnologia e Tendências, São Paulo: Editora SENAC, p. 3-20, 2004.

Kuroda, Y.; Nakao, M.; Kuroda, T.; Oyama, H.; Yoshihara, H. MVL: Medical VR Simulation Library. Studies in Health Technologies and Informatics, v. 111, p. 273-279, 2005. 
Kurt Rossman Kurt Rossman Laboratories for Radiologic Image Research. [On-line]. Disponível em <http://www-radiology.uchicago.edu/krl/ (Acessado em June, 10, 2010)

La Mura, F.; Corte, F.; Gribaudo, M.; Tosi, B.; Alciati, S.; Bordino, R.; Franceschinis, G. Collaborative Virtual Environments as Research and Teaching Instruments in the Field of Disaster Medicine: the "e-DISTRICT CiPro" Simulator. In: Information Visualization, 200\%. IV '07. 11th International Conference, 2007, p. 892-898.

Lamard, M.; Cazuguel, G.; Quellec, G.; Bekri, L.; Roux, C.; Cochener, B. Content based image retrieval based on wavelet transform coefficients distribution. In: Engineering in Medicine and Biology Society, 200\%. EMBS 2007. 29th Annual International Conference of the IEEE, 2007, p. 4532-4535.

LApIS Laboratório de aplicações de informática em saúde. [On-line].

Disponível em http://www. each.usp.br/lapis/ (Acessado em January, 25, 2011)

Latta, J. N.; Oberg, D. J. A Conceptual Virtual Reality Model. IEEE Computer Graphics and Applications, v. 14, p. 23-29, 1994.

Lau, R. W.; Chan, O.; Luk, M.; Li, F. W. LARGE - a collision detection framework for deformable objects. In: Proceedings of the ACM symposium on Virtual reality software and technology, New York, NY, USA: ACM, 2002, p. 113-120 (VRST'02, v.1).

LaViola, J. Bringing VR and Spatial 3D Interaction to the Masses through Video Games. Computer Graphics and Applications, IEEE, v. 28, n. 5, p. 10-15, 2008.

Li, H.; Lim, J. H.; Liu, J.; Wing Kee Wong, D.; Wong, T. Computer aided diagnosis of nuclear cataract. In: Industrial Electronics and Applications, 2008. ICIEA 2008. 3rd IEEE Conference on, 2008, p. 1841-1844.

Lima, L. Protótipo de ferramenta de realidade virtual para simulação de exame de punção da mama. Dissertação de Mestrado, Centro Universitário Eurípides de Marília, Marília(SP), 2004.

Lima, L.; Nunes, F. L. S. Utilização de realidade virtual em treinamento médico: um protótipo de ferramenta para exame de punção de mama. In: Anais do III Congresso Latino-Americano de Engenharia Biomédica, João Pessoa, SP, 2004, p. 1695-1698.

Lima, L.; Nunes, F. L. S.; Brega, J. R. F.; Sementille, Antonio Carlosand Takashi, R.; Rodello, I. Um protótipo para simulação de exame de punção de mama utilizando realidade virtual não imersiva. In: Proceedings of VII Symposim on Virtual Reality, São Paulo, SP, 2004a, p. 171-182. 
Lima, L.; Nunes, F. L. S.; Takashi, R.; Rodello, I.; Brega, J. R. F.; Sementille, A. C. Virtual reality for medical training: a prototype to simulate breast aspiration exam. In: Proceedings of the 2004 ACM SIGGRAPH international conference on Virtual Reality continuum and its applications in industry, New York, NY, USA: ACM, 2004b, p. 328-331 ( VRCAI '04, v.1).

Lindblad, A.; Turkiyyah, G. A physically-based framework for real-time haptic cutting and interaction with 3D continuum models. In: SPM '0\%: Proceedings of the 200\% ACM symposium on Solid and physical modeling, New York, NY, USA: ACM, 2007, p. $421-429$.

Lipton, L. Foundations of the Stereoscopic Cinema. São Paulo,SP: Van Nostrand Reinhold Co., 2005.

LNCC MACC-Medicina Assistida por Computação Científica. [On-line].

Disponível em <http://macc.Incc.br/> (Acessado em January, 25, 2011)

Luz, R. W. Sisfetus: Sistema de representação e manipulação de estruturas fetais a partir de imagens bidimensionais de ultra-som. Dissertação de Mestrado, Centro Universitário Eurípides de Marília, Marília(SP), 2004.

Lynko Hospital tycoon: Construa seu próprio hospital 3d. [On-line].

Disponível em http://www.lynko.com.br/jogos (Acessado em February, 8, 2011)

Ma, J.; Nickerson, J. V. Hands-on, simulated, and remote laboratories: A comparative literature review. ACM Comput. Surv., v. 38, n. 3, p. 7, 2006.

Machado, L.; Cardoso, A. Dispositivos de Entrada e Saída para Sistemas de Realidade Virtual. In: Fundamentos e Tecnologia de Realidade Virtual e Aumentada, VIII Symposium on Virtual Reality - Belém, p. 39-50, 2006.

Machado, L.; Moraes, R. Qualitative and Quantitative Assessment for a VR-Based Simulator. Studies in Health Technology and Informatics, p. 168-173, 2009.

Machado, L. S. Realidade Virtual no modelamento e Simulação de Procedimentos Invasivos em Oncologia Pediátrica: Um estudo de caso no Transplante de Medula Óssea. Tese de Doutorado, Escola Politécnica - Universidade de São Paulo, São Paulo, 2003.

Machado, L. S.; Moraes, R.; Nunes, F. L. S.; Costa, R. M. E. M. Serious Games Baseados em Realidade Virtual para Educação Médica. Revista Brasileira de Educação Médica, 2010 . 
Machado, L. S.; Moraes, R. M.; Souza, D. F. L.; Souza, L. C.; Cunha, I. L. L. A Framework for Development of Virtual Reality-Based Training Simulators. In: Medicine Meets Virtual Reality 17, 2009, p. 174.

Manjunath, B.; Ma, W. Texture features for browsing and retrieval of image data. Pattern Analysis and Machine Intelligence, IEEE Transactions on, v. 18, n. 8, p. 837-842, 1996.

Marques, J. Realimentação de relevância para recuperação por conteúdo de imagens médicas visando diminuir a descontinuidade semântica. Dissertação (Mestrado em Ciências da Computação e Matemática Computacional), Instituto de Ciências Matemáticas e Computação, Universidade de São Paulo, São Carlos (SP), 2006.

Matheus, B. R. N.; Schiabel, H. Online Mammographic Images Database for Development and Comparison of CAD Schemes. Journal of Digital Imaging, p. 1618-727X, 2010 .

Matsumoto, M. M. S.; Lemos, P.; Yoneyama, T.and Furuie, S. S. Cardiac Phase Detection in Intravascular Ultrasound Images. In: Proceedings of Medical Imaging 2008: Ultrasonic Imaging and Signal Processing, 2008, p. 69200D-1-69200D-9.

McColl, R.; Brown, I.; Seligman, C.; Lim, F.; Alsaraira, A. Haptic Rendering Perception Studies For Laparoscopic Surgery Simulation. In: Engineering in Medicine and Biology Society, 2006. EMBS '06. 28th Annual International Conference of the IEEE, 2006, p. 833-836.

Menezes, E.; Santos, T. H. "Multidisciplinaridade" (verbete). Dicionário Interativo da Educação Brasileira - Educa Brasil. [On-line].

Disponível em http://www.educabrasil.com.br/eb/dic/dicionario.asp?id=90 (Acessado em January, 27, 2011)

Microsoft DirectX Developer Center. [On-line].

Disponível em http://msdn.microsoft.com/en-us/directx (Acessado em January, 20, 2011)

Moraes, R. R. C. Sistema para recuperação de imagens por conteúdo para internet. Trabalho de Conclusão de Curso (Bacharelado em Sistemas de Informação), Escola de Artes, Ciências e Humanidades - Universidade de São Paulo, São Paulo (SP), 2010.

Moustakas, J.; Marias, K.; Dimitriadis, S.; Orphanoudakis, S. A Two-Level CBIR Platform with Application to Brain MRI Retrieval. In: Multimedia and Expo, 2005. ICME 2005. IEEE International Conference on, 2005, p. 1278-1281. 
Muhler, K.; Tietjen, C.; Ritter, F.; Preim, B. The Medical Exploration Toolkit: An Efficient Support for Visual Computing in Surgical Planning and Training. IEEE Transactions on Visualization and Computer Graphics, v. 16, n. 1, p. 133-146, 2010.

Nema DICOM Homepage. [On-line].

Disponível em <http://medical.nema.org/> (Acessado em January, 25, 2011)

Netto, A. V.; Machado, L. S.; Oliveira, M. C. F. Realidade Virtual: Definições, Dispositivos e Aplicações. Revista Eletrônica de Iniciação Científica, v. II, 2002.

Nishikawa, R.; Giger, M.; Doi, K.; Metz, C. E.; Yin, F.-F.; Vyborny, C.; Schmidt, R. Effect of case selection on the performance of computer-aided detection schemes. Medical Physics, v. 21, p. 265-269, 1994.

Nishikawa, R.; Giger, M.; Doi, K.; Vyborny, C.; Schmidt, R. Computer-aided detection of clustered microcalcifications: an improved method for grouping detected signals. Medical Physics, v. 20(6), p. 1661-1666, 1993.

North, M.; North, S. M.; Coble, J. R. Virtual Reality Therapy: an effective treatment for phobias. In: Virtual Environments in Clinical Psychology and Neuroscience, Ios Press, p. 1, 1998.

Nowinski, W. Virtual Reality in brain intervention: models and applications. In: Engineering in Medicine and Biology Society, 2005. IEEE-EMBS 2005. 27th Annual International Conference of the, 2005, p. 4164-4167.

NRC Grand Challenges in Computing Research for 2010 and beyond. [On-line]. Disponível em http://www . ukcrc.org.uk/grand-challenge/2010.cfm (Acessado em October, 13, 2009)

Nunes, F. L. S. Introdução ao Processamento de Imagens Médicas para Auxílio ao Diagnóstico. In: Atualizações em Informática, PUC-Rio, p. 73-126, 2006.

Nunes, F. L. S.; Costa, R. M. E. M. RV para a área médica: requisitos, dispositivos e implementação. In: Realidade Virtual e Aumentada na prática, Sociedade Brasileira de Computação, p. 119-146, 2008a.

Nunes, F. L. S.; Costa, R. M. E. M. The virtual reality challenges in the health care area: a panoramic view. In: SAC 08: Proceedings of the 2008 ACM symposium on Applied computing, New York, NY, USA: ACM, 2008b, p. 1312-1316. 
Nunes, F. L. S.; Delamaro, M. E.; Oliveira, R. A. P. Oráculo gráfico como apoio na avaliação de sistemas de auxílio ao diagnóstico. In: Anais do XXIX Congresso da Sociedade Brasileira de Computação (CSBC 2009) - IX Workshop de Informática Médica (WIM 2009), Bento Gonçalves - RS, Brasil: SBC, 2009a, p. 2077-2080.

Nunes, F. L. S.; Machado, L.; Costa, R. M. E. M. Aplicações de realidade virtual e aumentada, cáp. Realidade Virtual e Realidade Aumentada aplicadas à Saúde Porto Alegre - RS, Brasil: Sociedade Brasileira de Computação, p. 69-89, 2009b.

Nunes, F. L. S.; Melo, C. R. M.; Corrêa, C. G.; Tori, R.; Barbosa, J. H. A.; Picchi, F.; Nakamura, R. A importância da avaliação na engenharia de requisitos em sistemas de Realidade Virtual e Aumentada: um estudo de caso. In: de Computação, S. B., ed. Proceedings of XII Symposium on Virtual and Augmented Reality, Natal (RN), 2010, p. $51-62$.

Nunes, F. L. S.; Oliveira, A. C. M. T. G.; Rossato, D. J.; Machado, M. I. C. ViMeTWizard: Uma ferramenta para instanciação de um framework de Realidade Virtual para treinamento médico. In: Proceedings of XXXIII Conferencia Latinoamericana de Informática, San José, Costa Rica: XXXIII Conferencia Latinoamericana de Informática, 2007a, p. 1-8.

Nunes, F. L. S.; Schiabel, H.; Benatti, R. A computer system to record and retrieve information from a ma.mmographic images database by internet. In: Proceedings of the World Congress on Medical Physics and Biomedical Engineering, Sidney, Australia, 2003, p. 25-31.

Nunes, F. L. S.; Schiabel, H.; Goes, C. E. Contrast enhancement in dense breast images to aid clustered microcalcifications detection. Journal of Digital Imaging, v. 20, n. 1, p. 53-66, 2007b.

Ogre3D OGRE - Open Source 3D Graphics Engine. [On-line]. Disponível em http://www.ogre3d.org/ (Acessado em January, 25, 2011)

Oliveira, A. C. M. T. G.; Delfino, S. R.; Nunes, F. L. S. Integration of a virtual reality framework with a 3D simulation system. In: Proceedings of The 16th annual medicine meets virtual reality conference - MMVR16, Long Beach, California, 2007a.

Oliveira, A. C. M. T. G.; Nunes, F. L. S. ViMeT and ViMetWizard: Process of Building a Framework and an Instantiation Tool for Programming Application in Medical Training Domain Using Free Technology. In: Proceedings of The 2009 Annual Meeting of the Society for Imaging Informatics in Medicine, Charlotte (NC), 2007, p. 2050-52. 
Oliveira, A. C. M. T. G.; Nunes, F. L. S. Building an Open Source Framework for Virtual Medical Training. Journal of Digital Imaging, v. 23, n. 6, p. 706-720, 2010.

Oliveira, A. C. M. T. G.; Nunes, F. L. S.; Bezerra, A. Concepção e Implementação de um Framework para Simulação de Exames de Punção usando Realidade Virtual. In: Proceedings of IX Simposium on Virtual and Augmented Reality, Petrópolis (RJ), 2007b, p. 253-262.

Oliveira, A. C. M. T. G.; Pavarini, L.; Nunes, F. L. S.; Botega, L. C.; Rossato, D. J.; Bezerra, A. Virtual Reality Framework for Medical Training: implementation of a deformation classa using Java. In: Proceedings of ACM International Conference on Virtual Reality Continuum and Its Applications, Hong Kong, 2006.

Oliveira, R. A. P.; Delamaro, M. E.; Nunes, F. L. S. Estrutura para Utilização de Recuperação de Imagens Baseada em Conteúdo em Oráculos de Teste de Software com Saída Gráfica. In: Anais do IV Workshop e Visão Computacional, Bauru (SP), 2008.

Oliveira, R. A. P.; Delamaro, M. E.; Nunes, F. L. S. O-FIm - Oracle for Images. In: Anais da XVI Sessão de Ferramentas do Simpósio Brasileiro de Engenharia de Software (SBES 2009), Fortaleza - CE, Brasil: UFC, 2009a, p. 1-6.

Oliveira, R. A. P.; Delamaro, M. E.; Nunes, F. L. S. Oráculos de Teste para Domínios GUI: Uma Revisão Sistemática. In: Anais SAST 2009 - Workshop Brasileiro de Teste de Software Sistemático e Automatizado, Gramado (RS): UFC, 2009b.

Olszewski, R.; Villamil, M. B.; Trevisan, D. G.; Nedel, L. P.; Freitas, C. M. D. S.; Reychler, H.; Macq, B. Towards an integrated system for planning and assisting maxillofacial orthognathic surgery. Computer Methods and Programs in Biomedicine, v. 91, p. 13-21, 2008.

Paiva, J. G. S.; A., A. C.; Lopes, E.; Jr, E. L. Interface para criação de rotas automotivas virtuais no tratamento de fobias de direção. In: Workshop de Aplicações de Realidade Virtual, Uberlândia, MG, 2005.

Panda3D Panda3D - Free 3D Game Engine. [On-line].

Disponível em http://www.panda3d.org/ (Acessado em January, 25, 2011)

Paris, A. C. Análise da eficiência de recuperação por conteúdo de imagens médicas, utilizando extratores de textura baseados em wavelet e wavelet packet. Mestrado em Engenharia Elétrica, Escola de Engenharia de São Carlos - USP, São Carlos, 2008. 
Parraga, A.; Susin, A.; Pettersson, J.; Macq, B.; Craene, M. D. 3D Atlas Building in the Context of Head and Neck Radiotherapy Based on Dense Deformation Fields. In: SIBGRAPI '0\%: Proceedings of the XX Brazilian Symposium on Computer Graphics and Image Processing, Washington, DC, USA: IEEE Computer Society, 2007, p. 321-328.

Pavarini, L. Estudo e implementação do método massa-mola para deformação em ambientes virtuais de treinamento médico usando a api java 3d. Dissertação de Mestrado, Centro Universitário Eurípides de Marília, Marília(SP), 2006.

Pedrini, H.; Schwartz, W. R. Análise de Imagens Digitais: Princípios, Algoritmos e Aplicações. Editora Thomson Learning Edições Ltda., 2007.

Petrakis, E.; Faloutsos, C.; Lin, K.-I. ImageMap: an image indexing method based on spatial similarity. Knowledge and Data Engineering, IEEE Transactions on, v. 14, n. 5, p. 979-987, 2002.

Pimentel, K.; Teixeira, K. Virtual reality - through the new looking glass. New York: McGraw-Hill, 1995.

Pinheiro, L. M.; Acra, L. A. O conhecimento de recursos alternativos em pesquisa com animais de laboratório. Estudos de Biologia, v. 29, n. 67, p. 157-163, 2007.

Pinho, M. S.; Kirner, C. Uma introdução à realidade virtual. [On-line].

Disponível em <http://grv. inf .pucrs.br/Pagina/TutRV/tutrv.htm> (Acessado em May, 10, 2010)

Pires, S. R.; Flores, E. L.; Barcelos, C. A. Z.; Batista, M. A. Interpolation of Computerized Tomography Slices using 3D Digital Inpainting. In: Computer Graphics and Image Processing, Brazilian Symposium on, Los Alamitos, CA, USA: IEEE Computer Society, 2006, p. 129-138.

Rahman, M.; Bhattacharya, P.; Desai, B. A Framework for Medical Image Retrieval Using Machine Learning and Statistical Similarity Matching Techniques With Relevance Feedback. Information Technology in Biomedicine, IEEE Transactions on, v. 11, n. 1, p. 58-69, 2007.

Ramalho Jr., F.; Ferraro, N. G.; Soares, P. A. T. Os fundamentos da física. 6a. ed. São Paulo: Editora Moderna, 1993.

Ramos, F. M.; Nunes, F. L. S.; Botega, L. C. Construção de Atlas de Anatomia e Fisiopatologia do Câncer de Mama utilizando Realidade Virtual. In: Proceedings of XVIII Simpósio Brasileiro de Computação Gráfica e Processamento de Imagens - 
IV Workshop de Teses de Dissertações em Computação Gráfica e Processamento de Imagens (WTDCGPI), Natal (RN), 2005a.

Ramos, F. M.; Nunes, F. L. S.; Botega, L. C.; Damasceno, E.; Pavarini, L. Atlas Virtual da Mama e Fisiopatologia do Câncer de Mama utilizando Java3D. In: Workshop de Aplicações de Realidade Virtual, Uberlândia, MG, 2005b.

Rao, R. B.; Bi, J.; Fung, G.; Salganicoff, M.; Obuchowski, N.; Naidich, D. LungCAD: a clinically approved, machine learning system for lung cancer detection. In: KDD '0\%: Proceedings of the 13th ACM SIGKDD international conference on Knowledge discovery and data mining, New York, NY, USA: ACM, 2007, p. 1033-1037.

Razente, H.; Barioni, M. C. N.; Traina, A. J. M.; Traina Jr., C. Recuperação de Imagens Médicas por Conteúdo em um Sistema de Gerenciamento de Banco de Dados de Código Livre. In: X Congresso Brasileiro de Informática em Saúde (CBIS), 2006, p. $1561-1566$.

Razente, H. L.; Barioni, M. C. N.; Traina, A. J. M.; Traina, Jr., C. Aggregate similarity queries in relevance feedback methods for content-based image retrieval|. In: $S A C$ '08: Proceedings of the 2008 ACM symposium on Applied computing, New York, NY, USA: ACM, 2008, p. 869-874.

Reitinger, B.; Bornik, A.; Beichel, R.; Schmalstieg, D. Liver Surgery Planning Using Virtual Reality. IEEE Computer Graphics and Applications, v. 26, n. 6, p. 36-47, 2007.

Ren, L. J.; Barnaghi, P. Semantic media in medical information systems. In: Semantic Media Adaptation and Personalization, Second International Workshop on, 2007, p. 27-31.

Rezende, L.; Segre, L.; Campos, G. Iterative method for identification and mapping of competences in curriculum construction to computer science. In: Rettberg, A.; Bobda, C., eds. New Trends and Technologies in Computer-Aided Learning for Computer-Aided Design, v. 192 de IFIP International Federation for Information Processing, Springer Boston, p. 107-119, 2005.

Ribeiro, M. X.; Traina, A.; Traina Jr, C.; Azevedo-Marques, P. M. An Association Rule-Based Method to Support Medical Image Diagnosis With Efficiency. Multimedia, IEEE Transactions on, v. 10, n. 2, p. 277-285, 2008. 
Rizzato, A. C. Realidade Virtual Aplicada à Educação. Monografia - Curso de Especialização em Tecnologia da Informação, Faculdade de Ciências, Universidade Estadual Paulista - Campus Bauru, 2007.

Rodrigues, M. A. F.; Silva, W. B.; Neto, B.; Escóssia, M.; Ribeiro, I. M. M. P. Um Sistema de Realidade Virtual para Tratamento Ortodôntico. In: Proceedings of Symposium on Virtual Reality, Belém (PA): Sociedade Brasileira de Computação, 2006, p. $433-444$.

Rosa, N. A.; Felipe, J. C.; Traina, A. J. M.; Traina, C.; Rangayyan, R. M.; Azevedo-Marques, P. M. Using relevance feedback to reduce the semantic gap in content-based image retrieval of mammographic masses. In: Engineering in Medicine and Biology Society, 2008. EMBS 2008. 30th Annual International Conference of the IEEE, 2008, p. 406-409.

Rubner, Y.; Tomasi, C.; Guibas, L. A metric for distributions with applications to image databases. Computer Vision, 1998. Sixth International Conference on, p. 59-66, 1998.

Russ, J. C. Image Processing Handbook, Fourth Edition. Boca Raton, FL, USA: CRC Press, Inc., 2002.

Sales, F. J. R.; Falcao, J. L. A. A.; Falcao, B. A. A.; Furuie, S. S.; Lemos, P. Análise dos efeitos causados pelo implante de stents coronários em imagens de ultra-som intravascular com histologia virtual. In: Anais do XXI Congresso Brasileiro de Engenharia Biomédica, 2008, p. 0956-1-0956-4.

Sandri, S.; Correa, C. Lógica Nebulosa. In: Anais da Escola de Redes Neurais, São Paulo (SP), 1999.

Santos, A. P. O. Recuperação de imagens mamográficas baseada em conteúdo. Trabalho de COnclusão de Curso (Bacharelado em Ciência da Computação), Centro Universitário Eurípides de Marília, Marília(SP), 2006.

Santos, A. P. O.; Nunes, F. L. S.; Delamaro, M. E. Implementação de uma Ferramenta para Recuperação de Imagens Mamográficas Baseada em Conteúdo. In: Anais do III Workshop de Visão Computacional, São José do Rio Preto (SP), 2007a, p. 247-252.

Santos, A. P. O.; Nunes, F. L. S.; Delamaro, M. E. Recuperação de Imagens Mamográficas Baseada em Conteúdo. In: Proceedings of the WUW - Workshop of Undergraduate Work of the XXth Brazilian Symposium on Computer Graphics and Image Processing, Belo Horizonte (MG), 2007b, p. 149-152. 
Santos, S. H. O. VRVis Manager - uma ferramenta para visualização de grandes volumes de dados usando realidade virtual. Dissertação de Mestrado, Centro Universitário Eurípides de Marília, Marília(SP), 2010.

Santos, S. H. O.; Sabatine, R. J.; Nunes, F. L. S. Uma ferramenta para visualização de informação para área de negócios. In: Anais do WRVA 2008 - 5o. Workshop de Realidade Virtual e Aumentada, 2008.

Sayeg, N. Avaliação morfofuncional. [On-line], Online.

Disponível em http://www. alzheimermed.com.br (Acessado em September, 13, 2010)

SBC Grand Challenges in Computing Research in Brazil- 2006 - 2016, Workshop Report - May 8-9, 2006. [On-line], Online.

Disponível em http://www.sbc.org.br (Acessado em January, 30, 2011)

Shaw, A. C. Sistemas e software de tempo real. Bookman, São Paulo, 2003.

Shojaii, R.; Alirezaie, J.; Khan, G.; Babyn, P. Automatic honeycomb lung segmentation in pediatric ct images. In: Signal Processing and Its Applications, 200\%. ISSPA $200 \%$. 9th International Symposium on, Belém (PA): Sociedade Brasileira de Computação, 2007, p. 3-14.

Silberchatz, A.; Korth, H. F.; Sundarshan, S. Database system concepts. McGraw-Hill, 2005.

Silva, A.; Falcão, A. X.; Magalhães, L. A new CBIR Approach based on Relevance Feedback and Optimum-Path Forest Classification. Journal of Winter School of Computer Graphics, v. 18, p. 73-80, 2010.

Smith, J. Integrated spatial and feature image systems: retrieval, compression and analysis. PhD Dissertation, Columbia University, New Your - NY, 1997.

Soler, L.; Nicolau, S.; Fasquel, J.-B.; Agnus, V.; Charnoz, A.; Hostettler, A.; Moreau, J.; Forest, C.; Mutter, D.; Marescaux, J. Virtual reality and augmented reality applied to laparoscopic and notes procedures. In: Biomedical Imaging: From Nano to Macro, 2008. ISBI 2008. 5th IEEE International Symposium on, 2008, p. 1399-1402.

Sonka, M.; Zhao, F.; Zhang, H.; Wahle, A.; Stolpen, A.; Scholz, T. Early detection of aortic aneurysm risk from 4-D MR image data. In: Computers in Cardiology, 2006, 2006, p. 69-72. 
Souza, D. F. L.; Valdek, M. C. O.; Moraes, R. M.; Machado, L. SITEG Sistema Interativo de Treinamento em Exame Ginecológico. In: Proceedings of Symposium on Virtual Reality, Belém (PA): Sociedade Brasileira de Computação, 2006, p. 445-456.

Sun Microsystems Java 3D API Tutorial. [On-line].

Disponível em http://java.sun.com/developer/onlineTraining/java3d/ (Acessado em January, 30, 2011)

Suzuki, F. T. I.; Matias, M. V.; Silva, M. T. A.; Oliveira, M. P. M. A. T. O uso de videogames, jogos de computador e internet por uma amostra de universitários da Universidade de São Paulo. Jornal Brasileiro de Psiquiatria, v. 58, p. 162-168, 2009.

Disponível em http://www.scielo.br/pdf/jbpsiq/v58n3/04.pdf (Acessado em January, 27, 2011)

Swain, M. J.; Ballard, D. H. Color indexing. International Journal of Computer Vision, v. 7, n. 1, p. 11-32, 1991.

Tang, C.-Y.; Chin, W.; Chui, Y.-P.; Poon, W.-S.; Heng, P.-A. A Virtual Reality-based Surgical Simulation System for Virtual Neuroendoscopy. In: Integration Technology, 200\%. ICIT '0\%. IEEE International Conference on, 2007, p. 253-258.

Tarr, M. J.; Warren, W. H. Virtual Reality in behavioral neuroscience and beyond. Nature Neuroscience, v. 5, p. 1089-1092, 2002.

Thrive The incredible adventures of the amazing food detective. [On-line].

Disponível em https://members.kaiserpermanente.org (Acessado em February, 8, 2011)

Tori, R.; ; Tokunaga, D. M.; Nakamura, R.; ; Nunes, F. L. S.; Corrêa, C. G.; Picchi, F. L. Visualização Não-fotorrealística no Design de Interação do Ambiente VIDA. In: Anais do IX Congresso Brasileiro de Pesquisa e Desenvolvimento em Design, 2010, p. 1-8.

Tori, R.; Kirner, C.; Siscoutto, R. Fundamentos e Tecnologia de Realidade Virtual e Aumentada. Porto Alegre: Editora SBC, 2006.

Tori, R.; Nunes, F. L. S.; Gomes, V. H. P.; Tokunaga, D. M. VIDA: Atlas Anatômico 3D Interativo para Treinamento a Distância. In: Anais do WIE 2009 - X Workshop de Informática na Escola - XXIX Congresso da Sociedade Brasileira de Computação, Sociedade Brasileira de Computação, Porto Alegre (RS), 2009a.

Tori, R.; Nunes, F. L. S.; Nakamura, R.; Junior, J. L. B.; Corrêa, C. G.; Tokunaga, D. M. Design de Interação para um Atlas Virtual de Anatomia Usando Realidade Aumentada e Gestos. In: Proceedings of Interaction 2009 - South America, 2009b, p. 1-8. 
Torres, R.; Falcão, A.; Gonçalves, M.; Papa, J.and Zhang, B.; Fan, W.; Fox, E. A genetic programming framework for content-based image retrieval. Pattern Recognition, v. 42, p. 283-292, 2009.

Traina Jr, C.; Santos Filho, R. F.; Traina, A. J. M.; Vieira, M. R.; Faloutsos, C. The omni-family of all-purpose access methods: A simple and effective way to make similarity search more efficient. The VLDB Journal, v. 16, p. 483-505, 2007.

Traina Jr., C.; Traina, A.; Faloutsos, C.; Seeger, B. Fast Indexing and Visualization of Metric Data Sets using Slim-Trees. IEEE Transactions on Knowledge and Data Engineering, v. 14, n. 2, p. 244-260, 2002.

Trevisan, D. G.; Nicolas, V.; Macq, B.; Nedel, L. P. MedicalStudio: a medical component-based framework. In: Workshop de Imagens Médicas (WIM), Recife, PE, 2007.

Trevisan, D. G.; Nicolas, V.; Macq, B.; Nedel, L. P. A medical Component-based Framework for Image Guided Surgery. In: Multimodal User Interfaces From Signals to Interaction, Berlin: Springer, p. 271-180, 2008.

Uchiyama, Y.; Yokoyama, R.; Ando, H.; Asano, T.; Kato, H.; Yamakawa, H.; Hara, T.; Iwama, T.; Hoshi, H.; Fujita, H. Improvement of Automated Detection Method of Lacunar Infarcts in Brain MR Images. In: Engineering in Medicine and Biology Society, 200\%. EMBS 200\%. 29th Annual International Conference of the IEEE, 2007, p. $1599-1602$.

Unesco Unesco Science Report 2010 The Current Status of Science around the World. [On-line].

Disponível em <http://unesdoc.unesco.org/images/0018/001899/189958e.pdf> (Acessado em January, 27, 2011)

Vasconcelos, N. On the efficient evaluation of probabilistic similarity functions for image retrieval. Information Theory, IEEE Transactions on, v. 50, n. 7, p. 1482-1496, 2004.

Virk, S.; McConville, K. Virtual Reality Applications in Improving Postural Control and Minimizing Falls. In: Engineering in Medicine and Biology Society, 2006. EMBS '06. 28th Annual International Conference of the IEEE, 2006, p. 2694-2697.

Wagner, J. M.; Noo, F.; Clackdoyle, R.; Bal, G.; Christian, P. Attenuation Correction for Rotating Slant-Hole (RSH) SPECT using Exact Rebinning. IEEE Transactions on Nuclear Science, v. 50, n. 1, p. 110-116, 2003. 
Wainer, J.; de Campos, C. J. R.; Ramos, M. P.; Lopes, P.; Salomão, P. L.; Sigulem, D. O que é Pesquisa em Informática em Saúde? RITA, v. 13, n. 1, p. 42-56, 2006.

Wan Ahmad, W. S. H. M.; Fauzi, M. F. A. Comparison of different feature extraction techniques in content-based image retrieval for CT brain images. In: Multimedia Signal Processing, 2008 IEEE 10th Workshop on, 2008, p. 503-508.

Wang, Y.; Zheng, J.; Zhou, H.; Shen, L. Medical image processing by denoising and contour extraction. In: Information and Automation, 2008. ICIA 2008. International Conference on, 2008, p. 618-623.

Web3D Consortium X3D for Developers. [On-line].

Disponível em http://java.sun.com/developer/onlineTraining/java3d/ (Acessado em January, 15, 2011)

Xiang-min, X.; Feng-le, Z.; Yue, X. The Study of Mammary Disease CAD System. In: Complex Medical Engineering, 200\%. CME 200\%. IEEE/ICME International Conference on, 2007, p. 676-679.

Yaacoub, F.; Hamam, Y.; Abche, A. Collision Detection in Computer Simulations for Wrist Arthroscopic Surgery Training. In: EUROCON, 200\%. The International Conference on "Computer as a Tool", 2007, p. 2088-2095.

Yapa, R. D.; Koichi, H. A connected component labeling algorithm for grayscale images and application of the algorithm on mammograms. In: SAC 'O\%: Proceedings of the 2007 ACM symposium on Applied computing, New York, NY, USA: ACM, 2007, p. $146-152$.

Zhang, W.-L.; Wang, X.-Z. Feature Extraction and Classification for Human Brain CT Images. In: Machine Learning and Cybernetics, 2007 International Conference on, 2007, p. 1155-1159.

Zhou, X. S.; Zillner, S.; Moeller, M.; Sintek, M.; Zhan, Y.; Krishnan, A.; Gupta, A. Semantics and CBIR: a medical imaging perspective. In: CIVR '08: Proceedings of the 2008 international conference on Content-based image and video retrieval, New York, NY, USA: ACM, 2008, p. 571-580.

Zhu, W.; Zhou, C.; Xu, D.; Xu, J. A Multi-feature CBIR Method Using in the Traditional Chinese Medicine Tongue Diagnosis. In: Pervasive Computing and Applications, 2006 1st International Symposium on, 2006, p. 831-836.

Zill, D. G. Equações diferenciais com aplicações em modelagem. 3a. ed. São Paulo: Thomson, 2003. 
Zyda, M. From visual simulation to virtual reality to games. Computer, v. 38, n. 9, p. 25-32, 2005. 